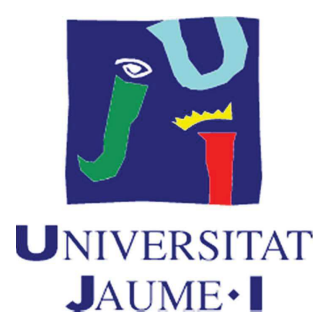

Programa de Doctorado en Tecnologías Industriales y Materiales

Escuela de Doctorado de la Universitat Jaume I

\title{
Desarrollo y caracterización de compuestos biodegradables basados en polihidroxialcanoatos y fibras lignocelulósicas para aplicaciones de un solo uso
}
Memoria presentada por Estefanía Lidón Sánchez Safont para optar al grado de doctora por la Universitat Jaume I

Autora:

Estefanía Lidón Sánchez Safont
Dirigida por:

José Gámez Pérez Luis Cabedo Mas 



\section{Financiación recibida}

Esta tesis doctoral ha sido financiada a través de los siguientes proyectos de investigación:

- Ministerio de Economía y Competitividad (proyecto MAT2012-38947-C02-01)

- Generalitat Valenciana (GV/2014/123)

- Ministerio de Economía y Competitividad (AGL2015-63855-C2-2-R)

- $\quad$ Pla de Promoció de la Investigació de la Universitat Jaume I (UJI-B2016-35)

- H2020 EU Project YPACK (H2020-SFS-2017-1, Reference 773872)

Han contribuido también a la financiación de este trabajo los siguientes centros mediante la cesión de sus instalaciones o recursos para estancias de investigación o colaboraciones puntuales:

Estancias de investigación:

- Centro tecnológico Leartiker S. Coop., Markina-Xemein, España

Colaboraciones:

- Grupo de investigación Novel Materials and Nanotechnology del Instituto de Agrotecnología y Tecnología de alimentos (IATA) del Consejo Superior de Investigaciones Científicas (CSIC)

- Instituto de Tecnología de Materiales de la Universitat Politècnica de València-Campus de Alcoy 
A mi familia... 


\title{
Agradecimientos
}

\author{
"Cuando aprendamos a dar y recibir esta energía universal, querida Lieserl, \\ comprobaremos que el amor todo lo vence, todo lo trasciende y todo lo puede, \\ porque el amor es la quinta esencia de la vida" \\ (Extracto de una supuesta carta de Albert Einstein a su hija Lieserl)
}

Alguien me ha enseñado que esta vida es un proceso continuo de aprendizaje y que las mayores enseñanzas, aquellas que nos permiten avanzar, son las que obtenemos de nuestra relación con los demás. Por eso, todas y cada una de las experiencias que vivimos debemos vivirlas plenamente, con lo bueno y con lo malo porque todo es importante, todo es necesario. Pero, sobre todo, debemos vivirlas bien atentos, prestando atención a lo verdaderamente importante, a las personas. Por eso, quiero dedicar estas líneas a agradecer de corazón a todas las personas que me han acompañado en esta experiencia y de las que, sin duda, he aprendido mucho.

En primer lugar quiero agradecer a los que me han enseñado la verdadera esencia de la vida. Adrián, Mamá, Maite, Caterina, gràcies per recolzar-me, gràcies per estar sempre, gràcies per voler-me. A toda mi familia, abuela Encarna, abuelo Emilio, tío Javier, tía Lourdes, Óscar, José Manuel, Aitana, Tere, Arturo y a toda mi familia, gràcies. A mis ángeles, gràcies per cuidar-me. A ti Papá, por ser mi luz, te quiero. A tots, us vull moltíssim!

A mis directores de tesis, José Gámez Pérez y Luis Cabedo Mas, por haber confiado en mí y haberme dado la oportunidad de realizar esta tesis, por ayudarme, por enseñarme, por guiarme, por sus consejos y por transmitirme su pasión por la investigación. José, al final, casi siempre tienes razón...Luis, açò no ha sigut una "piuà", pero casi...

A todas las personas que han formado o forman parte del grupo PIMA. Ha sido y es un placer trabajar con todos y cada uno de vosotros. Y, por supuesto, compartir momentos divertidos, almuerzos, comidas, cenas, cafés, laser games...sois todos geniales. A los profesores Julio Suay, Jorge García, José Javier Gracenea y, en especial, a Raúl Izquierdo que fue mi profesor de Ciencia de Materiales y el que me dio la oportunidad de comenzar en el grupo. A los técnicos de laboratorio Pepe Ortega y Raquel Oliver. Pepe y Raquel, gràcies pel recolzament experimental, però, per damunt de tot, gràcies per estar sempre ahí, disposats a escoltar y compartir penes $y$ alegries companys, gràcies per la vostra amistat. A todos los pimit@s: Ane, Montse, Sara, Javi, Adrià, Jenny, Fran, Nuno, Ma José, Jaume, Lourdes, Aziz, Patricia, Tomás, Braulio, Andreia...y a todos los compañeros que han pasado por el grupo. Jenny, que et puc dir...vam començar juntes 
aquesta aventura amb els nostres amics els PHA y el que ens han fet riure i plorar...el millor de tot, els "ratets" de xarradeta y cafenet, ara els farem "paina". Adrià, he tingut molta sort de trovar-me amb tú, eres un gran amic. Fran y Nuno, compañeros de batalla, ya estamos en la recta final...no sé si habrá bastante café para amenizar nuestros, tan necesarios, momentos de confidencias y, bueno vale...va, algo de "procrastineo" también. La templanza de Fran, junto con mi mezcla de pesimismo y buen humor y la mezcla de optimismo y sarcasmo de Nuno hacen muy buen equipo. Sois geniales. Esto ya está hecho chicos, iVAMOS!.

Quiero agradecer también a nuestros compañeros del IATA: Chema, Sergi, Carmen, Cris, Kelly, Bea, María..., con los que además de proyectos y trabajo, también he tenido el gusto de compartir muy buenos momentos en congresos, comidas $\mathrm{y}$, como no, laser game.

También a nuestros amigos de Alcoi, siempre dispuestos a colaborar con nosotros, en especial, a Rafa Balart y Luis Quiles.

Me gustaría agradecer, también, a todos los técnicos de los Servicios Centrales de Instrumentación Científica (SCIC) de la UJI por su disponibilidad y ayuda en la preparación de muestras y asesoramiento técnico.

A todos los compañeros de mi estancia en Leartiker por hacerme sentir una más y abrirme de par en par las puertas de sus laboratorios. A Amaia, Aitor, Ane, Nerea, Ricardo, Aizeti, Goiatz...y, en especial, a mis supervisores Alex Arrillaga y Jon Anakabe. Trabajar con vosotros ha sido un verdadero placer, he aprendido muchísimo y me llevo una experiencia realmente provechosa e inolvidable. Eskerrik asko!!

A mis amigos de la residencia, en especial a Karen. Amiguita, coincidimos poco tiempo pero sabes que tienes una amiga en España para siempre. A los amigos de Markina, especialmente a Amalia. Amalia, te agradezco muchísimo que me abrieras las puertas de tu casa, sabes que te quiero muchísimo, pronto nos vemos por Markina, para un buen pintxo pote con Rakel, Ainhoa, Peio..y los que se apunten. Ah, y el marmitako en el Olaia. Txakolina, txakolina...

Por último, a todos mis amigos (Xispaets, Bastida...no pongo nombres que no me quiero dejar a nadie ;-)...), que han tenido mucha paciencia durante estos últimos años y han sabido comprender todos mis "Cuando acabe la tesis..."

A todos vosotros y todas aquellas personas que de forma consciente o inconsciente me han ayudado durante este tiempo. iMUCHAS GRACIAS! 


\section{Resumen}

El uso de plásticos ha supuesto una revolución en el diseño y desarrollo de materiales en el último siglo. No obstante, el extendido uso de plásticos convencionales (>300 millones de ton/año) conlleva ciertos problemas asociados a su procedencia no renovable (petróleo), a la elevada huella de carbono derivada de su producción y al enorme volumen de residuos generados. El impacto medioambiental asociado a los residuos plásticos radica en sus bajas tasas de biodegradación, suponiendo su acumulación en vertederos y, en el peor de los casos, su incorporación al medio ambiente.

De entre los distintos enfoques encaminados a reducir esta problemática, uno de los que mayor interés está despertando es el desarrollo de composiciones biodegradables (preferiblemente de origen renovable) que permitan sustituir a los plásticos convencionales, haciendo un uso responsable de los recursos y contribuyendo al desarrollo sostenible y la economía circular. Este enfoque tiene un particular interés en aquellas aplicaciones que supongan una mayor generación de residuos o que tengan un mayor riesgo de acabar en el medio ambiente (p. ej., envase o productos desechables).

Los polihidroxialcanoatos (PHA), biopoliésteres de origen bacteriano, se presentan como parte de esta solución debido, principalmente, a su origen renovable, su biodegradabilidad, y a un conjunto de propiedades comparables a algunos polímeros convencionales. Sin embargo, todavía presentan elevados costes de producción así como ciertas limitaciones técnicas que condicionan su competitividad, entre las que cabe destacar su baja tenacidad, una acusada fragilización con el tiempo y su estrecha ventana de procesado.

Esta tesis se ha centrado en la obtención y caracterización de compuestos basados en PHA, concretamente polihidroxibutirato (PHB) y poli(hidroxibutirato-co-hidroxivalerato) PHBV, y fibras de origen vegetal (o lignocelulósico). El uso de fibras lignocelulósicas implica potencialmente la reducción de costes, extendiendo el concepto "green" del producto y contribuyendo a la economía circular.

Los resultados presentados en este trabajo se pueden dividir en dos bloques. El primero de ellos dedicado a estudiar la relación composición-estructura-propiedades-comportamiento de compuestos $\mathrm{PHA} /$ fibra, así como la valorización de distintos residuos de origen vegetal como materiales de refuerzo y el estudio de la compatibilización fibra-matriz mediante extrusión reactiva. El segundo bloque está dirigido a la mejora de la aplicabilidad del PHBV para el desarrollo de productos de pieza inyectada desde un enfoque más industrial. En este bloque se 
han desarrollado compuestos triples mediante la adición de fibras de celulosa de alta pureza y un modificador de impacto, poliuretano termoplástico (TPU), a una matriz de PHBV. Se ha estudiado el efecto de cada uno de los aditivos sobre las propiedades del PHBV y la compatibilización de las distintas fases mediante extrusión reactiva.

Las composiciones obtenidas en esta tesis han demostrado ser técnicamente viables para su aplicación en el desarrollo de productos de un solo uso, especialmente aquellos con un final de vida dirigido al compostaje. 


\section{Abstract}

The use of plastics has meant a revolution in the design and development of materials in the last century. Nevertheless, the widespread use of conventional plastics (> 300 million tons / year) entails certain problems associated with their non-renewable origin (oil), the high carbon footprint derived from their production and the enormous volume of waste generated. The environmental impact associated with plastic waste lies in its low rates of biodegradation, assuming its accumulation in landfills and, in the worst case, its incorporation into the environment.

Among the different approaches pointed on reducing this problem, one of the most interesting is the development of biodegradable compositions (preferably renewable) that replace conventional plastics, making responsible use of resources and contributing to the sustainable development and the circular economy. This approach has a particular interest in those applications involving a great generation of waste or having a higher risk of ending up in the environment (eg packaging or disposable products).

Polyhydroxyalkanoates (PHA), bacterial biopolyesters, are presented as part of this solution mainly due to their renewable origin, biodegradability, and overall properties comparable to some commodities. However, they still have high production costs as well as certain technical limitations that restrict their competitiveness, among which are their low toughness, embrittlement over time and a narrow processing window.

This thesis has focused on the obtention and characterization of composites based on PHAs, concretely polyhydroxybutyrate (PHB) and poly (hydroxybutyrate-co-hydroxyvalerate) PHBV, and vegetal fibers (lignocellulosic). The use of lignocellulosic fibers potentially implies the reduction of costs, extending the green concept of the product and contributing to the circular economy.

The results presented in this work can be divided into two blocks. The first one dedicated to study the PHA/fiber composition-structure-properties-behavior relationship, as well as the valorization of different vegetal residues as reinforcement materials and the study of the fibermatrix compatibilization through reactive extrusion. The second block aims at improving the applicability of the PHBV for injected part products from an industrial point of view. In this block, triple systems have been developed by the addition of high purity cellulose fibers and an impact modifier, thermoplastic polyurethane (TPU), to a PHBV matrix. The effect of each additive on the properties of PHBV has been studied. The compatibilization of the different phases by reactive extrusion has been also evaluated. 
The compositions obtained in this thesis have proved to be technically viable for their application in the development of single-use products, especially those with an end of life aimed at composting. 


\section{Resum}

L'ús de plàstics ha suposat una revolució en el disseny i desenvolupament de materials en l'últim segle. No obstant açò, l'estès ús de plàstics convencionals ( $>300$ milions de tones/any) comporta certs problemes associats a la seua procedència no renovable (petroli), a l'elevada petjada de carboni derivada de la seua producció i a l'enorme volum de residus generats. L'impacte mediambiental associat als residus plàstics radica en les seues baixes taxes de biodegradació, suposant la seua acumulació en abocadors i, en el pitjor dels casos, la seua incorporació al medi ambient.

D'entre els diferents enfocaments encaminats a reduir aquesta problemàtica, un dels quals major interès està despertant és el desenvolupament de composicions biodegradables (preferiblement d'origen renovable) que permeten substituir als plàstics convencionals, fent un ús responsable dels recursos i contribuint al desenvolupament sostenible i l'economia circular. Aquest enfocament té un particular interès en aquelles aplicacions que suposen una major generació de residus o que tinguen un major risc d'acabar en el medi ambient (p. ex., envàs o productes d'un sol ús).

Els polihidroxialcanoats (PHA), biopolièsters d'origen bacterià, es presenten com a part d'aquesta solució, principalment, a causa del seu origen renovable, la seua biodegradabilitat, i a un conjunt de propietats comparables a alguns polímers convencionals. No obstant açò, encara presenten elevats costos de producció així com certes limitacions tècniques que condicionen la seua competitivitat, entre les quals cal destacar la seua baixa tenacitat, una acusada fragilització amb el temps i una estreta finestra de processament.

Aquesta tesi s'ha centrat en l'obtenció i caracterització de compostos basats en PHA, concretament polihidroxibutirat (PHB) i poli (hidroxibutirat-co-hidroxivalerat) PHBV, i fibres d'origen vegetal (o lignocel/lulósic). L'ús de fibres lignocel-lulósiques implica potencialment la reducció de costos, estenent el concepte "green" del producte i contribuint a l'economia circular.

Els resultats presentats en aquest treball es poden dividir en dos blocs. El primer d'ells dedicat a estudiar la relació composició-estructura-propietats-comportament de compostos PHA/fibra, així com la valorització de diferents residus d'origen vegetal com a materials de reforç i l'estudi de la compatibilització fibra-matriu mitjançant extrusió reactiva. El segon bloc està dirigit a la millora de l'aplicabilitat del PHBV per al desenvolupament de productes de peça injectada des d'un enfocament més industrial. En aquest bloc s'han desenvolupat compostos triples mitjançant l'addició de fibres de cel·lulosa d'alta puresa i un modificador d'impacte, poliuretà termoplàstic 
(TPU), a una matriu de PHBV. S'ha estudiat l'efecte de cadascun dels additius sobre les propietats del PHBV i la compatibilització de les diferents fases mitjançant extrusió reactiva.

Les composicions obtingudes en aquesta tesi han demostrat ser tècnicament viables per a la seua aplicació en el desenvolupament de productes d'un sol ús, especialment aquells amb un final de vida dirigit al compostatge. 


\section{Estructura de la tesis}

Esta tesis se ha estructurado en cinco secciones como se muestra en la Figura 1: Introducción, Marco teórico, Resultados, Análisis general de resultados y Conclusiones y trabajos futuros.

En la sección Introducción se contextualiza este trabajo de investigación. Así, se describe la situación actual de la producción y demanda de plásticos, la gestión de sus residuos y la posición actual de los bioplásticos en el mercado, así como las expectativas de futuro encaminadas a lograr una economía del plástico más sostenible. Se plantea la motivación de este trabajo indicando las fortalezas y limitaciones para la aplicabilidad de los polihidroxialcanoatos(PHA) como sustitutos de los plásticos convencionales. Se establece el objetivo general y los objetivos específicos de esta tesis y se resalta el interés científico, tecnológico y socioeconómico de este trabajo.

En la sección Marco teórico se hace una revisión en mayor profundidad del estado del arte en el campo de los biopolímeros, centrando la atención en los PHA, polihidroxibutirato (PHB) y poli(hidroxibutirato-co-hidroxivalerato)(PHBV) y el desarrollo de compuestos basados en PHA y fibras lignocelulósicas, así como las estrategias empleadas encaminadas a mejorar las propiedades de estos materiales.

La presente tesis doctoral se ha realizado por compendio de artículos, por lo que los principales resultados de la investigación se recogen en la sección Resultados divididos en seis capítulos que siguen el formato habitual de las publicaciones científicas: resumen, introducción, materiales y métodos, discusión de resultados y conclusiones. Estos seis capítulos se han dividido en dos bloques temáticos, el primero de ellos se ha centrado, bajo un punto de vista más científico, en el estudio de la relación composición-estructura-propiedades-comportamiento de compuestos basados en PHA y fibras lignocelulósicas. El segundo bloque, con un enfoque más industrial, se ha centrado en el desarrollo de compuestos compostables basados en PHBV y celulosa con tenacidad mejorada para aplicaciones de inyección obtenidos mediante procesado en equipamiento semi-industrial.

Los principales resultados derivados de cada uno de los capítulos se analizan de forma conjunta en la sección Análisis general de resultados. Finalmente, en la sección Conclusiones y trabajos futuros se exponen las conclusiones más relevantes que se pueden extraer de este trabajo y a partir de ellas se plantean posibles líneas futuras de investigación. 


\begin{tabular}{|c|c|c|}
\hline \multicolumn{3}{|c|}{ INTRODUCCIÓN (Contextualización y definición de objetivos) } \\
\hline \multicolumn{3}{|c|}{ MARCO TEÓRICO } \\
\hline \multirow{6}{*}{ RESULTADOS } & \multirow{4}{*}{$\begin{array}{c}\text { Relación composición- } \\
\text { estructura-propiedades- } \\
\text { comportamiento de compuestos } \\
\text { PHA/fibra }\end{array}$} & $\begin{array}{l}\text { Capítulo I- Poly(3-Hydroxybutyrate-co-3- } \\
\text { Hydroxyvalerate)/Purifi ed Cellulose Fiber } \\
\text { Composites by Melt Blending: } \\
\text { Characterization and Degradation in } \\
\text { Composting Conditions }\end{array}$ \\
\hline & & $\begin{array}{c}\text { Capítulo II- Biocomposites of different } \\
\text { lignocellulosic wastes for sustainable food } \\
\text { packaging applications }\end{array}$ \\
\hline & & $\begin{array}{l}\text { Capítulo III- Effect of the purification } \\
\text { treatment on the valorization of natural } \\
\text { cellulosic residues as fillers in PHB-based } \\
\text { composites for short shelf life applications }\end{array}$ \\
\hline & & $\begin{array}{l}\text { Capítulo IV-Study of the compatibilization } \\
\text { effect of different reactive agents in } \\
\text { PHB/natural fiber based composites. }\end{array}$ \\
\hline & Bloque B & $\begin{array}{c}\text { Capítulo V-PHBV/TPU/Cellulose compounds } \\
\text { for compostable injection molded parts } \\
\text { with improved thermal and mechanical } \\
\text { performance }\end{array}$ \\
\hline & $\begin{array}{c}\text { PHBV para productos de pieza } \\
\text { inyectada }\end{array}$ & $\begin{array}{l}\text { Capítulo VI- Toughness Enhancement of } \\
\text { PHBV/TPU/Cellulose Compounds with } \\
\text { Reactive Additives for Compostable Injected } \\
\text { Parts in Industrial Applications }\end{array}$ \\
\hline \multicolumn{3}{|c|}{ ANÁLISIS GENERAL DE RESULTADOS } \\
\hline \multicolumn{3}{|c|}{ CONCLUSIONES Y TRABAJOS FUTUROS } \\
\hline
\end{tabular}

Figura 1. Estructura de la tesis 


\section{Índice}

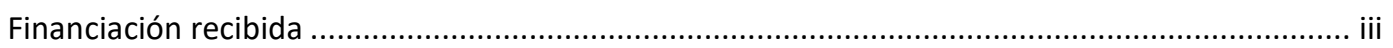

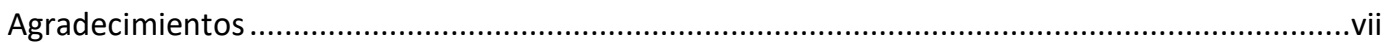

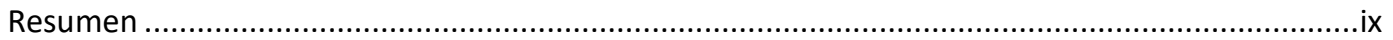

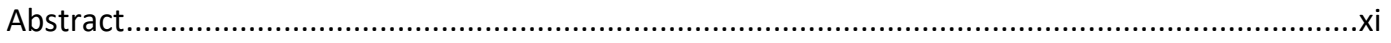

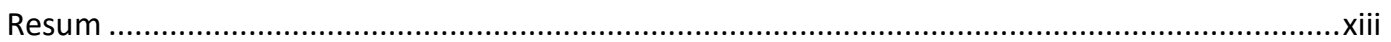

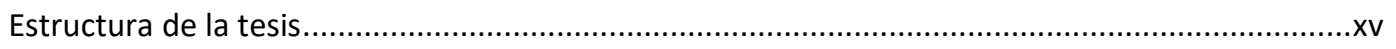

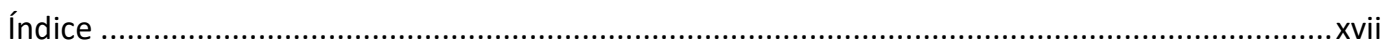

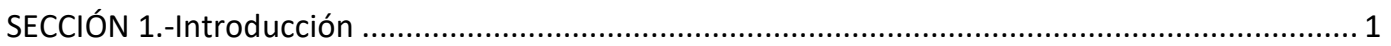

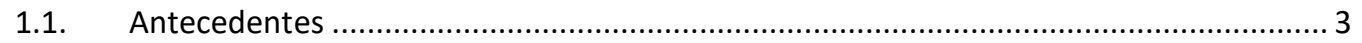

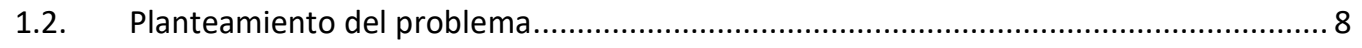

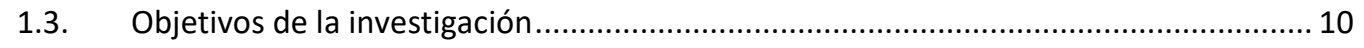

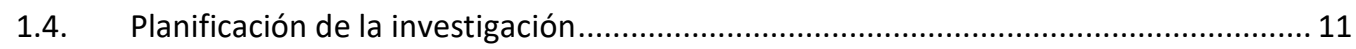

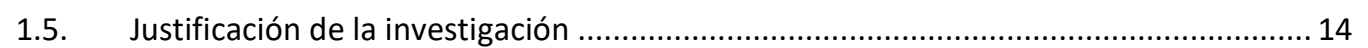

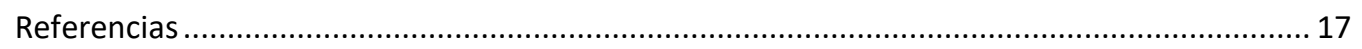

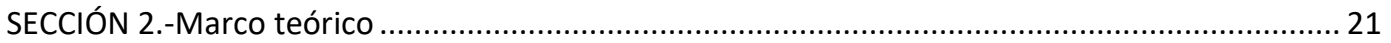

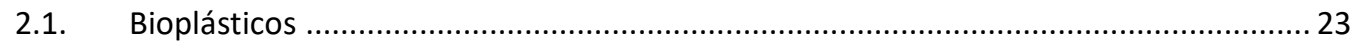

2.2. Polihidroxialcanoatos (PHA): polihidroxibutirato (PHB) y polihidroxibutirato-co-

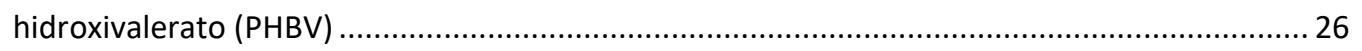

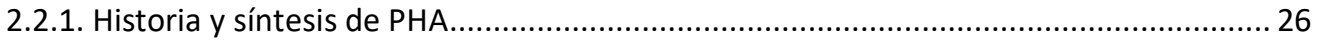

2.2.2. Estructura y propiedades generales de los PHA ................................................. 28

2.2.3. Relación estructura-propiedades del PHB y el PHBV .............................................. 29

2.2.3.1. Estructura cristalina y microestructura ..................................................... 30

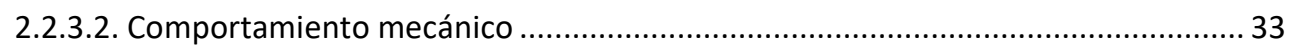

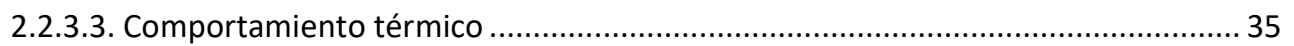

2.3. Valoración de la aplicabilidad industrial del PHB y el PHBV ....................................... 36

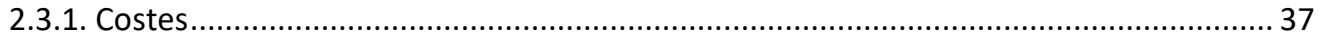




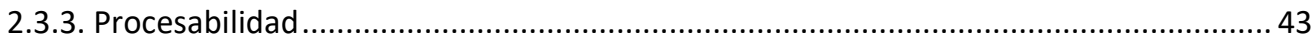

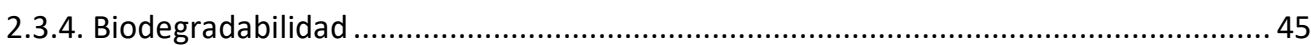

2.4. Compuestos de matriz polimérica basados en fibras lignocelulósicas......................... 47

2.4.1. Estructura, composición y propiedades generales de las fibras lignocelulósicas ......... 47

2.4.2. Fibras lignocelulósicas en compuestos de matriz polimérica ................................... 51

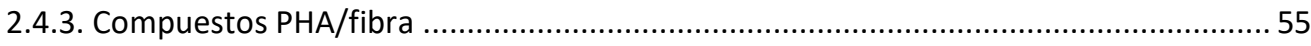

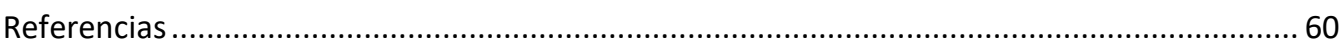

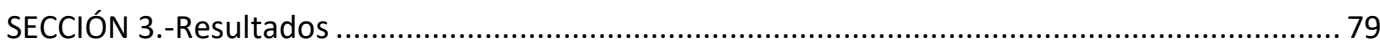

Bloque A.- Relación composición-estructura-propiedades-comportamiento de compuestos

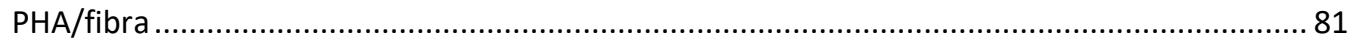

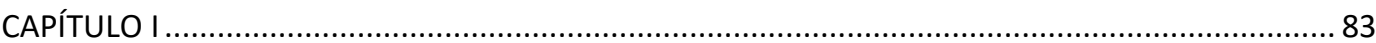

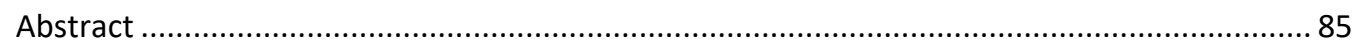

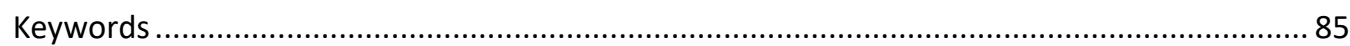

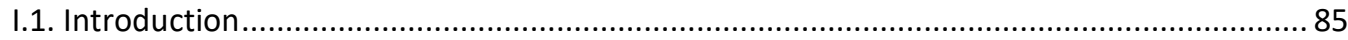

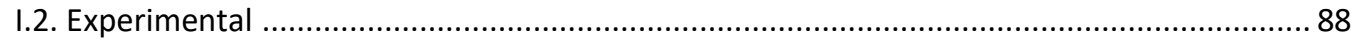

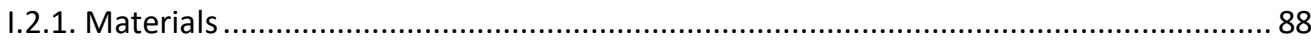

I.2.2. PHBV/cellulose composite preparation ............................................................. 88

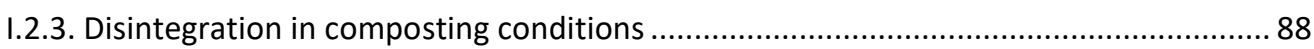

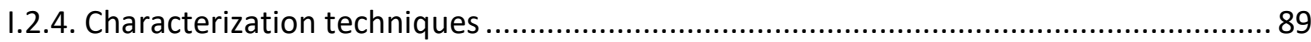

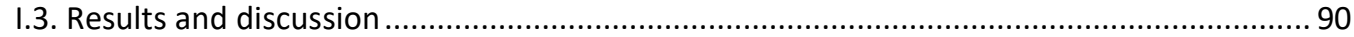

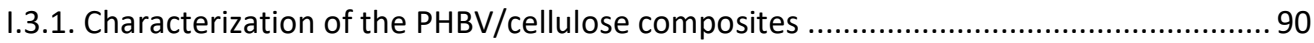

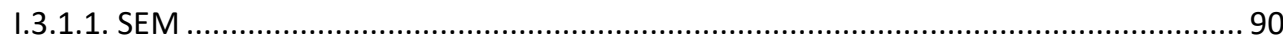

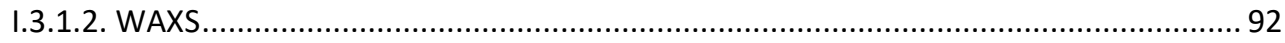

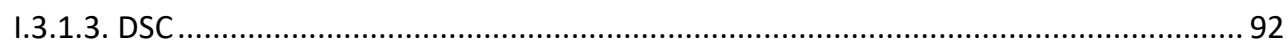

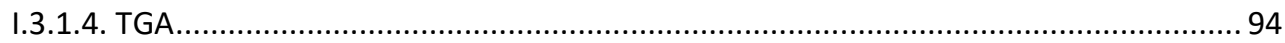

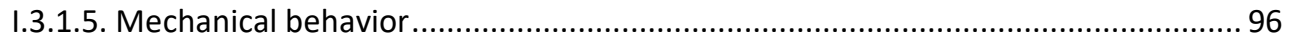




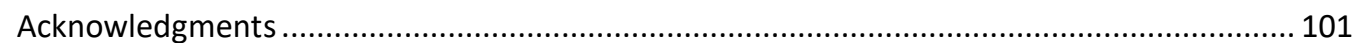

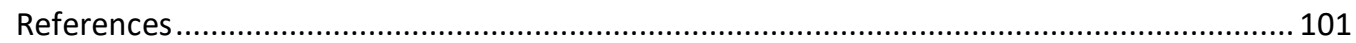

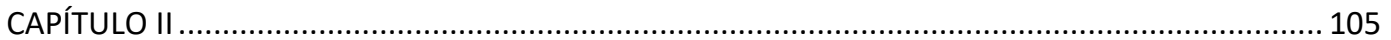

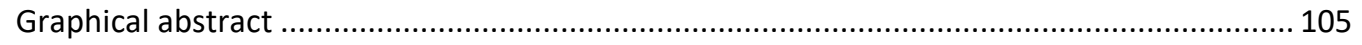

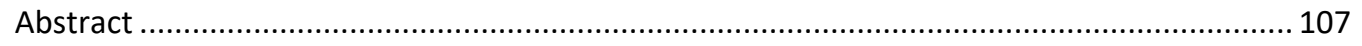

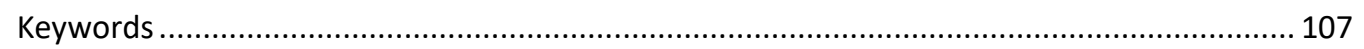

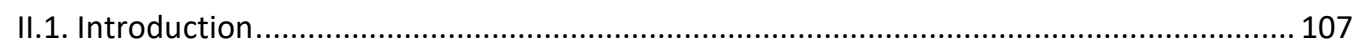

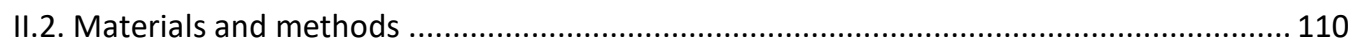

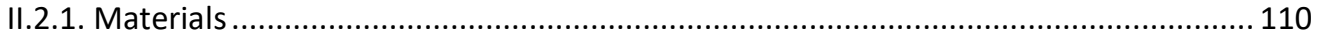

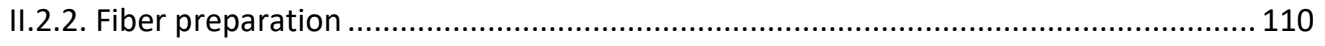

II.2.3. PHB/Fiber composites preparation............................................................... 112

II.2.4. Fiber and composites characterization ........................................................... 112

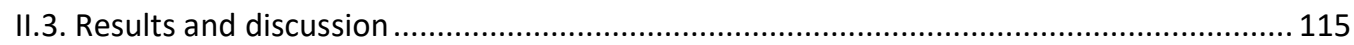

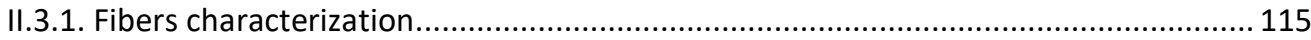

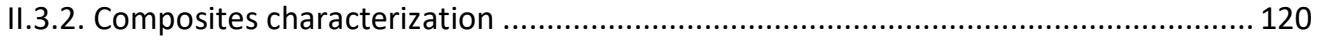

II.3.2.1. Scanning electron microscopy (SEM) ...................................................... 120

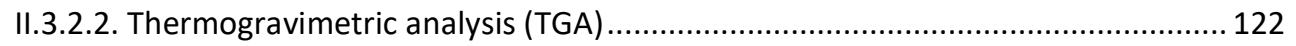

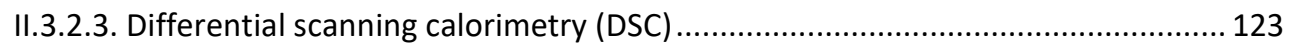

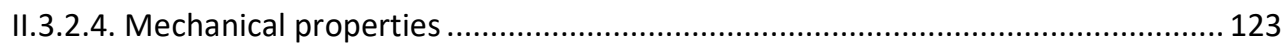

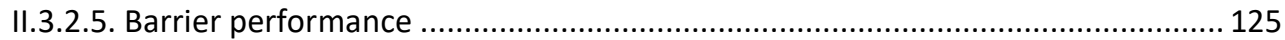

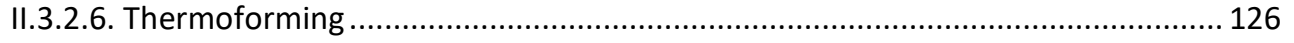

II.3.2.7. Disintegration in composting conditions ................................................. 127

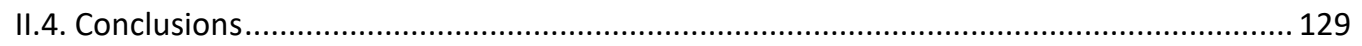

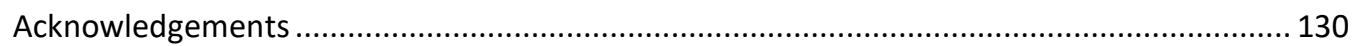

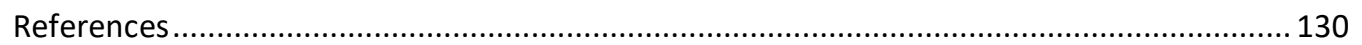




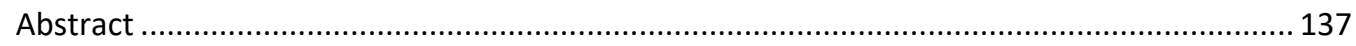

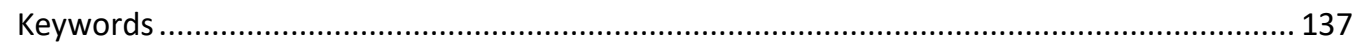

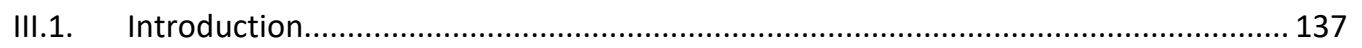

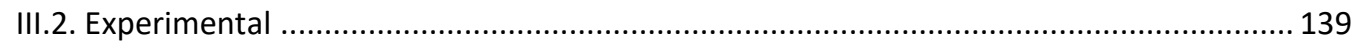

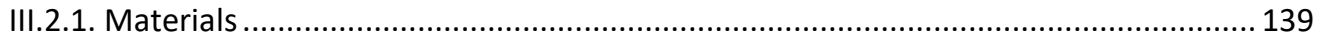

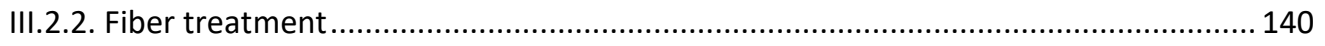

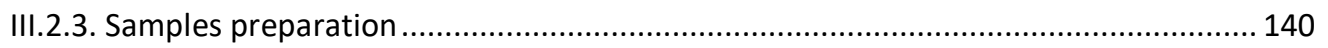

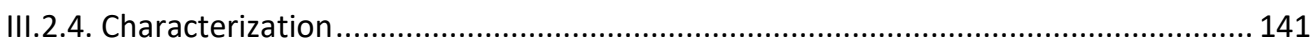

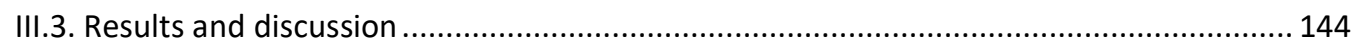

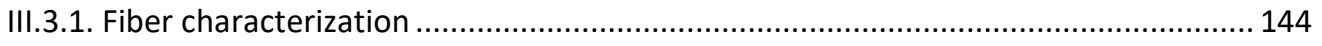

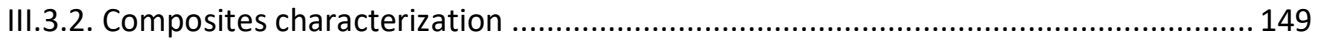

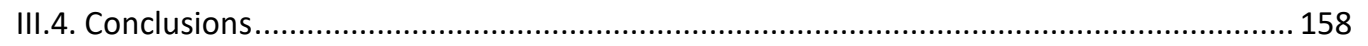

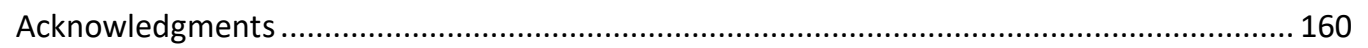

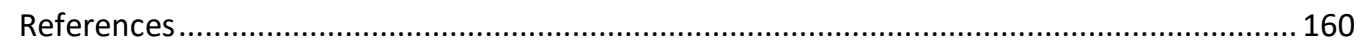

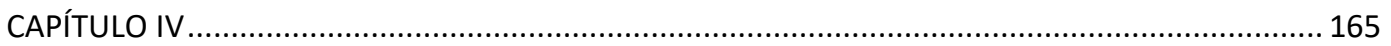

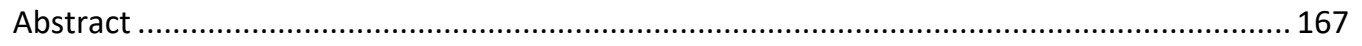

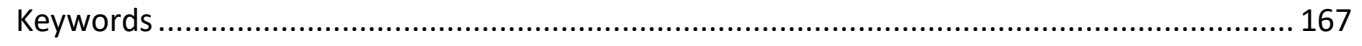

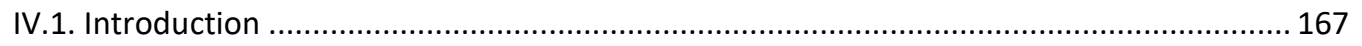

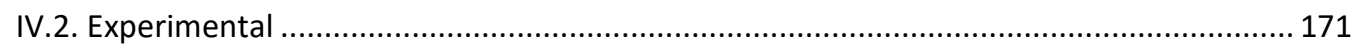

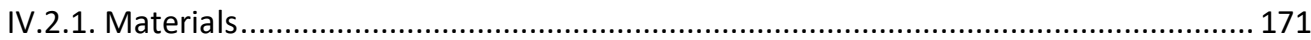

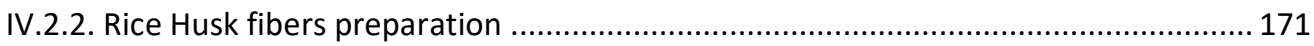

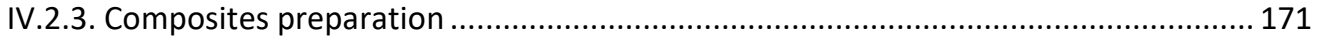

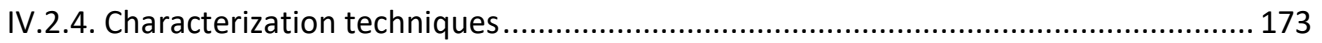

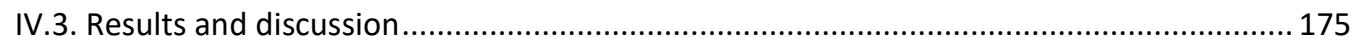

Influence of reactive agents in PHB/Cellulose composites................................................ 175

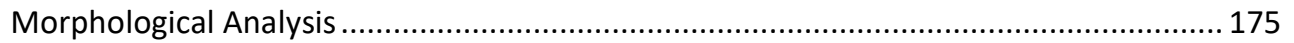




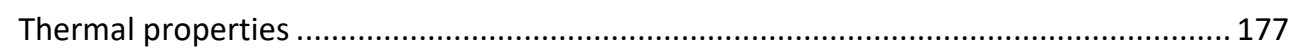

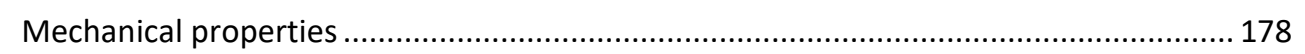

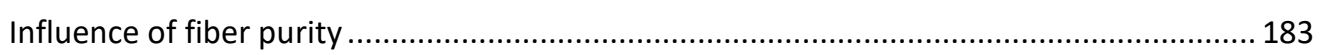

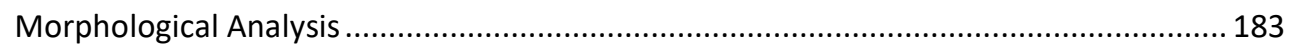

Mechanical properties ……………………………….............................................. 184

Thermoforming ability ............................................................................................. 186

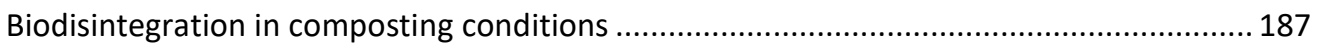

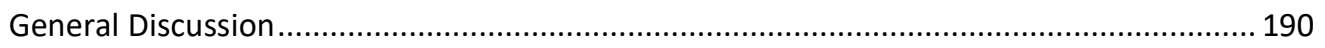

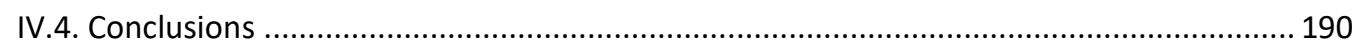

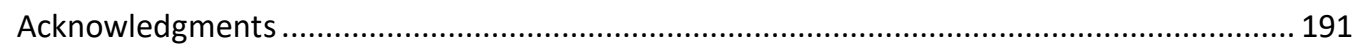

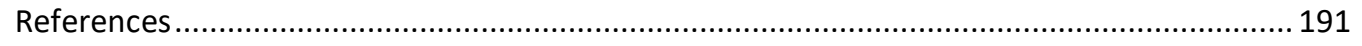

Bloque B.- Mejora de la aplicabilidad del PHBV para productos de pieza inyectada ................ 197

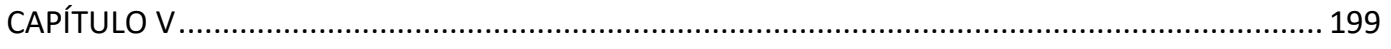

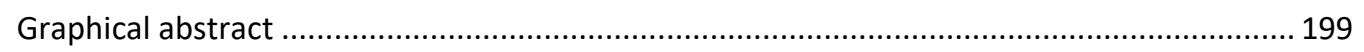

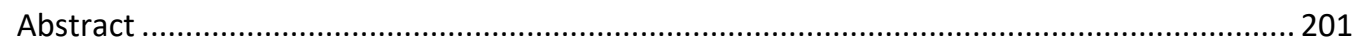

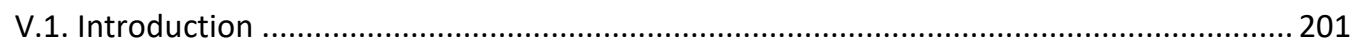

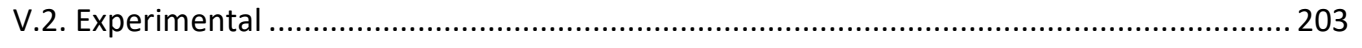

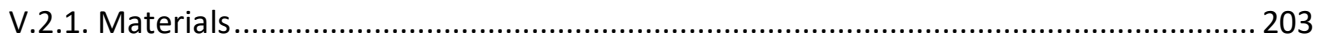

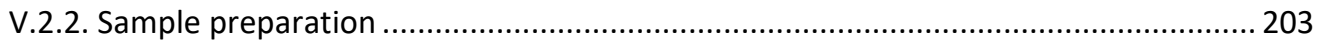

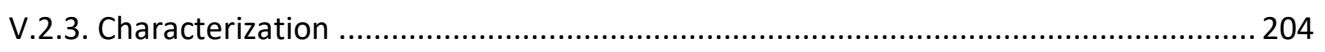

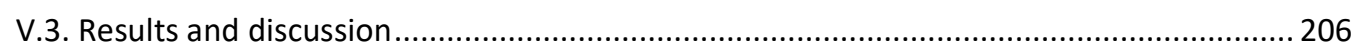

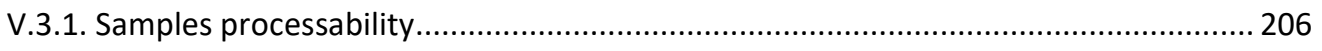

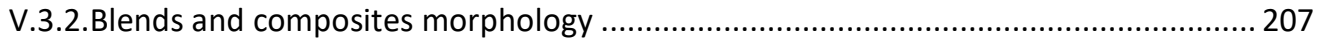

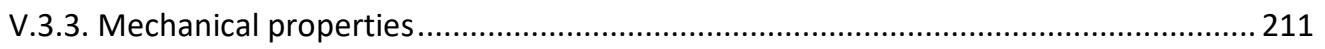

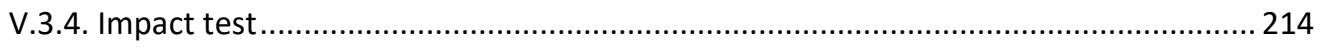

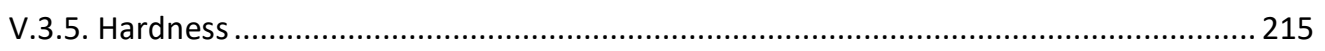

V.3.6. DSC 
V.3.7.TGA

V.3.8. HDT 219

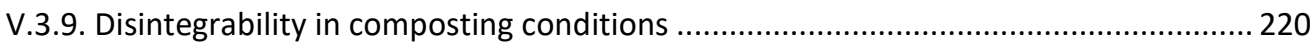

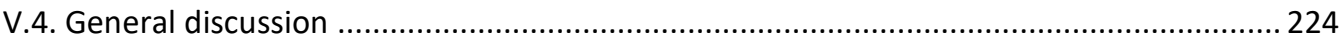

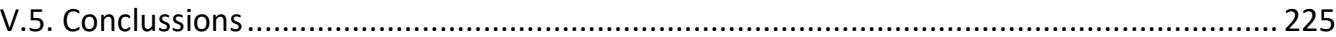

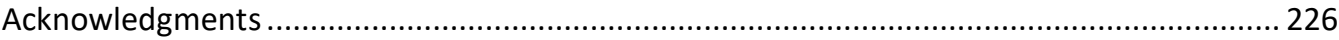

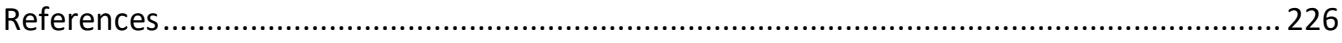

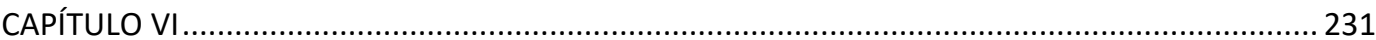

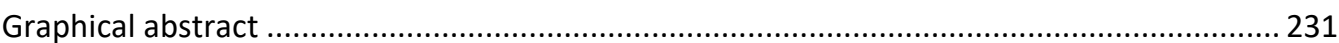

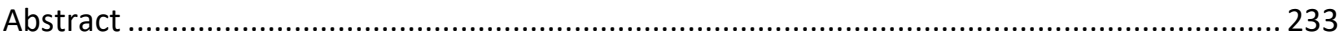

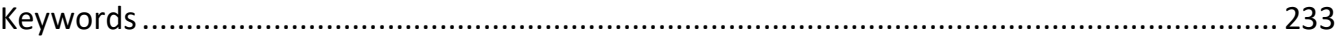

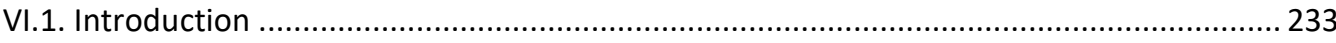

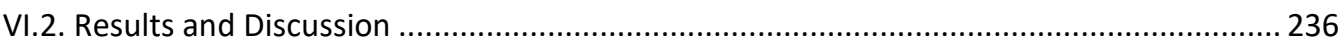

VI.2.1. Preparation of Compounds and Analysis of Their Processability ........................... 236

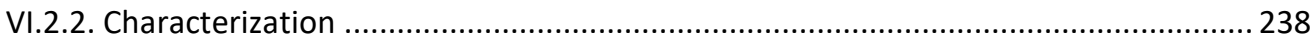

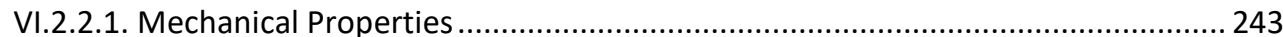

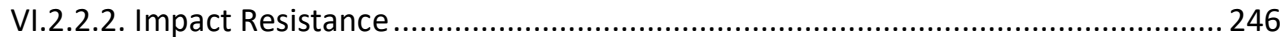

VI.2.2.3. Heat Deflection Temperature HDT-A......................................................... 249

VI.2.2.4. Biodisintegration in Composting Conditions .................................................. 251

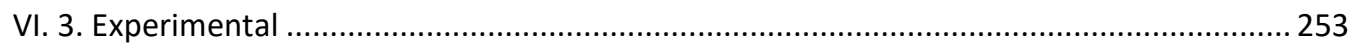

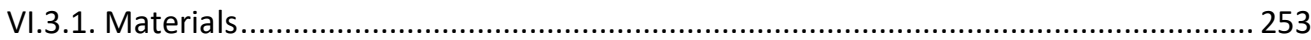

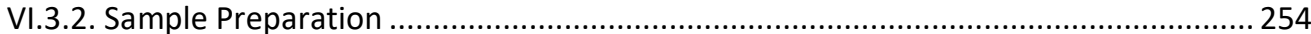

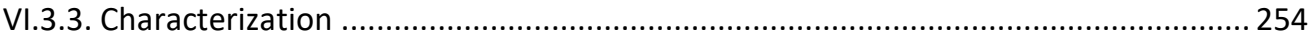

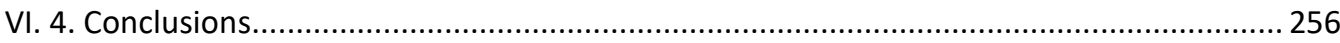

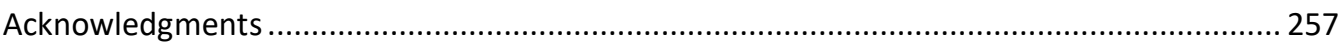

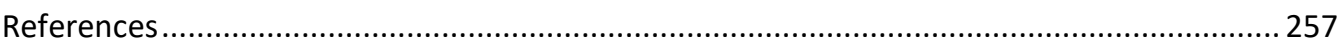

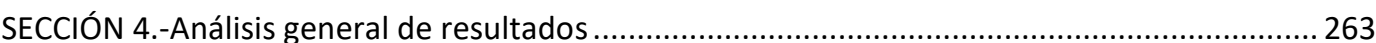


SECCIÓN 5.-Conclusiones y trabajos futuros

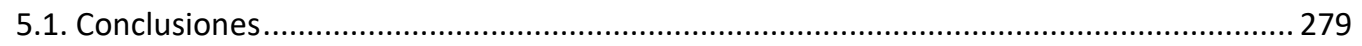

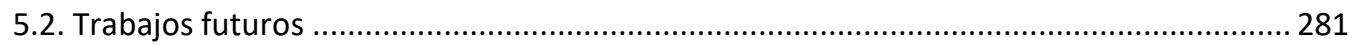

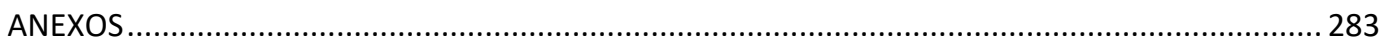

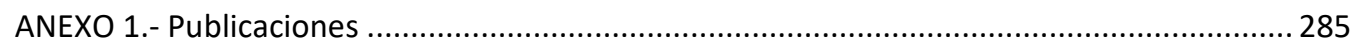

ANEXO 2.- Pimera página de las publicaciones de esta tesis ............................................ 289

ANEXO 3.- Lista de abreviaturas y símbolos ............................................................ 293

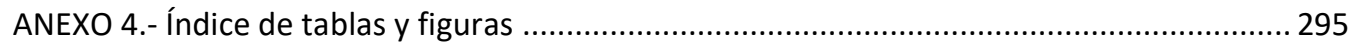

xxiii 

"Incluso la gente que afirma que no podemos hacer nada para cambiar nuestro destino, mira antes de cruzar la calle"

(Stephen Hawking)

\section{SECCIÓN 1.-Introducción}




\subsection{Antecedentes}

Desde mediados del siglo pasado la incorporación de los plásticos al mercado ha supuesto una indiscutible mejora del confort y la calidad de vida, estando presentes en prácticamente cualquier aspecto de nuestra vida cotidiana y también a nivel industrial. Su versatilidad y el impresionante desarrollo tecnológico de las últimas décadas, han propiciado su uso en un gran número de aplicaciones, convirtiéndolos en prácticamente imprescindibles. En efecto, la producción de plásticos se ha multiplicado por veinte desde 1960, llegando a alcanzarse una producción global de 335 millones de toneladas ( 50 millones de toneladas en la UE) en 2016 [1], y se espera que se duplique en los próximos 20 años [2]. En la Figura 1.1. se muestra la distribución de la demanda anual de plásticos en la Unión Europea por actividades económicas y tipo de plástico, así como la distribución de la generación de residuos de plástico y su gestión.

Demanda anual UE: $~ 50$ millones de toneladas
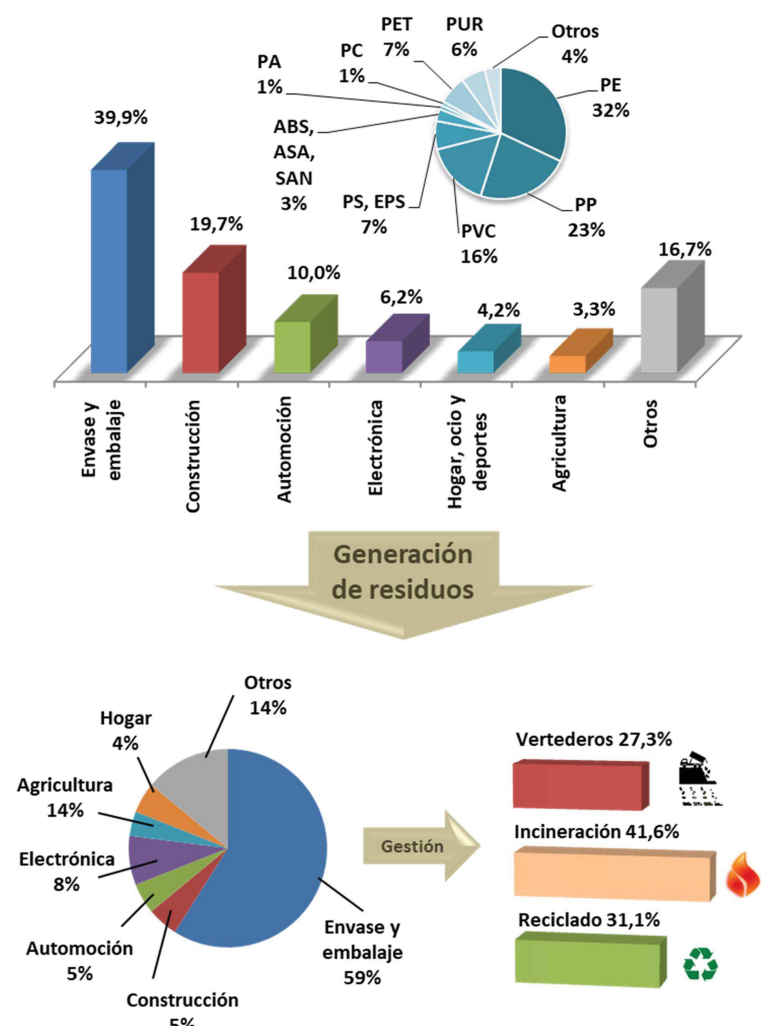

Figura 1.1. Situación actual de la demanda de plásticos y de la generación y tratamiento de los residuos asociados en la Unión Europea (Fuente: Plastics Europe [1,3]) 
Actualmente, de la demanda global de plásticos, aproximadamente el $90 \%$ corresponden a plásticos estándar, el $10 \%$ a plásticos técnicos y menos del $1 \%$ a plásticos de altas prestaciones [3].Como se aprecia en la Figura 1.1. el mercado actual de plásticos está dominado por los plásticos derivados del petróleo, siendo las poliolefinas las que representan el grupo mayoritario ( 55\%). El sector económico que mayor cantidad de plástico consume es el del envase y embalaje ( 40\%). En la Tabla 1.1 se recogen algunos ejemplos de productos fabricados con los principales plásticos convencionales en este sector.

Tabla 1.1. Ejemplos de aplicación de los plásticos convencionales más usados en el sector del envase

\begin{tabular}{|l|l|}
\hline $\begin{array}{l}\text { HDPE- Polietileno de alta } \\
\text { densidad }\end{array}$ & $\begin{array}{l}\text { Bolsas, botellas de leche, botellas de champú, recipientes } \\
\text { de detergentes ... }\end{array}$ \\
\hline $\begin{array}{l}\text { LDPE- Polietileno de baja } \\
\text { densidad }\end{array}$ & $\begin{array}{l}\text { Bolsas de congelado, bolsas de suero, tapas flexibles, } \\
\text { sacos... }\end{array}$ \\
\hline PP- Polipropileno & $\begin{array}{l}\text { Bandejas para microondas, envases de alimentos (yogur, } \\
\text { salsa de tomate, margarina...), vasos, tetinas, tapones, } \\
\text { cubiteras... }\end{array}$ \\
\hline PVC- Policloruro de vinilo & Recipientes de comida para llevar, botellas blísteres, ... \\
\hline PET- Tereftalato de polietileno & $\begin{array}{l}\text { Botellas de bebidas, envases de detergente, cosméticos y } \\
\text { medicamentos, bandejas para horno y microondas... }\end{array}$ \\
\hline PS- Poliestireno & $\begin{array}{l}\text { Envases de alimentos de espuma de poliestireno, } \\
\text { hueveras, tazas, platos y cubiertos desechables... }\end{array}$ \\
\hline
\end{tabular}

En la UE se generan anualmente $\sim 26$ millones de toneladas de residuos de plástico, aproximadamente el $60 \%$ de los cuales corresponde a envases. El $31.1 \%$ de los residuos se recogen para su reciclado, el 41,6\% para la incineración con recuperación de energía y el 27,3\% se depositan en vertederos [1] (Fig. 1.1.). Además, aunque no se conoce la cifra exacta de residuos plásticos que acaban en vertederos incontrolados o en la naturaleza, se estima que cada año entre 150000 y 500000 toneladas de plástico acaban en los océanos en Europa y entre 5 y 13 millones de toneladas a nivel mundial [4]. Otra alarma medioambiental emergente es el vertido al medioambiente de microplásticos. Los microplásticos son fragmentos de pequeño tamaño (presentes, por ejemplo, en productos como la pasta de dientes, cosméticos, pinturas, etc), que no solo suponen un alto riesgo para el entorno, sino también de salud pública ya que, además de acumularse en distintos ambientes amenazando los ecosistemas, pueden pasar a formar parte de la cadena alimenticia [5]. 
La disposición en vertederos es la opción más desfavorable para la gestión de residuos. En general, debido a su naturaleza química, los plásticos tradicionales derivados del petróleo no son biodegradables y/o tienen tasas de degradación en el ambiente muy bajas [6]. En el caso de las poliolefinas, su elevada hidrofobicidad limita la susceptibilidad enzimática, por lo que son altamente resistentes a la degradación microbiana [7]. Algunos materiales que alegan, de forma incorrecta, propiedades de biodegradabilidad, como el plástico "oxodegradable», se ha comprobado que lejos de ofrecer alguna ventaja medioambiental suponen un nuevo motivo de preocupación debido a su rápida fragmentación en trozos minúsculos [8].

La incineración controlada de residuos plásticos puede utilizarse para la recuperación enregética. No obstante, la combustión incontrolada, da lugar a elevadas emisiones de $\mathrm{CO}_{2}$ y $\mathrm{CO}$, así como de sustancias altamente nocivas y contaminantes. Por ejemplo, en el caso de plásticos que contienen halógenos como el PVC, o aditivos como retardantes de llama bromados, metales pesados, etc, pueden producirse emisiones de gases ácidos, contaminantes orgánicos persistentes como dioxinas, etc [9].

Se estima que en la producción de plásticos convencionales y la incineración de residuos plásticos cada año se emiten $\sim 400$ millones de toneladas de $\mathrm{CO}_{2}[10]$.

De las opciones de gestión de residuos actuales, el reciclado se podría considerar una de las más interesantes de cara al aprovechamiento de recursos. No obstante, la reutilización y el reciclado de plásticos siguen siendo muy bajos en comparación con otros materiales como el vidrio o el metal. Algunas de las principales limitaciones técnicas del reciclado de plásticos son la modificación de propiedades del material en el proceso, la dificultad para realizar una correcta separación de los residuos plásticos, la contaminación de los mismos o la presencia de aditivos $[9,11,12]$. El uso de plásticos reciclados está particularmente limitado en el sector del envase alimentario, ya que puede suponer un riesgo para la salud por la posibilidad de migración de sustancias no aptas para el contacto alimentario $[9,12]$.

Considerando el escenario actual del plástico, resulta evidente la necesidad de impulsar la implantación efectiva y el desarrollo e investigación de nuevas alternativas sostenibles a los plásticos convencionales, teniendo en cuenta la evaluación del impacto del ciclo de vida del producto (LCA, por sus siglas en inglés) desde su origen hasta el final de su vida útil y retirada. En este sentido, es posible actuar sobre tres aspectos fundamentales: a) el origen de las materias primas, b) la eficiencia y sostenibilidad de los procesos productivos y de transformación, y c) la adecuada gestión de los residuos generados. 
Los bioplásticos de base biológica, es decir, formulados a partir de polímeros procedentes de fuentes renovables, resultan de gran interés atendiendo a que su uso permite reducir la dependencia de los plásticos convencionales derivados del petróleo y, en consecuencia, la huella de carbono asociada a estos productos $[6,13]$.

Los polímeros procedentes de fuentes renovables comprenden un gran grupo de polímeros con estructuras químicas y tasas de biodegradación muy variadas. A este grupo pertenecen desde polímeros sintetizados por microorganismos como los polihidroxialcanoatos (PHA) o extraídos directamente de la biomasa como la celulosa, los obtenidos por síntesis química como el poliácido láctico (PLA), hasta polímeros similares a los convencionales pero sintetizados a partir de monómeros procedentes de fuentes renovables, como es el caso de las biopoliolefinas [14]. Esto ofrece la posibilidad de desarrollar un amplio rango de formulaciones plásticas con propiedades ajustables potencialmente capaces de cubrir prácticamente todo el espectro de aplicaciones dominado actualmente por los polímeros derivados del petróleo.

Los bioplásticos de base biológia y además biodegradables o compostables resultan especialmente interesantes desde dos puntos de vista. Por una parte, la biodegradabilidad es una propiedad deseable para aquellos productos que tengan un riesgo potencial de acabar en el medio ambiente. Por otra parte, los productos biodegradables resultan muy atractivos para aplicaciones de vida útil corta donde la biodegradabilidad resulte ventajosa, como es el caso, por ejemplo, del envase y embalaje o los productos de un solo uso como cubertería desechable, pajitas, etc [6]. Considerando que los residuos asociados a este sector representan la mayor fracción en la generación global de residuos, resulta de extrema importancia su adecuada gestión. Particularmente, en el caso del envase de alimentos, el uso de bioplásticos biodegradables permitiría desecharlos junto con los restos de comida como bioresiduo [15]..

En diciembre de 2015 la Comisión Europea adoptó un Plan de acción de la UE para la economía circular [16] en el que citaba a los plásticos como una prioridad clave. En mayo de 2018, Bruselas propuso un nuevo paquete de medidas entre las que se encuentra la prohibición de productos de plástico de un solo uso (vasos, cubiertos, pajitas) a partir de 2020 y su sustitución por materiales biodegradables [17]. Así, a nivel estatal, la Comisión de Medio Ambiente del Congreso ha acordado llevar a cabo las modificaciones legislativas necesarias para su prohibición a partir del 1 de enero de 2020 y ha propuesto que dichos productos se fabriquen con al menos un $50 \%$ de sustancias biodegradables a partir de 2020 y con un 60\% a partir de 2025 [18].

En este contexto, atendiendo a la jerarquía general para el tratamiento de residuos establecida en la Directiva Marco de Residuos [19]: a) prevención; b) preparación para la reutilización; c) 
reciclado; d) otro tipo de valorización, por ejemplo, la valorización energética; y e) eliminación. La comisión establece la jerarquía mostrada en la Figura 1.2. para el tratamiento de bioresiduos [20]:

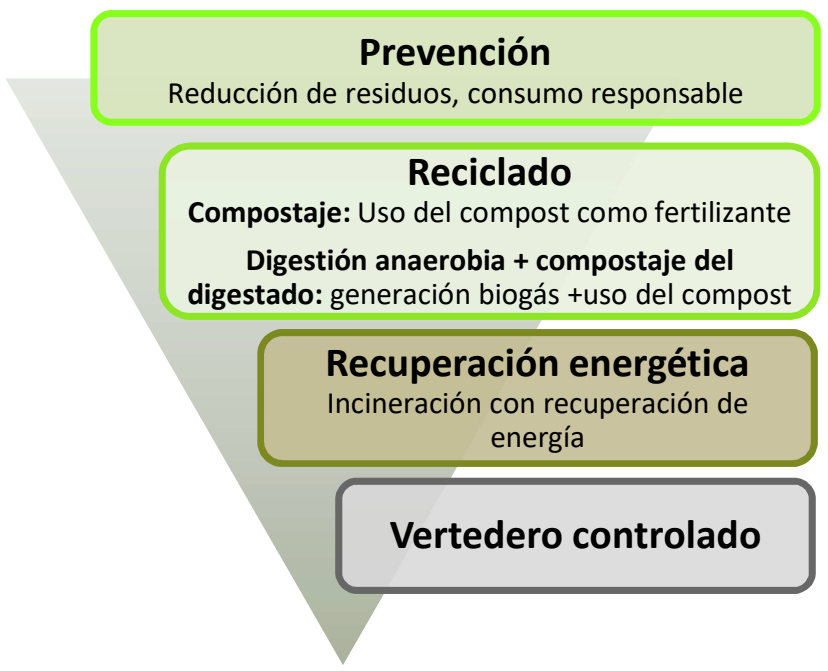

Figura 1.2. Jerarquía de gestión de bioresiduos

Bajo estas premisas, las opciones preferentes para la gestión de residuos de bioplásticos encaminadas a promover el desarrollo sostenible y la economía circular serían: el reciclado mecánico, en el caso de los bioplásticos de base biológica no biodegradables, o el reciclado biológico (compostaje), en el caso de los bioplásticos biodegradables. En la Figura 1.3. se muestran distintas opciones de economía circular de los bioplásticos.

Así pues, en consonancia con las iniciativas de desarrollo sostenible impulsadas por la Comisión Europea, los bioplásticos contribuirían a la creación de una nueva economía del plástico más sostenible, con pocas emisiones de carbono y eficiente en el uso de la energía y los recursos. Desafortunadamente, la incorporación de estos materiales al mercado es todavía incipiente y está limitada a aplicaciones muy concretas, representando una fracción muy baja de la demanda actual, $\sim 1 \%$ de la producción mundial [14,21]. No obstante, los bioplásticos se postulan como una de las soluciones más atractivas a la problemática ambiental y socioeconómica asociada a la industria del plástico y, resulta lógico pensar, que se convertirán en la realidad futura de este mercado. 


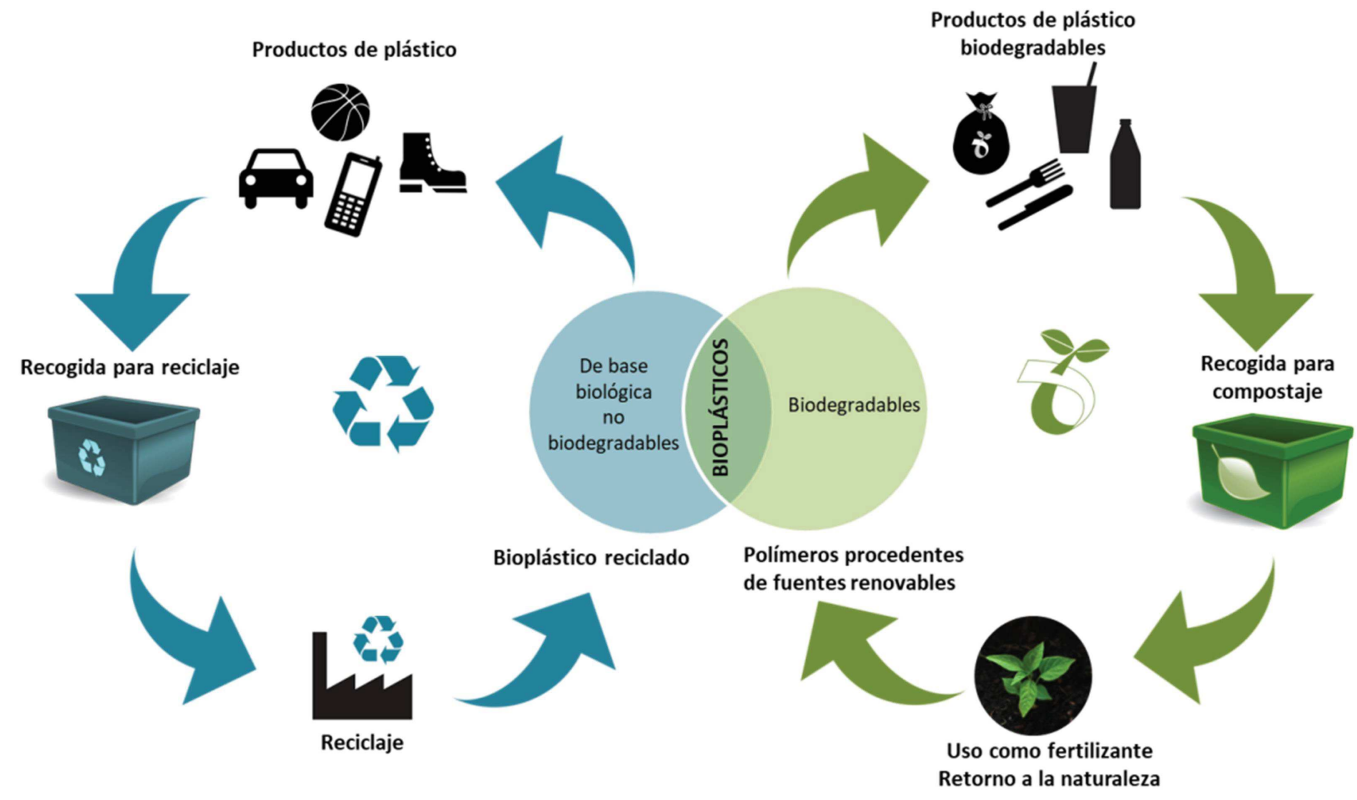

Figura 1.3. Opciones de economía circular de bioplásticos

\subsection{Planteamiento del problema}

Tal como se ha planteado anteriormente, para el desarrollo de productos en los que la biodegradabilidad es un requisito deseable (p.ej envase, productos desechables, etc), los biopolímeros de base biológica y biodegradables se postulan como potenciales sustitutos de los plásticos convencionales [14,22]. De entre los distintos biopolímeros, los polihidroxialcanoatos (PHA), una familia de biopoliésteres de origen bacteriano, y más concretamente el polihidroxibutirato (PHB) y el copolímero poli(hidroxibutirato-co-hidroxivalerato) (PHBV), han despertado un gran interés en las últimas décadas [23-25]. Las principales razones que hacen a estos biopólimeros particularmente interesantes para este tipo de aplicaciones son, por supuesto, su origen natural, ausencia de toxicidad, su biodegradabilidad en diferentes ambientes incluido el marino, su compostabilidad tanto a escala de laboratorio como industrial, así como en compostaje doméstico y propiedades comparables a algunos de los polímeros tradicionales [2629]. Son biopoliésteres termoplásticos que pueden ser procesados mediante técnicas convencionales. El PHB y PHBV (de bajo contenido en valerato) poseen unas propiedades mecánicas comparables al PP en términos de rigidez y resistencia mecánica [30]. Presentan 
buena resistencia térmica (elevada temperatura de deflexión al calor, HDT) [31]. Son polímeros semicristalinos con un elevado índice de cristalinidad lo que les proporciona unas buenas propiedades barrera, comparables e incluso superiores al PET [32]. Sin embargo, presentan ciertas limitaciones que dificultan su aplicabilidad industrial, entre las que cabe destacar:

- $\quad$ Elevado coste de producción en comparación con otros poliésteres biodegradables como, por ejemplo, el poli ácido láctico (PLA) [25,33].

- Baja tenacidad: baja ductilidad (deformación a rotura $<5 \%$ y baja resistencia al impacto) $[25,34,35]$

- Dificultad de procesado: baja estabilidad térmica en fundido y estrecha ventana de procesado [36,37].

- $\quad$ Fragilización por cristalización secundaria y envejecimiento físico de la fase amorfa $[38,39]$.

Con el fin de contrarrestar una de las principales limitaciones, como es la de su todavía elevado coste de producción, la adición de una segunda fase de bajo coste que no comprometa o que incluso contribuya a mejorar las propiedades de estos polímeros resulta ser una de las soluciones más convenientes [40]. En este sentido, las fibras naturales de origen vegetal (o lignocelulósicas) ofrecen numerosas ventajas. Son muy abundantes en la naturaleza y pueden obtenerse a partir de residuos (agrícolas, industria agro-alimentaria, limpieza de montes o playas), por lo que tienen un muy bajo coste y su uso permite la valorización de un residuo contribuyendo a la economía circular. Aunque sus propiedades dependen de su origen (fuente vegetal), en general, poseen baja densidad, elevada rigidez y resistencia específicas, por lo que resultan muy adecuadas como material de refuerzo [41,42]. No obstante, se trata de materiales muy hidrófilos por lo que, generalmente, su compatibilidad con la matriz polimérica hidrófoba es baja. Por este motivo, la adhesión interfacial fibra-matriz resulta un factor clave en las propiedades finales del compuesto [43].

En este contexto, este trabajo se centra en el desarrollo de compuestos PHA/Fibra que sean biodesintegrables en condiciones de compostaje y procesables mediante técnicas convencionales encaminados a aplicaciones de corta vida útil prestando especial atención a la relación composición-estructura-propiedades y a aquellos factores que limitan su aplicabilidad. 


\subsection{Objetivos de la investigación}

El objetivo principal de esta tesis es el desarrollo, caracterización y optimización de propiedades de compuestos basados en polihidroxialcanoatos (PHA) y fibras de origen lignocelulósico para la obtención de materiales compostables de coste reducido dirigidos a aplicaciones de corta vida útil, como el envasado o la elaboración de productos desechables.

Con el fin de alcanzar la consecución de dicho objetivo, se plantean los siguientes objetivos específicos:

- Desarrollo y caracterización de compuestos basados en poli (hidroxibutirato-cohidroxivalerato) (PHBV) y fibras de celulosa de alta pureza (TC90)

- Estudio de la influencia del contenido de fibra sobre la morfología, las propiedades mecánicas y térmicas y la biodesintegración en condiciones de compostaje de los compuestos desarrollados (Capítulo I).

- Estudio de la valorización de distintos residuos de origen vegetal (cáscara de almendra (AS), cáscara de arroz (RH) y residuos de Posidonia Oceanica (SG)) como materiales de refuerzo en compuestos basados en polihydroxibutirato (PHB)

- Estudio del efecto del tratamiento de purificación de fibras procedentes de residuos vegetales (AS, $\mathrm{RH}$ ) sobre la composición, las características morfológicas y la estabilidad térmica de las fibras (Capítulos II y III).

- Análisis de la influencia del tipo, morfología, naturaleza y contenido de fibra sobre la morfología, comportamiento mecánico, comportamiento térmico, propiedades barrera, biodesintegración en compostaje y termoconformabilidad de los compuestos desarrollados (Capítulo II).

- Evaluación de la influencia de la pureza de la fibra sobre el comportamiento mecánico y térmico de los compuestos desarrollados ( Capítulo III).

- Estudio de la compatibilización de compuestos PHB/fibra mediante agentes de extrusión reactiva: peróxido de dicumilo (DCP), diisocianato de hexametileno (HMDI), éter diglicidílico de resorcinol (RDGE) e isocianurato de triglicidilo (TGIC).

- Influencia del tipo de agente reactivo sobre la adhesión interfacial fibra-matriz (Capítulo IV).

- Influencia de la pureza de la fibra sobre la efectividad del agente reactivo (HMDI) (Capítulo IV).

- Influencia de la adición de los agentes reactivos sobre la biodesintegrabilidad en condiciones de compostaje (Capítulo IV). 
- Efecto del envejecimiento en compuestos PHB/fibra

- Influencia de la fibra y los agentes reactivos sobre el comportamiento mecánico y la cristalinidad (Capítulos III y IV).

- Mejora de la tenacidad de compuestos PHBV/celulosa obtenidos mediante extrusión e inyección a escala de procesado semi-industrial

- Efecto de la adición de un modificador de impacto (poliuretano termoplástico, TPU) sobre la procesabilidad, la morfología, el comportamiento mecánico y el comportamiento térmico, así como la biodesintegración en condiciones de compostaje de los compuestos desarrollados (Capítulo V).

- Compatibilización de sistemas ternarios PHBV/TPU/Celulosa mediante agentes reactivos: diisocianato de hexametileno (HMDI), oligómero de estireno-acrilato funcionalizado con grupos epóxido (Joncryl ${ }^{\circledR}$ ADR-4368) e isocianurato de triglicidilo (TGIC) (Capítulo VI).

\subsection{Planificación de la investigación}

Esta investigación se ha dividido en dos bloques principales:

En un primer bloque (Capítulos I-IV) se ha estudiado la relación composición-estructurapropiedades-comportamiento de compuestos $\mathrm{PHA} /$ fibra considerando algunos aspectos fundamentales para su aplicabilidad en la industria del envasado, como son su comportamiento mecánico y térmico, sus propiedades barrera, su biodesintegrabilidad en condiciones de compostaje, su termoconformabilidad y el efecto del envejecimiento sobre su comportamiento mecánico. Dado que uno de los factores clave para explotar el potencial de los compuestos polímero/fibra es la adhesión interfacial de las fases, se ha prestado una especial atención a la mejora de la interacción fibra-matriz, evaluando aspectos como la influencia del tipo y pureza de las fibras y el uso de agentes de compatibilización.

Como resinas se han empleado PHB y PHBV y como fibras, celulosa comercial de alta pureza y fibras procedentes de residuos vegetales. Las fibras procedentes de residuos empleadas en estas composiciones han sido: cáscara de almendra ( $\mathrm{AS})$, cáscara de arroz $(\mathrm{RH})$ y residuos procedentes de la limpieza de playas, compuestos principalmente de Posidonia Oceanica (SG). Las fibras han sido utilizadas sin ningún tratamiento previo (exceptuando operaciones de secado y reducción de tamaño), o bien, sometidas a dos tratamientos distintos de purificación dirigidos a eliminar las impurezas y los componentes no celulósicos de la fibra. El primero de ellos, T1, (Capítulo II) ha consistido en un tratamiento combinado con hidróxido de sodio y peróxido de hidrogeno; el 
segundo ha sido un tratamiento combinado con hidróxido de sodio y ácido peracético, T2 (Capítulo III).

En una primera aproximación los materiales han sido obtenidos mediante mezclado en fundido en un mezclador interno (Capítulos I y II) y, con fines de escalabilidad, posteriormente se ha empleado la extrusión doble husillo por tratarse de una técnica de compounding más eficiente y mucho más extendida en la industria (Capítulos III y IV).

La metodología seguida en cada uno de los trabajos de este bloque se esquematiza en la Figura 1.4.

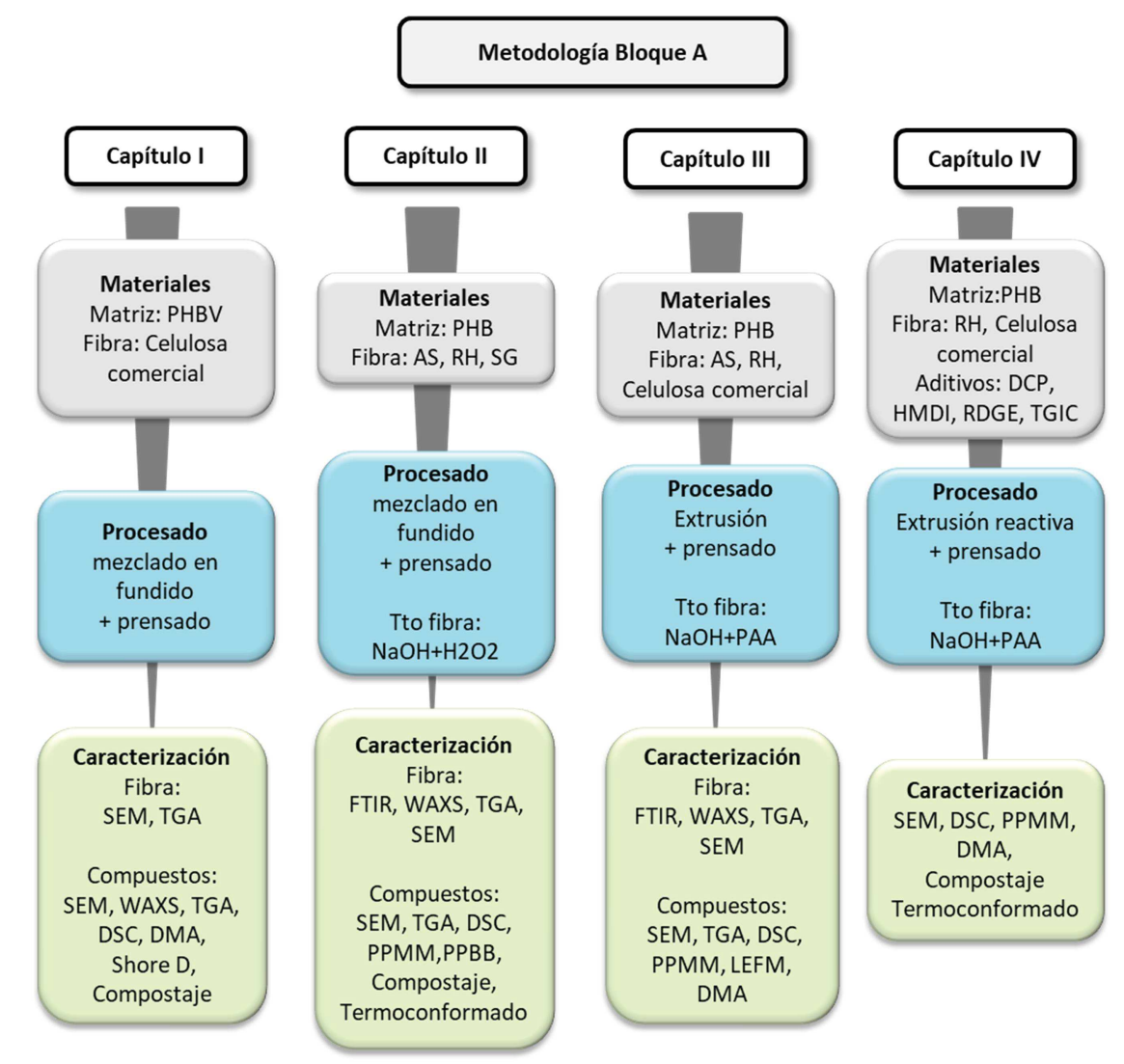

Figura 1.4. Metodología seguida en los Capítulos I-IV (la nomenclatura abreviada utilizada en esta figura se puede consultar en la lista de abreviaturas y símbolos) 
En el segundo bloque (Capítulos $\mathbf{V}-\mathbf{V I}$ ), bajo un enfoque mucho más industrial, se han desarrollado compuestos triples mediante la adición de celulosa y de un modificador de impacto, poliuretano termoplástico (TPU) dirigidos a aplicaciones de pieza inyectada. En este caso, se ha prestado un especial interés a la mejora de la tenacidad de estos compuestos (PHBV/TPU/Celulosa) sin comprometer su biodesintegrabilidad en condiciones de compostaje, buscando un balance de rigidez-resistencia térmica-tenacidad apropiado para este tipo de aplicaciones. Asimismo, se ha estudiado la compatibilización de las fases mediante la adición de agentes reactivos: diisocianato de hexametileno (HMDI), oligómero de estireno-acrilato funcionalizado con grupos epóxido (Joncryl ${ }^{\circledR}$ ADR-4368) e isocianurato de triglicidilo (TGIC). En este caso todos los materiales empleados han sido de origen comercial y el procesado (extrusión doble husillo y moldeo por inyección) se ha llevado a cabo en equipamiento semi-industrial. La metodología seguida en estos trabajos se resume en el esquema de la Figura 1.5. 
Metodología Bloque B
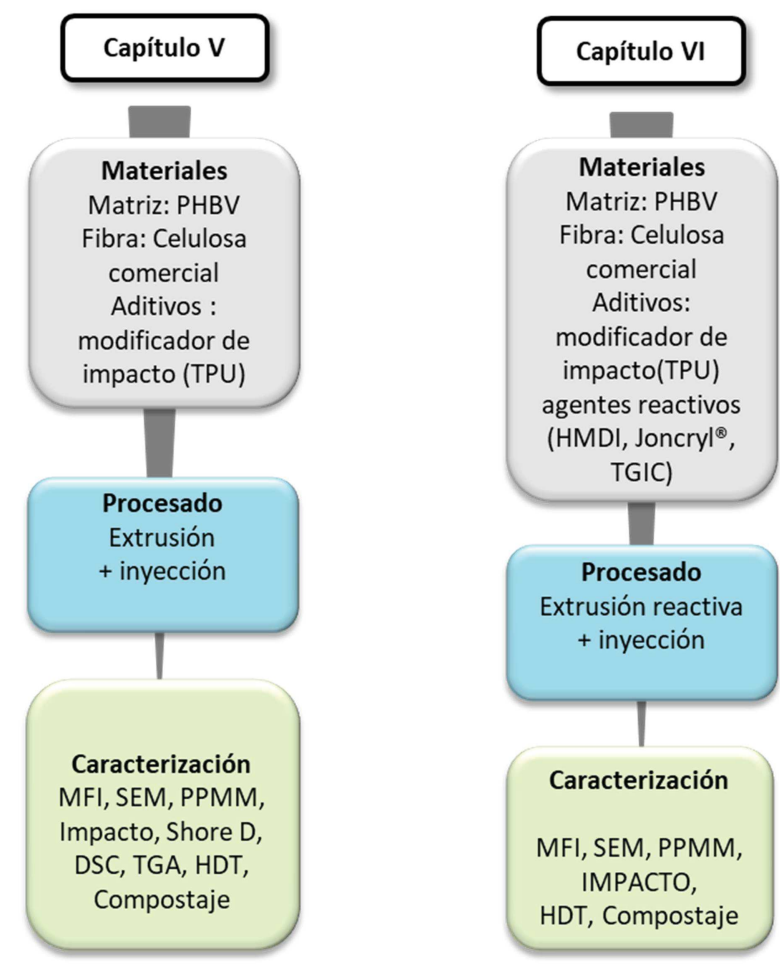

Figura 1.5. Metodología seguida en los Capítulos V y VI (la nomenclatura abreviada utilizada en esta figura se puede consultar en la lista de abreviaturas y símbolos)

\subsection{Justificación de la investigación}

Como se ha planteado, existe una necesidad socioeconómica y medioambiental real de transformación del mercado actual del plástico dirigida a crear una economía del plástico más sostenible, respetuosa con el medio ambiente y que haga un uso eficiente de los recursos. Esta necesidad se pone de manifiesto en los distintos planes de acción propuestos por la UE [16] y en los retos sociales del programa de investigación, desarrollo e innovación Horizonte 2020 [44]. Para lograr dicha transformación es necesario aunar esfuerzos por parte de las instituciones públicas, la comunidad científica, el sector industrial y la sociedad en general.

Las expectativas de futuro de los bioplásticos basados en polihidroxialcanoatos como posibles sustitutos de los plásticos convencionales en determinadas aplicaciones (p.ej. envase o productos 
desechables) son muy prometedoras. Estos biopolímeros han recibido un especial interés por parte de la comunidad científica y buena prueba de ello es el elevado y creciente número de publicaciones científicas relacionadas en las últimas décadas (Figura 1.6.a). Asimismo, el desarrollo de compuestos basados en fibras naturales de origen vegetal es también un tema de especial interés y actualidad (Figura 1.6.b).

Sin embargo, como ya se ha mencionado en el apartado 1.2., siguen existiendo importantes retos para conseguir que estos materiales sean plenamente competitivos tanto desde el punto de vista económico como técnico. Aunque se han realizado grandes avances en lo referente a un mayor conocimiento de la estructura y propiedades físico químicas de estos biopolímeros siguen existiendo carencias, sobre todo, en su comportamiento en servicio o en el procesado a escala industrial. Es importante destacar que muchos de los trabajos que se pueden encontrar en la bibliografía utilizan técnicas de procesado a escala de laboratorio o materiales no disponibles comercialmente o de elevado coste, por lo que los resultados no son claramente escalables.

Este trabajo contribuye a ampliar el conocimiento en el desarrollo de compuestos basados en PHA y fibras lignocelulósicas. Para garantizar que los resultados de esta investigación sean susceptibles de ser trasladados a aplicaciones industriales se emplean técnicas de mezclado en fundido convencionales y todos los materiales (resinas y aditivos) están disponibles a nivel comercial. En el caso de las fibras lignocelulósicas procedentes de residuos, estas se han seleccionado teniendo en cuenta la proximidad geográfica y el volumen generado para garantizar el suministro y contribuir a la economía circular, siempre bajo el enfoque de la posibilidad de transferencia de los resultados a la industria a corto plazo. 
Documents by year

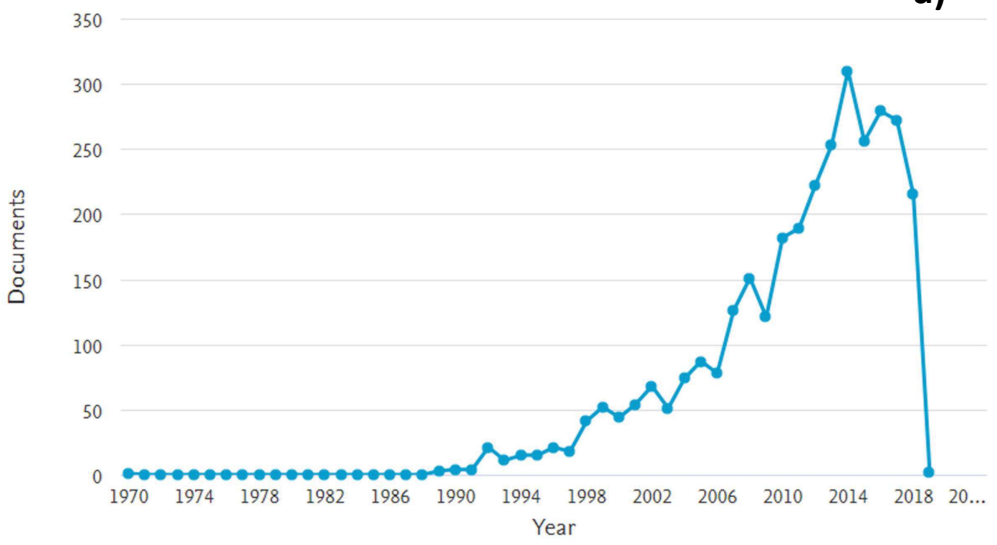

Documents by year

b)

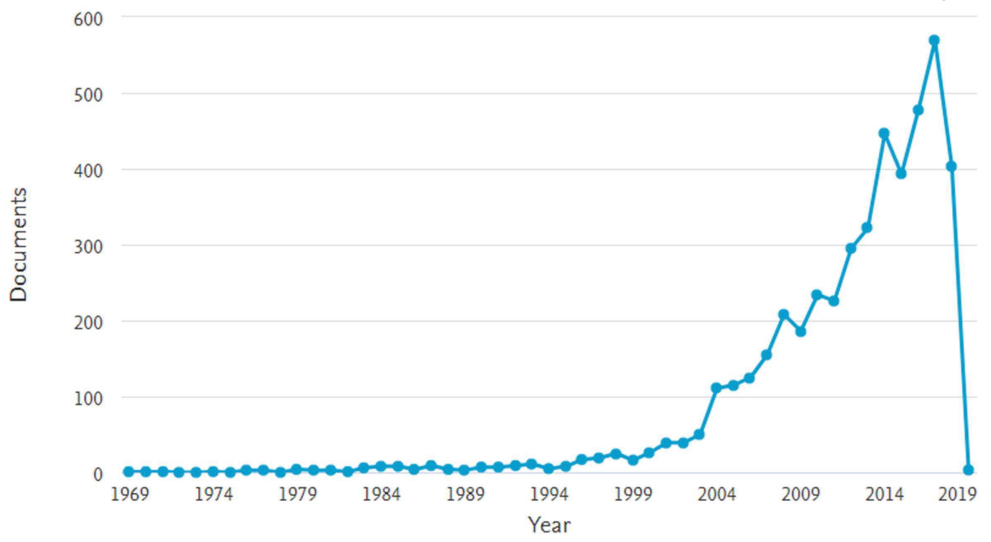

Figura 1.6. Publicaciones relacionadas con polihidroxialcanoatos (a) y con compuestos de matriz polimérica basados en fibras vegetales (b) (fuente:Scopus [45])

Por tanto, esta investigación resulta especialmente relevante:

- Desde el punto de vista científico y tecnológico, contribuyendo a ampliar el conocimiento en el campo de los materiales compuestos en base PHA/fibras lignocelulósicas y la difusión de los resultados derivados de la misma mediante publicaciones en revistas científicas y comunicaciones en congresos. Asimismo, se ha procedido a la solicitud de una patente a partir de los resultados obtenidos en la línea de investigación dentro de la que se encuadra este trabajo de tesis. 
- Desde el punto de vista socioeconómico y medioambiental, contribuyendo al desarrollo de productos respetuosos con el medio ambiente y fácilmente transferibles a la industria y que promueven el desarrollo sostenible y la economía circular. En efecto, las colaboraciones con Empresas ubicadas en la Comunidad Valenciana (CV) facilitan la transferencia del conocimiento generado directamente al tejido industrial de la CV.

Como ya ha sido mencionado, recientemente se han puesto en marcha directrices tanto a nivel autonómico y estatal, como europeo para la prohibición de plásticos de un solo uso (platos, vasos, cubiertos, pajitas) a partir de 2020 [17],[18]. El texto presentado en el congreso de los diputados plantea que dichos productos se fabriquen con al menos un $50 \%$ de sustancias biodegradables a partir de 2020 y con un 60\% a partir de 2025 [18]. Actualmente todavía no existen composiciones en el mercado que permitan reemplazar a los plásticos convencionales en el $100 \%$ de las aplicaciones afectadas por estas normativas. Por lo que los materiales desarrollados en esta investigación se presentan como una solución potencialmente viable como alternativa a los productos actuales.

Además, resulta particularmente importante destacar que la Comunidad Valenciana (CV) es un destino turístico de gran relevancia, por lo que el uso de envases no biodegradables y artículos de un solo uso durante la temporada de verano es una complicación importante en la gestión de residuos y en el impacto ambiental que produce la actividad turística. Por lo tanto, el desarrollo de materiales biodegradables que puedan usarse en estos sectores contribuiría a un menor impacto ambiental de la actividad humana en los periodos vacacionales, aumentando la calidad del sector turístico.

\section{Referencias}

[1] Plastics Europe-Association of Plastics Manufacturers. Plastics-the Facts 2017: Analysis of European plastics production, demand and waste data., (n.d.). http://www.plasticseurope.org/en/resources/publications/plastics-facts-2017.

[2] European Commission, COM/2018/028 final, COMMUNICATION FROM THE COMMISSION TO THE EUROPEAN PARLIAMENT, THE COUNCIL, THE EUROPEAN ECONOMIC AND SOCIAL COMMITTEE AND THE COMMITTEE OF THE REGIONS, A European Strategy for Plastics in a Circular Economy, (n.d.). http://eur-lex.europa.eu/legal-content/EN/TXT/?qid=1516265440535\&uri=COM:2018:28:FIN.

[3] Plastics Europe Market Research Group (PEMRG) / ConsulticMarketing \& Industrieberatung GmbH World, Plastics Production 2006 -2015, (n.d.). www. plasticseurope.org.

[4] J.R. Jambeck, R. Geyer, C. Wilcox, T.R. Siegler, M. Perryman, A. Andrady, R. Narayan, K.L. Law, Plastic waste inputs from land into the ocean, Science (80-. ). 347 (2015) 768-771. doi:10.1126/science.1260352. 
[5] J.L. Conkle, C.D. Báez Del Valle, J.W. Turner, Are We Underestimating Microplastic Contamination in Aquatic Environments?, Environ. Manage. 61 (2018) 1-8. doi:10.1007/s00267-017-0947-8.

[6] S. Lambert, M. Wagner, Environmental performance of bio-based and biodegradable plastics: The road ahead, 46 (2017) 6855-6871. doi:10.1039/c7cs00149e.

[7] J. Arutchelvi, M. Sudhakar, A. Arkatkar, M. Doble, S. Bhaduri, P.V. Uppara, Biodegradation of polyethylene and polypropylene, Indian J. Biotechnol. 7 (2008) 9-22.

[8] N.L. Thomas, J. Clarke, A.R. McLauchlin, S.G. Patrick, Oxodegradable plastics: degradation, environmental impact and recycling, Proc. Inst. Civ. Eng. - Waste Resour. Manag. 165 (2012) 133140. doi:10.1680/warm.11.00014.

[9] J.N. Hahladakis, C.A. Velis, R. Weber, E. lacovidou, P. Purnell, An overview of chemical additives present in plastics: Migration, release, fate and environmental impact during their use, disposal and recycling, J. Hazard. Mater. 344 (2018) 179-199. doi:10.1016/j.jhazmat.2017.10.014.

[10] International Burn Injury Database - IBID, (n.d.). https://www.ibidb.org/ (accessed February 8, 2018).

[11] N. Malik, P. Kumar, S. Shrivastava, S.B. Ghosh, An overview on PET waste recycling for application in packaging, Int. J. Plast. Technol. 21 (2017) 1-24. doi:10.1007/s12588-016-9164-1.

[12] S. Palkopoulou, C. Joly, A. Feigenbaum, C.D. Papaspyrides, P. Dole, Critical review on challenge tests to demonstrate decontamination of polyolefins intended for food contact applications, Trends Food Sci. Technol. 49 (2016) 110-120. doi:10.1016/j.tifs.2015.12.003.

[13] T.A. Hottle, M.M. Bilec, A.E. Landis, Sustainability assessments of bio-based polymers, Polym. Degrad. Stab. 98 (2013) 1898-1907. doi:10.1016/j.polymdegradstab.2013.06.016.

[14] M. Rujnić-Sokele, A. Pilipović, Challenges and opportunities of biodegradable plastics: A mini review, Waste Manag. Res. 35 (2017) 132-140. doi:10.1177/0734242X16683272.

[15] M.N.S. Kumar, Z. Yaakob, Siddaramaiah, Biobased Materials in Food Packaging Applications, in: Handb. Bioplastics Biocomposites Eng. Appl., John Wiley \& Sons, Inc., Hoboken, NJ, USA, 2011: pp. 121-159. doi:10.1002/9781118203699.ch5.

[16] European Commission, COM/2015/614, COMMUNICATION FROM THE COMMISSION TO THE EUROPEAN PARLIAMENT, THE COUNCIL, THE EUROPEAN ECONOMIC AND SOCIAL COMMITTEE AND THE COMMITTEE OF THE REGIONS, Closing the loop -An EU action plan for the Circular Economy Closing the loop - An EU act, (n.d.). https://ec.europa.eu/transparency/regdoc/rep/1/2015/EN/12015-614-EN-F1-1.PDF (accessed February 8, 2018).

[17] E. Press, Bruselas propone prohibir los platos, cubiertos, bastoncillos y pajitas para beber de plástico, (n.d.). http://www.europapress.es/sociedad/medio-ambiente-00647/noticia-bruselaspropone-prohibir-platos-cubiertos-bastoncillos-pajitas-beber-plastico-20180528123950.html (accessed September 10, 2018).

[18] El Congreso decide prohibir los utensilios de plástico de un solo uso en 2020, (n.d.). https://www.efe.com/efe/espana/portada/el-congreso-decide-prohibir-los-utensilios-de-plasticoun-solo-uso-en-2020/10010-3579458 (accessed September 10, 2018).

[19] European Commission. Waste Framework Directive (2008/98/EC), (n.d.). http://ec.europa.eu/environment/waste/framework/framework_directive.htm.

[20] European Commission, Supporting Environmentally Sound Decisions for Bio-Waste Management-A practical guide to Life Cycle Thinking (LCT) and Life Cycle Assessment (LCA), (n.d.). http://eplca.jrc.ec.europa.eu/uploads/waste-Guidance-on-LCT-LCA-applied-to-BIO-WASTE- 
Management-Final-ONLINE.pdf (accessed February 8, 2018).

[21] Market - European Bioplastics e.V., (n.d.). http://www.european-bioplastics.org/market/ (accessed February 11, 2018).

[22] S. Thakur, J. Chaudhary, B. Sharma, A. Verma, S. Tamulevicius, V.K. Thakur, Sustainability of bioplastics: Opportunities and challenges, Curr. Opin. Green Sustain. Chem. 13 (2018) 68-75. doi:10.1016/j.cogsc.2018.04.013.

[23] K. Khosravi-Darani, D.Z. Bucci, Application of Poly(hydroxyalkanoate) In Food Packaging: Improvements by Nanotechnology, Chem. Biochem. Eng. Q. 29 (2015) 275-285. doi:10.15255/CABEQ.2014.2260.

[24] A. Anjum, M. Zuber, K.M. Zia, A. Noreen, M.N. Anjum, S. Tabasum, Microbial production of polyhydroxyalkanoates (PHAs) and its copolymers: A review of recent advancements, Int. J. Biol. Macromol. 89 (2016) 161-174. doi:10.1016/j.ijbiomac.2016.04.069.

[25] M. Koller, Poly(hydroxyalkanoates) for food packaging - application and attempts towards implementation, Appl. Food Biotechnol. 1 (2014) 1-13. doi:10.22037/afb.v1i1.7127.g6247.

[26] G. Keskin, G. Kızıl, M. Bechelany, C. Pochat-Bohatier, M. Öner, Potential of polyhydroxyalkanoate (PHA) polymers family as substitutes of petroleum based polymers for packaging applications and solutions brought by their composites to form barrier materials, Pure Appl. Chem. 89 (2017) 18411848. doi:10.1515/pac-2017-0401.

[27] E. Bugnicourt, P. Cinelli, A. Lazzeri, V. Alvarez, Polyhydroxyalkanoate (PHA): Review of synthesis, characteristics, processing and potential applications in packaging, Express Polym. Lett. 8 (2014) 791-808. doi:10.3144/expresspolymlett.2014.82.

[28] Y. Wang, J. Yin, G.Q. Chen, Polyhydroxyalkanoates, challenges and opportunities, Curr. Opin. Biotechnol. 30 (2014) 59-65. doi:10.1016/j.copbio.2014.06.001.

[29] B.G. Hermann, L. Debeer, B. De Wilde, K. Blok, M.K. Patel, To compost or not to compost: Carbon and energy footprints of biodegradable materials' waste treatment, Polym. Degrad. Stab. 96 (2011) 1159-1171. doi:10.1016/j.polymdegradstab.2010.12.026.

[30] C.P. Rivero, Y. Hu, T.H. Kwan, C. Webb, C. Theodoropoulos, W. Daoud, C.S.K. Lin, Bioplastics From Solid Waste, in: Curr. Dev. Biotechnol. Bioeng. Solid Waste Manag., Elsevier, 2016: pp. 1-26. doi:10.1016/B978-0-444-63664-5.00001-0.

[31] N. Peelman, P. Ragaert, K. Ragaert, M. Erkoç, W. Van Brempt, F. Faelens, F. Devlieghere, B. De Meulenaer, L. Cardon, Heat resistance of biobased materials, evaluation and effect of processing techniques and additives, Polym. Eng. Sci. 58 (2018) 513-520. doi:10.1002/pen.24760.

[32] D. Cava, E. Giménez, R. Gavara, J.M. Lagaron, Comparative Performance and Barrier Properties of Biodegradable Thermoplastics and Nanobiocomposites versus PET for Food Packaging Applications, J. Plast. Film Sheeting. 22 (2006) 265-274. doi:10.1177/8756087906071354.

[33] P.B.S. Albuquerque, C.B. Malafaia, Perspectives on the production, structural characteristics and potential applications of bioplastics derived from polyhydroxyalkanoates, Int. J. Biol. Macromol. 107 (2018) 615-625. doi:10.1016/j.ijbiomac.2017.09.026.

[34] B. Laycock, P. Halley, S. Pratt, A. Werker, P. Lant, The chemomechanical properties of microbial polyhydroxyalkanoates, Prog. Polym. Sci. 38 (2013) 536-583. doi:10.1016/j.progpolymsci.2012.06.003.

[35] J.C.C. Yeo, J.K. Muiruri, W. Thitsartarn, Z. Li, C. He, Recent advances in the development of biodegradable PHB-based toughening materials: Approaches, advantages and applications, Mater. 
Sci. Eng. C. 92 (2018) 1092-1116. doi:10.1016/J.MSEC.2017.11.006.

[36] Q.-S. Liu, M.-F. Zhu, W.-H. Wu, Z.-Y. Qin, Reducing the formation of six-membered ring ester during thermal degradation of biodegradable PHBV to enhance its thermal stability, Polym. Degrad. Stab. 94 (2009) 18-24. doi:10.1016/j.polymdegradstab.2008.10.016.

[37] J. González-Ausejo, E. Sanchez-Safont, J.M. Lagaron, R.T. Olsson, J. Gamez-Perez, L. Cabedo, Assessing the thermoformability of poly(3-hydroxybutyrate-co-3-hydroxyvalerate)/poly(acid lactic) blends compatibilized with diisocyanates, Polym. Test. 62 (2017) 235-245. doi:10.1016/j.polymertesting.2017.06.026.

[38] W.V. Srubar, Z.C. Wright, A. Tsui, A.T. Michel, S.L. Billington, C.W. Frank, Characterizing the effects of ambient aging on the mechanical and physical properties of two commercially available bacterial $\begin{array}{llllll}\text { thermoplastics, } & \text { Polym. } & \text { Degrad. } & \text { Stab. } & 97 & \text { (2012) }\end{array}$ doi:10.1016/j.polymdegradstab.2012.04.011.

[39] Y.-M. Corre, S. Bruzaud, J.-L. Audic, Y. Grohens, Morphology and functional properties of commercial polyhydroxyalkanoates: A comprehensive and comparative study, Polym. Test. 31 (2012) 226-235. doi:10.1016/j.polymertesting.2011.11.002.

[40] N.G. Marie-Alix Berthet, Hélène Angellier-Coussy, Valérie Guillard, Vegetal fiber-based biocomposites: Which stakes for food packaging applications?, J. Appl. Polym. Sci. 133 (2016).42528 (1-18) doi:10.1002/app.42528.

[41] P.H.F. Pereira, M. de F. Rosa, M.O.H. Cioffi, K.C.C. de C. Benini, A.C. Milanese, H.J.C. Voorwald, D.R. Mulinari, Vegetal fibers in polymeric composites: a review, Polímeros. 25 (2015) 9-22. doi:10.1590/0104-1428.1722.

[42] A. K. Mohanty, M. Misra, G. Hinrichsen, Biofibres, biodegradable polymers and biocomposites: An overview, Macromol. Mater. Eng. 276-277 (2000) 1-24. doi:10.1002/(SICI)14392054(20000301)276:1<1::AID-MAME1>3.0.CO;2-W.

[43] T. Väisänen, A. Haapala, R. Lappalainen, L. Tomppo, Utilization of agricultural and forest industry waste and residues in natural fiber-polymer composites: A review, Waste Manag. 54 (2016) 62-73. doi:10.1016/j.wasman.2016.04.037.

[44] Horizonte2020, (n.d.). https://eshorizonte2020.es/ (accessed September 10, 2018).

[45] Scopus, (n.d.). https://www.scopus.com/ (accessed September 10, 2018). 
"Saber que sabemos lo que sabemos y saber que no sabemos

lo que no sabemos, ese es el verdadero conocimiento"

(Nicolás Copérnico)

SECCIÓN 2.-Marco teórico 
El objetivo de este capítulo es establecer el marco de conocimiento científico en el que se enmarca este trabajo de investigación haciendo una revisión del estado del arte referente a los temas tratados en esta tesis. Al tratarse de un tema de gran actualidad e interés científico, la bibliografía existente es muy amplia por lo que en esta revisión se recogen aquellas aportaciones más relevantes que han servido, a su vez, para argumentar y justificar los resultados derivados de esta investigación. Asimismo, cada uno de los capítulos de resultados recoge, en su sección introductoria, una breve revisión referente a los temas concretos de cada trabajo.

\subsection{Bioplásticos}

En las últimas décadas ha habido un interés creciente en el desarrollo de bioplásticos como sustitutos potenciales de los plásticos convencionales. En este sentido, existe un gran interés en el desarrollo de nuevas formulaciones basadas en polímeros de base biológica que permitan reducir la dependencia de los plásticos derivados del petróleo, disminuyendo así la huella de carbono de estos productos. Asimismo, el foco de atención se ha centrado especialmente en los bioplásticos biodegradables para determinadas aplicaciones en las que esta propiedad resulte ventajosa desde un punto de vista medioambiental (gestión de residuos mediante compostaje, productos plásticos con riesgo potencial de acabar en el medio ambiente) o técnico (p.ej. aplicaciones biomédicas)[1,2].

En este punto, resulta interesante hacer una pequeña aclaración de la terminología, ya que existe cierta confusión respecto a los términos biplástico, biopolímero, polímero de base biológica y polímero biodegradable. Los bioplásticos representan un amplio grupo de plásticos basados en polímeros que pueden ser obtenidos a partir de fuentes renovables, de recursos fósiles o una mezcla de ambos. Por tanto, un bioplástico puede ser de base biológica y/o biodegradable [3]. La IUPAC define los biopolímeros como "Macromoléculas producidas por organismos vivos (incluyendo proteínas, ácidos nucleicos y polisacáridos)" [4]. No obstante el uso más extendido de este término hace referencia a todos aquellos polímeros obtenidos a partir de fuentes renovables. Los polímeros biodegradables son aquellos susceptibles de ser degradados por acción de microorganismos (bacterias, hongos, algas) [2,5].Y, por último, los polímeros de base biológica son aquellos sintetizados a partir de moléculas procedentes, en su totalidad o en parte, de la biomasa (p.ej. bio-poliolefinas, bio-politereftalato de etileno, bio-poliuretano, etc.), pero no tienen por qué ser, necesariamente, biodegradables [5,6]. Por tanto, aunque, en ocasiones, estos términos se empleen indistintamente es importante recalcar que un biopolímero puede no ser biodegradable (como ocurre en el caso particular de los politioésteres [7]) o, en el extremo 
opuesto, un polímero derivado de recursos fósiles puede ser biodegradable (p.ej. policaprolactona $\mathrm{PCL}$ ) [8].

Teniendo en cuenta estas consideraciones, los bioplásticos se basan en polímeros de base biológica y/o polímeros biodegradables (de base biológica o derivados del petróleo) que pueden clasificarse en función de su biodegradabilidad, origen y proceso de síntesis como sigue [3,9-11]:.

\section{1) Polímeros biodegradables}

a) Biopolímeros obtenidos directamente de la biomasa: en este grupo se incluyen los carbohidratos como la celulosa, el almidón, el quitosano, etc.; las proteínas de origen vegetal como la proteína de maíz o el gluen; las proteínas de origen animal como la gelatina, el colágeno, etc; $y$, por último, los lípidos como las ceras o los ácidos grasos.

b) Biopolímeros de origen microbiano: polímeros obtenidos por fermantación microbiana como los polihidroxialcanoatos (PHA) o polisacáridos microbianos como el pululano o el curdulano

c) Polímeros biodegradables de origen sintético

c.1.- Obtenidos a partir de la biomasa: biopolímeros obtenidos por síntesis química convencional a partir de monómeros procedentes de la biomasa como el poli ácido láctico (PLA)

c.2.- Obtenidos a partir de recursos fósiles: polímeros obtenidos por síntesis química convencional a partir de monómeros y polímeros procedentes de recursos fósiles como el poli (ácido glicólico) (PGA), la poli ( $\varepsilon$-caprolactona) $(\mathrm{PCL})$, el poli (succinato de butileno) (PBS) ${ }^{1}$, el poli (alcohol vinílico) (PVA), etc.

\section{2) Polímeros de base biológica no biodegradables}

En este grupo se encuentran los polímeros no biodegradables en los que al menos uno de sus monómeros procede de fuentes renovables como, por ejemplo, el bio-polietileno, biopolipropileno, bio-poliamidas, bio-poliuretanos, etc.

Si nos centramos en los polímeros de base biológica biodegradables, en diversos artículos de revisión $[3,9,11,12]$ se destaca que, a pesar de su enorme potencial debido a su origen renovable y su biodegradabilidad, siguen existiendo ciertos aspectos clave que limitan su aplicación. En general, estas limitaciones están relacionadas con unas propiedades mecánicas, térmicas y de barrera inferiores a los polímeros convencionales. Estos polímeros suelen presentar también una

\footnotetext{
${ }^{1}$ Recientemente se ha documentado que tanto el ácido succínico (SA) como el butanediol (BD) pueden obtenerse a partir de fuentes renovables [6]
} 
alta sensibilidad al agua, una baja estabilidad en su vida útil debido al envejecimiento y diversos problemas de procesado. Asimismo, la mayoría de ellos todavía tienen costes de producción muy elevados en comparación con los polímeros tradicionales. Por tanto, los principales retos para mejorar su competitividad se centran en la mejora de la estabilidad de la producción, su procesabilidad y sus propiedades [6].

Los biopoliésteres, en concreto el poli ácido láctico (PLA) y los polihidroxialcanoatos (PHA) son los que han despertado un mayor interés científico y tecnológico y, aunque de forma gradual, están consiguiendo abrirse un hueco en el mercado $[13,14]$. Su biodegradabilidad, biocompatibilidad, así como la posibilidad de ser procesados mediante técnicas convencionales de procesado de termoplásticos, los hacen potencialmente adecuados para un gran número de aplicaciones, entre las que cabría destacar la industria del envase y embalaje, la industria agrícola o las aplicaciones biomédicas [15-18]. Aunque por su naturaleza y biodegradabilidad resultan especialmente aptos para la obtención de productos de vida útil relativamente corta, cada vez se están realizando más avances para ajustar las propiedades de estos materiales y adaptarlos a aplicaciones de pieza duradera o semi-duradera dirigidas por ejemplo a la industria automovilística o la electrónica [19-21].

En el caso concreto del PLA, su amplia disponibilidad, así como su amplia ventana de procesado derivada de su estado amorfo en las condiciones de procesado habituales y su relativamente alta resistencia mecánica y módulo elástico, han propiciado su presencia en el mercado a unos precios relativamente competitivos dentro de los plásticos técnicos, especialmente para aplicaciones de envase, textiles o biomédicas. Sin embargo, el PLA presenta unas bajas propiedades barrera a gases y vapores, y en algunos casos, propiedades insuficientes relacionadas con la resistencia térmica (p.ej. baja temperatura de deflexión al calor HDT), baja resistencia al impacto y baja flexibilidad, factores que limitan su aplicación [22-24].

Los polihidroxialcanoatos (PHA) comprenden una amplia familia de poliésteres de origen microbiano que pueden ser sintetizados por un gran número de bacterias e incluso plantas [25]. El polihidroxibutirato (PHB) y el copolímero poli(hydroxibutirato-co-hidroxivalerato) (PHBV) son dos de los polímeros más comunes de esta familia y que mayor interés han atraído. Estos polímeros resultan muy atractivos ya que presentan propiedades físicas comparables a algunos polímeros convencionales como el polipropileno (PP) [15], y unas excelentes propiedades barrera en comparación con otros polímeros biodegradables como el PLA (similares al tereftalato de polietileno, PET, en el caso del PHBV [26]). Sin embargo, su fragilidad, baja estabilidad debida al envejecimiento, estrecha ventana de procesado, baja tenacidad y baja elongación a rotura, unidas a su todavía elevado coste de producción dificultan su aplicación [27,28]. 
De entre los distintos enfoques dirigidos a abordar los retos de los PHA, se pueden destacar el mezclado con otros polímeros y el desarrollo de compuestos $[27,29,30]$. Las fibras naturales de origen vegetal resultan especialmente atractivas para reducir el coste de los materiales basados en PHA mejorando a su vez algunas de sus propiedades y contribuyendo a un diseño de producto basado en la economía circular [21,31].

En los siguientes apartados se analizará en profundidad el origen, propiedades, procesabilidad y limitaciones técnicas del PHB y PHBV, así como las distintas estrategias encaminadas a mejorar la aplicabilidad industrial de estos materiales.

\subsection{Polihidroxialcanoatos (PHA): polihidroxibutirato (PHB) y polihidroxibutirato-co-hidroxivalerato (PHBV)}

\subsubsection{Historia y síntesis de PHA}

Los polihidroxialkanoatos (PHA) son biopolímeros naturales sintetizados y acumulados en forma de gránulos intracelulares (Figura 2.1) como reserva de carbono y energía por diferentes microorganismos procariotas cuando existe una limitación de nutrientes esenciales (nitrógeno, oxígeno o fósforo) ${ }^{2}$ en presencia de una fuente de carbono en exceso [25]. Este tipo de estructuras granulares fueron observadas por primera vez por Beijerink en 1888 en el interior de células de Rhizobium, aunque no pudo definir su función ni composición [32]. En 1923 el científico francés, Maurice Lemoinge notificó la producción de ácido 3-oxibutírico en Bacillus subtilis [33]. En 1927, consiguió extraer y aislar la sustancia con cloroformo de células de Bacillus megaterium y probó que se trataba de un polímero, el poli 3-hidroxibutirato (PHB) [34]. Lemoige y sus colaboradores notificaron diferentes acumulaciones de PHB variando el medio de crecimiento y fueron los primeros en describir un método para cuantificarlo [35]. Macrae y Wilkinson (1958) demostraron que la función del PHB en la célula era la de reserva de carbono y energía y fueron los primeros en proponer una ruta biosintética al observar que la acumulación tenía lugar especialmente cuando la relación de glucosa a nitrógeno en el medio de crecimiento era alta $[32,36]$.

\footnotetext{
${ }^{2}$ En determinados tipos de bacterias la síntesis puede darse sin necesidad de limitación de nutrientes. P.ej. Escherichia coili recombinante [50]
} 


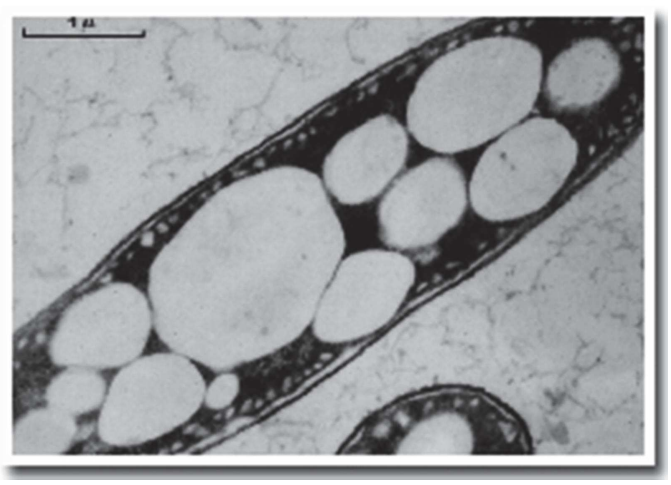

Figura 2.1. Micrografía de una sección ultrafina de una célula de Azotobacter chroococcum tratada con ácido fenilacético en la que se observan gránulos de PHB [Imagen publicada por Nuti y colaboradores en la revista Canadian Journal of Microbiology en 1972 [37]]

No fue hasta principios de la década de 1960 cuando empezó a reconocerse el potencial del PHB y comenzó a explorarse su producción. Los primeros intentos de comercialización de PHB fueron llevados a cabo por la compañía W.R. Grace \& Co (USA), donde los trabajos de Baptist y Weber dieron lugar a diversas patentes [38-40]. Sin embargo, debido a la baja eficiencia del proceso de síntesis, el bajo rendimiento de extracción, problemas con la pureza del polímero y el elevado coste, la empresa tuvo que cerrar.

Varios años más tarde, en 1974, Wallen y Rohwedder documentaron la extracción de un polímero que contenía unidades de de hidroxibutirato (HB), hidroxivalerato (HV), hidroxihexanoato $(\mathrm{HHx})$ e hidroxiheptanoato $(\mathrm{HHp})$ en lodos de aguas residuales activados [41] . Desde entonces se han identificado alrededor de 150 monómeros de PHA con masas moleculares entre 50000 y 1000000 Da y más de 300 bacterias pertenecientes a alrededor de 90 géneros de especies microbianas capaces de sintetizar estos polímeros $[25,42,43]$

La empresa pionera en la producción a escala comercial de PHA fue la compañía inglesa Imperial Chemical Industries (ICI) que empezó a comercializar el copolímero PHBV bajo el nombre de BIOPOL $^{\circledast}$ que fue distribuido por Monsanto y posteriormente por Metabolix $[44,45]$. En la actualidad existen diferentes empresas que producen y comercializan PHA entre las que se pueden destacar Biomer Inc. (Alemania), Bio-on (Italia), Goodfellow Cambridge Ltd. (Reino Unido) Kaneka (Singapur), Meredian (EUA), Metabolix (EUA), Mitsubishi Gas Chemicals (Japón), PHB Industrial S/A (Brasil), Tianan Biological Materials (China) o Tianjin Green Biosciences (China) La capacidad de producción de estas empresas es todavía baja (alrededor de 1000-20000 
toneladas/año) y el precio de estos polímeros, aunque se ha reducido sustancialmente en los últimos años, supera los $5 € /$ kg en la mayoría de los casos $[45,46]$.

El proceso de producción de PHA comprende distintas etapas que, de forma muy general, pueden dividirse en: cultivo bacteriano, fermentación en el medio (fuente de carbono), síntesis y acumulación de PHA, extracción y purificación. El tipo de polímero o copolimero sintetizado depende, fundamentalmente, de la fuente de carbono y el cultivo celular seleccionados. Los costes de este proceso son elevados, y se pueden atribuir, principalmente, al coste de las materias primas usadas como fuente de carbono y a las etapas de extracción y purificación del polímeron $[28,47]$.

\subsubsection{Estructura y propiedades generales de los PHA}

Los polihidroxialcanoatos son poliésteres lineales formados por monómeros de ácidos hidroxialcanoicos unidos mediante enlaces éster. El enlace se produce entre el grupo carboxilo de un monómero con el grupo hidroxilo del monómero adyacente [32]. La estructura general de los PHA se muestra en la Figura 2.2.

Los PHA se pueden clasificar en tres grupos en función del número de carbonos del monómero o monómeros que los componen: a) de longitud de cadena corta (scl-PHA, de 3-5 C), b) de longitud de cadena media (mcl-PHA, de 6-14 C), y c)de longitud de cadena larga (Icl-PHA, >15 C)[48].

Por tanto, los PHA comprenden una amplia familia de polímeros cuyas características y propiedades físicas y químicas como las temperaturas de fusión y de transición vítrea, cristalinidad, etc., dependen fuertemente de la composición de los monómeros constituyentes (más de 150) [43].

En general, los scl-PHA ${ }^{3}$ como el polihidroxibutirato (PHB) o el copolimero polihidroxibutirato-cohidroxivalerato (PHBV) son termoplásticos rígidos y frágiles. Poseen una elevada cristalinidad, baja temperatura de transición vítrea y alta temperatura de fusión [50]. Los mcl- y Icl-PHA son elastómeros termoplásticos con baja cristalinidad, baja resistencia mecánica y elevada elongación a rotura, y poseen temperaturas de transición vítrea y fusión inferiores a los Scl-PHA [51].

\footnotetext{
${ }^{3}$ En este grupo se encuentra también p.ej el $\mathrm{P}(4 \mathrm{HB})$ que posee una elevada flexibilidad [49]
} 


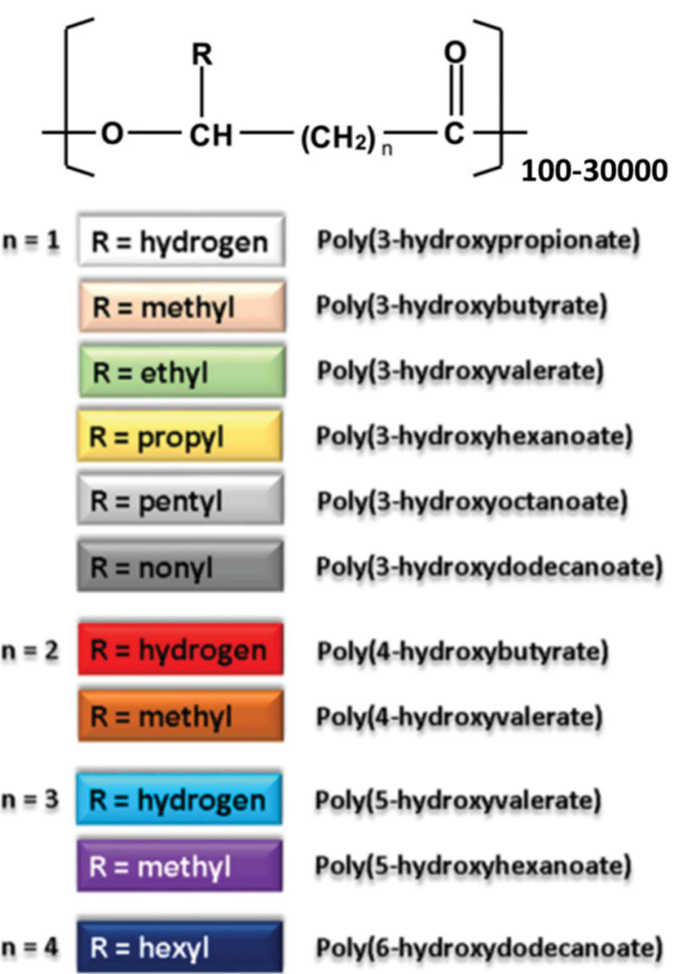

Figura 2.2. Estructura general de los PHA [Imagen adaptada de la referencia [28]]

Algunas características generales de los PHA son su biodegradabilidad intrínseca debido a su origen microbiano, su biocompatibilidad y no toxicidad. Los PHA son solubles en cloroformo y otros hidrocarburos clorados. Son hidrófobos, insolubles en agua y relativamente resistentes a la degradación hidrolítica. Son inertes y estables en aire. Tienen buena resistencia ultra violeta y baja resistencia a ácidos y bases [45,52].

Por su relevancia científica y tecnológica y por tratarse de los materiales seleccionados para el presente estudio, a continuación se analizará en mayor profundidad la relación estructurapropiedades del PHB y el PHBV.

\subsubsection{Relación estructura-propiedades del PHB y el PHBV}

Como ha sido descrito anteriormente, tanto el PHB como el PHBV son biopolímeros pertenecientes a la familia de los polihidroxialcanoatos, concretamente a los scl-PHA. Por tanto, 
comparten sus características generales. Así pues, son en general, termoplásticos rígidos y frágiles, biodegradables, biocompatibles y no tóxicos. Son hidrófobos, insolubles en agua y relativamente resistentes a la degradación hidrolítica. Son solubles en cloroformo y otros hidrocarburos clorados. Tienen buena resistencia ultra violeta y baja resistencia a ácidos y bases $[45,52]$. No obstante, sus propiedades concretas están íntimamente relacionadas con su estructura química, su masa molecular y su estructura cristalina.

El polihidroxibutirato ( $\mathrm{PHB}$ ) es un homopolímero del 3-hidroxibutirato (3HB) cuyo peso molecular puede variar entre 10000 y 3000000 Da en función del microorganismo que lo produce, de la fuente de carbono, la concentración de nutrientes disponibles y las condiciones de crecimiento como el pH o la temperatura $[43,44]$. El PHB es un polímero semicristalino con una elevada cristalinidad ( $>60 \%)$, tiene baja temperatura de transición vítrea, elevada temperatura de fusión y posee una baja viscosidad en fundido [45]. Debido a su elevada cristalinidad presenta buenas propiedades barrera, con una baja permeabilidad a oxígeno, agua y aromas [53,54]. Respecto a sus propiedades mecánicas, se trata de un polímero rígido y frágil, con una baja elongación a rotura y baja resistencia al impacto $[15,45]$.

El polihidroxibutirato-co-hidroxivalerato (PHBV) es un copolímero al azar de 3-hidroxibutirato $(3 \mathrm{HB})$ y 3-hidroxivalerato (HV) cuyas propiedades dependen del contenido en HV. Así, para contenidos muy bajos de HV sus propiedades son cercanas a las del PHB y cuanto mayor es el contenido molar de HV, la resistencia al impacto y la elongación a rotura aumentan, mientras que las temperaturas de transición vítrea y de fusión, la cristalinidad, la rigidez, la resistencia mecánica y las propiedades barrera disminuyen [12,52].

Por su importancia desde el punto de vista técnico, a continuación se describe en mayor profundidad su estructura cristalina y su relación con el comportamiento mecánico y térmico de estos polímeros.

\subsubsection{Estructura cristalina y microestructura}

Las propiedades del PHB y el PHBV y, en consecuencia su comportamiento, están fuertemente influenciadas por su microestructura. Para poder comprender mejor su influencia es importante conocer dicha microestructura y las unidades cristalinas básicas que la constituyen.

Los polímeros semicristalinos, como es el caso del PHB y el PHBV, tienen la capacidad de adquirir cierto ordenamiento espacial para reducir la energía libre del sistema formando estructuras cristalinas. En un primer nivel de ordenación, las cadenas poliméricas mantienen un orden con las cadenas adyacentes definiendo estructuras cristalinas caracterizadas por los parámetros de red 
de la celdilla unidad. Tanto el $\mathrm{P}(3 \mathrm{HB})$ como el $\mathrm{P}(3 \mathrm{HV})$ presentan una estructura cristalina cuya celda unidad es ortorrómbica y cristalizan típicamente en la forma $\alpha$ (configuración de hélice levógira y cadenas antiparalelas) $[55,56]$.En un segundo nivel, las cadenas poliméricas se pliegan sobre sí mismas y se apilan para formar lamelas cuyo espesor generalmente oscila entre 4 y 12 nanómetros en el caso del PHB y el PHBV dependiendo de las condiciones de cristalización $[57,58]$. En un tercer nivel, estas lamelas están agrupadas formando estructuras microscópicas denominadas esferulitas. Dichas esferulitas se forman por el crecimiento en dirección radial de varias lamelas que se ramifican a partir de un núcleo de cristalización presentando una morfología bandeada característica. El crecimiento de la esferulita progresa hasta verse limitado por una esferulita adyacente [58] (Fig. 2.3.).

EI PHB presenta una elevada cristalinidad (porcentaje de fracción cristalina), una baja densidad de nucleación y, en general, una baja velocidad de cristalización, aunque este último factor depende de la temperatura $[45,52,59]$. Estos factores conducen a la formación de grandes esferulitas que generalmente presentan grietas y fisuras (Fig. 2.4) debidas a diferencias de expansión térmica a lo largo del radio y la circunferencia generando tensiones internas, lo que confiere fragilidad al material $[60,61]$.

El copolímero PHBV presenta isodimorfismo [62]. El isodimorfismo es una condición poco habitual que presentan ciertos copolímeros al azar semicristalinos. Un copolímero presenta isodmorfismo cuando se detectan dos fases cristalinas que contienen ambos monómeros en el rango de composiciones. Para contenidos molares inferiores al 40\% el PHBV cristaliza en la celda unitaria del $\mathrm{P}(3 \mathrm{HB})$ y por encima, en la celda unitaria del $\mathrm{P}(3 \mathrm{HV})$ [56]. Esta inclusión del $\mathrm{P}(3 \mathrm{HV})$ en la celda unidad del $\mathrm{P}(3 \mathrm{HB})$ produce distorsiones que resultan en una menor "perfección" cristalina dando lugar a cristales más pequeños, con más defectos y menor fragilidad, lo que se traduce en una mayor flexibilidad y tenacidad del material [63]. 


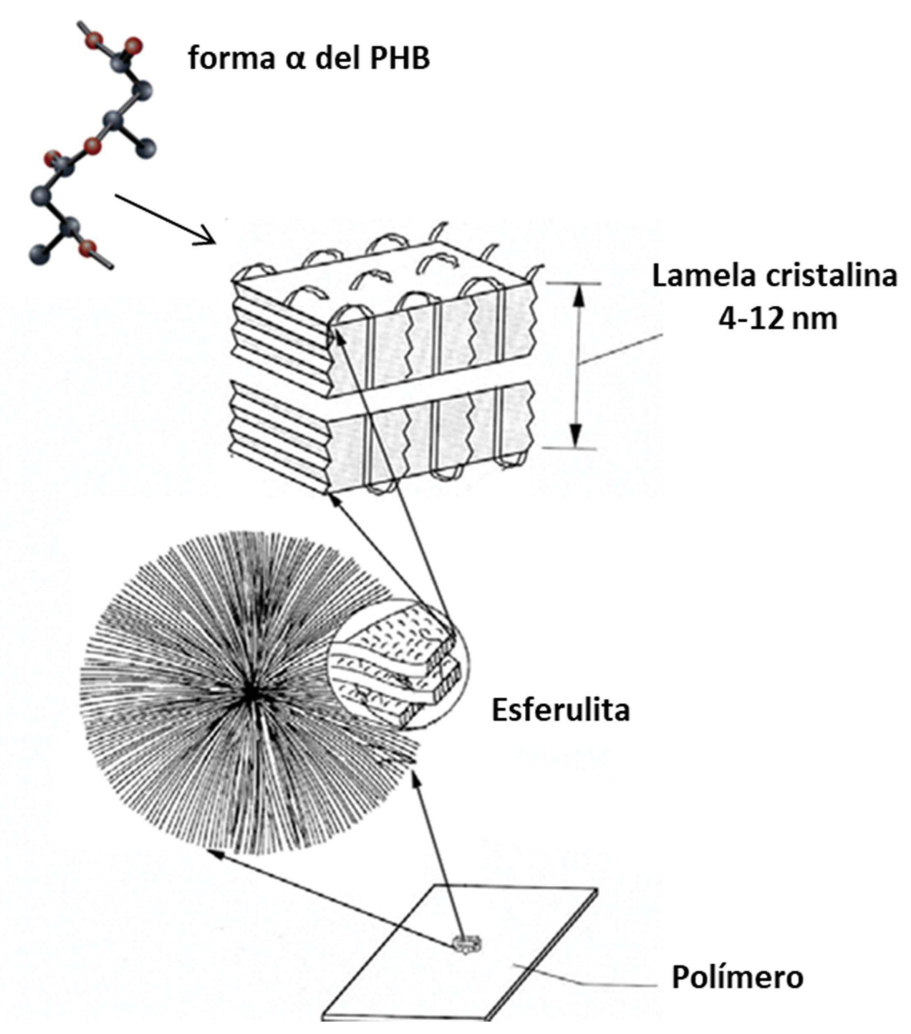

Figura 2.3. Niveles estructurales en polímeros semicristalinaos [Imagen adaptada de la referencia [64]]

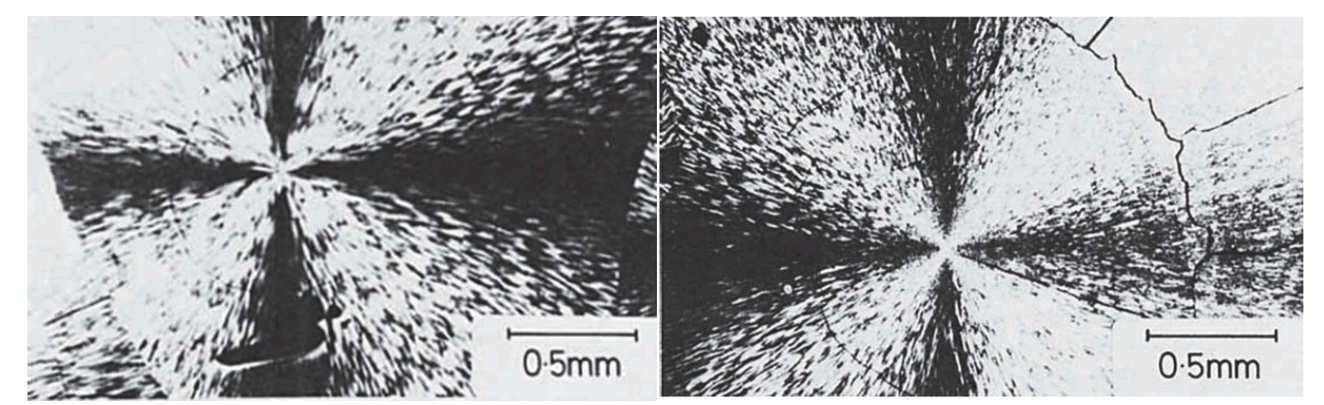

Figura 2.4. Micrografías ópticas de esferulitas de PHB mostrando grietas y fisuras [Imágenes publicadas por Barham y eller en la revista Journal of Polymer Science Part B: Polymer Physics en 1986 [60] ]

No obstante, diversos autores apuntan que para contenidos bajos de hidroxivalerato, las unidades de $\mathrm{P}(3 \mathrm{HV})$ quedan preferentemente excluidas del cristal [65-67]. Por esta razón, la microestructura y propiedades generales del PHBV de bajo contenido en hidroxivalerato son 
cercanas a las del PHB, como es el caso del PHBV utilizado en esta tesis, que presenta un contenido molar de hidroxivalerato del $3 \%$.

Dentro de las esferulitas los cristales o lamelas están envueltos por una fase amorfa de cadenas desordenadas que no se han incorporado al cristal (espacio interlamelar). Parte de estas cadenas del espacio interlamelar pueden incorporarse posteriormente a la fase cristalina en lo que se conoce como cristalización secundaria. La representación estructural de este tipo de polímeros como dominios cristalinos separados por una fase amorfa se puede explicar, generalmente de forma satisfactoria, mediante un modelo de tres fases. El modelo de tres fases contempla la existencia de una fracción de fase amorfa de baja movilidad, la fracción rígida amorfa (RAF), que conecta la fase amorfa de alta movilidad (MAF) con la fase cristalina [68-72].

\subsubsection{Comportamiento mecánico}

Tanto el PHB como el PHBV de bajo contenido en hidroxivalerato son polímeros rígidos y presentan un comportamiento mecánico frágil. Poseen valores relativamente elevados de módulo elástico y resistencia mecánica y una baja elongación a rotura $(<5 \%)$. Son poco tenaces, con una baja ductilidad y una baja resistencia al impacto. Además, su fragilidad tiene una marcada dependencia con el tiempo $[45,50,73]$

Esta elevada fragilidad, así como la progresiva fragilización con el tiempo, están fuertemente determinadas por su microestructura que, además, depende en gran medida de las condiciones de cristalización, es decir, de la historia térmica del material durante su procesado.

En general este comportamiento mecánico se atribuye en la literatura por un lado a la fragilidad intrínseca de las esferulitas que generalmente presentan un gran tamaño con fisuras internas debido a la baja densidad de nucleación [59-61]; por otro lado, la fragilización progresiva se atribuye a dos fenómenos: un proceso de cristalización secundaria [59,74-76] y un envejecimiento físico de la fase amorfa [77-80]. Tal y como resaltan Crétois et al.[77], no existe un claro consenso para explicar la fragilización del PHB y el PHBV con el tiempo aunque está ampliamente aceptado que se produce una combinación de ambos fenómenos [77,81,82]. En el primero de los casos, en el proceso de cristalización secundaria, pequeños cristalitos se unen a las lamelas y pueden actuar como puntos de unión entre lamelas aunque producen una constricción de la fase amorfa [74]. El fenómeno de envejecimiento físico de la fase amorfa en polímeros semicristalinos fue estudiado por Struik $[83,84]$ que propuso la coexistencia de dos tipos de fase amorfa: una fase amorfa no alterada, y una fase amorfa alterada con movilidad restringida adyacente a los cristales. Así definió dos transiciones vítreas, la correspondiente a la 
fase amorfa de alta movilidad y la correspondiente a la desvitrificación de la fase amorfa de movilidad restringida. De un modo similar, el modelo de tres fases contempla la existencia de la fase cristalina, la RAF y la MAF [68-72]. El fenómeno de envejecimiento físico ocurre por la progresiva densificación de la fase amorfa dando lugar a una mayor proporción de RAF y una mayor constricción de la misma. Sin embargo, tal como apuntan Esposito et al. [79] resulta complejo y existe cierta controversia tanto para explicar el desarrollo de la RAF, que depende fuertemente de las condiciones de cristalización, así como las reorganizaciones estructurales que ocurren tanto en la RAF como en la MAF $[81,85,86]$. En efecto, los estudios llevados a cabo por Esposito et al.[79] sugieren que un modelo de dos fases complejo denominado "continuum of mobility" podría explicar de forma más satisfactoria la movilidad de la fase amorfa en el PHBV en condiciones de cristalización en frio (Fig. 2.5).

Respecto a la contribución que tienen cada uno de los fenómenos mencionados a la fragilización del PHB, son varios los autores que apuntan a que es el envejecimiento físico de la fase amorfa el que mayor impacto tiene [73,77,82]. De acuerdo a los trabajos de Crétois et al.[77] dicho envejecimiento físico tiene un carácter reversible (mediante la aplicación de un tratamiento térmico de recocido) mientras que la cristalización secundaria es irreversible. No obstante, la reversibilidad del envejecimiento físico es únicamente temporal.

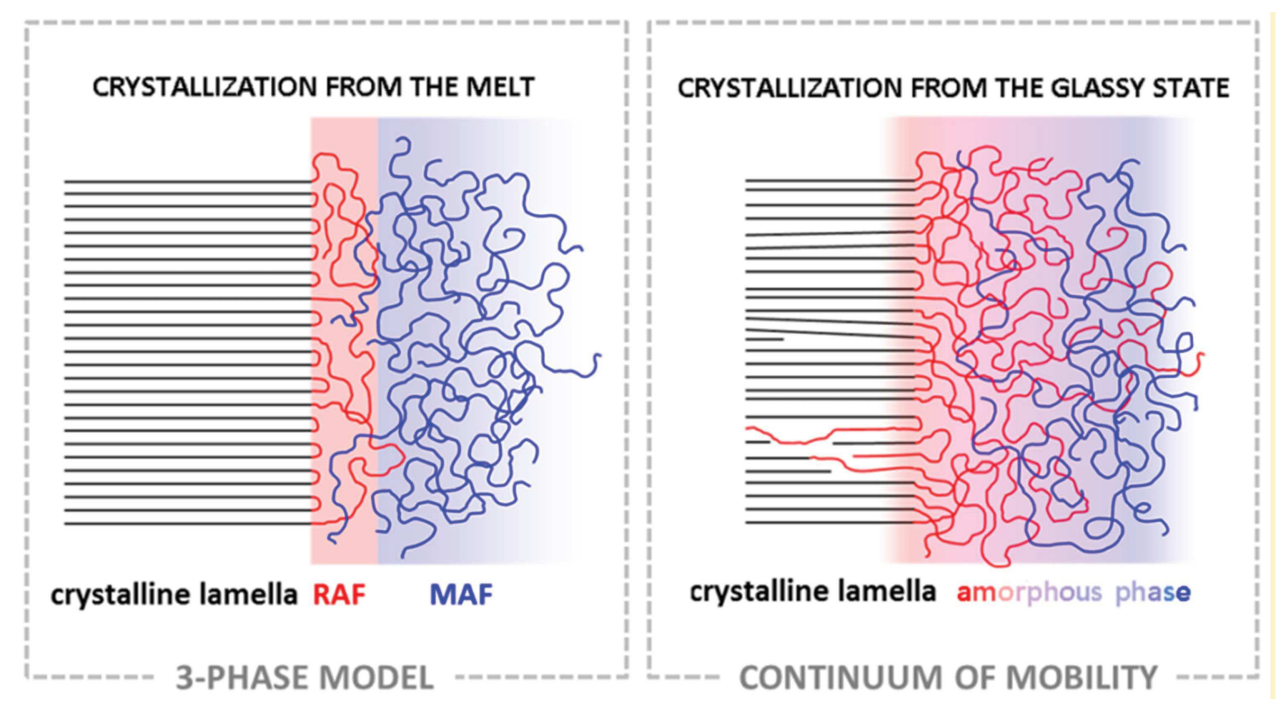

Figura 2.5. Representación esquemática del modelo de tres fases y del modelo "continuum of mobility" propuesto por Esposito et al.[79]. [Imagen tomada de la referencia [79]] 


\subsubsection{Comportamiento térmico}

Tanto el PHB como el PHBV de bajo contenido en hidroxivalerato presentan una temperatura de transición vítrea alrededor de 5-10ㄷ y una elevada temperatura de fusión ( 170C) debido a su elevada cristalinidad [32]. Aunque, en general, los polímeros semicristalinos con temperaturas de transición vítrea relativamente bajas suelen tener también baja resistencia térmica, la elevada cristalinidad del PHB y el PHBV (>60\%) hace que presenten una relativamente alta resistencia térmica. Sus temperaturas de deflexión al calor (HDT) son superiores a los 100 ㄷ, valores muy por encima de los correspondientes a otros biopolímeros como el PLA amorfo (HDT 50 으) $[87,88]$. Sin embargo, estos polímeros son muy sensibles a la degradación térmica.

El PHB y el PHBV descomponen térmicamente a temperaturas cercanas a su temperatura de fusión (generalmente por encima de 190 C). La degradación térmica de estos polímeros ocurre por un mecanismo de escisión de cadenas al azar por eliminación cis, también conocido como transposición de Maclafferty [50,89].

Este proceso de degradación va acompañado de la liberación de subproductos de la degradación como ácido crotónico y otros oligómeros que, a su vez, catalizan la reacción de degradación como apuntan Kopinke et al.[90]. Este proceso de degradación resulta en una brusca caída de la masa molecular y una reducción acusada de la viscosidad del fundido [45].

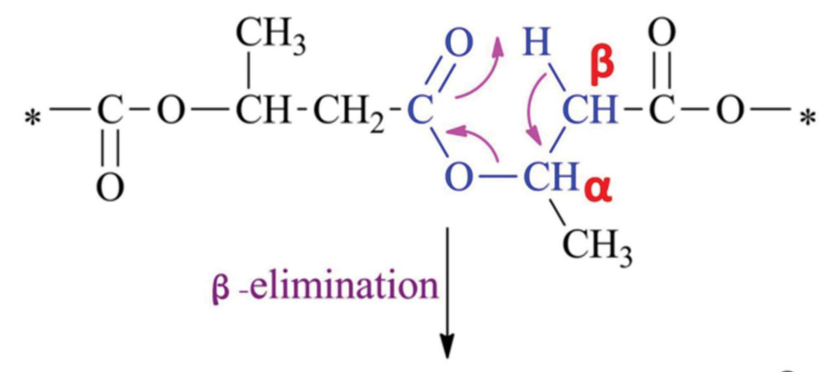<smiles>CC=CC(=O)OC</smiles>

Figura 2.6. Mecanismo de degradación térmica de los PHA [Imagen extraída de la referencia [50] (adaptada de la referencia [89])] 


\subsection{Valoración de la aplicabilidad industrial del PHB y el PHBV}

Como ya ha sido mencionado, el interés de estos polímeros radica en su potencial como alternativa más respetuosa con el medio ambiente a los polímeros convencionales, especialmente para aplicaciones de corta vida útil (envase, productos desechables...) [44,53]. En este contexto, desde el punto de vista medioambiental y de aprovechamiento de recursos, su biodegradabilidad y origen natural pueden considerarse grandes ventajas [14,91]. Desde el punto de vista técnico, algunas de sus fortalezas son su posibilidad de procesado mediante técnicas convencionales de termoplásticos, un conjunto de propiedades físico químicas cercanas a algunos polímeros convencionales, unas propiedades mecánicas en términos de rigidez y resistencia mecánica comparables al PP [14,15], propiedades barrera similares al PET [53,54], y relativamente buena resistencia química y relativamente elevada resistencia térmica $[45,52]$. En la Tabla 2.1. se recogen algunas de las propiedades promedio del PHB y el PHBV en comparación con otros polímeros de uso común.

Tabla 2.1. Propiedades promedio del PHB y el PHBV en comparación con el PLA y algunos polímeros de uso común (PP, PE, PET) [Datos extraídos de las referencias [14,54,64,88,92]]

\begin{tabular}{|c|c|c|c|c|c|c|c|}
\hline & PHB & PHBV & PLA & PP & HDPE & LDPE & PET \\
\hline $\begin{array}{l}\text { Densidad } \\
\left(\mathrm{g} / \mathrm{cm}^{3}\right)\end{array}$ & $1,17-1,25$ & 1,25 & $1,25-1,29$ & $\begin{array}{l}0,91- \\
0,94\end{array}$ & $\geq 0,94$ & $0,88-0,94$ & 1,38 \\
\hline $\begin{array}{c}\text { Temperatura de } \\
\text { transición } \\
\text { vítrea, } \mathrm{T}_{\mathrm{g}},(\mathrm{O} \mathrm{C})\end{array}$ & -10 a 15 & -10 a 25 & 50 a 65 & -20 & -110 a -30 & -125 a -30 & 69 \\
\hline $\begin{array}{l}\text { Temperatura de } \\
\text { fusión, } T_{m},(O C)\end{array}$ & $153-175$ & $145-180$ & $126-190$ & $160-186$ & $106-134$ & $112-136$ & $245-265$ \\
\hline $\begin{array}{c}\text { Cristalinidad, } X_{c} \text {, } \\
(\%)\end{array}$ & $60-70$ & $50-70$ & - & 60 & $40-50$ & $64-80$ & - \\
\hline $\begin{array}{l}\text { Temperatura de } \\
\text { deflexión al } \\
\text { calor, HDT, (ㅇ) }\end{array}$ & - & 107,8 & $65^{*}$ & 60-105 & $45-85$ & $35-50$ & 80-115 \\
\hline $\begin{array}{c}\text { Módulo } \\
\text { elástico, E, } \\
\text { (GPa) }\end{array}$ & $0,4-3,8$ & $1,2-4,6$ & $0,3-3,8$ & $0,8-2$ & $0,5-1,4$ & $0,1-0,4$ & $1,7-3,5$ \\
\hline Resistencia & $18-27$ & $25-40$ & $12-23$ & $25-98$ & $15-40$ & $5-25$ & $70-177$ \\
\hline
\end{tabular}




\begin{tabular}{|c|c|c|c|c|c|c|c|}
\hline & PHB & PHBV & PLA & PP & HDPE & LDPE & PET \\
\hline $\begin{array}{c}\text { mecánica, } \sigma_{\mathrm{R}}, \\
(\mathrm{MPa})\end{array}$ & & & & & & & \\
\hline $\begin{array}{l}\text { Elongación a } \\
\text { rotura, } \varepsilon_{\mathrm{R}} \text { (\%) }\end{array}$ & $1,8-17$ & $2,5-30$ & $12-26$ & $>100$ & $>20$ & $>100$ & $70-180$ \\
\hline $\begin{array}{c}\text { Permeabilidad } \\
\text { a agua } \\
\left(\mathrm{g} / \mathrm{s} \mathrm{m}^{2} \mathrm{~Pa}\right)\end{array}$ & & $3,0 \cdot 10^{-12}$ & & & & & $5,5 \cdot 10^{-12}$ \\
\hline $\begin{array}{c}\text { Permeabilidad } \\
\text { a limoneno } \\
\left(\mathrm{g} / \mathrm{s} \mathrm{m}^{2} \mathrm{~Pa}\right)\end{array}$ & & $2,8 \cdot 10^{-11}$ & & & & & $1,8 \cdot 10^{-10}$ \\
\hline
\end{tabular}

*Para PLA amorfo

No obstante, existen diferentes factores que limitan su aplicabilidad industrial, entre los que cabe destacar: su todavía elevado coste en comparación a otros biopolímeros del mercado, su baja ductilidad y tenacidad, su envejecimiento con el tiempo así como dificultades de procesado [45,93-95].

A continuación se analizarán con mayor detalle las principales limitaciones para la aplicabilidad industrial del PHB y el PHBV, así como las principales estrategias dirigidas a contrarrestarlas. Asimismo, se abordará una de sus fortalezas como es su biodegradabilidad tomando en especial consideración su degradación en compostaje.

\subsubsection{Costes}

Uno de los principales factores limitantes, si no el mayor de ellos, para la aplicabilidad industrial de los PHA es su todavía elevado coste en comparación con los polímeros convencionales e incluso con otros biopolímeros como, por ejemplo, el PLA [96,97]. Por tanto, una de las claves para impulsar la efectiva incorporación de estos polímeros al mercado es reducir su precio. En este sentido, existen dos líneas de actuación principales:

i) Reducir los costes en origen, actuando sobre el proceso productivo.

La reducción de costes en la producción de PHA es un tema que está siendo intensamente investigado en los últimos años y existe bastante bibliografía al respecto. En distintos artículos de revisión publicados en los últimos años se recogen los principales avances realizados en esta materia $[28,32,47,48,52,98-100]$. Los autores destacan tres enfoques encaminados a reducir los 
costes de producción: la selección de las cepas y tipo de cultivo, la selección de la fuente de carbono y la optimización del proceso de extracción y purificación. En el primer caso se destacan las investigaciones relacionadas con la identificación de microorganismos adecuados para obtener altos rendimientos de acumulación de PHA en función de la fuente de carbono y los beneficios e inconvenientes del uso de cultivos puros de bacterias, cultivo mixto o cultivo abierto (p.ej lodos activados). También se destacan los avances realizados en la síntesis a partir de plantas modificadas genéticamente [101] o microalgas [102], aunque en estos casos los rendimientos son todavía bajos. El principal foco de atención se ha centrado en la evaluación de la idoneidad de diferentes fuentes de carbono como sustratos. En este sentido, se ha puesto especial interés en materias primas procedentes de recursos renovables que resulten más económicas y que, preferiblemente, no compitan con recursos alimentarios. Entre las distintas materias primas que están siendo motivo de estudio se pueden destacar las de origen lignocelulósico procedentes de residuos agrícolas como por ejemplo paja de trigo [103] o arroz [104] o bagazo de caña de azúcar [105], los subproductos de la industria alimentaria como el suero lácteo [106], residuos de almidón, aceites residuales, pulpa de frutas [105], entre otros, o los residuos solídos urbanos y las aguas residuales municipales [107]. También se está estudiando la co-producción de PHA en biorefinerias [108]. Respecto al proceso de recuperación y purificación de PHA, el proceso más extendido es el de extracción mediante disolventes orgánicos (cloroformo). Se han estudiado distintos procesos alternativos como el de lisis celular seguida de extracción acuosa [42], digestión enzimática [109] o extracción con $\mathrm{CO}_{2}$ supercrítico [109]. Sin embargo estas técnicas siguen teniendo problemáticas de elevado coste, seguridad y escalabilidad.

ii) Reducir el precio del producto final mediante el desarrollo de composiciones que permitan abaratar el producto

La incorporación de una segunda fase más económica en proporciones relativamente elevadas que no comprometa o incluso consiga mejorar las propiedades del material es una opción muy atractiva para favorecer la competitividad de los PHA. La reducción del coste global del producto se puede conseguir: mediante el mezclado con otros polímeros biodegradables o no biodegradables como, por ejemplo, almidón, proteína de soja, poly(butylene adipate-coterephtalate)(PBAT), poly(vinyl acetate) (PVA), poly methyl methacrylate (PMMA), entre otros; la incorporación de aditivos como plastificantes de bajo coste; la adición de cargas o refuerzos inorgánicos como arcillas, u orgánicos como fibras de origen vegetal [10,12,21,110-112]. 
Atendiendo no solo a la reducción de costes o a la mejora de propiedades, sino también a mantener el concepto "green" del producto, una de las opciones que mayor interés ha despertado es el desarrollo de compuestos basados en fibras vegetales (lignocelulósicas).El uso de fibras lignocelulósicas además de tener un impacto positivo en el precio final del producto, permite garantizar su biodegradabilidad y mantener e incluso mejorar las propiedades del material $[110,112,113]$. Además, contribuye a un diseño de producto basado en la economía circular ya que puede ser una opción viable para la valorización de residuos vegetales [31]. Tanto por su relevancia actual, como por ser objeto de estudio de esta tesis, los compuestos basados en fibras lignocelulósicas se tratarán con mayor profundidad en el apartado 2.4. de esta sección.

\subsubsection{Comportamiento mecánico}

Como ya ha sido mencionado anteriormente, el PHB y el PHBV de bajo contenido en hidroxivalerato, son polímeros rígidos y frágiles debido a su elevada cristalinidad y baja densidad de nucleación. Además, debido a la cristalización secundaria y al envejecimiento físico experimenta una fragilización muy acusada con el tiempo.

En la bibliografía pueden encontrarse diferentes estrategias dirigidas a mejorar el comportamiento mecánico de estos polímeros y son varios los artículos de revisión en los que se recopilan y analizan de forma extensa dichas estrategias [11,12,27,52,110,111,114]. De entre los distintos enfoques más empleados se pueden destacar:

a) Adición de agentes nucleantes

Una de las estrategias más empleadas para contrarrestar la baja densidad de nucleación de los PHA es la incorporación de agentes nucleantes. Estos aditivos se añaden en bajas proporciones (generalmente $<1 \%$ ) y actúan como puntos de nucleación heterogénea favoreciendo la formación de un mayor número de esferulitas de menor tamaño, contribuyendo a acelerar la velocidad de cristalización y pueden ayudar a limitar la cristalización secundaria. Esta morfología se traduce en una mayor elongación a rotura y mayor resistencia al impacto [52]. Existen una gran variedad de agentes nucleantes [115-118] aunque algunos de los más utilizados son el nitruro de boro (BN) y el talco $[118,119]$.

b) Desarrollo de compuestos y nanocompuestos

El desarrollo de compuestos y nanocompuestos mediante la adición de cargas y nanocargas es uno de los enfoques más extendidos para mejorar tanto el comportamiento mecánico como otras propiedades de los PHA. 
En general, mediante la adición de pequeñas cantidades de partículas de tamaño nanométrico, normalmente inferiores al 5\%, se consigue una importante mejora de las propiedades mecánicas, la estabilidad térmica y las propiedades barrera del material. No obstante, para lograr estas mejoras se requiere una dispersión homogénea de las nanoparticulas en la matriz y una buena compatibilidad entre ambas fases. Teniendo en cuenta esta consideración, las nanopartículas pueden actuar como agentes nucleantes favoreciendo la cristalización del polímero y como agentes de refuerzo. En condiones de buena adhesión y debido a la elevada superficie específica de las partículas se consigue una efectiva transferencia de esfuerzos en el material dando lugar a un incremento importante del módulo elástico y la resistencia mecánica. Además, los materiales empleados como cargas generalmente poseen una buena estabilidad térmica por lo que cuando se consigue una fina dispersión en la matriz este parámetro se ve favorecido. Por otro lado, la presencia de partículas de tamaño nanométrico homogéneamente dispersas en la matriz aumenta la tortuosidad de los caminos de difusión, lo que tiene un impacto positivo en las propiedades barrera del material $[9,11,12]$. Las nanocargas más empleadas tradicionalmente son las arcillas laminares organomodificadas [58,120,121], sepiolita [122,123], nanotubos de haloisita $[124,125]$, nanotubos de carbono, o nanocristales de celulosa $[12,126]$, entre otros.

En el caso de los compuestos poliméricos, se emplean cargas o refuerzos de tamaño micrométrico o macroscópico, generalmente en cantidades relativamente elevadas. En general los materiales empleados como refuerzo deben poseer unas buenas propiedades específicas, es decir, relativamente elevada rigidez y resistencia mecánica y baja densidad. Lógicamente, la mejora en las propiedades mecánicas es este caso, también dependerá en gran medida de la dispersión y compatibilidad con la matriz, así como de las características geométricas de las partículas y, por supuesto, de su contenido volumétrico. Generalmente, mediante el desarrollo de compuestos se consigue una mejora del módulo elástico y, en función de las características del refuerzo y de la interacción con la matriz, otras propiedades como la resistencia mecánica o la resistencia al impacto se ven mejoradas. Además de la mejora de propiedades, en este caso, si el material de refuerzo empleado tiene un bajo precio se consigue una reducción importante del coste del material, como ya ha sido discutido en el apartado anterior [21,64].

Existe una gran variedad de materiales de refuerzo y cargas empleados en el desarrollo de compuestos de matriz polimérica, pueden ser fibras largas o cortas, continuas o discontinuas, partículas esféricas, etc. Algunas de las cargas y refuerzos tradicionales son, por ejemplo, la fibras de vidrio, de carbono o aramida, el carbonato de calcio, microesferas de vidrio partículas metálicas etc. [21] Sin embargo, en las últimas décadas, uno de los materiales que mayor interés ha despertado son las fibras de origen vegetal debido a su bajo coste, su abundancia y 
disponibilidad, su biodegradabilidad y buenas propiedades mecánicas específicas [127-129]. Como ya ha sido mencionado, por su interés se tratarán en mayor profundidad en el apartado 2.4 .

\section{c) Mezclado con otros polímeros}

El mezclado de polímeros es una técnica ampliamente extendida ya que su implementación resulta sencilla y económica. Mediante el mezclado en fundido del PHB o el PHBV con otros polímeros es posible contrarrestar algunas de sus limitaciones técnicas. No obstante, la mejora de propiedades dependerá no solo de las características de los polímeros escogidos, sino también de la miscibilidad y compatibilidad entre los distintos polímeros de la mezcla $[130,131]$.

La bibliografía referente a mezclas polímericas basadas en PHA encaminadas a mejorar su comportamiento mecánico es muy extensa. Sin embargo, con el propósito de mejorar la ductilidad y tenacidad de estos polímeros se pueden distinguir dos enfoques, el mezclado con otros polímeros amorfos o semicristalinos o la adición de elastómeros como modificadores de impacto.

En el primero de los casos el mezclado del PHB con otros polímeros biodegradables de origen natural o sintético (revisado en $[94,112,114,132]$ ) como almidón termoplástico, otros PHA, la policaprolactona (PCL), el ácido poliláctico (PLA), o el adipato-terftalato de polibutileno (PBAT) ha sido ampliamente estudiado. Este último (PBAT), ha despertado un gran interés debido a su elevada flexibilidad y elongación a rotura [94]. En el caso de las mezclas de PHB o PHBV con PLA, aunque la adición de PLA incide positivamente en la cristalización del PHA y en ciertos aspectos de su procesabilidad ampliando la ventana de procesado, en muchos casos no se observa una mejora de la elongación a rotura. Sin embargo, mediante la compatibilización de las fases, por ejemplo con diisocianatos, la ductilidad se ve mejorada [133].

El segundo enfoque corresponde a la adición de elastómeros como modificadores de impacto. Los elastómeros son polímeros muy flexibles, que presentan una elevada tenacidad y, por tanto, elevada capacidad de absorción de energía de impacto. En mezclas inmiscibles, esta segunda fase elastomérica queda dispersa en la matriz. La morfología concreta dependerá de la existencia o no de miscibilidad parcial de los componentes, de la compatibilidad y/o afinidad de las fases, de las condiones de mezclado, etc. En condiciones de mezclado en fundido habituales, inmiscibilidad de las fases y relativa compatibilidad entre ambas, generalmente la morfología que se obtiene se conoce como "drop in matrix". En este tipo de morfología la fase elastomérica queda finamente dispersa en forma de pequeñas gotas o dominios y la mejora de la tenacidad se produce por el 
mecanismo conocido como "rubber toughening mecanism" incrementando la capacidad de absorción de energía de impacto de la matriz [134]. El tamaño de gota y el espesor de ligamento (distancia entre gotas) juegan un papel muy importante en la mejora de tenacidad, en la medida en que cuanto menor sean ambos la matriz tendrá una mayor capacidad para mantener la deformación y una mayor capacidad de absorción de energía [135-138]. Así, mediante el uso de compatibilizantes, es posible reducir el tamaño de la fase dispersa (ya que se reduce la tensión superficial) y favorecer el incremento de tencidad [131].

Algunos de los elastómeros empleados para mejorar la tenacidad de biopoliésteres son el etilvinilacetato (EVA) [139], el caucho natural epoxidado (ENR) [140,141] o el poliuretano termoplástico (TPU) [50,142]. Este último tiene un especial interés ya que potencialmente algunos de los monómeros utilizados para su síntesis pueden ser de base biológica [143]. Aunque son numerosos los trabajos publicados de mezclas de PLA/TPU, existe relativamente poca bibliografía relacionada con el uso de TPU como aditivo en matrices de PHB o PHBV y, particularmente, relativa al desarrollo de mezclas de PHB o PHBV y TPU mediante técnicas de mezclado en fundido. Wang et al.[144] prepararon mezclas de PHBV y TPU mediante la técnica de solvent casting observando una reducción en la cristalinidad y una mejora de la tenacidad. En trabajos previos de nuestro grupo de investigación, se han preparado mezclas de PHBV y TPU mediante mezclado en fundido y prensado en caliente [145] o mediante extrusión monohusillo [146]. En ambos casos se ha observado una mejora de la elongación a rotura y la tenacidad, a expensas de la reducción de la rigidez y resistencia mecánica, así como de las propiedades barrera. Además se ha observado cierta falta de adhesión entre las fases. La compatibilización de mezclas PLA/TPU utilizando diisocianatos [147,148] o silanos [149] ha sido estudiada por varios autores. Dichas estrategias podrían ser aplicables a mezclas basadas en PHA y TPU.

d) Adición de plastificantes

Uno de los enfoques más utilizados para mejorar la flexibilidad de polímeros rígidos es la adición de plastificantes. Generalmente, los plastificantes son moléculas orgánicas relativamente pequeñas que alteran las propiedades reológicas y mecánicas del polímero. Reducen la fragilidad, mejoran la flexibilidad y la tenacidad, reducen la cristalinidad, disminuyen la temperatura de transición vítrea y de fusión y reducen la viscosidad del polímero [64,111]. En algunos casos pueden contribuir también a reducir la cristalización secundaria como ha sido publicado por Kelly et al.[150] al incorporar polietilenglicol al PHBV. Algunos de los plastificantes más utilizados en composiciones basadas en PHA son el polietilenglicol [150,151], el citrato de trietilo, el citrato de tributilo ,el citrato de acetiltributilo [152] o el aceite de soja [153], entre otros. 
e) Otras modificaciones (modificaciones físicas, modificaciones químicas )

Otros tipos de modificaciones encaminadas a mejorar la tenacidad del PHB o el PHBV comprenden distintas estrategias de modificación física o química. Así por ejemplo, se puede inducir la generación de la forma cristalina $\beta$ mediante técnicas de estirado combinadas con tratamientos térmicos de recocido. En la forma cristalina $\beta$ existe una gran cantidad de moléculas de enlace entre lamelas lo que le confiere al material excelentes propiedades mecánicas, tanto en términos de rigidez como de ductilidad, además estas propiedades son mucho más estables con el tiempo [154-156].

La mejora de las propiedades mecánicas puede conseguirse mediante la modificación de la estructura química del polímero. La estructura química de los PHA puede modificarse mediante técnicas como, por ejemplo, la copolimerización de injerto o de bloque con otros polímeros [50]. Otra posibilidad es inducir el entrecruzamiento de las cadenas. Fei et al.[157] observaron una mejora considerable de la elongación a rotura al entrecruzar el PHBV usando como iniciador peróxido de dicumilo (DCP).

\subsubsection{Procesabilidad}

EI PHB y el PHBV de bajo contenido en hidroxivalerato, son polímeros termoplásticos que pueden ser procesados mediante técnicas convencionales de procesado como el mezclado en fundido, la extrusión o la inyección. Sin embargo, como ha sido analizado anteriormente, algunas de sus características y propiedades como su elevada cristalinidad, su baja densidad de nucleación, la dependencia de la velocidad de cristalización con la temperatura, su estrecha ventana de procesado debida a la elevada cristalinidad y elevada temperatura de fusión, así como su alta sensibilidad a la degradación térmica dificultan su procesabilidad $[45,47,53,89,158,159]$

Algunas de las estrategias descritas para mejorar las propiedades mecánicas de los PHA también son aplicables a la mejora de su procesabilidad. Así, por ejemplo, el uso de agentes nucleantes o la adición de nanocargas favorece la nucleación y velocidad de cristalización y pueden contribuir a mejorar la estabilidad térmica $[9,11,12]$. El uso de plastificantes o el mezclado con otros polímeros puede ampliar la ventana de procesado reduciendo las temperaturas de cristalización o fusión [64,111]. La estabilidad térmica puede ser mejorada mediante la adición de extensores de cadena [160,161]. La viscosidad en fundido puede modificarse tanto mediante la incorporación de una segunda fase rígida, el mezclado con otros polímeros o plastificantes o el 
uso de extensores de cadena. Por tanto, mediante un diseño adecuado de las composiciones y una selección apropiada de los aditivos es posible mejorar la procesabilidad de los PHA.

No obstante, además de un diseño adecuado de la composición resulta esencial un correcto ajuste de los parámetros de operación así como de las etapas de acondicionamiento. Así pues, el correcto secado de los materiales antes de su procesado resulta esencial para prevenir la degradación térmica ya que esta se ve favorecida por la presencia de humedad a alta temperatura ya que promueve la degradación hidrolítica [94]. Las temperaturas y velocidades de mezclado deben ser escogidas cuidadosamente para evitar que existan zonas de alta temperatura en las que pueda iniciarse la degradación térmica, especialmente si el material va a ser sometido a varios ciclos térmicos.

En el procesado por extrusión, debido a que la velocidad de cristalización de estos polímeros es más rápida a temperaturas comprendidas entre los 60 y los $130 \circ \mathrm{C}$ [94] dependiendo del grado empleado, puede resultar conveniente reducir la temperatura en la boquilla e, incluso, enfriar el polímero en baño de agua para evitar problemas de pegado, por ejemplo, durante la peletización. En el caso de la obtención por extrusión monhusillo y calandrado, el ajuste adecuado de la temperatura del rodillo y el uso de sprays antiadherentes puede evitar también los problemas de pegado. De forma similar, en el moldeo por inyección, mediante el correcto ajuste de la temperatura del molde se puede favorecer la cristalización rápida del polímero, evitar los problemas de pegado en el molde y favorecer la estabilidad dimensional previniendo contracciones debidas a la cristalización.

Tal como ha sido mencionado, estos materiales resultan particularmente atractivos para aplicaciones de corta vida útil como puede ser el envasado de alimentos. Una de las técnicas más empleadas en esta industria es el termoconformado. En líneas generales, esta técnica consiste en el calentamiento de una película de plástico hasta alcanzar un estado semiplástico y el posterior conformado sobre un molde que puede ser positivo o negativo mediante el estirado de la lámina por aplicación de presión o vacío. En polímeros amorfos las temperaturas de termoconformado utilizas están ligeramente por encima de su temperatura de transición vítrea, mientras que en el caso de polímeros semicristalinos las temperaturas de termoconformado se sitúan en las inmediaciones de la temperatura de fusión [64]. Por tanto, el termoconformado de polímeros semicristalinos resulta más complicado dado que tienen ventanas de procesado más estrechas $[162,163]$. En el caso particular del PHB y el PHBV esta técnica resulta particularmente difícil, ya que presentan una alta cristalinidad y una temperatura de fusión elevada y relativamente cercana a su temperatura de degradación térmica por lo que su ventana de procesado es muy estrecha. Debido a su elevada cristalinidad el material mantiene su rigidez hasta temperaturas 
muy cercanas a la de fusión y una vez alcanzada dicha temperatura se produce una caída brusca de la viscosidad. Esta falta de estabilidad de la lámina se traduce en defectos asociados a una mala reproducibilidad de molde y una distribución de espesores deficiente. Además, durante el enfriamiento, se pueden producir defectos debidos a contracciones provocadas por la recristalización del material. La bibliografía relacionada con el termoconformado de PHB o PHBV es muy limitada [158,164]. En un trabajo previo de este grupo de investigación [158] se estudió la termoconformabilidad del PHBV y se propuso una metodología para evaluarla. Asimismo, se estudió la mejora de la termoconformabilidad de este polímero mediante el desarrollo de mezclas con PLA compatibilizadas con diisocianatos. En dicho trabajo se evidencian las dificultades de termoconformado del PHBV y como el mezclado con un polímero amorfo y la compatibilización de la mezcla con diisocianatos, permite ampliar la ventana de procesado y mejorar la reproducibilidad del molde y la distribución de espesores.

\subsubsection{Biodegradabilidad}

Una de las propiedades que hace al PHB y al PHBV especialmente atractivos para aplicaciones de corta vida útil como la de envasado o la fabricación de productos desechables es su biodegradabilidad. En este sentido, resulta especialmente interesante su biodegradabilidad en diferentes ambientes así como su compostabilidad ya que, en la mayoría de los casos, los residuos derivados de estos productos se desechan junto a la fracción orgánica de los residuos y el compostaje puede ser considerado como una opción viable para su tratamiento.

En su sentido más amplio, la IUPAC define los polímeros biodegradables como [4] "polímeros susceptibles de ser degradados por actividad biología, cuya degradación va acompañada de una reducción de su masa molecular". No obstante, a efectos prácticos, para que un plástico pueda considerarse biodegradable en un determinado ambiente o en condiciones de compostaje debe cumplir una serie de requisitos específicos de acuerdo a la normativa establecida. En el caso concreto del compostaje, de acuerdo a la norma ASTM-D883 [165] relativa a la terminología de plásticos, un plástico compostable se define como "un plástico que experimenta degradación biológica durante el compostaje para dar lugar a dióxido de carbono, agua, compuestos inorgánicos y biomasa a una velocidad comparable a otros materiales compostables conocidos y sin dejar residuos visualmente detectables o tóxicos". Teniendo en cuenta esta definición un plástico será compostable si es biodegradable, biodesintegrable y los productos de su degradación no son tóxicos $[2,166]$. 
Existen diferentes normas que permiten evaluar estos tres requisitos y que establecen los periodos de tiempo máximos y los porcentajes mínimos de biodegradación o biodesintegración para que un material pueda considerarse compostable. Así pues las normas ISO 17088 [167] o ASTM 6400 [168] establecen las especificaciones para plásticos compostables, las normas ISO 14855-1 [169], ISO 14855-2 [170] y ASTM D5338 [171] permiten evaluar la biodegradabilidad en compostaje y las normas ISO 20200 [172] y ISO 16929 [173] permiten evaluar la desintegrabilidad en compostaje. Finalmente la norma EN 13432 [174] define los criterios para que un envase pueda ser etiquetado como biodegradable o compostable (Figura 2.7) y contempla la evaluación de la calidad y toxicidad del compost resultante [166].

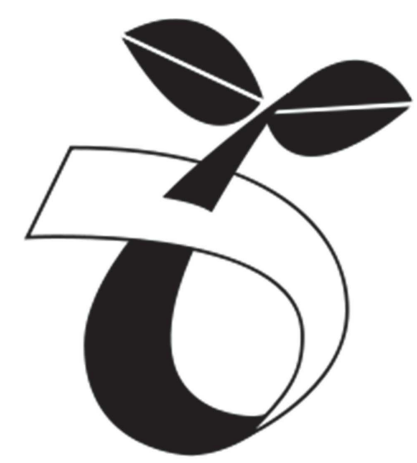

Figura 2.7. Logotipo de envase compostable de acuerdo a la norma EN 13432.

La biodegradabilidad y/o biodesintegrabilidad del PHB y el PHBV en diferentes ambientes incluido el marino, así como en compostaje tanto a escala de laboratorio, como industrial o doméstico ha sido ampliamente estudiada y demostrada [159,175-178]. No obstante, a la hora de desarrollar nuevas formulaciones e introducir nuevos aditivos a las composiciones, resulta indispensable estudiar su influencia en la biodegradabilidad y/o compostabilidad de estos matriales. En esta tesis se ha estudiado la biodesintegrabilidad en condiciones controladas de compostaje de las composiciones desarrolladas mediante la norma ISO 20200 [172] que permite determinar el grado de desintegración del material midiendo la masa seca de material recuperado tras un tiempo determinado de ensayo después de pasar por un tamiz de $2 \mathrm{~mm}$. De acuerdo a las diferentes normas mencionadas, un material pude considerarse biodesintegrable cuando se alcanza un grado de desintegración superior al $90 \%$ en un periodo máximo establecido por la norma (180 días de acuerdo a la norma EN 13432 [174]). 


\subsection{Compuestos de matriz polimérica basados en fibras lignocelulósicas}

El uso de fibras vegetales o lignocelulósicas como refuerzo en materiales compuestos de matriz polimérica ha generado un enorme interés en las últimas décadas, como ha sido puesto de manifiesto en la Sección 1 de esta memoria atendiendo al gran número de publicaciones relacionadas en los últimos años (ver Figura 1.6.).

En general, las fibras lignocelulósicas presentan elevadas propiedades específicas debido a su baja densidad, son no abrasivas, al contrario que otros refuerzos tradicionales (p.ej. fibra de vidrio), son muy abundantes y de bajo coste y son biodegradables. El creciente interés demostrado en el uso de estos materiales viene motivado no solo por cuestiones técnicas sino también por cuestiones socio-económicas y medioambientales. Desde el punto de vista técnico, en general, estos materiales resultan adecuados como refuerzos debido a su baja densidad, buena resistencia y elevada rigidez específica. Desde el punto de vista económico ya que al tratarse de materiales muy abundantes y baratos pueden contribuir a reducir los costes del producto. Finalmente, desde el punto de vista medioambiental debido a su origen natural y biodegradabilidad y a la posibilidad de valorización de residuos de origen vegetal. En efecto, el desarrollo de materiales compuestos basados en fibras lignocelulósicas y polímeros biodegradadbles y de base biológica, como los PHA, está en consonancia con un concepto de producto dirigido a fomentar el desarrollo sostenible y la economía circular [31,127,179,180].

En los siguientes apartados se describen la estructura y composición típicas de las fibras vegetales y sus propiedades generales. Asimismo se hace una revisión de su uso como refuerzo en matrices poliméricas, centrando la atención en los PHA y en los factores clave que determinan el comportamiento de los compuestos polímero/fibra.

\subsubsection{Estructura, composición y propiedades generales de las fibras lignocelulósicas}

Las fibras vegetales o lignocelulósicas se encuentran en la naturaleza formando parte de los tejidos vegetales de árboles, plantas, frutos, semillas, etc. Por tanto, aunque comparten ciertas características generales, su composición y propiedades concretas dependen de numerosos factores como la fuente de origen, su localización en la planta, la edad de la planta, la época del año, los métodos de extracción empleados, etc [93,181,182]. Estos materiales se pueden obtener 
a partir de fuentes primarias, es decir, a partir de plantas cultivadas por su elevado contenido en fibra; a partir de fuentes secundarias, aquellas en las que la fibra se obtiene como un subproducto; o incluso terciarias, en las que la fibra se obtiene a partir de residuos de origen vegetal como una forma de valorización del mismo [31,113]. En función de la localización en la planta, las fibras vegetales se pueden agrupar en fibras bastas o de líber (cáñamo, lino, yute), fibras de hoja (sisal, abacá, agave), de semillas o frutos (algodón, coco, cáscaras), de hierba, de caña (bambú), de tallo (paja de trigo, de arroz o de maíz) o de madera (dura o blanda)[113,180,182,183]. En el caso de los residuos vegetales, la clasificación dentro de uno de los grupos mencionados puede resultar complicada ya que, a menudo, pueden estar formados por mezclas, por ejemplo, de cáscaras, tallos y hierbas.

Las fibras vegetales pueden considerarse en esencia materiales compuestos. A grandes rasgos, están formadas por fibras de celulosa semicristalina embebidas en una matriz amorfa compuesta principalmente por hemicelulosas y lignina y otros componentes minoritarios como pectina, ceras o ácidos grasos, de ahí que también se denominen fibras lignocelulósicas [184-186]. Estas fibras elementales están unidas entre sí formando "paquetes" para configurar diferentes tejidos vegetales con distintas funcionalidades dentro de la planta [180]. En la Figura 2.8. se muestra la estructura característica de las fibras vegetales elementales.

Estas fibras están formadas por un canal central denominado lumen encargado del transporte de nutrientes y otras sustancias a la planta, la pared celular y la capa intercelular o lamela media. La pared celular está formada, a su vez, por diferentes capas compuestas por microfibrillas de celulosa dispuestas en diferentes orientaciones en función de la capa a la que pertenecen y del tipo de tejido vegetal. En la pared celular primaria las microfibras de celulosa están dispuestas al azar en una matriz de pectina, hemicelulosa, lignina y proteínas. En la pared celular secundaría que está dividida en tres capas (interna, media y externa), las microfibras de celulosa están dispuestas en una orientación espiral o helicoidal caracterizada por un determinado ángulo. Esta orientación particular de las microfibrillas de celulosa tiene una marcada influencia en las propiedades mecánicas de la fibra. La capa intercelular o lamela media está compuesta principalmente de pectina que actúa como material de unión entre diferentes fibras $[127,180,187]$.

Como ha sido mencionado, los principales constituyentes de las fibras lignocelulósicas son la celulosa, la lignina y las hemicelulosas, y en menor proporción, la pectina, las ceras, proteínas ácidos grasos y otros componentes y extractos en función del tipo de planta. 


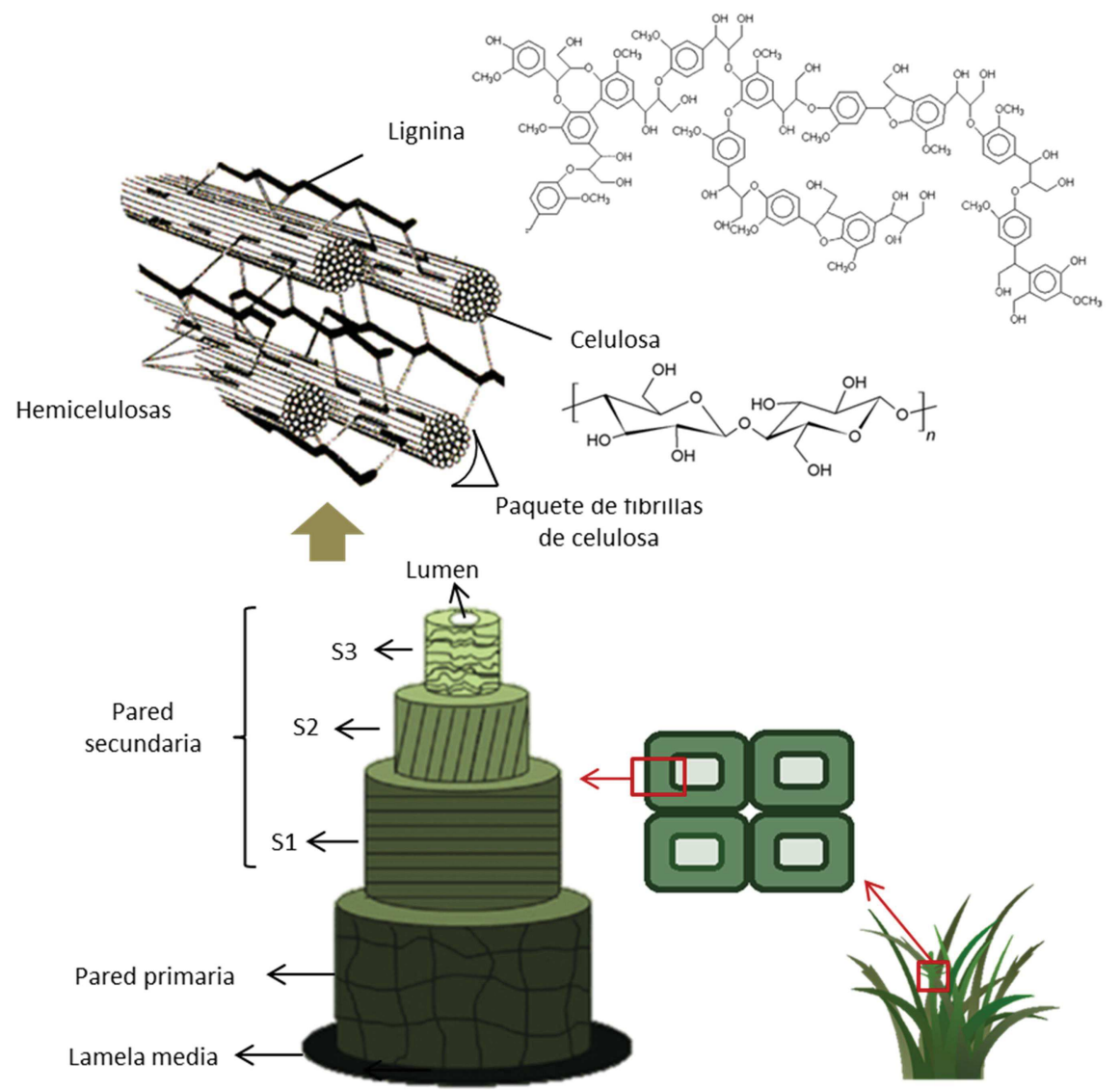

Figura 2.8. Representación esquemática de la estructura de las fibras lignocelulósicas

Generalmente, la celulosa representa alrededor del 40 o 50\% de la masa seca de las fibras [188] y puede llegar incluso hasta el 80 \%, por ejemplo, en fibras de algodón [189]. Es un polisacárido hidrófilo lineal de cadena larga formado por unidades de $\beta$-D glucosa unidas mediante enlaces $\beta$ $(1 \rightarrow 4)$ glucosídico $[127,187]$. Cada unidad monomérica posee tres grupos hidroxilo que pueden establecer puentes de hidrógeno con otros grupos hidroxilo dentro de la misma cadena o con cadenas adyacentes para formar microfibras de celulosa. Existen seis formas polimórficas de la

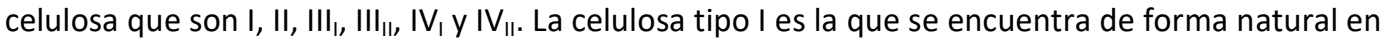
las plantas y puede presentar dos subalomorfos, la forma $I_{\alpha}$ y la forma $I_{\beta}$. En ambas, las cadenas están alineadas de forma paralela y difieren en la disposición de los puentes de hidrógeno $[187,188]$. Las fibrillas de celulosa presentan zonas de elevada cristalinidad y regiones amorfas. En general, la celulosa presente en la madera o las plantas presenta una cristalinidad de alrededor del 60-70\% [187,188]. 
Las hemicelulosas son polisacáridos amorfos de cadena corta entre los que se encuentran la glucosa, la xilosa, la manosa, la galactosa o la arabinosa [184-186,188]. Estos componentes pueden representar hasta un $25-40 \%$ de la masa seca de las fibras [188].

La lignina actúa como componente de soporte en las plantas. Es un polímero amorfo tridimensional complejo constituido tanto por unidades alifáticas como aromáticas [187]. Se forma por la deshidrogenación de moléculas de fenilpropano y su posterior unión mediante enlaces éster, éter o carbono-carbono $[112,188]$. Las principales unidades monoméricas de la lignina son el alcohol cumarílico, coniferílico y sinapílico [187]. La composición exacta de la lignina depende de la planta e incluso difiere en los diferentes tejidos dentro de la misma [188]. El contenido en lignina depende de la especie vegetal, el tipo de tejido y la edad de la planta y puede variar mucho de unas fibras a otras desde contenidos alrededor del $5 \%$, por ejemplo en fibras de lino, hasta contenidos cercanos al 50\%, por ejemplo en fibras de coco [31].

Las pectinas son el principal componente de la lámina media de la pared celular. Son heteropolisacáridos ramificados capaces de formar geles semirrígidos en presencia de agua e iones calcio. Estas estructuras ramificadas proporcionan rigidez a la planta [112]. La parte externa de los tejidos vegetales está recubierta por una cutícula bioprotectora formada por ceras y otros componentes lipófilos. Además de estos componentes, cada planta presenta constituyentes propios en función de la especie en cuestión [188].

Las propiedades de las fibras lignocelulósicas dependen tanto de sus características microestructurales como de su composición (contenido en celulosa, lignina, hemicelulosas, etc.), que a su vez son función del tipo de planta, del tipo de tejido vegetal, la edad de la planta, la época de recolección, las condiciones climáticas, el almacenamiento, el método de extracción de la fibra, etc $[179,190]$. Por tanto, teniendo en cuenta el gran número de especies vegetales que existen y todas las variables que influyen, las propiedades de las fibras lignocelulósicas varían notablemente de un caso a otro. No obstante, presentan algunas propiedades comunes. Son fibras biodegradables, de naturaleza hidrófila con una gran capacidad de absorción de agua, tienen baja densidad y elevadas propiedades mecánicas específicas y presentan una relativamente baja estabilidad térmica $[127,180,190]$.

En general, las propiedades mecánicas de las fibras, rigidez y resistencia mecánica, están muy relacionadas con su composición, microstructura y presencia de defectos. Principalmente el contenido de celulosa, el ángulo microfibrilar, la cristalinidad o el diámetro de fibrilla tienen una mayor influencia. Aunque como resaltan Mohanty et al. [93] resulta complicado establecer una relación directa debido a la compleja microestructura de las fibras, en general, fibras con 
diámetro pequeño, elevado contenido en celulosa, elevada cristalinidad y bajo ángulo microfibrilar presentan elevada resistencia mecánica y rigidez. El contenido en lignina también tiene una marcada influencia sobre la microestructura y la morfología de las fibras y, por tanto, sobre sus propiedades mecánicas [93,184]. Las ceras y otras sustancias lipídicas determinan, en gran medida, la mojabilidad y las características adhesivas de las fibras [93].

La estabilidad térmica de las fibras también está íntimamente relacionada con su composición. Yang et al [191]. estudiaron la pirolisis de los principales componentes de las fibras mediante TGA-DSC. Las hemicelulosas inician su degradación térmica a relativamente bajas temperaturas, alrededor de $220^{\circ} \mathrm{C}$, la degradación térmica de la celulosa ocurre en un rango de temperaturas comprendido entre 315 y 400 으, mientras que la degradación térmica de la lignina se produce lentamente en un amplio rango de temperaturas (150-900ㄷ).

Los diferentes componentes de las fibras también presentan distinto comportamiento frente a la degradación fotoquímica o la biodegradación. La lignina es más sensible a la degradación ultravioleta, seguida de las hemicelulosas y la celulosa. La degradación biológica es más rápida en las hemicelulosas, seguida de las regiones amorfas de la celulosa y finalmente en las regiones cristalinas de la celulosa y en la lignina $[93,192]$.

\subsubsection{Fibras lignocelulósicas en compuestos de matriz polimérica}

Una de las estrategias más utilizadas para mejorar las propiedades en polímeros y/o abaratar sus costes es el uso de rellenos. Los materiales de relleno se pueden clasificar en dos grandes grupos, las cargas y los refuerzos. Las cargas tienen como principal objetivo abaratar el coste del producto reduciendo la cantidad de resina necesaria. La función de los materiales de refuerzo es proporcionar rigidez y resistencia mecánica a la matriz polimérica [21,64]. Por tanto, la eficiencia de dicho refuerzo dependerá de las propiedades de la matriz, de las propiedades del refuerzo y de sus características geométricas y de la adhesión entre ambas fases. Los materiales de refuerzo pueden ser fibras largas o cortas, orientadas o no, microfibras, partículas o nano refuerzos, y deben poseer elevada rigidez y resistencia mecánica [21].

Debido al gran número de fibras lignocelulósicas existentente, su disponibilidad y bajo coste y sus excelentes propiedades mecánicas específicas, este tipo de materiales resultan adecuados tanto como cargas, como como refuerzos, cubriendo un amplio rango de posibilidades. Sin embargo, presentan ciertas limitaciones, entre las que cabe destacar su relativamente baja estabilidad térmica y su elevada hidrofilicidad $[31,179,182,192]$. En la Tabla 2.2. se recogen algunas de las 
principales ventajas e inconvenientes de las fibras lignocelulósicas para su uso en compuestos de matriz polimérica.

Tabla 2.2. Principales ventajas e inconvenientes de las fibras lignocelulósicas en materiales compuestos de matriz polimérica [adaptada de la referencia [179]]

\begin{tabular}{cc}
\hline Ventajas & Inconvenientes \\
\hline $\begin{array}{c}\text { Origen renovable, abundancia y bajo coste } \\
\text { Biodegradabilidad/Compostabilidad* } \\
\text { Baja densidad }\end{array}$ & $\begin{array}{c}\text { Calidad y propiedades variables } \\
\text { Relativamente baja estabilidad térmica } \\
\text { Elevada rigidez y resistencia mecánica específica } \\
\text { Reciclabilidad }\end{array}$ \\
$\begin{array}{c}\text { Elevada absorción de humedad } \\
\text { Ro abrasivas para los equipos de procesado } \\
\text { degradación biológica y/o ambiental) }\end{array}$ \\
\hline
\end{tabular}

El elevado carácter hidrófilo de estas fibras hace que presenten una baja compatibilidad con las matrices poliméricas, generalmente hidrófobas. Dado que la interacción fibra-matriz es un factor determinante en las propiedades finales del compuesto, en la bibliografía se han documentado diferentes estrategias dirigidas a mejorarla (revisadas en [31,112,187,193-198]). Estas estrategias se centran en dos enfoques principales: a) la modificación de las fibras mediante métodos físicos, químicos o biológicos para mejorar su mojabilidad o favorecer el anclaje físico y/o químico con la matriz polimérica y b) Establecer enlaces químicos entre la fibra y la matriz.

\title{
a) Modificación de las fibras
}

\author{
a.1. - Modificaciones físicas \\ Los métodos físicos van dirigidos a introducir modificaciones estructurales y \\ superficiales en las fibras que permitan modificar la energía superficial de las mismas \\ mejorando así la compatibilidad con la matriz y/o modificar su topografía favoreciendo \\ el anclaje mecánico con el polímero. Algunos de los tratamientos físicos de fibras \\ incluyen el estirado, el calandrado, tratamientos térmicos, descarga corona o \\ tratamiento con plasma $[113,180,198]$. Siendo estos dos últimos los más populares \\ dentro de este grupo $[199,200]$.
}




\section{a.2. - Modificaciones químicas}

El pretratamiento de las fibras puede dar lugar a superficies más "limpias" o introducir cambios químicos que favorezcan la adhesión con la matriz polimérica [180]. Los tratamientos químicos de modificación de las fibras pueden aplicarse para modificar la tensión superficial y la polaridad de las fibras o bien para activar los grupos hidroxilo de su superficie o introducir nuevos grupos funcionales que permitan en anclaje con la matriz [201]. Existen un gran número de métodos de modificación química de fibras basados en la purificación o "lavado" de las fibras (eliminación de ceras y otros componentes no celulósicos, deslignificación), la impregnación de las fibras o la funcionalización superficial de las mismas [198].

Uno de los tratamientos más populares es el tratamiento alcalino con hidróxido de sodio. Este tratamiento consigue eliminar parcialmente componentes no celulósicos de las fibras, principalmente lignina y ceras, y promueve la disrupción de los enlaces de hidrógeno en la estructura reticulada de las fibras incrementando el número de sitios reactivos en la superficie de las mismas. Además introduce una mayor rugosidad superficial y puede favorecer la desfibrilación y la reducción del diámetro de las fibras $[113,181]$. Con la eliminación de componentes no celulósicos se obtienen fibras con un mayor contenido de celulosa lo que da lugar, en principio, a una mayor cristalinidad de las fibras, mejores prestaciones mecánicas, mayor homogeneidad de propiedades, mayor blancura, reducción de tamaño y posibilidad de procesado a mayores temperaturas dado que al eliminar, principalmente, las hemicelulosas el onset de la degradación térmica se desplaza a mayores temperaturas [202].

Otros métodos populares de purificación de las fibras o deslignificación incluyen la extracción con disolventes orgánicos [203], el uso de permanganato potásico, hipoclorito sódico, ácido acético o ácido peracético, entre otros [127]. El uso de compuestos clorados es bastante habitual en el pretratamiento de fibras lignocelulósicas, sin embargo, da lugar a la generación de vertidos contaminates por lo que la tendencia se decanta cada vez más hacia el uso de tratamientos totalmente libres de cloro [204-206]. El tratamiento con ácido peracético ha ganado cierta popularidad, ya que ha demostrado ser efectivo y medioambientalmente respetuoso [207-209].

Respecto a los métodos de funcionalización superficial en la bibliografía se han descrito diversas estrategias basadas en la funcionalización con silanos, isocianatos, acetilación, esterificación, acrilinización, etc [187,210,211]. 


\section{a.3.- Modificaciones biológicas}

Una alternativa a los métodos físicos y químicos de modificación de fibras es la modificación biológica mediante hongos o enzimas. Algunas de las ventajas de estos métodos es que permiten eliminar componentes pécticos o hemicelulósicos de forma selectiva con un bajo coste energético y pueden ser reciclables $[180,201]$.

\section{b) Anclaje químico fibra-matriz}

El anclaje químico de la fibra a la matriz se puede conseguir mediante técnicas ex-situ basadas, principalmente, en estrategias de copolimerización o "grafting" de las fibras con uno o varios monómeros (también se incluirían es este grupo algunas estrategias de funcionalización superficial descritas más arriba), o la compatibilización in-situ directamente con la matriz mediante procesado reactivo [187].

El procesado reactivo consiste en la adición de agentes reactivos durante el mezclado en fundido que interaccionen tanto con la matriz como con la fibra para promover su compatibilización. Esta técnica ha despertado un enorme interés debido a que la compatibilización se lleva a cabo en una sola etapa, por lo que resulta una técnica sencilla y efectiva desde el punto de vista económico. Además no supone un coste adicional de energía ni conlleva la generación de vertidos ni otros residuos.

Los agentes reactivos más habituales incluyen peróxidos (p.ej. DCP) capaces de generar especies radicalarias intermedias para generar el enlace químico entre el polímero y la fibra o un agente de compatibilización adicional [212-214], o reactivos bifuncionales o multifuncionales capaces de reaccionar con la fibra y con el polímero como, por ejemplo, isocianatos [215-217], epoxis [218-220] o diferentes anhídridos carboxílicos [215,221-224], entre otros.

Los diferentes tratamientos de modificación de fibras y/o anclaje químico con el polímero, además de influir en la adhesión fibra-matriz y, por tanto, en el comportamiento mecánico de los compuestos, también pueden afectar a la capacidad de absorción de agua de las fibras [225], la estabilidad térmica de los compuestos o la biodegradabilidad de los mismos. Por ejemplo, la eliminación de impurezas y de componentes no celulósicos puede tener un impacto positivo en la estabilidad térmica de las fibras, sin embargo, en algunos casos el tratamiento químico puede deteriorar la estructura de la fibra y la estabilidad térmica puede verse reducida [202]. Los diferentes agentes compatibilizantes o de acoplamiento pueden, en algunos casos, reducir la velocidad de biodegradación. Dicho comportamiento ha sido observado, por ejemplo, en 
compuestos compatibilizados con anhídrido maleico [226] o ácido acrílico [227], en los que la velocidad de degradación se redujo con respecto a los compuestos sin compatibilizar.

\subsubsection{Compuestos PHA/fibra}

El desarrollo de compuestos basados en PHA y fibras lignocelulósicas ha sido intensamente investigado en las últimas décadas. Bhardwaj et al [228] apuntan que la relativa naturaleza polar de los PHA y la presencia de grupos carbonilo $(>C=O)$ capaces de establecer puentes de hidrógeno con los grupos hidroxilo de las fibras lignocelulósicas hacen que exista una mejor compatibilidad fibra-matriz en comparación con otros polímeros como, por ejemplo, el polipropileno. En efecto, la presencia de puentes de hidrógeno entre las fibras y la matriz polimérica ha sido confirmada por espectroscopia infrarroja por Gunning et al [229] en compuestos de PHB y fibras de yute. Torres-Tello et al. [230] también observaron cierta compatibilidad entre el PHB y el PHBV y fibras de agave. En este caso, la incorporación de las fibras supuso un aumento del módulo elástico, tanto a flexión como a tracción, de la resistencia al impacto y una ligera mejora de la estabilidad térmica. Rossa et al.[231] observaron una mejora del módulo elástico y la resistencia mecánica, así como un aumento de la temperatura de deflexión al calor (HDT) en compuestos de PHBV y fibras de Carauá, sin embargo, la estabilidad térmica se redujo.

A pesar de esa cierta compatibilidad y, aunque los resultados varían de unos trabajos a otros en función del tipo de fibra, el tipo de compuesto (fibras continuas o discontinuas, tamaño de las fibras, etc.) y la técnica de procesado, en general, en compuestos basados en PHA y fibras lignocelulósicas no sometidas a ningún pretratamiento, se observa una falta de adhesión entre la fibra y la matriz. En la mayoría de los casos, aunque se observa un efecto de refuerzo caracterizado por un aumento del módulo elástico, la resistencia mecánica y la elongación a rotura se ven negativamente afectadas debido a esa falta de adhesión, que hace que las fibras actúen como concentradores de tensiones [95,232-238]. Otras propiedades, como la estabilidad térmica, también se ven negativamente afectadas en la mayoría de los casos $[233,235,236,239]$, aunque depende, en gran medida, del tipo de fibra y las condiciones de procesado.

Respecto a la influencia de las fibras sobre la cinética de cristalización y la cristalinidad de los PHA, los resultados son muy variables. En algunos casos la presencia de las fibras no parece tener ningún efecto sobre las temperaturas de cristalización y fusión del polímero ni sobre el índice de cristalinidad, en otros se ven afectados de diferente manera en función de la matriz, del contenido de fibra, el tipo de fibra, de su tamaño o de su geometría. Sin embargo, resulta 
complicado establecer una correlación. Por ejemplo, Torres-Tello et al.[230] no observaron variaciones en estos parámetros en compuestos $\mathrm{PHB} /$ agave mientras que en los compuestos PHBV/agave observaron una reducción de la cristalinidad con el contenido en fibra y un aumento de la temperatura de fusión. Estos autores atribuyen dichas diferencias a que las fibras pueden actuar tanto como agentes nucleantes promoviendo la cristalización, como restringir el movimiento de las cadenas dificultando la misma. Berthet et al [236]. observaron una reducción de la temperatura de cristalización y una ligera disminución de la cristalinidad en compuestos de PHBV y paja de trigo y PHBV y residuos de molienda de la aceituna, atribuidas, también, a una restricción en el movimiento de las cadenas poliméricas debido a la presencia de las fibras. Sin embargo, Avella et al. [240] observaron un aumento en la velocidad de cristalización en compuestos de PHBV y paja de trigo debido a un efecto nucleante de las fibras. Krishnaprasad et al.[232] también observaron un efecto nucleante de las fibras en compuestos de PHB y microfibras de bambú. Scalioni et al. [241] también encontraron un efecto nucleante de las fibras en compuestos de PHB y fibras de caraua. En este caso, observaron la formación de capas transcristalinas alrededor de las fibras, un aumento del espesor lamelar, una disminución del tamaño de cristalito y una transición esferulita-axialita de los cristales.

Son muchas las estrategias documentadas para mejorar el comportamiento de compuestos PHA/fibra. Dichas estrategias van principalmente dirigidas a mejorar la adhesión fibra-matriz, ya sea mediante la modificación de las fibras, de la matriz o el uso de aditivos o agentes reactivos de compatibilización.

Dufresne et al. [242] estudiaron el efecto de la modificación mediante plasma de fibras procedentes de harina de madera de abeto y de hueso de aceituna sobre las propiedades de compuestos de matriz PHBV. Estos autores observaron una mala adhesión entre las fibras y la matriz incluso en las fibras tratadas por plasma, por lo que dicho tratamiento no produjo una mejora de las propiedades mecánicas. Ventura et al.[243], por el contrario, sí que notificaron una mejora en las propiedades mecánicas, tanto en rigidez como en resistencia mecánica, en compuestos de PHB y fibras de lino tratadas mediante plasma, atribuida a una mayor adhesión fibra-matriz inducida por el tratamiento.

Son varios los autores que han estudiado diferentes tratamientos químicos de purificación de fibras lignocelulósicas y/o de modificación química superficial (eliminación de ceras, deslignificación, acetilación, uso de egentes de acoplamiento como silanos, etc.) y su influencia sobre las propiedades de compuestos de base PHA. Melo et al [243]. estudiaron el efecto de diferentes pretratamientos químicos en fibras de carnauba en compuestos de matriz PHB. Dichos tratamientos incluían: tratamiento alcalino con $\mathrm{NaOH}$, y diferentes tratamientos combinados de 
$\mathrm{NaOH}+$ permanganato potásico, $\mathrm{NaOH}$ + acetilación y $\mathrm{NaOH}+$ peróxido de hidrógeno. Este último fué el que proporcionó unos mejores resultados dando lugar a una mayor mojabilidad de las fibras por la matriz, que se tradujo en un incremento del módulo elástico y la resistencia mecánica. En efecto, la observación mediante SEM de la superficie de las fibras reveló una mayor rugosidad, en este caso, respecto a las fibras no tratadas favoreciendo también la adhesión. Ahankari et al. [244] también observaron una clara mejora de las propiedades mecánicas y la adhesión fibra-matriz en compuestos de PHBV y fibras de paja de trigo, tallo de soja y paja de maíz tratadas con $\mathrm{NaOH}$. En efecto, los valores de módulo elástico y resistencia mecánica de los compuestos con fibras tratadas fueron superiores, incluso, a los correspondientes al PHBV virgen, aunque la elongación a rotura y la resistencia al impacto fueron inferiores a las del polímero virgen. Además el tratamiento supuso una mejora de la estabilidad térmica de los compuestos. Estos autores también observaron una mayor compatibilidad de las fibras con el PHBV que con el PP.

El uso de agentes de acoplamiento como el anhídrido maleico [215,221,224,226,245-247], diferentes silanos [221,226,247-250] o ácido acrílico [227,245], mediante técnicas de funcionalización de las fibras o bien, mediante técnicas de grafting con la matriz, ha demostrado, en general, una mejora de la compatibilidad fibra-matriz. El uso de otros aditivos como,por ejemplo, plastificantes para mejorar la compatibilidad fibra matriz también ha sido explorado $[251,252]$. En estos casos, aunque se observa cierta mejora de la mojabilidad de la fibra por la matriz debida a la adsorción del plastificante sobre la superficie de esta, el plastificante puede migrar a la matriz afectando a sus propiedades.

Una de las estrategias que mayor interés ha despertado es la compatibilización reactiva ya que se trata de una técnica que comprende una sola etapa $y$, por tanto, resulta sencilla, económicamente viable y más respetuosa con el medio ambiente que otras técnicas en términos de consumo de energía adicional o generación de vertidos [214,218]. Existen diferentes agentes reactivos de compatibilización o acoplamiento que poseen grupos funcionales capaces de reaccionar in-situ durante la etapa de mezclado en fundido con los abundantes grupos hidroxilo presentes en la superficie de las fibras e, incluso, con los grupos hidroxilo y carboxilo terminales del polímero estableciendo así enlaces entre las fibras y la matriz y mejorando, por tanto, la adhesión entre ambos componentes. Algunos de los agentes reactivos más comunes contienen grupos anhídrido maleico (PHA-g-MA) [215,222-224], grupos epoxy [215], grupos isocianato [203,215,253] o poliésteres terminados en carboxilo [215]. El uso de peróxidos, como el peróxido de dicumilo [213,214,254], como iniciadores de compatibilización reactiva por generación de especies radicalarias intermedias que permiten la formación de enlaces aleatorios entre la fibra y 
la matriz, también es una estrategia muy común. En la Tabla 2.3. se recogen algunos ejemplos de diferentes trabajos documentados en la bibliografía relacionados con la compatibilización reactiva de compuestos $\mathrm{PHA} /$ fibra y los principales resultados obtenidos.

Lógicamente, la mejora de la adhesión matriz-fibra tiene un impacto positivo sobre las propiedades mecánicas. No obstante, la elevada fragilidad del PHA hace que los compuestos $\mathrm{PHA} /$ fibra presenten, en general, una baja tenacidad. Aunque, en algunos casos, la incorporación de las fibras puede suponer una cierta mejora de la resistencia al impacto, la ductilidad de los compuestos es baja y está limitada por las propiedades de la matriz. Por tanto, la incorporación y compatibilización de fibras lignocelulósicas puede combinarse con las diferentes estrategias para mejorar las propiedades de la matriz (descritas en el apartado 2.3 de esta sección). Así, por ejemplo, Nagarajan et al. [203] han estudiado las propiedades de mezclas de PHBV/PBAT con diferentes contenidos de fibra de pasto varilla (Panicum virgatum) y el efecto del uso de pMDI como compatibilizante observando una mejora general del comportamiento mecánico. Estos autores sugieren que el pMDI actúa no solo compatibilizando las fibras con la matriz sino, también, mejorando la interacción de las dos fases poliméricas por reacciones de extensión de cadena. Zhang et al.[141] han estudiado el comportamiento de mezlas de PHBV/PBAT, un modificador de impacto (caucho natural epoxidado, ENR) y fibras de miscanthus obtenidas por extrusión reactiva con DCP. Estos autores observaron que el DCP y el ENR actúan de forma colaborativa en la compatibilización de las diferentes fases. El efecto combinado de los diferentes componentes da lugar a unas propiedades balanceadas en términos rigidez, resistencia mecánica, tenacidad y resistencia térmica.

Tabla 2. 3. Algunos ejemplos de compatibilización reactiva en compuestos PHA/fibra

\begin{tabular}{|c|c|c|c|c|}
\hline Matriz & Fibra & $\begin{array}{l}\text { Agente } \\
\text { reactivo }\end{array}$ & Resultados & Ref. \\
\hline PHBV & Miscanthus & $\begin{array}{l}\text { DCP(peróxido } \\
\text { de dicumilo) }\end{array}$ & $\begin{array}{l}\text { Adhesión fibra-matriz mejorada. } \\
\text { Grafting evidenciado por FTIR. Mejora } \\
\text { de la resistencia mecánica y la } \\
\text { elongación a rotura. Reducción de Tm } \\
\text { pero Xc no varía. }\end{array}$ & [213] \\
\hline
\end{tabular}




\begin{tabular}{|c|c|c|c|c|}
\hline Matriz & Fibra & $\begin{array}{l}\text { Agente } \\
\text { reactivo }\end{array}$ & Resultados & Ref. \\
\hline PHBV & Miscanthus & $\mathrm{DCP}$ & $\begin{array}{l}\text { Mejora de la adhesión fibra-matriz. } \\
\text { Mejora de la resistencia mecánica a } \\
\text { tracción y flexión. Reducción del } \\
\text { módulo elástico atribuida a } \\
\text { disminución de Xc. Reducción de la } \\
\text { estabilidad térmica. }\end{array}$ & [214] \\
\hline $\begin{array}{c}\mathrm{PHB} / \mathrm{PH} \\
\mathrm{BV}\end{array}$ & $\alpha$-celulosa & DCP & $\begin{array}{l}\text { Adhesión fibra-matriz mejorada. } \\
\text { Mejora del módulo elástico y la } \\
\text { resistencia mecánica. Disminución de } \\
\text { Xc. La estabilidad térmica no se ve } \\
\text { afectada. }\end{array}$ & [254] \\
\hline \multirow[t]{2}{*}{ PHB } & \multirow[t]{2}{*}{$\begin{array}{l}\text { Harina de } \\
\text { madera de } \\
\text { pino }\end{array}$} & $\begin{array}{c}\text { pMDI (poli } \\
\text { diisocianato de } \\
\text { difenilmetano) } \\
\text { Uralac } \\
\text { (poliéster } \\
\text { terminado en } \\
\text { carboxilo) } \\
\text { DER(resina } \\
\text { epoxy) }\end{array}$ & $\begin{array}{c}\text { En general efecto de } \\
\text { compatibilización: } \mathrm{pMDI}>\text { Uralac > } \\
\text { DER } \approx \text { PHB-g-MA } \\
\text { Mejora de la rigidez y la resistencia } \\
\text { mecánica. Mejora de la resistencia al } \\
\text { agua. } \\
\text { La Xc no se ve afectada con el pMDI } \\
\text { pero aumenta Tc y Tm (mayor } \\
\text { perfección cristalina). }\end{array}$ & [215] \\
\hline & & PHB-g-MA & & \\
\hline PHBV & Cáñamo & PHBV-g-MA & $\begin{array}{l}\text { Adhesión mejorada. Mejora de la } \\
\text { rigidez, la resistencia mecánica y la } \\
\text { resistencia al impacto. La estabilidad } \\
\text { térmica y termo-oxidativa no se ven } \\
\text { afectadas. }\end{array}$ & [222] \\
\hline
\end{tabular}




\begin{tabular}{|c|c|c|c|c|}
\hline Matriz & Fibra & $\begin{array}{l}\text { Agente } \\
\text { reactivo }\end{array}$ & Resultados & Ref. \\
\hline PHBV & $\begin{array}{l}\text { Fibra de } \\
\text { bambú }\end{array}$ & pMDI & $\begin{array}{l}\text { Adhesión mejorada. Aumento de la } \\
\text { rigidez y la resistencia mecánica. } \\
\text { Disminución de la resistencia al } \\
\text { impacto por inhibición el efecto "pull- } \\
\text { out". }\end{array}$ & [253] \\
\hline PHBV & $\begin{array}{l}\text { Harina de } \\
\text { madera de } \\
\text { pino (WF) } \\
\qquad y \\
\text { WF sometida } \\
\text { a tratamiento } \\
\text { con un órgano } \\
\text { polisiloxano }\end{array}$ & pMDI & $\begin{array}{l}\text { En tratamiento con el órgano } \\
\text { polisiloxano tuvo un efecto negativo } \\
\text { sobre las propiedades mecánicas. } \\
\text { PHBV-g-MA: Incremento de la } \\
\text { resistencia mecánica, el módulo } \\
\text { elástico y el parámetro de adhesión } \\
\text { pMDI: ligero incremento de la } \\
\text { resistencia mecánica }\end{array}$ & [217] \\
\hline
\end{tabular}

\section{Referencias}

[1] M. Rujnić-Sokele, A. Pilipović, Challenges and opportunities of biodegradable plastics: A mini review, Waste Manag. Res. 35 (2017) 132-140. doi:10.1177/0734242X16683272.

[2] S. Lambert, M. Wagner, Environmental performance of bio-based and biodegradable plastics: The road ahead, 46 (2017) 6855-6871. doi:10.1039/c7cs00149e.

[3] M.M. Reddy, S. Vivekanandhan, M. Misra, S.K. Bhatia, A.K. Mohanty, Biobased plastics and bionanocomposites: Current status and future opportunities, Prog. Polym. Sci. 38 (2013) 16531689. doi:10.1016/j.progpolymsci.2013.05.006.

[4] IUPAC, Compendium of Chemical Terminology 2nd ed. (the "Gold Book") by A. D. McNaught and A. Wilkinson. Blackwell Scientific Publications, Oxford (1997). XML on-line corrected version: http://goldbook.iupac.org (2006-) created by M. Nic, J. Jirat, B. Kosata; upd, 2014. doi:http://dx.doi.org/10.1351/goldbook.103352.

[5] M. Vert, Y. Doi, K.H. Hellwich, M. Hess, P. Hodge, P. Kubisa, M. Rinaudo, F. Schué, Terminology for biorelated polymers and applications (IUPAC recommendations 2012), 84 (2012) 377-410.

[6] H. Nakajima, P. Dijkstra, K. Loos, The Recent Developments in Biobased Polymers toward General and Engineering Applications: Polymers that are Upgraded from Biodegradable Polymers, Analogous to Petroleum-Derived Polymers, and Newly Developed, Polymers (Basel). 9 (2017) 523 (1-26). doi:10.3390/polym9100523.

[7] A. Steinbüchel, Non-biodegradable biopolymers from renewable resources: Perspectives and impacts, Curr. Opin. Biotechnol. 16 (2005) 607-613. doi:10.1016/j.copbio.2005.10.011. 
[8] M. Funabashi, F. Ninomiya, M. Kunioka, Biodegradability Evaluation of Polymers by ISO 14855-2., Int. J. Mol. Sci. 10 (2009) 3635-3654. doi:10.3390/ijms10083635.

[9] J.-W. Rhim, H.-M. Park, C.-S. Ha, Bio-nanocomposites for food packaging applications, Prog. Polym. Sci. 38 (2013) 1629-1652. doi:10.1016/j.progpolymsci.2013.05.008.

[10] P. Bordes, E. POLLET, L. Averous, Nano-biocomposites: Biodegradable polyester/nanoclay systems, Prog. Polym. Sci. 34 (2009) 125-155. doi:10.1016/j.progpolymsci.2008.10.002.

[11] J.M. Lagaron, A. Lopez-Rubio, Nanotechnology for bioplastics: opportunities, challenges and strategies, Trends Food Sci. Technol. 22 (2011) 611-617. doi:10.1016/j.tifs.2011.01.007.

[12] M.H. Mousa, Y. Dong, I.J. Davies, Recent advances in bionanocomposites: Preparation, properties, and applications, Int. J. Polym. Mater. Polym. Biomater. 65 (2016) 225-254. doi:10.1080/00914037.2015.1103240.

[13] Market - European Bioplastics e.V., (n.d.). http://www.european-bioplastics.org/market/ (accessed February 11, 2018).

[14] C.P. Rivero, Y. Hu, T.H. Kwan, C. Webb, C. Theodoropoulos, W. Daoud, C.S.K. Lin, Bioplastics From Solid Waste, in: Curr. Dev. Biotechnol. Bioeng. Solid Waste Manag., Elsevier, 2016: pp. 1-26. doi:10.1016/B978-0-444-63664-5.00001-0.

[15] S. Pilla, Handbook of Bioplastics and Biocomposites Engineering Applications, 2011. doi:10.1002/9781118203699.

[16] E. Ruiz-Hitzky, F.M. Fernandes, Progress in bionanocomposites: From green plastics to biomedical applications, Prog. Polym. Sci. 38 (2013) 1391. doi:10.1016/j.progpolymsci.2013.07.004.

[17] M. Pietrini, L. Roes, M.K. Patel, E. Chiellini, Comparative life cycle studies on poly(3hydroxybutyrate)-based composites as potential replacement for conventional petrochemical plastics, Biomacromolecules. 8 (2007) 2210-2218. doi:10.1021/bm0700892.

[18] K. Khosravi-Darani, D.Z. Bucci, Application of Poly(hydroxyalkanoate) In Food Packaging: Improvements by Nanotechnology, Chem. Biochem. Eng. Q. 29 (2015) 275-285. doi:10.15255/CABEQ.2014.2260.

[19] V. Nagarajan, A.K. Mohanty, M. Misra, Perspective on Polylactic Acid (PLA) based Sustainable Materials for Durable Applications: Focus on Toughness and Heat Resistance, ACS Sustain. Chem. Eng. 4 (2016) 2899-2916. doi:10.1021/acssuschemeng.6b00321.

[20] S. Torres-Giner, N. Montanes, V. Fombuena, T. Boronat, L. Sanchez-Nacher, Preparation and characterization of compression-molded green composite sheets made of poly(3-hydroxybutyrate) reinforced with long pita fibers, Adv. Polym. Technol. 37 (2018) 1305-1315. doi:10.1002/adv.21789.

[21] D.R. Tobergte, S. Curtis, Biocomposites: Desing and Mechanical Performance, Elsevier Inc., 2013. doi:10.1017/СBO9781107415324.004.

[22] P. Russo, D. Acierno, G. Filippone, Mechanical performance of polylactic based formulations, in: Biocomposites, Elsevier, 2015: pp. 17-37. doi:10.1016/B978-1-78242-373-7.00002-0.

[23] I. Widiastuti, Polylactide nanocomposites for packaging materials: A review, in: American Institute of Physics Inc., 2016: p. 30020. doi:10.1063/1.4941486.

[24] Y. Yang, L. Zhang, Z. Xiong, Z. Tang, R. Zhang, J. Zhu, Research progress in the heat resistance, toughening and filling modification of PLA, Sci. China Chem. 59 (2016) 1355-1368. doi:10.1007/s11426-016-0222-7. 
[25] A.M. Gumel, M.S.M. Annuar, Y. Chisti, Recent Advances in the Production, Recovery and Applications of Polyhydroxyalkanoates, J. Polym. Environ. 21 (2013) 580-605. doi:10.1007/s10924012-0527-1.

[26] D. Cava, E. Giménez, R. Gavara, J.M. Lagaron, Comparative Performance and Barrier Properties of Biodegradable Thermoplastics and Nanobiocomposites versus PET for Food Packaging Applications, J. Plast. Film Sheeting. 22 (2006) 265-274. doi:10.1177/8756087906071354.

[27] A. Rivera-Briso, Á. Serrano-Aroca, A.L. Rivera-Briso, Á. Serrano-Aroca, Poly(3-Hydroxybutyrate-co-3Hydroxyvalerate): Enhancement Strategies for Advanced Applications, Polymers (Basel). 10 (2018) 732(1-28). doi:10.3390/polym10070732.

[28] P.B.S. Albuquerque, C.B. Malafaia, Perspectives on the production, structural characteristics and potential applications of bioplastics derived from polyhydroxyalkanoates, Int. J. Biol. Macromol. 107 (2018) 615-625. doi:10.1016/j.jjbiomac.2017.09.026.

[29] E. Ten, L. Jiang, J. Zhang, M.P. Wolcott, Mechanical performance of polyhydroxyalkanoate (PHA)based biocomposites, in: Biocomposites, Elsevier, 2015: pp. 39-52. doi:10.1016/B978-1-78242-3737.00008-1.

[30] A. Javadi, S. Pilla, S. Gong, L.-S. Turng, Biobased and Biodegradable PHBV-Based Polymer Blends and Biocomposites: Properties and Applications, in: Handb. Bioplastics Biocomposites Eng. Appl., John Wiley \& Sons, Inc., Hoboken, NJ, USA, 2011: pp. 372-396. doi:10.1002/9781118203699.ch14.

[31] T. Väisänen, A. Haapala, R. Lappalainen, L. Tomppo, Utilization of agricultural and forest industry waste and residues in natural fiber-polymer composites: A review, Waste Manag. 54 (2016) 62-73. doi:10.1016/j.wasman.2016.04.037.

[32] J. Możejko-Ciesielska, R. Kiewisz, Bacterial polyhydroxyalkanoates: Still fabulous?, Microbiol. Res. 192 (2016) 271-282. doi:10.1016/j.micres.2016.07.010.

[33] M. Lemoigne, Production d'acide $\beta$-oxybutyrique par certaines bactéries du groupe du Bacillus subtilis, CR. Hebd. Seances Acad. Sci. 176 (1923): 1761

[34] M. Lemoigne, Chemical origin of the products of dehydration and of polymerization of $\beta$ hydroxybutyric acid. Hydroxybutyric fermentation, Bull Soc Chim Biol. 9 (1927): 446-453

[35] M. Lemoigne, N. Grelet, M. Croson, Sur l'origine des lipides beta hydroxybutyriques formes par processus microbien, Bull Soc Chim Biol, 32 (1950) 719-721.

[36] R.W. Lenz, R.H. Marchessault, Bacterial polyesters: biosynthesis, biodegradable plastics and biotechnology., Biomacromolecules. 6 (2005) 1-8. doi:10.1021/bm049700c.

[37] M.P. Nuti, M. De Bertoldi, A.A. Lepidi, Influence of phenylacetic acid on poly-P-hydroxybutyrate (PHB) polymerization and cell elongation in Azotobacter chroococcum Beij ., Can. J. Microbiol. 18 (1972) 1257-1261.

[38] Baptist James N; Werber Frank X, US 3107172 A, Molded product containing poly-betahydroxybutyric acid and method of making, US 3107172 A, 1960.

[39] Baptist James N; Werber Frank X, US 3182036 A, Plasticized poly-beta-hydroxybutyric acid and process, US 3182036 A, 1962.

[40] B.J. Noel, US3044942 A, Process for preparing poly-beta-hydroxybutyric acid, US3044942 A, 1960.

[41] W.K. Wallen, L. L.; Rohwedder, Poly-betahydroxyalkanoate from activated sludge., Environ. Sci. Technol. (1974) 576-579.

[42] T. Keshavarz, I. Roy, Polyhydroxyalkanoates: bioplastics with a green agenda, Curr. Opin. Microbiol. 
13 (2010) 321-326. doi:10.1016/j.mib.2010.02.006.

[43] A. Anjum, M. Zuber, K.M. Zia, A. Noreen, M.N. Anjum, S. Tabasum, Microbial production of polyhydroxyalkanoates (PHAs) and its copolymers: A review of recent advancements, Int. J. Biol. Macromol. 89 (2016) 161-174. doi:10.1016/j.ijbiomac.2016.04.069.

[44] S. Philip, T. Keshavarz, I. Roy, Polyhydroxyalkanoates: Biodegradable polymers with a range of applications, J. Chem. Technol. 247 (2007) 233-247. doi:10.1002/jctb.1667.

[45] E. Bugnicourt, P. Cinelli, A. Lazzeri, V. Alvarez, Polyhydroxyalkanoate (PHA): Review of synthesis, characteristics, processing and potential applications in packaging, Express Polym. Lett. 8 (2014) 791-808. doi:10.3144/expresspolymlett.2014.82.

[46] S. Chanprateep, Current trends in biodegradable polyhydroxyalkanoates, J. Biosci. Bioeng. 110 (2010) 621-632. doi:10.1016/j.jbiosc.2010.07.014.

[47] Y. Wang, J. Yin, G.Q. Chen, Polyhydroxyalkanoates, challenges and opportunities, Curr. Opin. Biotechnol. 30 (2014) 59-65. doi:10.1016/j.copbio.2014.06.001.

[48] M. Singh, P. Kumar, S. Ray, V.C. Kalia, Challenges and Opportunities for Customizing Polyhydroxyalkanoates, Indian J. Microbiol. 55 (2015) 235-249. doi:10.1007/s12088-015-0528-6.

[49] D.P. Martin, S.F. Williams, Medical applications of poly-4-hydroxybutyrate: a strong flexible absorbable biomaterial, Biochem. Eng. J. 16 (2003) 97-105. doi:10.1016/S1369-703X(03)00040-8.

[50] S. Wang, W. Chen, H. Xiang, J. Yang, Z. Zhou, M. Zhu, Modification and Potential Application of Short-Chain-Length Polyhydroxyalkanoate (SCL-PHA), Polymers (Basel). 8 (2016) 273. doi:10.3390/polym8080273.

[51] E. Akaraonye, T. Keshavarz, I. Roy, Production of polyhydroxyalkanoates: the future green materials of choice, J. Chem. Technol. Biotechnol. 85 (2010) 732-743. doi:10.1002/jctb.2392.

[52] B. Laycock, P. Halley, S. Pratt, A. Werker, P. Lant, The chemomechanical properties of microbial polyhydroxyalkanoates, Prog. Polym. Sci. 38 (2013) 536-583. doi:10.1016/j.progpolymsci.2012.06.003.

[53] G. Keskin, G. Kızıl, M. Bechelany, C. Pochat-Bohatier, M. Öner, Potential of polyhydroxyalkanoate (PHA) polymers family as substitutes of petroleum based polymers for packaging applications and solutions brought by their composites to form barrier materials, Pure Appl. Chem. 89 (2017) 18411848. doi:10.1515/pac-2017-0401.

[54] D. Cava, E. Giménez, R. Gavara, J.M. Lagaron, Comparative Performance and Barrier Properties of Biodegradable Thermoplastics and Nanobiocomposites versus PET for Food Packaging Applications, J. Plast. Film Sheeting. 22 (2006) 265-274. doi:10.1177/8756087906071354.

[55] M. Yokouchi, Y. Chatani, H. Tadokoro, K. Teranishi, H. Tani, Structural studies of polyesters: 5. Molecular and crystal structures of optically active and racemic poly ( $\beta$-hydroxybutyrate), Polymer (Guildf). 14 (1973) 267-272. doi:10.1016/0032-3861(73)90087-6.

[56] M. Scandola, G. Ceccorulli, M. Pizzoli, M. Gazzano, Study of the crystal phase and crystallization rate of bacterial poly(3-hydroxybutyrate-co-3-hydroxyvalerate), Macromolecules. 25 (1992) 1405-1410. doi:10.1021/ma00031a008.

[57] M. Fujita, T. Sawayanagi, T. Tanaka, T. Iwata, H. Abe, Y. Doi, K. Ito, T. Fujisawa, Synchrotron SAXS and WAXS Studies on Changes in Structural and Thermal Properties of Poly[(R)-3-hydroxybutyrate] Single Crystals during Heating, Macromol. Rapid Commun. 26 (2005) 678-683. doi:10.1002/marc.200500030. 
[58] L.N. Carli, O. Bianchi, G. Machado, J.S. Crespo, R.S. Mauler, Morphological and structural characterization of PHBV/organoclay nanocomposites by small angle X-ray scattering, Mater. Sci. Eng. C. 33 (2013) 932-937. doi:10.1016/j.msec.2012.11.023.

[59] G.J.M. de Koning, P.J. Lemstra, Crystallization phenomena in bacterial poly[(R)-3-hydroxybutyrate]: 2. Embrittlement and rejuvenation, Polymer (Guildf). 34 (1993) 4089-4094. doi:10.1016/00323861(93)90671-V.

[60] P.J. Barham, A. Keller, The relationship between microstructure and mode of fracture in polyhydroxybutyrate, J. Polym. Sci. Part B Polym. Phys. 24 (1986) 69-77. doi:10.1002/polb.1986.180240108.

[61] J. Martinez-Salazar, M. Sanchez-Cuesta, P.J. Barham, A. Keller, Thermal expansion and spherulite cracking in 3-hydroxybutyrate/3-hydroxyvalerate copolymers, J. Mater. Sci. Lett. 8 (1989) 490-492. doi:10.1007/BF00720717.

[62] T.L. Bluhm, G.K. Hamer, R.H. Marchessault, C.A. Fyfe, R.P. Veregin, Isodimorphism in bacterial poly( $\beta$-hydroxybutyrate-co- $\beta$-hydroxyvalerate), Macromolecules. $19 \quad$ (1986) 2871-2876. doi:10.1021/ma00165a035.

[63] W.J. Orts, D.L. VanderHart, T.L. Bluhm, R.H. Marchessault, Cocrystallization in random copolymers of poly( $\beta$-hydroxybutyrate- co - $\beta$-hydroxyvalerate) and its effect on crystalline morphology, Can. J. Chem. 73 (1995) 2094-2100. doi:10.1139/v95-258.

[64] T.A. Osswald, G. Menges, Materials Science of Polymers for Engineers, Carl Hanser Verlag GmbH \&amp; Co. KG, München, 2012. doi:10.3139/9781569905241.

[65] D.L. VanderHart, W.J. Orts, R.H. Marchessault, 13C NMR Determination of the Degree of Cocrystallization in Random Copolymers of Poly(.beta.-hydroxybutyrate-co-.beta.-hydroxyvalerate), Macromolecules. 28 (1995) 6394-6400. doi:10.1021/ma00123a002.

[66] N. Kamiya, M. Sakurai, Y. Inoue, R. Chujo, Y. Doi, Study of cocrystallization of poly(3hydroxybutyrate-co-3-hydroxyvalerate) by solid-state high-resolution carbon-13 NMR spectroscopy and differential scanning calorimetry, Macromolecules. $24 \quad$ (1991) 2178-2182. doi:10.1021/ma00009a006.

[67] K. Bonthrone, The biological and physical chemistry of polyhydroxyalkanoates as seen by NMR spectroscopy, FEMS Microbiol. Lett. 103 (1992) 269-277. doi:10.1016/0378-1097(92)90320-N.

[68] M. Alsleben, C. Schick, The melting of polymers - a three-phase approach, Thermochim. Acta. 238 (1994) 203-227. doi:10.1016/S0040-6031(94)85211-1.

[69] A. Sedighiamiri, T.B. Van Erp, G.W.M. Peters, L.E. Govaert, J.A.W. van Dommelen, Micromechanical modeling of the elastic properties of semicrystalline polymers: A three-phase approach, J. Polym. Sci. Part B Polym. Phys. 48 (2010) 2173-2184. doi:10.1002/polb.22099.

[70] O. Gueguen, S. Ahzi, A. Makradi, S. Belouettar, A new three-phase model to estimate the effective elastic properties of semi-crystalline polymers: Application to PET, Mech. Mater. 42 (2010) 1-10 doi:10.1016/J.MECHMAT.2009.04.012.

[71] H.-S. Kim, H.-S. Yang, H.-J. Kim, M. Kattan, Relaxations IN amorphous and semi-crystalline polyesters, J. Therm. Anal. Calorim. 76 (2004) 379-394. doi:10.1023/B:JTAN.0000028019.88096.e3.

[72] S.H. El-Taweel, G.W.H. Höhne, A.A. Mansour, B. Stoll, H. Seliger, Glass transition and the rigid amorphous phase in semicrystalline blends of bacterial polyhydroxybutyrate PHB with low molecular mass atactic R, S-PHB-diol, Polymer (Guildf). 45 (2004) 983-992. doi:10.1016/J.POLYMER.2003.12.007. 
[73] Y.-M. Corre, S. Bruzaud, J.-L. Audic, Y. Grohens, Morphology and functional properties of commercial polyhydroxyalkanoates: A comprehensive and comparative study, Polym. Test. 31 (2012) 226-235. doi:10.1016/j.polymertesting.2011.11.002.

[74] G.J.M. de Koning, A.H.C. Scheeren, P.J. Lemstra, M. Peeters, H. Reynaers, Crystallization phenomena in bacterial poly[(R)-3-hydroxybutyrate]: 3. Toughening via texture changes, Polymer (Guildf). 35 (1994) 4598-4605. doi:10.1016/0032-3861(94)90809-5.

[75] H. Alata, T. Aoyama, Y. Inoue, Effect of Aging on the Mechanical Properties of Poly(3hydroxybutyrate- co -3-hydroxyhexanoate), Macromolecules. 40 (2007) 4546-4551. doi:10.1021/ma070418i.

[76] F. Biddlestone, A. Harris, J.N. Hay, T. Hammond, The Physical Ageing of Amorphous Poly(hydroxybutyrate), Polym. Int. 39 (1996) 221-229. doi:10.1002/(SICI)10970126(199603)39:3<221::AID-PI511>3.0.CO;2-O.

[77] R. Crétois, J.M. Chenal, N. Sheibat-Othman, A. Monnier, C. Martin, O. Astruz, R. Kurusu, N.R Demarquette, Physical explanations about the improvement of PolyHydroxyButyrate ductility: Hidden effect of plasticizer on physical ageing, Polym. (United Kingdom). 102 (2016) 176-182. doi:10.1016/j.polymer.2016.09.017.

[78] B.L. Hurrell, R.E. Cameron, Physical ageing and the embrittlement of poly(hydroxybutyrate) on storage: a time resolved small angle X-ray scattering study, Polym. Int. 45 (1998) 308-312. doi:10.1002/(SICI)1097-0126(199803)45:3<308::AID-PI934>3.0.CO;2-V.

[79] A. Esposito, N. Delpouve, V. Causin, A. Dhotel, L. Delbreilh, E. Dargent, From a Three-Phase Model to a Continuous Description of Molecular Mobility in Semicrystalline Poly(hydroxybutyrate-cohydroxyvalerate), Macromolecules. 49 (2016) 4850-4861. doi:10.1021/acs.macromol.6b00384.

[80] M. Scandola, G. Ceccorulli, M. Pizzoli, The physical aging of bacterial poly(D- $\beta$-hydroxybutyrate), Die Makromol. Chemie, Rapid Commun. 10 (1989) 47-50. doi:10.1002/marc.1989.030100201.

[81] M.L. Di Lorenzo, M.C. Righetti, Evolution of crystal and amorphous fractions of poly[(R)-3hydroxybutyrate] upon storage, J. Therm. Anal. Calorim. 112 (2013) 1439-1446. doi:10.1007/s10973-012-2734-3.

[82] W.V. Srubar, Z.C. Wright, A. Tsui, A.T. Michel, S.L. Billington, C.W. Frank, Characterizing the effects of ambient aging on the mechanical and physical properties of two commercially available bacterial $\begin{array}{llllll}\text { thermoplastics, } & \text { Polym. } & \text { Degrad. } & \text { Stab. } & 97 & \text { (2012) }\end{array}$ doi:10.1016/j.polymdegradstab.2012.04.011.

[83] L.C.E. Struik, The mechanical and physical ageing of semicrystalline polymers: 1, Polymer (Guildf). 28 (1987) 1521-1533. doi:10.1016/0032-3861(87)90353-3.

[84] L.C.E. Struik, The mechanical behaviour and physical ageing of semicrystalline polymers: 2, Polymer (Guildf). 28 (1987) 1534-1542. doi:10.1016/0032-3861(87)90354-5.

[85] M.L. Di Lorenzo, M. Gazzano, M.C. Righetti, The Role of the Rigid Amorphous Fraction on Cold Crystallization of Poly(3-hydroxybutyrate), Macromolecules. 45 (2012) 5684-5691. doi:10.1021/ma3010907.

[86] M.-L. Cheng, Y.-M. Sun, Relationship between free volume properties and structure of poly(3hydroxybutyrate-co-3-hydroxyvalerate) membranes via various crystallization conditions, Polymer (Guildf). 50 (2009) 5298-5307. doi:10.1016/J.POLYMER.2009.09.035.

[87] N. Peelman, P. Ragaert, K. Ragaert, M. Erkoç, W. Van Brempt, F. Faelens, F. Devlieghere, B. De Meulenaer, L. Cardon, Heat resistance of biobased materials, evaluation and effect of processing 
techniques and additives, Polym. Eng. Sci. 58 (2018) 513-520. doi:10.1002/pen.24760.

[88] N. Peelman, P. Ragaert, K. Ragaert, B. De Meulenaer, F. Devlieghere, L. Cardon, Heat resistance of new biobased polymeric materials, focusing on starch, cellulose, PLA, and PHA, J. Appl. Polym. Sci. 132 (2015) 42305 (1-15). doi:10.1002/app.42305.

[89] Q.-S. Liu, M.-F. Zhu, W.-H. Wu, Z.-Y. Qin, Reducing the formation of six-membered ring ester during thermal degradation of biodegradable PHBV to enhance its thermal stability, Polym. Degrad. Stab. 94 (2009) 18-24. doi:10.1016/j.polymdegradstab.2008.10.016.

[90] F.-D. Kopinke, M. Remmler, K. Mackenzie, Thermal decomposition of biodegradable polyesters-I: Poly( $\beta$-hydroxybutyric acid), Polym. Degrad. Stab. 52 (1996) 25-38. doi:10.1016/01413910(95)00221-9.

[91] K. Numata, H. Abe, T. Iwata, Biodegradability of Poly(hydroxyalkanoate) Materials, Materials (Basel). 2 (2009) 1104-1126. doi:10.3390/ma2031104.

[92] S. Khanna, A.K. Srivastava, Recent advances in microbial polyhydroxyalkanoates, Process Biochem. (2005). doi:10.1016/j.procbio.2004.01.053.

[93] a. K. Mohanty, M. Misra, G. Hinrichsen, Biofibres, biodegradable polymers and biocomposites: An overview, Macromol. Mater. Eng. 276-277 (2000) 1-24. doi:10.1002/(SICI)14392054(20000301)276:1<1::AID-MAME1>3.0.CO;2-W.

[94] R. Muthuraj, M. Misra, A.K. Mohanty, Biodegradable compatibilized polymer blends for packaging applications: A literature review, J. Appl. Polym. Sci. 135 (2018) 45726. doi:10.1002/app.45726.

[95] M. Seggiani, P. Cinelli, N. Mallegni, E. Balestri, M. Puccini, S. Vitolo, C. Lardicci, A. Lazzeri, New BioComposites Based on Polyhydroxyalkanoates and Posidonia oceanica Fibres for Applications in a Marine Environment, Materials (Basel). 10 (2017)326(1-13). doi:10.3390/ma10040326.

[96] M. Koller, Poly(hydroxyalkanoates) for food packaging - application and attempts towards implementation, Appl. Food Biotechnol. 1 (2014) 1-13. doi:10.22037/afb.v1i1.7127.g6247.

[97] News - IfBB - Institute for bioplastics and biocomposites, (n.d.). https://www.ifbb-hannover.de/en/ (accessed September 29, 2018).

[98] S. Rodriguez-Perez, A. Serrano, A.A. Pantión, B. Alonso-Fariñas, Challenges of scaling-up PHA production from waste streams. A review, J. Environ. Manage. 205 (2018) 215-230. doi:10.1016/j.jenvman.2017.09.083.

[99] C. Nielsen, A. Rahman, A.U. Rehman, M.K. Walsh, C.D. Miller, Food waste conversion to microbial polyhydroxyalkanoates, Microb. Biotechnol. 10 (2017) 1338-1352. doi:10.1111/1751-7915.12776.

[100] M. Koller, L. Maršálek, M.M. de Sousa Dias, G. Braunegg, Producing microbial polyhydroxyalkanoate (PHA) biopolyesters in a sustainable manner, N. Biotechnol. 37 (2017) 24-38. doi:10.1016/j.nbt.2016.05.001.

[101] K.D. Snell, V. Singh, S.M. Brumbley, Production of novel biopolymers in plants: recent technological advances and future prospects, Curr. Opin. Biotechnol. 32 (2015) 68-75. doi:10.1016/J.COPBIO.2014.11.005.

[102] M. Koller, A. Muhr, G. Braunegg, Microalgae as versatile cellular factories for valued products, Algal Res. 6 (2014) 52-63. doi:10.1016/J.ALGAL.2014.09.002.

[103] M.T. Cesário, R.S. Raposo, M.C.M.D. de Almeida, F. van Keulen, B.S. Ferreira, M.M.R. da Fonseca, Enhanced bioproduction of poly-3-hydroxybutyrate from wheat straw lignocellulosic hydrolysates, N. Biotechnol. 31 (2014) 104-113. doi:10.1016/J.NBT.2013.10.004. 
[104] R. Sindhu, N. Silviya, P. Binod, A. Pandey, Pentose-rich hydrolysate from acid pretreated rice straw as a carbon source for the production of poly-3-hydroxybutyrate, Biochem. Eng. J. 78 (2013) 67-72. doi:10.1016/J.BEJ.2012.12.015.

[104] N. Wisuthiphaet, S.C. Napathorn, Optimisation of the use of products from the cane sugar industry for poly(3-hydroxybutyrate) production by Azohydromonas lata DSM 1123 in fed-batch cultivation, Process Biochem. 51 (2016) 352-361. doi:10.1016/J.PROCBIO.2015.12.009.

[106] A.F. Duque, C.S.S. Oliveira, I.T.D. Carmo, A.R. Gouveia, F. Pardelha, A.M. Ramos, M.A.M. Reis, Response of a three-stage process for PHA production by mixed microbial cultures to feedstock shift: impact on polymer composition, N. Biotechnol. 31 (2014) 276-288. doi:10.1016/J.NBT.2013.10.010.

[107] F. Valentino, F. Morgan-Sagastume, S. Campanari, M. Villano, A. Werker, M. Majone, Carbon recovery from wastewater through bioconversion into biodegradable polymers, N. Biotechnol. 37 (2017) 9-23. doi:10.1016/j.nbt.2016.05.007.

[108] G. Jiang, D. Hill, M. Kowalczuk, B. Johnston, G. Adamus, V. Irorere, I. Radecka, Carbon Sources for Polyhydroxyalkanoates and an Integrated Biorefinery, Int. J. Mol. Sci. 17 (2016) 1157(1-21). doi:10.3390/ijms17071157.

[109] K. Yasotha, M.K. Aroua, K.B. Ramachandran, I.K.P. Tan, Recovery of medium-chain-length polyhydroxyalkanoates (PHAs) through enzymatic digestion treatments and ultrafiltration, Biochem. Eng. J. 30 (2006) 260-268. doi:10.1016/J.BEJ.2006.05.008.

[110] L. Yu, K. Dean, L. Li, Polymer blends and composites from renewable resources, Prog. Polym. Sci. 31 (2006) 576-602. doi:10.1016/j.progpolymsci.2006.03.002.

[111] T. Mekonnen, P. Mussone, H. Khalil, D. Bressler, Progress in bio-based plastics and plasticizing modifications, J. Mater. Chem. A. 1 (2013) 13379-13398. doi:10.1039/c3ta12555f.

[112] L. Yu, Biodegradable Polymer Blends and Composites from Renewable Resources, John Wiley and Sons, 2009. doi:10.1002/9780470391501.

[113] O. Faruk, A.K. Bledzki, H.-P. Fink, M. Sain, Biocomposites reinforced with natural fibers: 2000-2010, Prog. Polym. Sci. 37 (2012) 1552-1596. doi:10.1016/J.PROGPOLYMSCI.2012.04.003.

[114] J.C.C. Yeo, J.K. Muiruri, W. Thitsartarn, Z. Li, C. He, Recent advances in the development of biodegradable PHB-based toughening materials: Approaches, advantages and applications, Mater. Sci. Eng. C. 92 (2018) 1092-1116. doi:10.1016/J.MSEC.2017.11.006.

[115] W.J. Liu, H.L. Yang, Z. Wang, L.S. Dong, J.J. Liu, Effect of nucleating agents on the crystallization of poly(3-hydroxybutyrate-co-3-hydroxyvalerate), J. Appl. Polym. Sci. 86 (2002) 2145-2152. doi:10.1002/app.11023.

[116] J. Qian, L. Zhu, J. Zhang, R.S. Whitehouse, Comparison of different nucleating agents on crystallization of poly(3-hydroxybutyrate-co-3-hydroxyvalerates), J. Polym. Sci. Part B Polym. Phys. 45 (2007) 1564-1577. doi:10.1002/polb.21157.

[117] T. Dong, T. Mori, T. Aoyama, Y. Inoue, Rapid crystallization of poly(3-hydroxybutyrate-co-3hydroxyhexanoate) copolymer accelerated by cyclodextrin-complex as nucleating agent, Carbohydr. Polym. 80 (2010) 387-393. doi:10.1016/J.CARBPOL.2009.11.036.

[118] J.A.S. Puente, A. Esposito, F. Chivrac, E. Dargent, Effect of boron nitride as a nucleating agent on the crystallization of bacterial poly(3-hydroxybutyrate), J. Appl. Polym. Sci. 128 (2013) 2586-2594. doi:10.1002/app.38182.

[119] W. Kai, Y. He, Y. Inoue, Fast crystallization of poly(3-hydroxybutyrate) and poly(3-hydroxybutyrate- 
co-3-hydroxyvalerate) with talc and boron nitride as nucleating agents, Polym. Int. 54 (2005) 780789. doi:10.1002/pi.1758.

[120] T.S. Daitx, L.N. Carli, J.S. Crespo, R.S. Mauler, Effects of the organic modification of different clay minerals and their application in biodegradable polymer nanocomposites of PHBV, Appl. Clay Sci. 115 (2015) 157-164. doi:10.1016/j.clay.2015.07.038.

[121] R. Crétois, N. Follain, E. Dargent, J. Soulestin, S. Bourbigot, S. Marais, L. Lebrun, Microstructure and barrier properties of PHBV/organoclays bionanocomposites, J. Memb. Sci. 467 (2014) 56-66. doi:10.1016/j.memsci.2014.05.015.

[122] J. González-Ausejo, J. Gámez-Pérez, R. Balart, J.M. Lagarón, L. Cabedo, Effect of the addition of sepiolite on the morphology and properties of melt compounded PHBV/PLA blends, Polym. Compos. (2017). doi:10.1002/pc.24538.

[123] A. Chikh, A. Benhamida, M. Kaci, I. Pillin, S. Bruzaud, Synergistic effect of compatibilizer and sepiolite on the morphology of poly(3-hydroxybutyrate-co-3-hydroxyvalerate)/poly(butylene succinate) blends, Polym. Test. 53 (2016) 19-28. doi:10.1016/j.polymertesting.2016.05.008.

[124] L.N. Carli, J.S. Crespo, R.S. Mauler, PHBV nanocomposites based on organomodified montmorillonite and halloysite: The effect of clay type on the morphology and thermal and mechanical properties, Compos. Part A Appl. Sci. Manuf. 42 (2011) 1601-1608. doi:10.1016/j.compositesa.2011.07.007.

[125] J.M. Lagarón, A. López-Rubio, M. José Fabra, On the use of tris(nonylphenyl) phosphite as a chain extender in melt-blended poly(hydroxybutyrate-co-hydroxyvalerate)/clay nanocomposites: Morphology, thermal stability, and mechanical properties, J. Appl. Polym. Sci. 133 (2016). doi:10.1002/app.42971.

[126] I.T. Seoane, E. Fortunati, D. Puglia, V.P. Cyras, L.B. Manfredi, Development and characterization of bionanocomposites based on poly(3-hydroxybutyrate) and cellulose nanocrystals for packaging applications, Polym. Int. 65 (2016) 1046-1053. doi:10.1002/pi.5150.

[127] P.H.F. Pereira, M. de F. Rosa, M.O.H. Cioffi, K.C.C. de C. Benini, A.C. Milanese, H.J.C. Voorwald, D.R. Mulinari, Vegetal fibers in polymeric composites: a review, Polímeros. 25 (2015) 9-22. doi:10.1590/0104-1428.1722.

[128] G. Bogoeva-Gaceva, M. Avella, M. Malinconico, a. Buzarovska, a. Grozdanov, G. Gentile, M.E. Errico, Natural fiber eco-composites, Polym. Compos. 28 (2007) 98-107. doi:10.1002/pc.20270.

[129] K.G. Satyanarayana, G.G.C. Arizaga, F. Wypych, Biodegradable composites based on lignocellulosic fibers-An overview, Prog. Polym. Sci. $34 \quad$ (2009) 982-1021. doi:10.1016/j.progpolymsci.2008.12.002.

[130] L.A. Utracki, Compatibilization of Polymer Blends, Can. J. Chem. Eng. 80 (2002) 1008-1016. doi:10.1002/cjce.5450800601.

[131] B. Imre, B. Pukánszky, Compatibilization in bio-based and biodegradable polymer blends, Eur. Polym. J. 49 (2013) 1215-1233. doi:10.1016/j.eurpolymj.2013.01.019.

[132] M. Arrieta, M. Samper, M. Aldas, J. López, On the Use of PLA-PHB Blends for Sustainable Food Packaging Applications, Materials (Basel). 10 (2017) 1008(1-26). doi:10.3390/ma10091008.

[133] J. González-Ausejo, E. Sánchez-Safont, J.M. Lagarón, R. Balart, L. Cabedo, J. Gámez-Pérez, Compatibilization of poly(3-hydroxybutyrate-co-3-hydroxyvalerate)-poly(lactic acid) blends with diisocyanates, J. Appl. Polym. Sci. 134 (2017) 1-11. doi:10.1002/app.44806.

[134] R. Toughening, B. Polymers, The Theory of Rubber Toughening of Brittle Polymers, (1971) 86-106. 
doi:10.1021/ba-1971-0099.ch007.

[135] S. Wu, Phase structure and adhesion in polymer blends: A criterion for rubber toughening, Polymer (Guildf). 26 (1985) 1855-1863. doi:10.1016/0032-3861(85)90015-1.

[136] A. Margolina, S. Wu, Percolation model for brittle-tough transition in nylon/rubber blends, Polymer (Guildf). 29 (1988) 2170-2173. doi:10.1016/0032-3861(88)90108-5.

[137] Z.H. Liu, X.D. Zhang, X.G. Zhu, Z.N. Qi, F.S. Wang, Effect of morphology on the brittle ductile transition of polymer blends: 1 . a new equation for correlating morphological parameters, Polymer (Guildf). 38 (1997) 5267-5273. doi:10.1016/S0032-3861(97)00075-X.

[138] Z.H. Liu, X.D. Zhang, X.G. Zhu, R.K.Y. Li, Z.N. Qi, F.S. Wang, C.L. Choy, Effect of morphology on the brittle ductile transition of polymer blends: 2 . Analysis on poly(vinyl chloride)/nitrile rubber blends, Polymer (Guildf). 39 (1998) 5019-5025. doi:10.1016/S0032-3861(98)00090-1.

[139] S.H. El-Taweel, M. Khater, L. Martino, M.-A. Berthet, H. Angellier-Coussy, N. Gontard, C. Zhu, C.T. Nomura, J.A. Perrotta, A.J. Stipanovic, J.P. Nakas, Mechanical and Thermal Behavior of Blends of Poly(hydroxybutyrate-co-hydroxyvalerate) with Ethylene Vinyl Acetate Copolymer, J. Macromol. Sci. Part B. 54 (2015) 1225-1232. doi:10.1080/00222348.2015.1085274.

[140] B. Adams, M. Abdelwahab, M. Misra, A.K. Mohanty, Injection-Molded Bioblends from Lignin and Biodegradable Polymers: Processing and Performance Evaluation, J. Polym. Environ. 26 (2018) 2360-2373. doi:10.1007/s10924-017-1132-0.

[141] K. Zhang, M. Misra, A.K. Mohanty, Toughened sustainable green composites from poly(3hydroxybutyrate-co-3-hydroxyvalerate) based ternary blends and miscanthus biofiber, ACS Sustain. Chem. Eng. 2 (2014) 2345-2354. doi:10.1021/sc500353v.

[142] V. Jost, O. Miesbauer, Effect of different biopolymers and polymers on the mechanical and permeation properties of extruded PHBV cast films, J. Appl. Polym. Sci. 135 (2018) 46153. doi:10.1002/app.46153.

[143] B.J. Rashmi, D. Rusu, K. Prashantha, M.-F. Lacrampe, P. Krawczak, Development of bio-based thermoplastic polyurethanes formulations using corn-derived chain extender for reactive rotational molding, Express Polym. Lett. 7 (2013) 852-862. doi:10.3144/expresspolymlett.2013.82.

[144] S. Wang, H. Xiang, R. Wang, C. Peng, Z. Zhou, M. Zhu, Morphology and properties of renewable poly(3-hydroxybutyrate- co -3-hydroxyvalerate) blends with thermoplastic polyurethane, Polym. Eng. Sci. 54 (2013) 1113-1119. doi:10.1002/pen.23655.

[145] A. Martínez-Abad, J. González-Ausejo, J.M. Lagarón, L. Cabedo, Biodegradable poly(3hydroxybutyrate-co-3-hydroxyvalerate)/thermoplastic polyurethane blends with improved mechanical and barrier performance, Polym. Degrad. Stab. 132 (2016) 52-61. doi:10.1016/j.polymdegradstab.2016.03.039.

[146] J. González-Ausejo, E. Sánchez-Safont, L. Cabedo, J. Gamez-Perez, Toughness Enhancement of Commercial Poly (Hydroxybutyrate-co-Valerate) (PHBV) by Blending with a Thermoplastic Polyurethane (TPU), J. Multiscale Model. 7 (2016) 1640008. doi:10.1142/S1756973716400084.

[147] S.K. Dogan, S. Boyacioglu, M. Kodal, O. Gokce, G. Ozkoc, Thermally induced shape memory behavior, enzymatic degradation and biocompatibility of PLA/TPU blends: "Effects of compatibilization," J. Mech. Behav. Biomed. Mater. 71 (2017) 349-361. doi:10.1016/j.jmbbm.2017.04.001.

[148] S.K. Dogan, E.A. Reyes, S. Rastogi, G. Ozkoc, Reactive compatibilization of PLA/TPU blends with a diisocyanate, J. Appl. Polym. Sci. 131 (2014)40251(1-10). doi:10.1002/app.40251. 
[149] S.-M. Lai, Y.-C. Lan, W.-L. Wu, Y.-J. Wang, Compatibility improvement of poly(lactic acid)/thermoplastic polyurethane blends with 3-aminopropyl triethoxysilane, J. Appl. Polym. Sci. 132 (2015) 42322(1-9). doi:10.1002/app.42322.

[150] C.A. Kelly, A.V.L. Fitzgerald, M.J. Jenkins, Control of the secondary crystallisation process in poly(hydroxybutyrate-co-hydroxyvalerate) through the incorporation of poly(ethylene glycol), Polym. Degrad. Stab. 148 (2018) 67-74. doi:10.1016/J.POLYMDEGRADSTAB.2018.01.003.

[151] D.F. Parra, J. Fusaro, F. Gaboardi, D.S. Rosa, Influence of poly (ethylene glycol) on the thermal, mechanical, morphological, physical-chemical and biodegradation properties of poly (3$\begin{array}{llllll}\text { hydroxybutyrate), } & \text { Polym. } & \text { Degrad. } & \text { Stab. } & 91 & \text { (2006) 1954-1959. }\end{array}$ doi:10.1016/J.POLYMDEGRADSTAB.2006.02.008.

[152] M. Râpə, R.N. Darie-Nitə, E. Grosu, E.E. Tənase, A.R. Trifoi, T. Pap, C. Vasile, Effect of plasticizers on melt processability and properties of PHB, J. Optoelectron. Adv. Mater. 17 (2015) 1778-1784.

[153] D.M. Panaitescu, C.A. Nicolae, A.N. Frone, I. Chiulan, P.O. Stanescu, C. Draghici, M. Iorga, M. Mihailescu, Plasticized poly(3-hydroxybutyrate) with improved melt processing and balanced properties, J. Appl. Polym. Sci. 134 (2017) 44810 (1-14). doi:10.1002/app.44810.

[154] T. Kabe, C. Hongo, T. Tanaka, T. Hikima, M. Takata, T. Iwata, High tensile strength fiber of poly[( R )3-hydroxybutyrate- co -( $\mathrm{R}$ )-3-hydroxyhexanoate] processed by two-step drawing with intermediate annealing, J. Appl. Polym. Sci. 132 (2015) 41258 (1-8). doi:10.1002/app.41258.

[155] J. Josefine Fischer, Y. Aoyagi, M. Enoki, Y. Doi, T. Iwata, Mechanical properties and enzymatic degradation of poly([R]-3-hydroxybutyrate-co-[R]-3-hydroxyhexanoate) uniaxially cold-drawn films, Polym. Degrad. Stab. 83 (2004) 453-460. doi:10.1016/j.polymdegradstab.2003.08.006.

[156] Y. Aoyagi, Y. Doi, T. Iwata, Mechanical properties and highly ordered structure of ultra-highmolecular-weight poly[(R)-3-hydroxybutyrate] films: Effects of annealing and two-step drawing, Polym. Degrad. Stab. 79 (2003) 209-216. doi:10.1016/S0141-3910(02)00273-2.

[157] B. Fei, C. Chen, S. Chen, S. Peng, Y. Zhuang, Y. An, L. Dong, Crosslinking of poly[(3-hydroxybutyrate)co-(3-hydroxyvalerate)] using dicumyl peroxide as initiator, Polym. Int. 53 (2004) 937-943. doi:10.1002/pi.1477.

[158] J. González-Ausejo, E. Sanchez-Safont, J.M. Lagaron, R.T. Olsson, J. Gamez-Perez, L. Cabedo, Assessing the thermoformability of poly(3-hydroxybutyrate-co-3-hydroxyvalerate)/poly(acid lactic) blends compatibilized with diisocyanates, Polym. Test. 62 (2017) 235-245. doi:10.1016/j.polymertesting.2017.06.026.

[159] B.G. Hermann, L. Debeer, B. De Wilde, K. Blok, M.K. Patel, To compost or not to compost: Carbon and energy footprints of biodegradable materials' waste treatment, Polym. Degrad. Stab. 96 (2011) 1159-1171. doi:10.1016/j.polymdegradstab.2010.12.026.

[160] S. Duangphet, D. Szegda, J. Song, K. Tarverdi, The Effect of Chain Extender on Poly(3hydroxybutyrate-co-3-hydroxyvalerate): Thermal Degradation, Crystallization, and Rheological Behaviours, J. Polym. Environ. 22 (2013) 1-8. doi:10.1007/s10924-012-0568-5.

[161] A.R. Kolahchi, M. Kontopoulou, Chain extended poly(3-hydroxybutyrate) with improved rheological properties and thermal stability, through reactive modification in the melt state, Polym. Degrad. Stab. 121 (2015) 222-229. doi:10.1016/J.POLYMDEGRADSTAB.2015.09.008.

[162] E. Giménez, J.M. Lagarón, M.L. Maspoch, L. Cabedo, J.J. Saura, Uniaxial tensile behavior and thermoforming characteristics of high barrier $\mathrm{EVOH}$-based blends of interest in food packaging, Polym. Eng. Sci. 44 (2004) 598-608. doi:10.1002/pen.20054. 
[163] E. Giménez, J.M. Lagarón, L. Cabedo, R. Gavara, J.J. Saura, Study of the thermoformability of ethylene-vinyl alcohol copolymer based barrier blends of interest in food packaging applications, J. Appl. Polym. Sci. 91 (2004) 3851-3855. doi:10.1002/app.13584.

[164] A. Guinault, A.S. Nguyen, G. Miquelard-Garnier, D. Jouannet, A. Grandmontagne, C. Sollogoub, The Effect of Thermoforming of PLA-PHBV Films on the Morphology and Gas Barrier Properties, Key Eng. Mater. 504-506 (2012) 1135-1138. doi:10.4028/www.scientific.net/KEM.504-506.1135.

[165] ASTM D883 - 17 Standard Terminology Relating to Plastics, (n.d.). https://www.astm.org/Standards/D883.htm (accessed September 18, 2018).

[166] G. Kale, T. Kijchavengkul, R. Auras, M. Rubino, S.E. Selke, S.P. Singh, Compostability of bioplastic packaging materials: an overview., Macromol. Biosci. 7 (2007) 255-77. doi:10.1002/mabi.200600168.

[167] ISO 17088:2012 - Specifications for compostable plastics, (n.d.). https://www.iso.org/standard/57901.html (accessed September 18, 2018).

[168] ASTM D6400 - 12 Standard Specification for Labeling of Plastics Designed to be Aerobically Composted in Municipal or Industrial Facilities, (n.d.). https://www.astm.org/Standards/D6400.htm (accessed September 18, 2018).

[169] ISO 14855-1:2012 - Determination of the ultimate aerobic biodegradability of plastic materials under controlled composting conditions -- Method by analysis of evolved carbon dioxide -- Part 1: General method, (n.d.). https://www.iso.org/standard/57902.html (accessed September 18, 2018).

[170] ISO 14855-2:2018 - Determination of the ultimate aerobic biodegradability of plastic materials under controlled composting conditions -- Method by analysis of evolved carbon dioxide -- Part 2: Gravimetric measurement of carbon dioxide evolved in a laboratory-scale test, (n.d.). https://www.iso.org/standard/72046.html (accessed September 18, 2018).

[171] ASTM D5338 - 15 Standard Test Method for Determining Aerobic Biodegradation of Plastic Materials Under Controlled Composting Conditions, Incorporating Thermophilic Temperatures, (n.d.). https://www.astm.org/Standards/D5338.htm (accessed September 18, 2018).

[172] ISO 20200:2015 - Plastics -- Determination of the degree of disintegration of plastic materials under simulated composting conditions in a laboratory-scale test, (n.d.). https://www.iso.org/standard/63367.html (accessed September 18, 2018).

[173] ISO 16929:2013 - Plastics -- Determination of the degree of disintegration of plastic materials under defined composting conditions in a pilot-scale test, (n.d.). https://www.iso.org/standard/62948.html (accessed September 18, 2018).

[174] Norma UNE-EN 13432:2001, (n.d.). https://www.une.org/encuentra-tu-norma/busca-tunorma/norma?c=N0024465 (accessed September 18, 2018).

[175] E. Rudnik, D. Briassoulis, Comparative Biodegradation in Soil Behaviour of two Biodegradable Polymers Based on Renewable Resources, J. Polym. Environ. 19 (2010) 18-39. doi:10.1007/s10924010-0243-7.

[176] M. V. Arcos-Hernandez, B. Laycock, S. Pratt, B.C. Donose, M. a. L. Nikolić, P. Luckman, A. Werker, P. a. Lant, Biodegradation in a soil environment of activated sludge derived polyhydroxyalkanoate (PHBV), Polym. Degrad. Stab. 97 (2012) 2301-2312. doi:10.1016/j.polymdegradstab.2012.07.035.

[177] Y.-X. Weng, Y.-Z.Y. Wang, X.-L. Wang, Y.-Z.Y. Wang, Biodegradation behavior of PHBV films in a pilot-scale composting condition, Polym. Test. 29 (2010) 579-587. doi:10.1016/j.polymertesting.2010.04.002. 
[178] C. Thellen, M. Coyne, D. Froio, M. Auerbach, C. Wirsen, J.A. Ratto, A Processing, Characterization and Marine Biodegradation Study of Melt-Extruded Polyhydroxyalkanoate (PHA) Films, J. Polym. Environ. 16 (2008) 1-11. doi:10.1007/s10924-008-0079-6.

[179] O. Faruk, A.K. Bledzki, H.-P. Fink, M. Sain, Progress Report on Natural Fiber Reinforced Composites, Macromol. Mater. Eng. 299 (2014) 9-26. doi:10.1002/mame.201300008.

[180] M. George, M. Chae, D.C. Bressler, Composite materials with bast fibres: Structural, technical, and environmental properties, Prog. Mater. Sci. 83 (2016) 1-23. doi:10.1016/j.pmatsci.2016.04.002.

[181] S. Kalia, B.S. Kaith, I. Kaur, Pretreatments of natural fibers and their application as reinforcing material in polymer composites-A review, Polym. Eng. Sci. 49 (2009) 1253-1272. doi:10.1002/pen.21328.

[182] M. Ramesh, K. Palanikumar, K.H. Reddy, Plant fibre based bio-composites: Sustainable and renewable green materials, Renew. Sustain. Energy Rev. 79 (2017) 558-584. doi:10.1016/J.RSER.2017.05.094.

[183] M.F.M. Alkbir, S.M. Sapuan, A.A. Nuraini, M.R. Ishak, Fibre properties and crashworthiness parameters of natural fibre-reinforced composite structure: A literature review, Compos. Struct. 148 (2016) 59-73. doi:10.1016/j.compstruct.2016.01.098.

[184] N. Reddy, Y. Yang, Biofibers from agricultural byproducts for industrial applications, Trends Biotechnol. 23 (2005) 22-27. doi:10.1016/j.tibtech.2004.11.002.

[185] A. Heredia, A. Jiménez, R. Guillén, Composition of plant cell walls, Z. Lebensm. Unters. Forsch. 200 (1995) 24-31. doi:10.1007/BF01192903.

[186] L.J. Gibson, The hierarchical structure and mechanics of plant materials., J. R. Soc. Interface. 9 (2012) 2749-66. doi:10.1098/rsif.2012.0341.

[187] L. Wei, A. McDonald, A Review on Grafting of Biofibers for Biocomposites, Materials (Basel). 9 (2016) 303. doi:10.3390/ma9040303.

[188] D. Jones, G.O. Ormondroyd, S.F. Curling, C.-M. Popescu, M.-C. Popescu, Chemical compositions of natural fibres, in: Adv. High Strength Nat. Fibre Compos. Constr., Elsevier, 2017: pp. 23-58. doi:10.1016/B978-0-08-100411-1.00002-9.

[189] N.P. Cheremisinoff, Handbook of engineering polymeric materials, Marcel Dekker, 1997.

[190] M.-A. Berthet, H. Angellier-Coussy, V. Guillard, N. Gontard, Vegetal fiber-based biocomposites: Which stakes for food packaging applications?, J. Appl. Polym. Sci. 133 (2016) 42528 (4-18). doi:10.1002/app.42528.

[191] H. Yang, R. Yan, H. Chen, D.H. Lee, C. Zheng, Characteristics of hemicellulose, cellulose and lignin pyrolysis, Fuel. 86 (2007) 1781-1788. doi:10.1016/j.fuel.2006.12.013.

[192] M. Fogorasi, I. Barbu, The potential of natural fibres for automotive sector - review, IOP Conf. Ser. Mater. Sci. Eng. 252 (2017) 12044(1-10). doi:10.1088/1757-899X/252/1/012044.

[193] M. Liu, A. Thygesen, J. Summerscales, A.S. Meyer, Targeted pre-treatment of hemp bast fibres for optimal performance in biocomposite materials: A review, Ind. Crops Prod. 108 (2017) 660-683. doi:10.1016/J.INDCROP.2017.07.027.

[194] S. Jayavani, H. Deka, T.O. Varghese, S.K. Nayak, Recent Development and Future Trends in Coir Fiber Reinforced Green Polymer Composites: Review and Evaluation, Polym. Compos. 37 (2015) 114. doi:10.1002/pc.23529.

[195] P. Stenstad, M. Andresen, B.S. Tanem, P. Stenius, Chemical surface modifications of microfibrillated 
cellulose, Cellulose. 15 (2008) 35-45. doi:10.1007/s10570-007-9143-y.

[196] A. Gandini, M.N. Belgacem, Modifying cellulose fiber surfaces in the manufacture of natural fiber composites, Woodhead Publishing Limited, 2011. doi:10.1533/9780857092281.1.3.

[197] D. Verma, S. Jain, Effect of Natural Fibers Surface Treatment and their Reinforcement in ThermoPlastic Polymer Composites: A Review, Curr. Org. Synth. 14 (2017) 186-199. doi:10.2174/1570179413666160921114114.

[198] A.K. Mohanty, M. Misra, L.T. Drzal, Surface modifications of natural fibers and performance of the resulting biocomposites: An overview, Compos. Interfaces. 8 (2001) 313-343. doi:10.1163/156855401753255422.

[199] P. Luna, A. Mariño, J. Lizarazo-Marriaga, O. Beltrán, Dry etching plasma applied to fique fibers: influence on their mechanical properties and surface appearance, Procedia Eng. 200 (2017) 141147. doi:10.1016/j.proeng.2017.07.021.

[200] S. Molina, Modification of Natural Fibers Using Physical Technologies and Their Applications for Composites, in: Lignocellul. Fibers Wood Handb., John Wiley \& Sons, Inc., Hoboken, NJ, USA, 2016: pp. 323-344. doi:10.1002/9781118773727.ch13.

[201] M. George, P.G. Mussone, D.C. Bressler, Surface and thermal characterization of natural fibres treated with enzymes, Ind. Crop. Prod. 53 (2014) 365-373. doi:10.1016/j.indcrop.2013.12.037.

[202] B.S. Ndazi, S. Karlsson, J. V. Tesha, C.W. Nyahumwa, Chemical and physical modifications of rice husks for use as composite panels, Compos. Part A Appl. Sci. Manuf. 38 (2007) 925-935. doi:10.1016/j.compositesa.2006.07.004.

[203] J.P. Borges, M.H. Godinho, A.F. Martins, A.C. Trindade, M.N. Belgacem, Cellulose-based composite films, Mech. Compos. Mater. 37 (2001) 257-264. doi:10.1023/A:1010650803273.

[204] S.M.L. Rosa, N. Rehman, M.I.G. De Miranda, S.M.B. Nachtigall, C.I.D. Bica, Chlorine-free extraction of cellulose from rice husk and whisker isolation, Carbohydr. Polym. 87 (2012) 1131-1138. doi:10.1016/j.carbpol.2011.08.084.

[205] B.M. Tofanica, A.C. Puitel, D. Gavrilescu, Environmental friendly pulping and bleaching of rapeseed stalk fibers, Environ. Eng. Manag. J. 11 (2012) 681-686.

[206] S. Tripathi, N. Sharma, I. Alam, N.K. Bhardwaj, Effectiveness of different green chemistry approaches during mixed hardwood bamboo pulp bleaching and their impact on environment, Int. J. Environ. Sci. Technol. (2018) 1-12. doi:10.1007/s13762-018-1887-4.

[207] L. Duan, W. Yu, Z. Li, Analysis of structural changes in jute fibers after peracetic acid treatment, 12 (2017) 33-42.

[208] X. Zhao, E. van der Heide, T. Zhang, D. Liu, Delignification of sugarcane bagasse with alkali and peracetic acid and characterization of the pulp, 5 (2010) 1565-1580.

[209] R. Kumar, F. Hu, C.A. Hubbell, A.J. Ragauskas, C.E. Wyman, Comparison of laboratory delignification methods, their selectivity, and impacts on physiochemical characteristics of cellulosic biomass, Bioresour. Technol. 130 (2013) 372-381. doi:10.1016/j.biortech.2012.12.028.

[210] B. Ly, W. Thielemans, A. Dufresne, D. Chaussy, M.N. Belgacem, Surface functionalization of cellulose fibres and their incorporation in renewable polymeric matrices, Compos. Sci. Technol. 68 (2008) 3193-3201. doi:10.1016/j.compscitech.2008.07.018.

[211] H.-Y. Yu, Z.-Y. Qin, Surface grafting of cellulose nanocrystals with poly(3-hydroxybutyrate-co-3hydroxyvalerate), Carbohydr. Polym. 101 (2014) 471-478. doi:10.1016/j.carbpol.2013.09.048. 
[212] R. Muthuraj, M. Misra, A.K. Mohanty, Biocomposite consisting of miscanthus fiber and biodegradable binary blend matrix: compatibilization and performance evaluation, RSC Adv. 7 (2017) 27538-27548. doi:10.1039/C6RA27987B.

[213] E. Rodi, V. Langlois, E. Renard, V. Sansalone, T. Lemaire, E.G. Rodi, V. Langlois, E. Renard, V. Sansalone, T. Lemaire, Biocomposites Based on Poly(3-Hydroxybutyrate-co-3-Hydroxyvalerate) (PHBHV) and Miscanthus giganteus Fibers with Improved Fiber/Matrix Interface, Polymers (Basel). 10 (2018) 509(1-20). doi:10.3390/polym10050509.

[214] R. Muthuraj, M. Misra, A.K. Mohanty, Reactive compatibilization and performance evaluation of miscanthus biofiber reinforced poly(hydroxybutyrate-co-hydroxyvalerate) biocomposites, J. Appl. Polym. Sci. 134 (2017) 44860 (1-10). doi:10.1002/app.44860.

[215] S. Anderson, J. Zhang, M.P. Wolcott, Effect of Interfacial Modifiers on Mechanical and Physical Properties of the PHB Composite with High Wood Flour Content, J. Polym. Environ. 21 (2013) 631639. doi:10.1007/s10924-013-0586-y.

[216] G. Carvalho, G. Piovezan, M. Pereira, A. Wellington, J. Carla, E. Radovanovic, S.L. F, Mechanical properties of a polyurethane hybrid composite with natural lignocellulosic fi bers, 110 (2017) 459465. doi:10.1016/j.compositesb.2016.11.035.

[217] C.M. Chan, L.-J. Vandi, S. Pratt, P. Halley, D. Richardson, A. Werker, B. Laycock, Mechanical properties of poly(3-hydroxybutyrate- co -3-hydroxyvalerate)/wood flour composites: Effect of interface modifiers, J. Appl. Polym. Sci. (2018) 46828(1-10) doi:10.1002/app.46828.

[218] M. Hao, H. Wu, Effect of in situ reactive interfacial compatibilization on structure and properties of polylactide/sisal fiber biocomposites, Polym. Compos. 39 (2017) E174-E187. doi:10.1002/pc.24484.

[219] M. Hao, H. Wu, F. Qiu, X. Wang, Interface Bond Improvement of Sisal Fibre Reinforced Polylactide Composites with Added Epoxy Oligomer, Materials (Basel). 11 (2018) 398(1-22). doi:10.3390/ma11030398.

[220] P. Nanthananon, M. Seadan, S. Pivsa-Art, H. Hiroyuki, S. Suttiruengwong, Biodegradable polyesters reinforced with eucalyptus fiber: Effect of reactive agents, in: 2017: p. 70012. doi:10.1063/1.5016739.

[221] W. V. Srubar, S. Pilla, Z.C. Wright, C.A. Ryan, J.P. Greene, C.W. Frank, S.L. Billington, Mechanisms and impact of fiber-matrix compatibilization techniques on the material characterization of PHBV/oak wood flour engineered biobased composites, Compos. Sci. Technol. 72 (2012) 708-715. doi:10.1016/J.COMPSCITECH.2012.01.021.

[222] M. Avella, G. Bogoeva-Gaceva, A. Buzõarovska, M. Emanuela Errico, G. Gentile, A. Grozdanov, Poly(3-hydroxybutyrate-co-3-hydroxyvalerate)-based biocomposites reinforced with kenaf fibers, J. Appl. Polym. Sci. 104 (2007) 3192-3200. doi:10.1002/app.26057.

[223] M.A. Gunning, L.M. Geever, J.A. Killion, J.G. Lyons, C.L. Higginbotham, Effect of Compatibilizer Content on the Mechanical Properties of Bioplastic Composites via Hot Melt Extrusion, Polym. Plast. Technol. Eng. 53 (2014) 1223-1235. doi:10.1080/03602559.2014.891235.

[224] L. Jiang, J. Huang, J. Qian, F. Chen, J. Zhang, M.P. Wolcott, Y. Zhu, Study of Poly(3-hydroxybutyrateco-3-hydroxyvalerate) (PHBV)/Bamboo Pulp Fiber Composites: Effects of Nucleation Agent and Compatibilizer, J. Polym. Environ. 16 (2008) 83-93. doi:10.1007/s10924-008-0086-7.

[225] M.S. Sreekala, S. Thomas, Effect of fibre surface modification on water-sorption characteristics of oil palm fibres, Compos. Sci. Technol. 63 (2003) 861-869. doi:10.1016/S0266-3538(02)00270-1.

[226] C.-S. Wu, Preparation, characterization and biodegradability of crosslinked tea plant-fibre- 
reinforced polyhydroxyalkanoate composites, Polym. Degrad. Stab. 98 (2013) 1473-1480. doi:10.1016/j.polymdegradstab.2013.04.013.

[227] C. Wu, Preparation and Characterization of Polyhydroxyalkanoate Bioplastic-Based Green Renewable Composites from Rice Husk, (2014) 384-392. doi:10.1007/s10924-014-0662-y.

[228] R. Bhardwaj, A.K. Mohanty, L.T. Drzal, F. Pourboghrat, M. Misra, Renewable resource-based green composites from recycled cellulose fiber and poly(3-hydroxybutyrate-co-3-hydroxyvalerate) bioplastic, Biomacromolecules. 7 (2006) 2044-2051.

[229] C.L.H. Michael A. Gunning, Luke M. Geever, John A. Killion, John G. Lyonsa, Mechanical and biodegradation performance of short natural fibre polyhydroxybutyrate composites, Polym. Test. 32 (2013) 1603-1611.

[230] E. V. Torres-Tello, J.R. Robledo-Ortíz, Y. González-García, A.A. Pérez-Fonseca, C.F. Jasso-Gastinel, E. Mendizábal, Effect of agave fiber content in the thermal and mechanical properties of green composites based on polyhydroxybutyrate or poly(hydroxybutyrate-co-hydroxyvalerate), Ind. Crops Prod. 99 (2017) 117-125. doi:10.1016/j.indcrop.2017.01.035.

[231] L.V. Rossa, L.C. Scienza, A.J. Zattera, Effect of curauá fiber content on the properties of poly(hydroxybutyrate- co -valerate) composites, Polym. Compos. 34 (2013) 450-456. doi:10.1002/pc.22432.

[232] R. Krishnaprasad, N.R. Veena, H.J. Maria, R. Rajan, M. Skrifvars, K. Joseph, Mechanical and Thermal Properties of Bamboo Microfibril Reinforced Polyhydroxybutyrate Biocomposites, J. Polym. Environ. 17 (2009) 109-114. doi:10.1007/s10924-009-0127-x.

[233] K.C. Batista, D. a. K. Silva, L. a. F. Coelho, S.H. Pezzin, a. P.T. Pezzin, Soil Biodegradation of PHBV/Peach Palm Particles Biocomposites, J. Polym. Environ. 18 (2010) 346-354. doi:10.1007/s10924-010-0238-4.

[234] A.T. Michel, S.L. Billington, Characterization of poly-hydroxybutyrate films and hemp fiber reinforced composites exposed to accelerated weathering, Polym. Degrad. Stab. 97 (2012) 870878. doi:10.1016/j.polymdegradstab.2012.03.040.

[235] A. Barghini, V.I. Ivanova, S.H. Imam, E. Chiellini, Poly-( $\varepsilon$-caprolactone) (PCL) and poly(hydroxybutyrate) (PHB) blends containing seaweed fibers: Morphology and thermal-mechanical properties, J. Polym. Sci. Part A Polym. Chem. 48 (2010) 5282-5288. doi:10.1002/pola.24327.

[236] M. Berthet, H. Angellier-coussy, D. Machado, L. Hilliou, A. Staebler, A. Vicente, N. Gontard, Exploring the potentialities of using lignocellulosic fibres derived from three food by-products as constituents of biocomposites for food packaging, Ind. Crop. Prod. 69 (2015) 110-122. doi:10.1016/j.indcrop.2015.01.028.

[237] N.M. Barkoula, S.K. Garkhail, T. Peijs, Biodegradable composites based on flax/polyhydroxybutyrate and its copolymer with hydroxyvalerate, Ind. Crops Prod. 31 (2010) 34-42. doi:10.1016/j.indcrop.2009.08.005.

[238] M.-A. Berthet, C. Mayer-Laigle, X. Rouau, N. Gontard, H. Angellier-Coussy, Sorting natural fibres: A way to better understand the role of fibre size polydispersity on the mechanical properties of biocomposites, Compos. Part A Appl. Sci. Manuf. 95 (2017) 12-21. doi:10.1016/j.compositesa.2017.01.011.

[239] J.D.S. Macedo, M.F. Costa, M.I.B. Tavares, R.M.S.M. Thiré, Preparation and characterization of composites based on polyhydroxybutyrate and waste powder from coconut fibers processing, Polym. Eng. Sci. 50 (2010) 1466-1475. doi:10.1002/pen.21669. 
[240] M. Avella, G. La Rota, E. Martuscelli, M. Raimo, P. Sadocco, G. Elegir, R. Riva, Poly(3hydroxybutyrate-co-3-hydroxyvalerate) and wheat straw fibre composites: Thermal, mechanical properties and biodegradation behaviour, J. Mater. Sci. 35 (2000) 829-836. doi:10.1023/A:1004773603516.

[241] L. V. Scalioni, M.C. Gutiérrez, M.I. Felisberti, Green composites of poly(3-hydroxybutyrate) and curaua fibers: Morphology and physical, thermal, and mechanical properties, 134 (2017). doi:10.1002/app.44676.

[242] A. Dufresne, D. Dupeyre, M. Paillet, Lignocellulosic flour-reinforced poly (hydroxybutyrate-covalerate) composites, J. Appl. Polym.. 87 (2003) 1302-1315.

[243] H. Ventura, J. Claramunt, M.A. Rodríguez-Pérez, M. Ardanuy, Effects of hydrothermal aging on the water uptake and tensile properties of PHB/flax fabric biocomposites, Polym. Degrad. Stab. 142 (2017) 129-138. doi:10.1016/j.polymdegradstab.2017.06.003.

[244] S.S. Ahankari, A.K. Mohanty, M. Misra, Mechanical behaviour of agro-residue reinforced poly(3hydroxybutyrate-co-3-hydroxyvalerate), (PHBV) green composites: A comparison with traditional polypropylene composites, Compos. Sci. Technol. 71 (2011) 653-657. doi:10.1016/j.compscitech.2011.01.007.

[245] B. Wang, M. Sain, The effect of chemically coated nanofiber reinforcement on biopolymer based nanocomposites, BioResources. 2 (2007) 371-388.

[246] N.S. Yatigala, D.S. Bajwa, S.G. Bajwa, Compatibilization improves physico-mechanical properties of biodegradable biobased polymer composites, Compos. Part A Appl. Sci. Manuf. 107 (2018) 315325. doi:10.1016/j.compositesa.2018.01.011.

[247] C.S. Wu, H.T. Liao, Y.X. Cai, Characterisation, biodegradability and application of palm fibrereinforced polyhydroxyalkanoate composites, Polym. Degrad. Stab. 140 (2017) 55-63. doi:10.1016/j.polymdegradstab.2017.04.016.

[248] A. Javadi, Y. Srithep, J. Lee, S. Pilla, C. Clemons, S. Gong, L. Turng, Processing and characterization of solid and microcellular PHBV / PBAT blend and its RWF / nanoclay composites, Compos. Part A. 41 (2010) 982-990. doi:10.1016/j.compositesa.2010.04.002.

[249] H. Ren, Y. Zhang, H. Zhai, J. Chen, Production and Evaluation of Biodegradable Composites Based on Polyhydroxybutyrate and Polylactic Acid Reinforced With Short and Long Pulp Fibers, Cellul. Chem. Technol. 49 (2015) 641-652.

[250] R.A. Shanks, A. Hodzic, S. Wong, Thermoplastic biopolyester natural fiber composites, J. Appl. Polym. Sci. 91 (2004) 2114-2121. doi:10.1002/app.13289.

[251] S. Wong, R.A. Shanks, A. Hodzic, Effect of additives on the interfacial strength of poly(l-lactic acid) and poly(3-hydroxy butyric acid)-flax fibre composites, Compos. Sci. Technol. 67 (2007) 2478-2484. doi:10.1016/j.compscitech.2006.12.016.

[252] S. Wong, R. Shanks, A. Hodzic, Properties of poly(3-hydroxybutyric acid) composites with flax fibres modified by plasticiser absorption, Macromol. Mater. Eng. 287 (2002) 647-655. doi:10.1002/14392054(200211)287:10<647::AID-MAME647>3.0.CO;2-4.

[253] L. Jiang, F. Chen, J. Qian, J. Huang, M. Wolcott, L. Liu, J. Zhang, Reinforcing and Toughening Effects of Bamboo Pulp Fiber on Poly(3-hydroxybutyrate- co -3-hydroxyvalerate) Fiber Composites, Ind. Eng. Chem. Res. 49 (2010) 572-577. doi:10.1021/ie900953z.

[254] L. Wei, N.M. Stark, A.G. Mcdonald, Interfacial improvements in biocomposites based on poly(3hydroxybutyrate) and poly(3-hydroxybutyrate-co-3-hydroxyvalerate) bioplastics reinforced and 
SECCIÓN 2.-Marco teórico

grafted with $\alpha$-cellulose fibers, (2015) 4800-4814. doi:10.1039/c5gc01568e. 
"Reunirse en equipo es el principio, mantenerse en equipo es el progreso, trabajar en equipo asegura el éxito",

(Henry Ford)

SECCIÓN 3.-Resultados 
Bloque A.- Relación composición-estructurapropiedades-comportamiento de compuestos PHA/fibra 


\section{CAPÍTULO I}

\section{Poly(3-Hydroxybutyrate-co-3-Hydroxyvalerate)/}

Purified Cellulose Fiber Composites by Melt Blending: Characterization and Degradation in Composting

\section{Conditions}

Estefanía Lidón Sánchez-Safont ${ }^{1}$, Jennifer González-Ausejo ${ }^{1}$, José Gámez-Pérez ${ }^{1}$, José María Lagarón $^{2}$, Luis Cabedo ${ }^{1}$

1- Polymers and Advanced Materials Group (PIMA), Universitat Jaume I, Spain

2- Novel Materials and Nanotechnology Group, IATA, CSIC, Spain

J. Renew. Mater. 2016, 4, 123. 


\begin{abstract}
Novel biodegradable composites based on poly (3-hydroxybutirate-co-3-hydroxyvalerate) (PHBV) and different contents of purified alpha-cellulose fibers $(3,10,25$ and 45\%) were prepared by melt blending and characterized. The composites were characterized by scanning electron microscopy (SEM), wide-angle X-ray scattering experiments (WAXS), thermogravimetric analysis (TGA), differential scanning calorimetry (DSC), dynamic mechanic analysis (DMA) and Shore D hardness measurements. Disintegrability in composting conditions was studied according to the ISO 20200 standard. Morphological results showed that high dispersion of the fibers was achieved during mixing. Good adhesion on the fiber-matrix interface was also detected by SEM. The addition of low and medium cellulose contents did not result in lower thermal resistance with respect to the neat PHBV. A reinforcing effect of the cellulose fibers was detected in all samples, this effect being more pronounced at high temperatures. The composting results show that the addition of the fibers did not affect the disintegrability of the PHBV, and thus compostable "green" low-cost PHBV/cellulose composites can be obtained.
\end{abstract}

\title{
Keywords
}

PHBV, cellulose, composites, biodegradation, ISO 20200

\section{I.1. Introduction}

Plastic packaging residues are one of the most serious problems in the management of municipal solid waste since they are mostly resistant to microbial degradation and remain semipermanently in landfills with the environmental impact that this implies $[1,2]$. Composting of biodegradable plastic packaging seems to be one of the most promising solutions for waste management, given the difficulty of separating the organic fraction of municipal waste [2]. Hence, in recent decades there has been a growing interest in the development of biodegradable bioplastics from renewable sources to replace conventional petroleum-based plastics for their use in almost all productive sectors, especially in the packaging and agricultural sectors $[3,4]$.

Among the commercially available biopolymers, biopolyesters have emerged as an alternative to commodities because of the combination of an easy processability in conventional equipment and good mechanical properties with the ability to biodegrade. Poly(lactic acid) (PLA) is the most 
widely known and frequently used biopolyester. However, some properties of PLA such as thermal stability and impact resistance are lower than those of the commodity polymers used for thermoplastic applications [5]. The low thermal resistance of PLA is a consequence of both a high glass transition temperature (around $70 \circ \mathrm{C}$ ) and a slow crystallization rate, especially at high molecular weights $[6,7]$. As a result, many processed products are amorphous and undergo changes in shape at temperatures above 55ㅇ, which makes PLA inappropriate for use in applications at relatively high temperatures.

Poly(hydroxybutyrate-co-hydroxyvalerate) (PHBV), a bacterial copolyester from the polyhydroxyalkanoate family (PHA) has gained a lot of attention, especially in the packaging field, because of its renewable and non-food competitive origin, biodegradability and performance close to that of some commodity polymers [8, 9]. Although the mechanical performance is similar to that of polypropylene (PP) $[10,11]$, the gas barrier properties to oxygen and aroma are close to those of the polyethylene terephthalate (PET) [12]. In contrast to PLA, PHBV presents a low glass transition temperature and a high degree of crystallinity (with a melting point above $160 \circ \mathrm{C}$ ), and therefore it is suitable for high temperature applications. Nevertheless, PHBV experiments show inferior mechanical performance at temperatures above $80 \circ \mathrm{C}$ and its high price handicaps its use in low-cost applications [13].

A possible way to reduce the price of PHBV, as well as increase its mechanical performance at high temperatures, is the addition of a second reinforcing phase to develop composite materials. It is well known that the dispersion of fibrillated microparticles or nanoparticles in a polymeric matrix improves the mechanical properties; also, the addition of cheaper loading in high proportions allows reduction in the product's final cost. In this context, the effect of the addition of inorganic fibers to biopolyester matrices on its mechanical, thermic and barrier properties has been widely studied $[14,15]$.

Within the current context of renewable raw materials, the scientific community has focused its interest on the use of natural fibers as a reinforcing agent for polymer composites because of its advantages in comparison with conventional synthetic or inorganic fillers $[16,17]$. In this regard, some of the advantages of natural fibers compared with conventional reinforcing materials are their low cost, low density, high hardness, good thermal properties, acceptable specific strength properties, good availability and biodegradability $[18,19]$. In addition, the usage of natural fibers as fillers in polymer composites would allow the use of by-products or residues from the agricultural and agroalimentary industry. Thus, natural fibers, such as cellulose and its derivatives, which are natural occurring biodegradable fillers, may exert a reinforcement effect on the PHBV matrix as well as reduce the final cost without compromising biodegradability [20]. 
In the present study, purified alpha-cellulose refined from wood-pulp manufacture was used, where lignin and hemicellulose, which degrade at lower temperatures than cellulose, are removed from the fibers. The advantages of using pure cellulose fibers as compared to unmodified plant fibers include:

(1) the possibility of processing at higher temperatures,

(2) a higher grade of homogeneity in molar mass and other characteristic properties of the material,

(3) higher strength than untreated natural fiber,

(4) smaller fiber size,

(5) high crystallinity levels which may help to promote higher barrier properties in composites.

Several studies have been carried out in the literature using cellulose fibers with a lignocellulosic nature, but fewer have been conducted using highly purified alpha-cellulose fibers [21-23].

Some studies related to the incorporation of natural lignocellulosic and cellulosic fibers in biopolyesters have been reported [24, 25]. Avella et al. reinforced PHBV with heat exploded wheat straw and hemp fibers [26]; Battegazzore et al. added cellulose derived from rice husk to poly(lactic acid) (PLA) matrices, finding an improvement in mechanical properties [27].

Assessment of the biodegradation of PHAs and PHBV in composting conditions and other environments have been investigated by several authors [8, 28-33]. However, to our knowledge, the biodisintegration behavior of composites of PHBV $(3 \% \mathrm{HV})$ /cellulose fibers obtained by melt blending according to the ISO 20200 standard [34] has not been reported yet.

Within this context, the purpose of this work is to obtain "green" low-cost composites from commercial PHBV and purified cellulose fibers using the melt blending technique. These composites must contain the highest possible amount of cellulose, increasing mechanical performance (particularly at high temperatures) while retaining their processability and thermal properties, and be degradable under standard lab-scale composting conditions (ISO 20200 standard). 


\section{I.2. Experimental}

\section{I.2.1. Materials}

Poly (3-hydroxybutirate-co-3-hydroxyvalerate) (PHBV) containing $3 \mathrm{~mol} \%$ of hydroxyvalerate was supplied by Tianan Biological Materials Co. (Ningbo, P. R. China) in pellet form (ENMATTM Y1000P). A purified alpha-cellulose fiber grade (also referred to as cellulose) (TC90) from CreaFill Fibers Corp. (US) was used. According to the manufacturer's specifications, these fibers have an average fiber length of $60 \mu \mathrm{m}$ and an average fiber width up to $20 \mu \mathrm{m}$. The alpha-cellulose content is $>99.5 \%$.

\section{I.2.2. PHBV/cellulose composite preparation}

PHBV and cellulose fibers were dried at $80{ }^{\circ} \mathrm{C}$ for two hours under vacuum before blending to remove moisture. PHBV/cellulose composites with 0, 3, 10, 25 and 45 wt\% fiber contents were obtained by melt blending with a ThermoHaake Rheomix Polylab internal mixer for six minutes at $180 \circ \mathrm{C}$ and a rotor speed of $100 \mathrm{rpm}$. In order to reduce thermal degradation during blending, the melt temperature was never allowed to reach 190 으. Each batch was then extracted from the mixing chamber manually and allowed to cool to room temperature in air. Materials generated in the mixing process were then hot pressed at 185 으 $\mathrm{C}$ and 3 bar for three minutes to produce plates of 0.8 and films of $0.2 \mathrm{~mm}$ nominal thickness. All the samples were stored in a vacuum desiccator at room temperature. The samples were named according to the following code: PHBV-XC where $X$ corresponds to the \%wt. cellulose fiber content.

\section{I.2.3. Disintegration in composting conditions}

Biodegradation of PHBV/cellulose composites was evaluated by measuring the disintegrability of the composite plate samples under lab-scale composting conditions. Disintegration tests were carried out according to the ISO 20200 standard [34]. Solid synthetic waste was prepared by mixing $10 \%$ of activated mature compost (VIGORHUMUS H-00, purchased from Burás Profesional, S.A., Girona, Spain), 40\% sawdust, 30\% rabbit feed, 10\% corn starch, 5\% sugar, $4 \%$ corn seed oil and $1 \%$ urea. The water content of the mixture was adjusted to $55 \%$. Composite samples were cut from hot pressed plates $\left(15 \times 15 \times 0.2 \mathrm{~mm}^{3}\right)$ and buried in compost bioreactors at 4-6 cm depth. The samples were placed inside iron mesh bags to simplify their extraction and 
allow the contact of the compost with the specimens. Bioreactors were incubated at 58ㄷ. The aerobic conditions were guaranteed by mixing the synthetic waste periodically and adding water according to the standard requirements. Three replicates of each sample were removed from the boxes at different composting times for analysis. Samples were washed with water and dried under vacuum at $40^{\circ} \mathrm{C}$ until a constant mass. The disintegration degree was calculated by normalizing the sample weight to the initial weight with equation (1) [35]:

$D=\frac{m_{i}-m_{f}}{m_{i}} \times 100$

where $m_{i}$ is the initial dry mass of the test material and $m_{f}$ is the dry mass of the test material recovered at different incubation stages. The disintegration study was completed by SEM and photographs of samples were taken for visual evaluation.

\section{I.2.4. Characterization techniques}

Morphology of PHBV/cellulose composites was examined by Scanning Electron Microscopy (SEM) with a JEOL 7001F. The samples were prepared by cryofracturing after immersion in liquid nitrogen for a few minutes. The surface morphology of composites at different composting times was also investigated by SEM. All the samples were previously coated by sputtering with a thin layer of Pt.

Wide angle X-ray scattering experiments (WAXS) were performed with a Bruker AXS D4 Endeavor

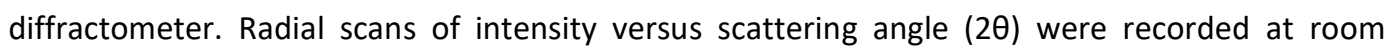
temperature in the range of 2 to 30 ㅇ (step size $=0.02 \circ(2 \theta)$, scanning rate $=8 \mathrm{~s} / \mathrm{step}$ ) with identical instrument settings provided by filtered $\mathrm{CuK}_{\alpha}$ radiation $(\lambda=1.54 \AA$ ), an operating voltage of $40 \mathrm{kV}$, and a filament current of $40 \mathrm{~mA}$.

Thermogravimetric analysis (TGA) was performed with a TG-STDA Mettler Toledo model TGA/STDA851e/LF/1600 to determine the thermal stability of the PHBV/cellulose composites. The samples with an initial weight typically about $4 \mathrm{mg}$ were heated from $50 \circ \mathrm{C}$ to $600 \circ \mathrm{C}$ with a heating rate of $10 \% \mathrm{C} / \mathrm{min}$ under nitrogen atmosphere. Main thermal parameters were determined from TGA curves, such as the initial decomposition temperature $\left(T_{5 \%}\right.$, temperature at $5 \%$ weight loss) and maximum decomposition rate temperature $\left(T_{d}\right)$.

Differential scanning calorimetry (DSC) of PHBV/cellulose composites was conducted on a PerkinElmer DSC 7 thermal analyzer with Ar as the purging gas. The calibration of the DSC was 
performed with an indium standard sample. Material samples weighing about 6 to $8 \mathrm{mg}$ were heated to $185^{\circ} \mathrm{C}$ at $40 \circ \mathrm{C} / \mathrm{min}$ and kept for $3 \mathrm{~min}$. to erase thermal history, followed by cooling to room temperature and heating to $185^{\circ} \mathrm{C}$ at $10^{\circ} \mathrm{C} / \mathrm{min}$. Melting temperatures $\left(\mathrm{T}_{\mathrm{m}}\right)$ and enthalpies $\left(\Delta H_{m}\right)$, as well as crystallization temperatures $\left(T_{c}\right)$ and enthalpies $\left(\Delta H_{c}\right)$ were calculated from the corresponding heating/cooling curves. The crystallinity degree $\left(X_{c}\right)$ of the PHBV phase of composites was determined by applying the following expression [36]:

$X_{c}(\%)=\frac{\Delta H_{m}}{w \cdot \Delta H_{m}^{0}} \times 100$

where $\Delta H_{m}(J / g)$ is the melting enthalpy of the polymer matrix, $\Delta H_{m}^{0}$ is the melting enthalpy of $100 \%$ crystalline PHBV (perfect crystal) $(146 \mathrm{~J} / \mathrm{g}$ ) [37] and $w$ is the polymer weight fraction of PHBV in the blend.

Dynamic mechanic analysis (DMA) experiments were conducted on hot pressed sample platelets $(10 \times 5 \times 0.8 \mathrm{~mm})$ in a Perkin Elmer DMA7e. Samples were heated from -20 oC to melting temperature with a heating rate of $5 \circ \mathrm{C} / \mathrm{min}$ at a constant frequency of $1 \mathrm{~Hz}$ in the three-point bending mode under Ar flow.

The hardness of PHBV and PHBV/cellulose composites was measured with a Shore D hardness tester Zwick 3100 Shore D (Zwick GmbH, Germany).

\section{I.3. Results and discussion}

\section{I.3.1. Characterization of the PHBV/cellulose composites}

\section{I.3.1.1. SEM}

Morphological characterization of the cellulose fibers as received and within the composites used in this work was performed with SEM (Figure I.1).

Figures I.1a and I.1b show SEM micrographs of the cellulose fibers at different magnifications. These fibers present a rod-shaped morphology with varying lengths up to $200 \mu \mathrm{m}$. In all cases, the diameter is contained within the $10-20 \mu \mathrm{m}$ range. The broken fibers in Figure $1.1 \mathrm{a}$ and I.1b are formed from a bundle of smaller fibrils [23]. 

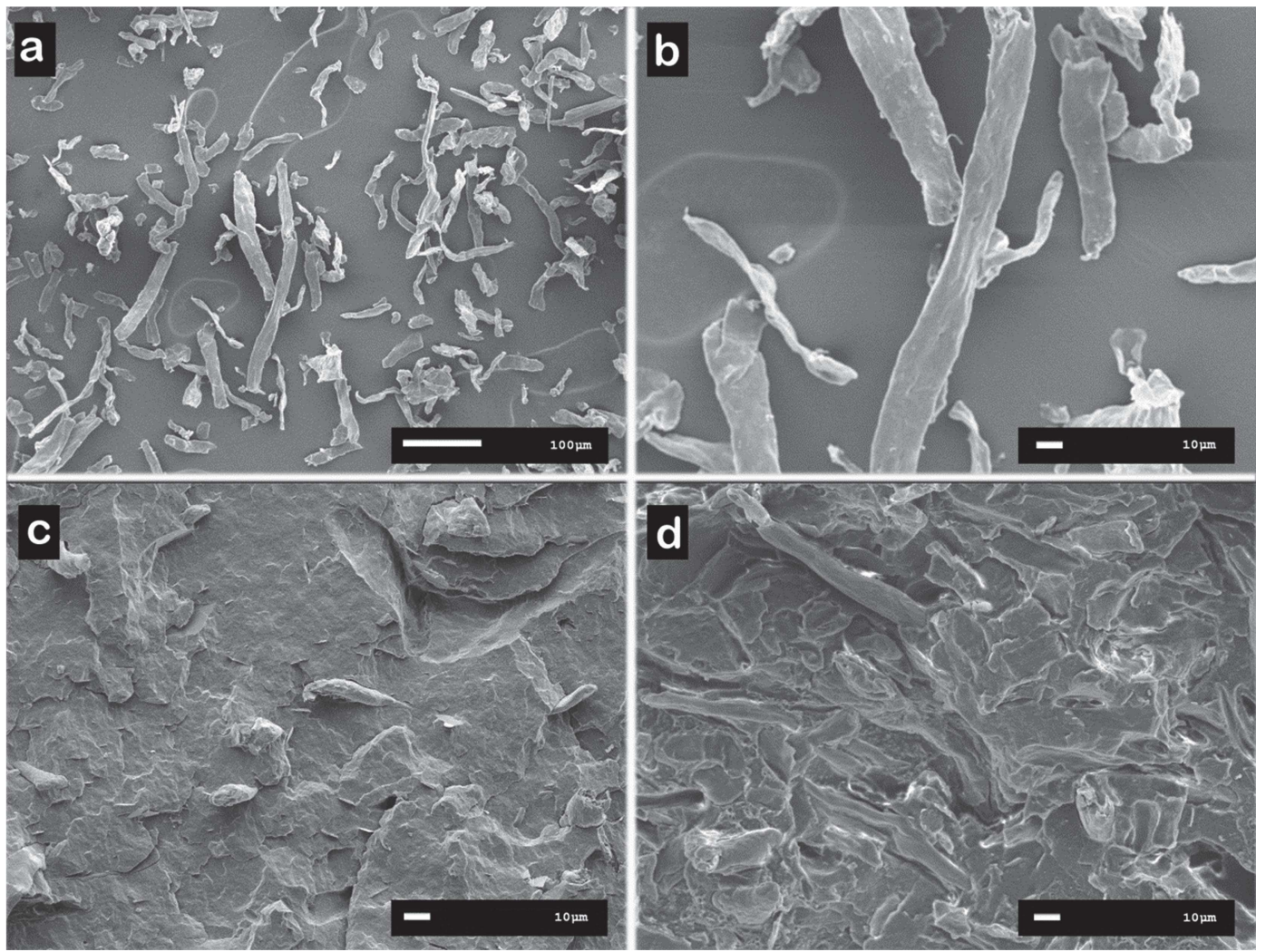

Figure I.1. SEM micrographs of cellulose fibers and PHBV/cellulose composites (a) cellulose low magnification (500x), (b) cellulose high magnification (150x), (c) PHBV-3C (500x) and (d) PHBV-45C (500x).

The PHBV/cellulose composite SEM micrographs shown in Figures I.1c and I.1d were obtained from the cryo-fractured surface of the composites with the lowest (3\%) and the highest (45\%) fiber content, respectively. The examination of the images reveals that a homogeneous dispersion of filler has been achieved. Indeed, no pull-out effect is observed, thus indicating a strong adhesion between the cellulose fibers and the polymer matrix. Broken fibers can be seen on the fractured surface. The good interaction between the cellulose fibers and the polyester matrix can be explained by the formation of a hydrogen-bonding-type interaction between carbonyl groups of PHBV and hydroxyl groups of the cellulose [38]. The morphology observed in the $3 w t \%$ and $45 w t \%$ samples is representative of all the compositions in the studied range. 


\section{I.3.1.2. WAXS}

WAXS experiments were conducted on the cellulose powder, the neat PHBV and all the composites studied. The X-ray patterns of the samples are shown in Figure I.2.

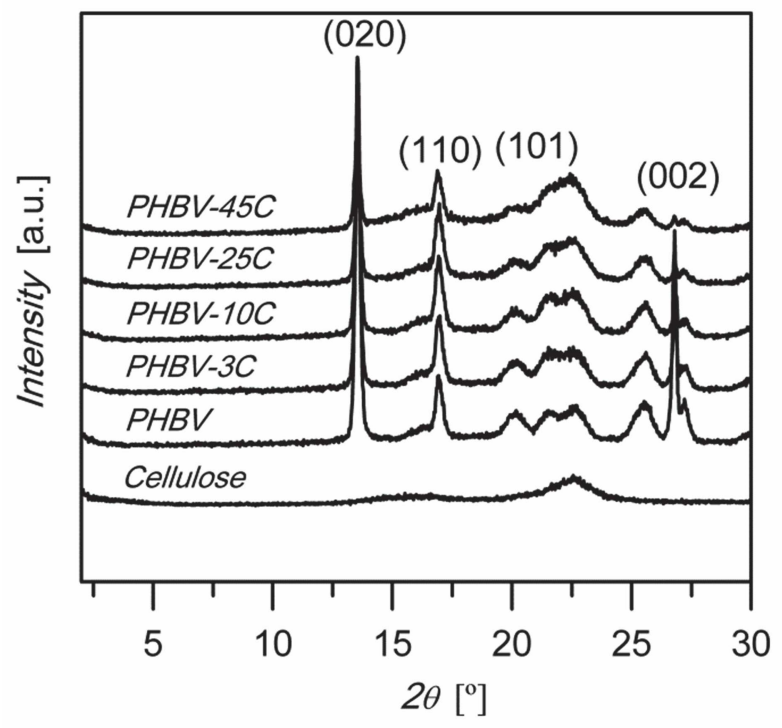

Figure I.2. WAXS patterns of the cellulose, the neat PHBV and the PHBV/cellulose composites with 3, 10, 25 and $45 \mathrm{wt} \%$ of cellulose.

Three characteristic peaks of PHBV were detected in both PHBV and PHBV/cellulose samples at

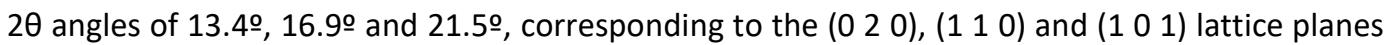
of the orthorhombic unit cell of PHBV [36,39]. The most intense peak at $2 \theta=26$ corresponds to the $(002)$ reflection of the boron nitride, which is present as a nucleating agent in the commercial grade used in this work. There were no changes in the diffraction peak positions of PHBV regardless of the fiber content. This suggests that the crystalline structure of PHBV does not change with the addition of cellulose. The decrease in intensity of the peaks can be explained by a dilution effect as the cellulose content is increased.

\section{I.3.1.3. DSC}

DSC measurements of PHBV/cellulose composites were performed in order to study the crystallization behavior of these materials. DSC curves of cooling and heating scans, after removal of the thermal history, are displayed in Figure I.3. From these curves the characteristic 
temperatures, enthalpies and crystallinity degree $\left(X_{c}\right)$ of the blends were determined. Results are summarized in Table I.1.

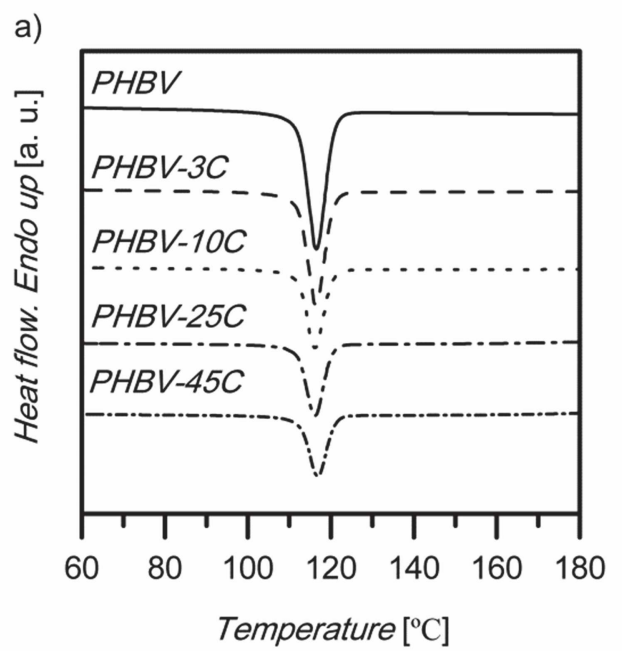

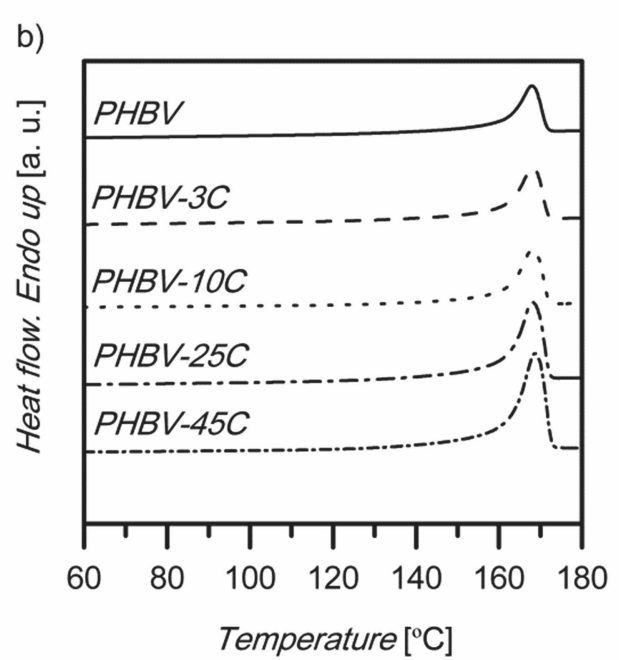

Figure I.3. DSC thermograms of a) the cooling scan and b) the heating scan and of the neat PHBV and the PHBV/cellulose composites containing 3, 10, 25 and 45 wt\% of cellulose.

PHBV shows an endothermic peak related to its melting point at $168.7^{\circ} \mathrm{C}$ and one exothermic peak at 116.4 o $C$ corresponding to crystallization. Pure PHBV presents a crystallinity degree $X_{c}$ of $67 \%$. This crystallinity degree is quite high because the PHBV used was a commercial grade containing boron nitride as a nucleating agent.

When cellulose was added to PHBV, no remarkable changes were found in the melting and crystallization peak positions. Regarding $X_{c}$ variations, PHBV/cellulose composites did not show significant differences. These results seem to contradict other works based on aliphatic polyesters $[26,40]$, where it has been reported that cellulosic fillers act as nucleating agents and show significant differences in thermal and crystallinity parameters. However, in our case this effect is not appreciable, probably because of the presence of the boron nitride. Therefore, it can be concluded that addition of cellulose fibers barely affects the melting/crystallization behavior of this particular PHBV grade. 

composites.

\begin{tabular}{cccccc}
\hline & $\mathrm{T}_{\mathrm{c}}(\mathbf{\circ} \mathrm{C})$ & $\boldsymbol{\Delta} \mathrm{H}_{\mathrm{c}}(\mathrm{J} / \mathrm{g})$ & $\mathrm{T}_{\mathrm{m}}(\mathbf{\circ})$ & $\Delta \mathrm{H}_{\mathrm{m}}(\mathrm{J} / \mathrm{g})$ & $\boldsymbol{X}_{\boldsymbol{c}}(\%)$ \\
\hline PHBV & 116.4 & $-87,9$ & 168,7 & 97,9 & 67 \\
PHBV-3C & 116.4 & $-87,5$ & 168,0 & 95,3 & 67 \\
PHBV-10C & 116.1 & $-83,9$ & 168,2 & 91,6 & 70 \\
PHBV-25C & 116.1 & $-70,0$ & 168,2 & 73,7 & 67 \\
PHBV-45C & 116.9 & $-63,0$ & 168,0 & 55,5 & 69 \\
\hline
\end{tabular}

\section{I.3.1.4. TGA}

Thermogravimetric analysis (TGA) was conducted to evaluate the thermal degradation of PHBV, cellulose and PHBV/cellulose composites. In Figure I.4 the TGA curves are shown. The onset degradation temperature ( $T_{5 \%}$, considered as the temperature at which a $5 \%$ weight loss occurs), the maximum degradation temperature ( $T_{d}$, corresponding to the DTG peak) and the residue (\%) at $600{ }^{\circ} \mathrm{C}$ were determined; results are summarized in Table I.2.

Thermogravimetric analysis (TGA) of cellulose revealed that the thermal degradation of these fibers takes place in a single weight loss step around $350 \stackrel{\circ}{\circ}$, with a residue of $15.8 \%$, in agreement with other works [41].

PHBV thermal degradation also takes place in a single weight loss step between 260 and $300 \circ \mathrm{C}$. This degradation occurs abruptly because of the chain scission reaction mechanism, leading to a dramatic loss of molecular weight and consequently a low thermal stability, as reported in the literature [42]. The onset degradation temperature of PHBV is $273 \circ \mathrm{C}$ and the maximum decomposition temperature is 290 ․ C.

In the case of PHBV/cellulose composites, it seems that the addition of low filler contents does not alter the thermal stability of PHBV. The addition of high contents of cellulose fibers, however, slightly decreases the onset degradation temperature and the maximum degradation temperature of the composites. This behavior is attributed to interactions between cellulose and PHBV, similarly to those reported by Petinakis et al. for PLA starch systems [43].

A secondary degradation peak was found around 350ㄷ in PHBV/cellulose samples, which was related to cellulose decomposition. The residue at $600^{\circ} \mathrm{C}$ was approximately $0.4 \%$ and increased with the cellulose addition up to $4.8 \%$ for the highest filler content. These residue values are 
lower than expected on account of the residue of cellulose. The deviation is probably owed to the formation of crotonic acid during the thermal degradation of the PHBV, which is able to hydrolyze cellulose [44], and consequently the residue values are lower.

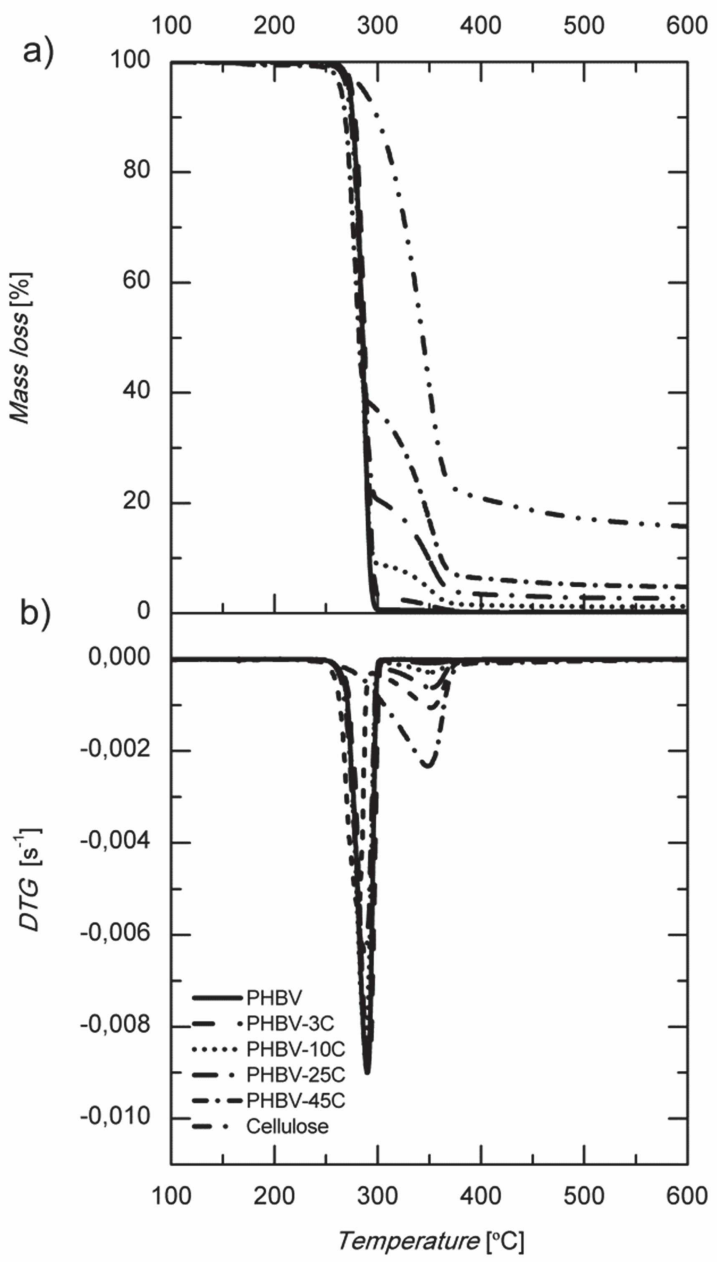

Figure 1.4. TGA curves of neat PHBV and PHBV/cellulose composites. 
Table 1.2. Parameters obtained from thermogravimetric analyses of neat PHBV and its composites.

\begin{tabular}{|c|c|c|c|}
\hline & $\mathrm{T}_{5 \%}(\mathrm{O} \mathrm{C})$ & $T_{d}(\stackrel{\circ}{ })$ & Residue(\%) at $600 \% \mathrm{C}$ \\
\hline PHBV & 273 & 290 & 0.4 \\
\hline PHBV-3C & 275 & 291 & 0.4 \\
\hline PHBV-10C & 272 & 287 & 1.3 \\
\hline PHBV-25C & 270 & 288 & 2.7 \\
\hline PHBV-45C & 264 & 281 & 4.8 \\
\hline Cellulose & 286 & 348 & 15.8 \\
\hline
\end{tabular}

\section{I.3.1.5. Mechanical behavior}

Dynamic mechanical analysis (DMA) was performed on PHBV and PHBV/cellulose composites to study the effect of the cellulose content on the mechanical performance throughout the whole temperature range from $T_{g}$ to melting temperature. The storage modulus ( $E^{\prime}$ ) and Tan- $\delta$ curves are shown in Figure 1.5, and dependence of the storage modulus on the temperature is summarized in Table I.3.

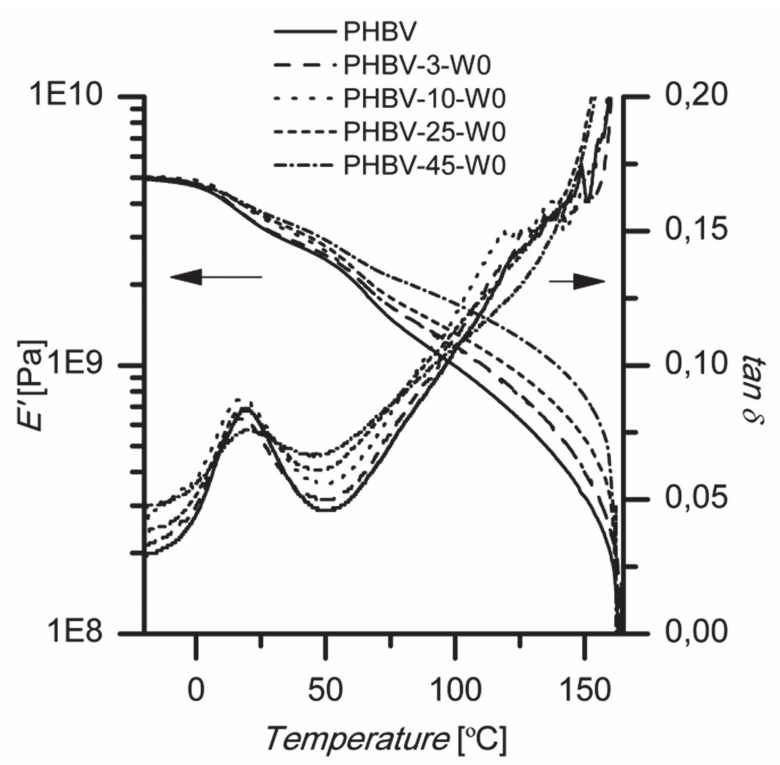

Figure 1.5. Storage modulus and Tan- $\delta$ curves obtained from the DMA of neat PHBV and its composites. 
At temperatures below glass transition no major differences in storage modulus were detected among the different materials. Indeed, all the studied samples showed a very stiff behavior. On the other hand, at temperatures above $T_{g}$, a rise in the storage modulus was observed as the addition of cellulose increased, therefore showing a good reinforcing effect. This effect can be attributed to the good interaction between the fillers and the biopolyester matrix, according to the SEM observation on the coherent interphase.

Table I.3. Storage modulus at diferent temperatures and Shore D hardness of PHBV and PHBV/cellulose composites.

\begin{tabular}{|c|c|c|c|}
\hline & \multicolumn{2}{|c|}{$\mathrm{E}^{\prime}(\mathrm{MPa})$} & \multirow{2}{*}{$\begin{array}{l}\text { Hardness at 250C } \\
\text { (Shore D) }\end{array}$} \\
\hline & $25 \div C$ & $100 \stackrel{\circ}{C}$ & \\
\hline PHBV & 3270 & 998 & $81 \pm 1$ \\
\hline PHBV-3C & 3310 & 1170 & $80 \pm 1$ \\
\hline PHBV-10C & 3560 & 1170 & $81 \pm 1$ \\
\hline PHBV-25C & 3630 & 1320 & $82 \pm 1$ \\
\hline PHBV-45C & 3740 & 1700 & $86 \pm 1$ \\
\hline
\end{tabular}

At high temperatures, the reinforcement provided by the cellulose fibers was even more noticeable as the matrix decreased its stiffness. In this context, the storage modulus of the pure PHBV at $100 \circ \mathrm{C}$ dropped to a value ca.1000 MPa; that containing $45 \mathrm{wt} \%$ of cellulose fibers presented a storage modulus of $1700 \mathrm{MPa}$, thus showing an increase of $70 \%$. Similar behavior was reported by Bhardwaj et al. [45] for other cellulosic fillers. The increment in the stiffness of the PHBV/cellulose composites at high temperatures improves the performance of this material in applications where temperatures close to or above the boiling point of the water are easily reached (such as food packaging applications).

Tan- $\delta$ vs. temperature plots are shown in Figure I.5. Tan- $\delta$ curves present a single peak at temperatures close to $20^{\circ} \mathrm{C}$ indicating the $\alpha$-relaxation of the composites, which can be attributed to the glass transition temperatures $\left(T_{g}\right)$. No remarkable differences in $T_{g}$ values were found for low cellulose contents with respect to the neat PHBV. However, for a $45 \%$ cellulose content Tan- $\delta$ peak was slightly shifted towards higher temperatures. This can be attributed to the limitation of chain mobility within the polymer matrix introduced by the fibers [38].

Additionally, Shore D hardness of PHBV and its composites was assessed. Results are summarized in Table I.3. From the results it can be concluded that with low filler contents there were no 
changes in hardness. Nevertheless, the highest loaded composition showed a significant increase of hardness. This increase is in accordance with the reinforcing effect observed in DMA analyses.

\section{I.3.1.6. Degradation in composting conditions of the PHBV/cellulose composites}

Disintegration in composting conditions was evaluated by measuring the weight loss of PHBV and PHBV/cellulose composite samples according to the ISO 20200 standard. Figure I.6 shows the disintegration rate of the samples as a function of time. Weight loss remains practically unchanged until the 20th day of composting. After 20 days the disintegration rate increases markedly to reach total disintegration in 47 days of testing. No significant differences in weight loss rate were observed among samples, so it seems that the cellulose addition does not affect the disintegration rate.

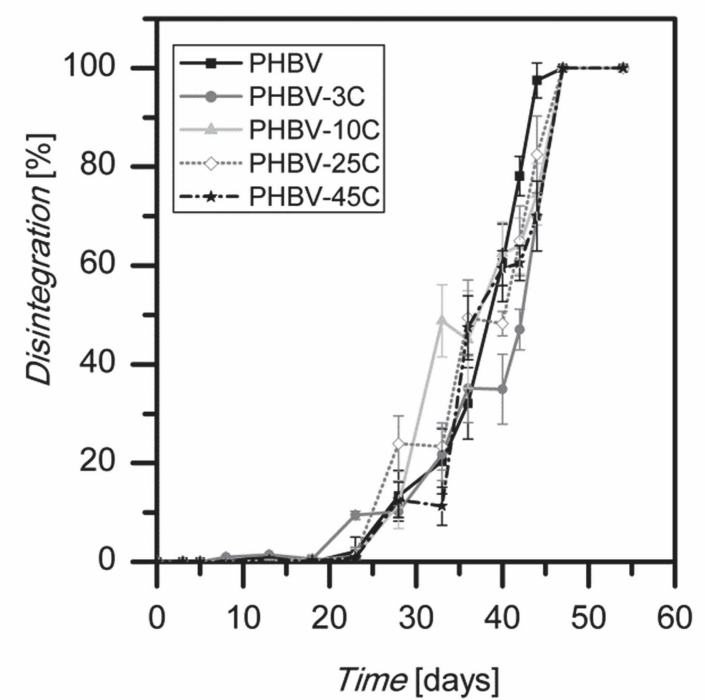

Figure I.6. Disintegrability (\%) of PHBV and PHBV/cellulose composites under composting conditions as a function of time.

Figure 1.7 shows the visual appearance of PHBV and PHBV/cellulose composite samples removed from compost at different composting times. No evident changes in the visual examination were detected in the first three weeks of composting, except for a slight surface roughening. This surface roughening indicates the beginning of the disintegration process. In fact, as reported in 
the literature, the degradation phenomenon occurred with erosion from the surface to the inside [9]. At 42 days clear physical changes on the surface and morphology of the samples were observed. All of the samples were broken into small pieces and showed similar roughening and physical alterations. At longer composting times, samples were more disintegrated, leaving small pieces less than $2 \mathrm{~mm}$ in size.

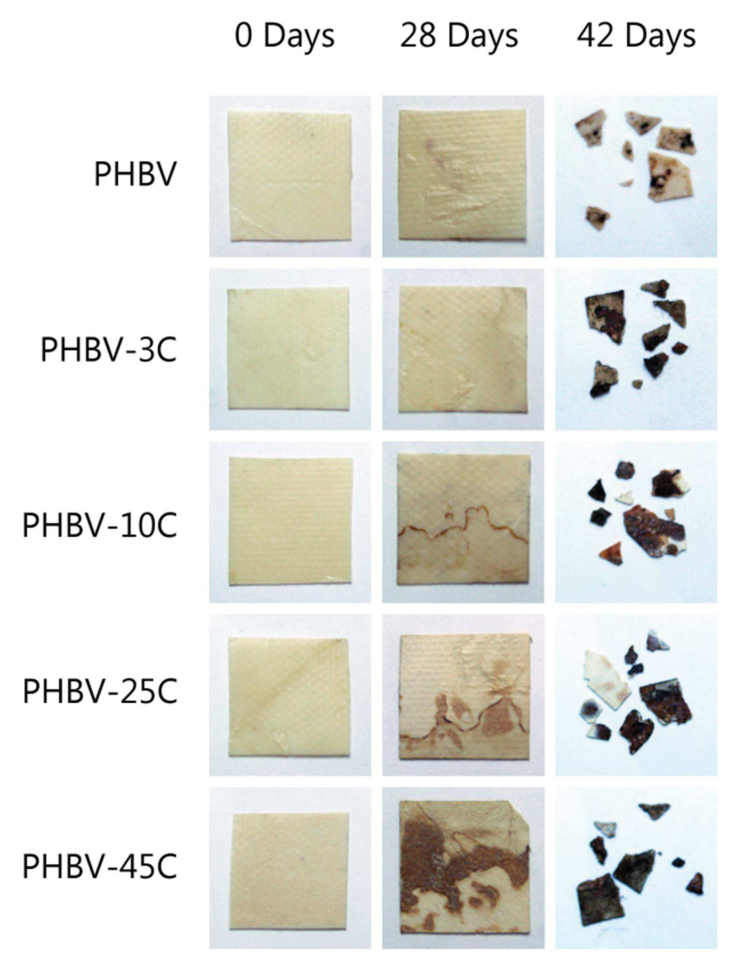

Figure I.7. Visual aspect of PHBV and PHBV/cellulose samples after 0, 28 and 42 days in composting conditions.

Figure I. 8 shows an SEM micrograph of the sample PHBV- 45 C at 40 days in composting conditions where the bacterial growth and the degradation advance can be observed. It can be assumed that the microorganisms attack the polymer amorphous phase in the first stages of the degradation process, following disintegration with assimilation of the crystal structures of the matrix and the filler [46]. 


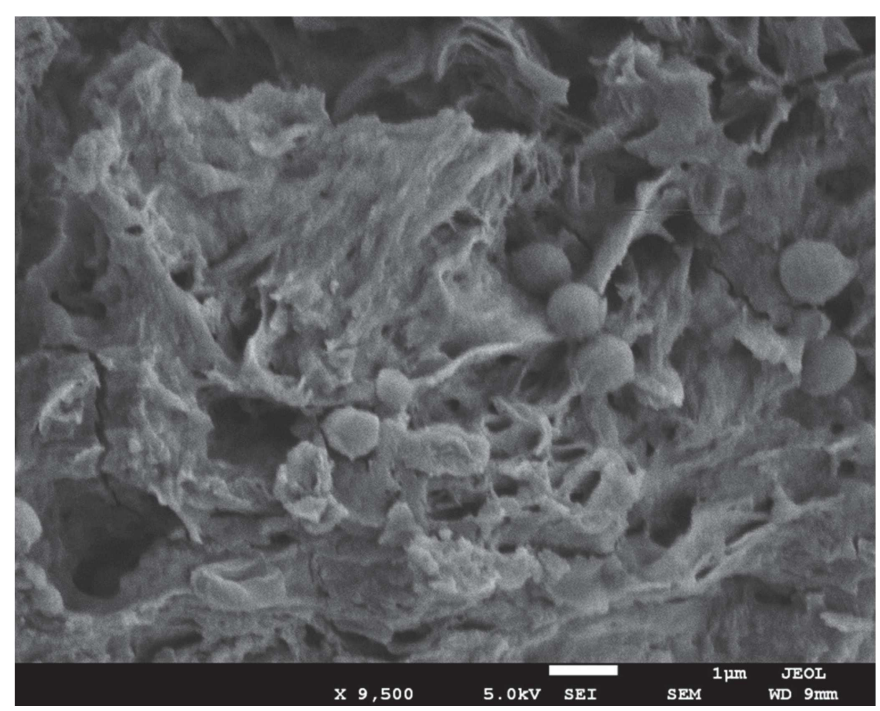

Figure I.8. SEM micrograph of the sample with $45 \%$ of cellulose contentent (PHBV-45C) at 40 days of the composting test.

\section{I.4. Conclusions}

In this work "green" low-cost PHBV/cellulose composites biodegradable under composting conditions (ISO 20200) were prepared by melt blending with 0, 3, 10, 25 and even $45 \%$ cellulose fiber content.

Good adhesion and homogeneous dispersion were obtained in all cases. Composites obtained had a similar thermal stability to that of pure PHBV. Only at $45 \%$ cellulose content did a significant decrease in onset degradation temperature $\left(T_{5 \%}\right)$ appear. Cellulose addition did not alter the crystal structure or the crystallinity degree. An increase of the storage modulus as cellulose content rose was noticed. This reinforcing effect was especially pronounced at high temperatures. Indeed, at $100 \circ \mathrm{C}$ the composite with $45 \%$ cellulose content showed an increase of $70 \%$ in the storage modulus with respect to neat PHBV. The PHBV/cellulose composites prepared were degradable in composting conditions and the addition of cellulose fibers did not affect the disintegration rate compared with neat PHBV. 


\section{Acknowledgments}

Financial support for this research from Ministerio de Economía y Competitividad (project MAT2012-38947-C02-01), Generalitat Valenciana (GV/2014/123), and Pla de Promoció de la Investigació de la Universitat Jaume I (PREDOC/2012/32) is gratefully acknowledged. The authors are also grateful to Raquel Oliver and José Ortega for experimental support.

\section{References}

[1] T. Ishigaki, W. Sugano, A. Nakanishi, M. Tateda, M. Ike, M. Fujita, The degradability of biodegradable plastics in aerobic and anaerobic waste landfill model reactors., Chemosphere. 54 (2004) 225-233. doi:10.1016/S0045-6535(03)00750-1.

[2] G. Kale, T. Kijchavengkul, R. Auras, M. Rubino, S.E. Selke, S.P. Singh, Compostability of bioplastic packaging materials: an overview., Macromol. Biosci. 7 (2007) 255-277. doi:10.1002/mabi.200600168.

[3] J.-W. Rhim, H.-M. Park, C.-S. Ha, Bio-nanocomposites for food packaging applications, Prog. Polym. Sci. 38 (2013) 1629-1652. doi:10.1016/j.progpolymsci.2013.05.008.

[4] D. Briassoulis, An Overview on the Mechanical Behaviour of Biodegradable Agricultural Films, J. Polym. Environ. 12 (2004) 65-81. doi:10.1023/B:JOOE.0000010052.86786.ef.

[5] E. Ruiz-Hitzky, F.M. Fernandes, Progress in Bionanocomposites: From green plastics to biomedical applications, Prog. Polym. Sci. 38 (2013) 1391. doi:10.1016/j.progpolymsci.2013.07.004.

[6] L. Nascimento, J. Gamez-Perez, O.O. Santana, J.I. Velasco, M.L. Maspoch, E. Franco-Urquiza, Effect of the Recycling and Annealing on the Mechanical and Fracture Properties of Poly(Lactic Acid), J. Polym. Environ. 18 (2010) 654-660. doi:10.1007/s10924-010-0229-5.

[7] J.C. Velazquez-Infante, J. Gamez-Perez, E.A. Franco-Urquiza, O.O. Santana, F. Carrasco, M. LI Maspoch, Effect of the unidirectional drawing on the thermal and mechanical properties of PLA films with different L -isomer content, J. Appl. Polym. Sci. 127 (2013) 2661-2669. doi:10.1002/app.37546.

[8] S. Luo, a. . Netravali, A study of physical and mechanical properties of poly(hydroxybutyrate-cohydroxyvalerate) during composting, Polym. Degrad. Stab. 80 (2003) 59-66. doi:10.1016/S01413910(02)00383-X.

[9] Y.-X. Weng, Y. Wang, X.-L. Wang, Y.-Z. Wang, Biodegradation behavior of PHBV films in a pilot-scale composting condition, Polym. Test. 29 (2010) 579-587. doi:10.1016/j.polymertesting.2010.04.002.

[10] S. Pilla, Handbook of Bioplastics and Biocomposites Engineering Applications, 2011. doi:10.1002/9781118203699.

[11] Biodegradable Polymers for Industrial Applications, Elsevier, 2005. doi:10.1016/B978-1-85573-9345.50021-0.

[12] D. Cava, E. Gimenez, R. Gavara, J.M. Lagaron, Comparative Performance and Barrier Properties of Biodegradable Thermoplastics and Nanobiocomposites versus PET for Food Packaging Applications, J. Plast. Film Sheeting. 22 (2006) 265-274. doi:10.1177/8756087906071354. 
[13] J.M. Lagaron, A. Lopez-Rubio, Nanotechnology for bioplastics: opportunities, challenges and strategies, Trends Food Sci. Technol. 22 (2011) 611-617. doi:10.1016/j.tifs.2011.01.007.

[14] P. Bordes, E. Pollet, L. Averous, Nano-biocomposites: Biodegradable polyester/nanoclay systems, Prog. Polym. Sci. 34 (2009) 125-155. doi:10.1016/j.progpolymsci.2008.10.002.

[15] M.D. Sanchez-Garcia, J.M. Lagaron, Novel clay-based nanobiocomposites of biopolyesters with synergistic barrier to UV light, gas, and vapour, J. Appl. Polym. Sci. 118 (2010) 188-199. doi:10.1002/app.31986.

[16] P. Wambua, J. Ivens, I. Verpoest, Natural fibres: can they replace glass in fibre reinforced plastics?, Compos. Sci. Technol. 63 (2003) 1259-1264. doi:10.1016/S0266-3538(03)00096-4.

[17] J.K. Pandey, S.H. Ahn, C.S. Lee, A.K. Mohanty, M. Misra, Recent Advances in the Application of Natural Fiber Based Composites, Macromol. Mater. Eng. 295 (2010) 975-989. doi:10.1002/mame.201000095.

[18] A. K. Mohanty, M. Misra, G. Hinrichsen, Biofibres, biodegradable polymers and biocomposites: An overview, Macromol. Mater. Eng. 276-277 (2000) 1-24. doi:10.1002/(SICI)14392054(20000301)276:1<1::AID-MAME1>3.0.CO;2-W.

[19] A. López-Rubio, J.M. Lagaron, M. Ankerfors, T. Lindström, D. Nordqvist, A. Mattozzi, et al., Enhanced film forming and film properties of amylopectin using micro-fibrillated cellulose, Carbohydr. Polym. 68 (2007) 718-727. doi:10.1016/j.carbpol.2006.08.008.

[20] G. Bogoeva-Gaceva, M. Avella, M. Malinconico, A. Buzarovska, A. Grozdanov, G. Gentile, et al., Natural fiber eco-composites, Polym. Compos. 28 (2007) 98-107. doi:10.1002/pc.20270.

[21] M. Haghighat, a. Zadhoush, S.N. Khorasani, Physicomechanical properties of ?-cellulose-filled styrene-butadiene rubber composites, J. Appl. Polym. Sci. 96 (2005) 2203-2211. doi:10.1002/app.21691.

[22] W. Qiu, T. Endo, T. Hirotsu, Interfacial interaction, morphology, and tensile properties of a composite of highly crystalline cellulose and maleated polypropylene, J. Appl. Polym. Sci. 102 (2006) 3830-3841. doi:10.1002/app.24846.

[23] a. Fendler, M.P. Villanueva, E. Gimenez, J.M. Lagarón, Characterization of the barrier properties of composites of HDPE and purified cellulose fibers, Cellulose. 14 (2007) 427-438. doi:10.1007/s10570-007-9136-x.

[24] L. Jiang, J. Huang, J. Qian, F. Chen, J. Zhang, M.P. Wolcott, et al., Study of Poly(3-hydroxybutyrateco-3-hydroxyvalerate) (PHBV)/Bamboo Pulp Fiber Composites: Effects of Nucleation Agent and Compatibilizer, J. Polym. Environ. 16 (2008) 83-93. doi:10.1007/s10924-008-0086-7.

[25] R. Krishnaprasad, N.R. Veena, H.J. Maria, R. Rajan, M. Skrifvars, K. Joseph, Mechanical and Thermal Properties of Bamboo Microfibril Reinforced Polyhydroxybutyrate Biocomposites, J. Polym. Environ. 17 (2009) 109-114. doi:10.1007/s10924-009-0127-x.

[26] R. Avella, M.; La Rota, G.; Martuscelli, E.; Raimo, M.; Sadocco, P.; Elegir, G.; Riva, PHBV and wheat straw fibre composites : thermal, mechanical properties and biodegradation, J. Mater. Sci. 5 (2000) 829-836.

[27] D. Battegazzore, S. Bocchini, J. Alongi, A. Frache, F. Marino, Cellulose extracted from rice husk as filler for poly(lactic acid): preparation and characterization, Cellulose. 21 (2014) 1813-1821. doi:10.1007/s10570-014-0207-5.

[28] K.C. Batista, D. a. K. Silva, L. a. F. Coelho, S.H. Pezzin, a. P.T. Pezzin, Soil Biodegradation of PHBV/Peach Palm Particles Biocomposites, J. Polym. Environ. 18 (2010) 346-354. 
[29] S.P.C. Gonçalves, S.M. Martins-Franchetti, D.L. Chinaglia, Biodegradation of the Films of PP, PHBV and Its Blend in Soil, J. Polym. Environ. 17 (2009) 280-285. doi:10.1007/s10924-009-0150-y.

[30] Y.-X. Weng, X.-L. Wang, Y.-Z. Wang, Biodegradation behavior of PHAs with different chemical structures under controlled composting conditions, Polym. Test. 30 (2011) 372-380. doi:10.1016/j.polymertesting.2011.02.001.

[31] K.A. Gutierrez-Wing, M.T. , Stevens, B.E., Theegala, C.S., Negulescu, I.I., Rusch, Aerobic Biodegradation of Polyhydroxybutyrate in Compost, Environ. Eng. Sci. 28 (2011) 477-488.

[32] S. Wang, C. Song, G. Chen, T. Guo, J. Liu, B. Zhang, et al., Characteristics and biodegradation properties of poly(3-hydroxybutyrate-co-3-hydroxyvalerate)/organophilic montmorillonite (PHBV/OMMT) nanocomposite, Polym. Degrad. Stab. 87 (2005) 69-76. doi:10.1016/j.polymdegradstab.2004.07.008.

[33] B.-I. Sang, K. Hori, Y. Tanji, H. Unno, Fungal contribution to in situ biodegradation of poly(3hydroxybutyrate- co -3-hydroxyvalerate) film in soil, Appl. Microbiol. Biotechnol. 58 (2002) 241247. doi:10.1007/s00253-001-0884-5.

[34] UNE-EN ISO, UNE-EN ISO 20200 Determinación del grado de desintegración de materiales plásticos bajo condiciones de compostaje simuladas en un laboratorio, (2006).

[35] A. Valdés García, M. Ramos Santonja, A.B. Sanahuja, M.D.C.G. Selva, Characterization and degradation characteristics of poly( $\varepsilon$-caprolactone)-based composites reinforced with almond skin residues, Polym. Degrad. Stab. 108 (2014) 269-279. doi:10.1016/j.polymdegradstab.2014.03.011.

[36] L.N. Carli, J.S. Crespo, R.S. Mauler, PHBV nanocomposites based on organomodified montmorillonite and halloysite: The effect of clay type on the morphology and thermal and mechanical properties, Compos. Part A Appl. Sci. Manuf. 42 (2011) 1601-1608. doi:10.1016/j.compositesa.2011.07.007.

[37] Y.-M. Corre, S. Bruzaud, J.-L. Audic, Y. Grohens, Morphology and functional properties of commercial polyhydroxyalkanoates: A comprehensive and comparative study, Polym. Test. 31 (2012) 226-235. doi:10.1016/j.polymertesting.2011.11.002.

[38] Y. Srithep, T. Ellingham, J. Peng, R. Sabo, C. Clemons, L.-S. Turng, et al., Melt compounding of poly (3-hydroxybutyrate-co-3-hydroxyvalerate)/nanofibrillated cellulose nanocomposites, Polym. Degrad. Stab. 98 (2013) 1439-1449. doi:10.1016/j.polymdegradstab.2013.05.006.

[39] J. Li, C. Sun, X. Zhang, Preparation, thermal properties, and morphology of graft copolymers in reactive blends of PHBV and PPC, Polym. Compos. 33 (2012) 1737-1749. doi:10.1002/pc.

[40] A. Dufresne, D. Dupeyre, M. Paillet, Lignocellulosic flour-reinforced poly (hydroxybutyrate-covalerate) composites, J. Appl. Polym.. 87 (2003) 1302-1315.

[41] M.D. Sanchez-Garcia, J.M. Lagaron, On the use of plant cellulose nanowhiskers to enhance the barrier properties of polylactic acid, Cellulose. 17 (2010) 987-1004. doi:10.1007/s10570-010-9430$\mathrm{x}$.

[42] Q.-S. Liu, M.-F. Zhu, W.-H. Wu, Z.-Y. Qin, Reducing the formation of six-membered ring ester during thermal degradation of biodegradable PHBV to enhance its thermal stability, Polym. Degrad. Stab. 94 (2009) 18-24. doi:10.1016/j.polymdegradstab.2008.10.016.

[43] E. Petinakis, X. Liu, L. Yu, C. Way, P. Sangwan, K. Dean, et al., Biodegradation and thermal decomposition of poly(lactic acid)-based materials reinforced by hydrophilic fillers, Polym. Degrad. Stab. 95 (2010) 1704-1707. doi:10.1016/j.polymdegradstab.2010.05.027. 
[44] P. Gatenholm, A. Mathiasson, Biodegradable natural composites. II. Synergistic effects of processing cellulose with PHB, J. Appl. Polym. Sci. 51 (1994) 1231-1237. doi:10.1002/app.1994.070510710.

[45] R. Bhardwaj, A.K. Mohanty, L.T. Drzal, F. Pourboghrat, M. Misra, Renewable resource-based green composites from recycled cellulose fiber and poly(3-hydroxybutyrate-co-3-hydroxyvalerate) bioplastic, Biomacromolecules. 7 (2006) 2044-2051.

[46] M.P. Arrieta, J. López, E. Rayón, a. Jiménez, Disintegrability under composting conditions of plasticized PLA-PHB blends, Polym. Degrad. Stab. 108 (2014) 307-318. doi:10.1016/j.polymdegradstab.2014.01.034. 


\section{CAPÍTULO II}

\section{Biocomposites of different lignocellulosic wastes for sustainable food packaging applications}

Estefanía Lidón Sánchez-Safont ${ }^{1}$, Abdulaziz Aldureid ${ }^{1}$, José María Lagarón ${ }^{2}$, José Gámez-Pérez ${ }^{1}$, Luis Cabedo ${ }^{1 *}$

1- Polymers and Advanced Materials Group (PIMA), Universitat Jaume I, Spain

2- Novel Materials and Nanotechnology Group, IATA, CSIC, Spain

\section{Graphical abstract}
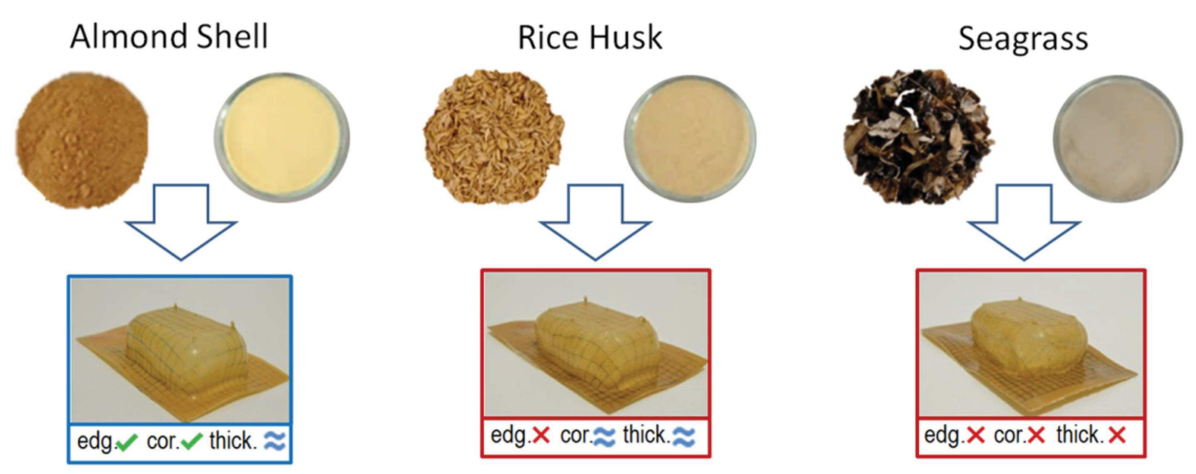

Compos. Part B Eng. 2018, 145, 215. 


\begin{abstract}
The suitability of three local lignocellulosic wastes i.e. almond shell (AS), rice husk (RH) and seagrass (SG) as fillers in PHB/Fiber composites applications has been studied. PHB/Fiber composites with $10 \mathrm{phr}$ and $20 \mathrm{phr}$ fiber content were prepared by melt blending. The influence of the fiber type (size, morphology and origin) and content on the morphological, mechanical and thermal properties of the as obtained composites has been assessed. To evaluate the potential use in food packaging applications, the barrier performance to water, thermoforming ability and disintegration in controlled composting conditions of the composites were also studied.

All the fibers have demonstrated to be apt for their use as fillers in PHB/Fiber composites, showing a reinforcing effect without affecting the crystallinity and the disintegration rate of PHB. The thermal stability and the water barrier performance of the composites were reduced by the presence of the fibers. Nevertheless, the addition of AS resulted in the best balance of properties, in terms of permeability and mechanical properties, finding an enhancement of the thermoforming ability of PHB when 10 phr of AS was added.
\end{abstract}

\title{
Keywords
}

PHB, natural fiber, biodegradable, biocomposite, waste valorization

\section{II.1. Introduction}

The combined use of a renewable-based biodegradable polymer together with a natural fiber filler, thus obtaining a biocomposite, pose a sustainable and technically promising alternative to replace the so-called "commodities" plastics in the food packaging sector. There are three main key factors to be considered. In the first place, the reduction of the dependence on petroleumbased materials, while moving towards renewable sources to produce plastics, which would decrease the release of old carbon to atmosphere. Secondly, the use of biodegradable polymer would allow the treatment of the package after its use in the same way as an organic compostable residue, therefore contributing to the reduction of polymeric solid waste that it is destined for landfill or incineration. Finally, the use of natural fibers as fillers opens the way for the valorization of agro-based residues, thus reducing the overall impact of the food production cycle. Altogether, the use of biocomposites made of biodegradable polymers from renewable 
resources and loaded with fillers derived from agro-based fiber wastes and other by-products, allows a more sustainable packaging by favoring a cradle to cradle concept and promoting the circular economy [1,2].

Among the different commercially available biopolymers, poly(3-hydroxybutyrate) (PHB) is one of the most interesting members of the polyhydroxyalkanoates family for food packaging applications. PHB is a thermoplastic that can be processed in conventional industrial polymer transformation equipment. It also possesses a good mechanical performance, in terms of stiffness and strength, similar or greater than some of the commodities (such as PP) and good barrier properties (comparable to PET). PHB is biodegradable in composting conditions and other environments such as marine water [3].Despite of the fact that PHB is an excellent candidate for sustainable packaging applications, it still presents some shortcomings that handicaps its extensive use in the food packaging sector. PHB presents high intrinsic fragility that increases with time due to the physical aging phenomenon. In addition,due to its high crystallinity, PHB exhibits a narrow processing window, thus hindering its processability in some common food packaging applications, such as thermoforming $[3,4]$. Another main limitation for its use in the packaging field is its high cost that still exceeds $5 € / \mathrm{kg}$ [3]. In this context, the use of a sustainable, inexpensive and rigid filler may counteract the increase in the price of the material by (a) decreasing the overall cost of the package and/or (b) reducing the thickness necessary in single layer packages $[1,2,5]$.

In general, some of the advantages of vegetal fibers are their natural abundance, low density, high specific stiffness and biodegradability [6]. The characteristic properties of vegetal fibers (e.g. morphology, aspect ratio, crystallinity) vary considerably depending on the source, their origin within the plant, the quality of plant locations, the age of the plant and the process used for their extraction. They may significantly influence the eventual biocomposite properties [7] Indeed, the high hydrophilicity and thermal instability of vegetal fibers are known to be their main drawbacks for their use as plastic fillers $[1,2,6,8]$.

The use of cellulosic waste and agro-based by-products as a source for high performance sustainable fillers represents an attractive and sustainable way of valorization. Numerous studies concerning natural fiber-based biocomposites can be found in the scientific literature. The suitability as fillers of different lignocellulosic fibers, such as wheat straw [9-11], flax fibers [1214], jute [15], coconut [16], kenaf [17] or olive pomace [11], etc., has been explored. As mentioned before, there is a great variability in the results as a function of the fiber 
characteristics, but also depending on the matrix type, surface treatment of the fibers and the use of coupling agents, specifically when it comes to mechanical performance.

In the present work, three local (near Valencia, Spain) cellulosic wastes will be prepared and assessed for their use as fillers in PHB biocomposites: Almond Shell (AS), Rice Husk (RH), and the cleaning beach wastes mainly composed by Seagrass (SG)(Posidonia Oceanica).

Almond is one of the main crops in Valencian Region, and its annual world production is of about 2.7 million of tons (data of 2014) [18]. Shell represents about the $35-75 \%$ of the total fruit weight and is normally discarded or burned as biomass fuel [19]. Few works have been published exploring the use of the almond shell as fillers in composite materials, focusing those cases in matrices like PP [20], PMMA [21] or Urea formaldehyde (UF) resin [19]. However, to the best of our knowledge, its use in biodegradable matrices has not been yet studied in depth.

Regarding the rice husk, the annual world production of rice can reach to more than 740 million tons [18]. Although, Rice Husk has been already employed in different fields, such as biofertilizer, silica source, bio-fuel, load in cements or pozzolanic materials [22]; its use as filler in natural fiber-based biocomposites would suppose an eco-friendly way for its valorization. Several studies can be found in bibliography regarding the use of $\mathrm{RH}$ as filler in polymeric matrices [23]; although only a few of them concerning PHB [24-27]. Most of those studies, however, are focused on the rice husk derivatives, such as lignin [25], ash [26] or cellulose nanocrystals [27], not on the fibers themselves.

Seagrass (Posidonia Oceanica) is the most abundant marine plant in the Mediterranean seabed. The accumulation of tons of dead seagrass in the coast every summer supposes an important impact in touristic beaches and its removal and disposal is an important problem for the coastal city councils. Its high salinity limits its use as common pruning or garden waste. Additionally, the high chlorine content may suppose a problem for its energetic valorization. Therefore, there is a need to find a suitable and sustainable way for the valorization of seagrass residue. Among the few works that have been published to date on the use of seagrass as reinforcement in polymer composites [28-30], only one of them focuses on its use as filler in PHA matrices [31], showing a reinforcing effect, a markedly increasing in impact energy-adsorbed capability and an enhancement of biodegradation in marine environment.

Within this context, the present work aims at exploring the valorization of these three different local lignocellulosic wastes (Almond Shell, Rice Husk and Seagrass) in PHB/Fiber composites, especially intended for food packaging applications. In search of an industrial viability, blending 
of the biocomposites has been conducted by a conventional melt-blending approach. A thorough study on the influence of the fiber characteristics (i.e. morphology and origin) and fiber content on the mechanical and thermal properties of the biocomposites has been carried out. In order to assess the potential applicability in the industrial packaging market, the barrier performance as well as the processability by means of thermoforming is also evaluated, as well as their disintegrability in controlled composting conditions.

\section{II.2. Materials and methods}

\section{II.2.1. Materials}

A commercial PHB grade (P309-E) was purchased from Biomer ${ }^{\circledR}$ (Krailling, Germany) in pellet form. Micronized almond shell (AS) was kindly supplied by Unió Corporació Alimentària (Reus, Spain). Rice husk $(\mathrm{RH})$ by-product from the rice production process was kindly provided by Herba Ingredients (Valencia, Spain). The residue from the beach cleaning services was supplied by the beach cleaning service of the city council of Benicàssim (Castelló, Spain). This residue is mainly composed by seagrass and some algae in smaller proportion (in advance, SG). Other common reagents, like Sodium hydroxide pellets (98\%), acetic acid (99\%) and hydrogen peroxide (30\%) were purchased from Sigma Aldrich.

\section{II.2.2. Fiber preparation}

The fiber preparation and purification consisted on a mechanical grinding and sieving to ensure comparable particle size, followed by a two-step purification treatment. The aim of such treatment was double: (a) to obtain a more crystalline cellulose and (b) to improve the surface characteristic of the fibers [32]. For doing so, the major part of waxes, lignin and hemicelluloses present in the raw material had to be removed. Figure II.1 shows the appearance of the different fibers used in this work: as received and after the different treatments applied to each fiber. 


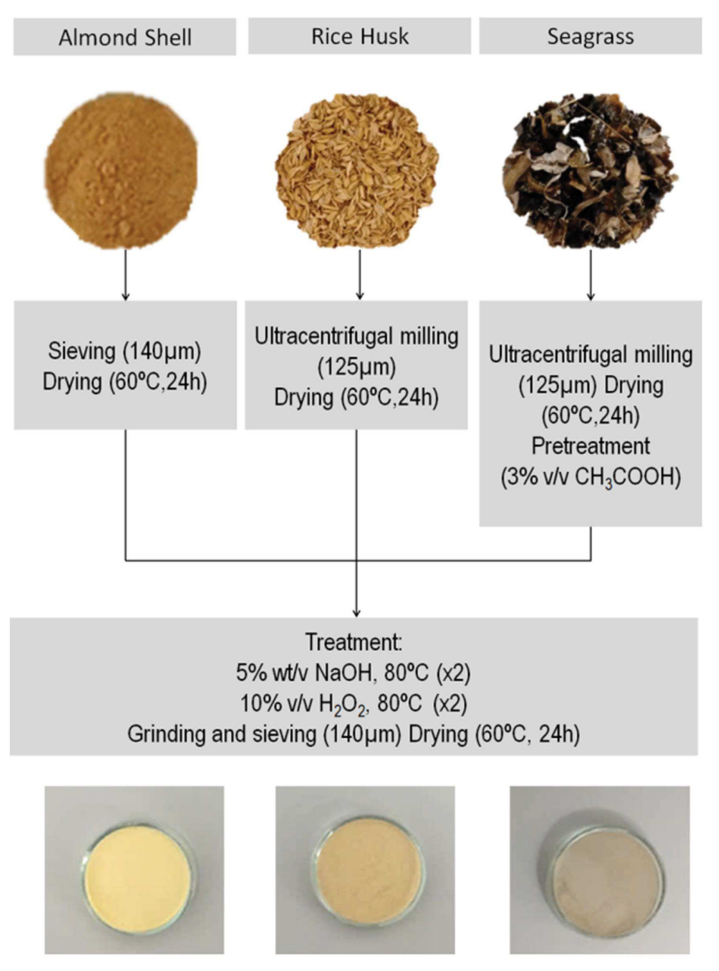

Figure II. 1. Schematic representation of the treatments applied to the three residues (AS, RH and SG) and the visual appearance before and after the treatment

The almond shell (AS) powder was grinded and sieved through a $140 \mu \mathrm{m}$ mesh. The native rice husk was grinded in an ultracentrifuge mill (Retsch ZM100) at $14000 \mathrm{rpm}$, equipped with a selection sieve of $125 \mu \mathrm{m}$. The SG was visually inspected and plastics, crustaceans and other impurities were manually removed, before further treatments. In order to remove the remaining sand and any water soluble impurities, SG was washed three times with tap water followed by three more washes in distilled water. The clean SG was then allowed to dry at room temperature for one week and then in an oven at $60^{\circ} \mathrm{C}$ for $24 \mathrm{~h}$ before grinding. SG was grinded in identical conditions as the $\mathrm{RH}$. Since it was detected calcium carbonate impurities in SG, prior to the purification treatment with $\mathrm{NaOH}$, a pre-treatment was applied, consisting on a supplementary washing with $3 \% \mathrm{v} / \mathrm{v}$ acetic acid for 1 hour at room temperature. This pre-treatment removed almost all carbonates proceeding from the microscopic crustaceans attached to the SG.

The purification treatment started with a suspension in an alkali solution of $\mathrm{NaOH}(5 \% \mathrm{w} / \mathrm{v})$ and stirred at $80 \circ \mathrm{C}$ for two hours. The alkali treatment was followed by a peroxide solution with $\mathrm{H}_{2} \mathrm{O}_{2}$ 
(10\% v/v in distilled water) for 2 hours at $80 \circ \mathrm{C}$. Each treatment was applied twice. The fibers were filtered and washed repeatedly in distilled water until neutral $\mathrm{pH}$ is reached. The purified powder was dried at $60^{\circ} \mathrm{C}$ for at least 24 hours before using. All the treatments were conducted maintaining a fiber:liquid ratio of 1:20. Finally, all the fibers were grinded again to break the aggregates formed during the filtration process and then sieved in a $140 \mu \mathrm{m}$ mesh. According to the literature, alkaline treatment $(\mathrm{NaOH})$ increases the fiber surface roughness and increments the cellulose exposed whilst peroxide treatment can decrease the hydrophilicity of the fibers thus improving its wettability and, therefore, the fiber-matrix interaction [32].

\section{II.2.3. PHB/Fiber composites preparation}

Prior to the blending step, all the treated fibers were dried at $60^{\circ} \mathrm{C}$ for 24 hours. The PHB pellets were dried at $60^{\circ} \mathrm{C}$ for $2 \mathrm{~h}$ using a Piovan DPA 10 (Santa Maria di Sala VE, Italy). Neat PHB and PHB/Fiber composites of 10 and 20 phr fiber content were prepared by melt blending in an internal mixer (Thermo Haake Rheomix Polylab). The blending step was in all cases of 4.5 minutes at $180^{\circ} \mathrm{C}$ and a rotor speed of $100 \mathrm{rpm}$. In order to reduce thermal degradation during blending, the melt temperature was never allowed to reach $190^{\circ} \mathrm{C}$. The so-obtained blends were then preheated for two minutes at $180 \mathrm{\circ} C$ and hot pressed at 3 bar for two minutes, to produce films of $0.35 \mathrm{~mm}$ nominal thickness for mechanical and thermoforming tests and films of $0.20 \mathrm{~mm}$ thickness for biodisintegration and barrier tests. All the samples were stored in a vacuum desiccator at room temperature for 15 days before any characterization, to guarantee full crystallization to take place [33]. The different formulations are named as PHB and PHB/10AS, $\mathrm{PHB} / 10 \mathrm{RH}$ and $\mathrm{PHB} / 10 \mathrm{SG}$ for the composites containing $10 \mathrm{phr}$ of the different fibers, and $\mathrm{PHB} / 20 \mathrm{AS}, \mathrm{PHB} / 20 \mathrm{RH}$ and PHB/20SG for the composites containing 20 phr of fibers.

\section{II.2.4. Fiber and composites characterization}

The moisture and the ash content of the three different untreated fibers were determined according to the TAPPI standards T210 and T211 respectively, while the treatment yields were calculated referred to the initial fiber dry weight.

The morphology of the different untreated and treated fibers and the composites was studied by scanning electron microscopy (SEM) using a high-resolution field-emission JEOL 7001F microscope. The average particle size and aspect ratio of the fibers were estimated from the SEM micrographs using image analysis software $\mathrm{Fiji}^{\circledR}$ (the number of particles measured for each 
sample was never below 250). Samples of the composite films were fractured in liquid nitrogen to avoid plastic deformation of the polymer matrix. Both fibers and composites were coated by sputtering with a thin layer of platinum prior to SEM analysis.

The crystallinity of the native and treated fibers was assessed by Wide angle X-ray scattering (WAXS) using a Bruker AXS D4 Endeavor diffractometer. Radial scans of intensity versus scattering angle $(2 \theta)$ were recorded at room temperature in the range of 2 to $40^{\circ}(2 \theta)$ (step size $=$ $0.02^{\circ}(2 \theta)$, scanning rate $=4 \mathrm{~s} /$ step) with filtered CuKa radiation $(\lambda=1.54 \mathrm{~A})$, an operating voltage of $40 \mathrm{kV}$, and a filament current of $40 \mathrm{~mA}$. The crystallinity was evaluated according to Seagal et al.[34] method, where the crystallinity index $C_{i}$ can be determined with the following equation (1):

$C_{i}(\%)=\frac{I_{002}-I_{a m}}{I_{002}} \times 100$

Where $\mathrm{I}_{002}$ is the maximum intensity of the (002) lattice diffraction peak of cellulose located at a diffraction angle of around $22^{\circ}(2 \theta)$ and $I_{a m}$ is the intensity scattered by the amorphous phase of the sample measured at around $180(2 \theta)$.

Fourier infrared (FT-IR) spectra of the native and treated fibers were recorded by a Jasco FT/IR6200 equipped with an attenuated total reflection (ATR) accessory in the range of $400-4000 \mathrm{~cm}^{-1}$ in transmission mode.

Thermogravimetric analysis (TGA) of the untreated and treated fibers, as well as the PHB and its composites, was performed with a TG-STDA Mettler Toledo model TGA/STDA851e/LF/1600 analyzer. The samples with an initial mass of typically about $15 \mathrm{mg}$ were heated from 50 to $600{ }^{\circ} \mathrm{C}$ at a heating rate of $10^{\circ} \mathrm{C} / \mathrm{min}$ under nitrogen flow. The thermal stability of the both the fibers and the PHB/Fiber composites was evaluated and the residue at $600{ }^{\circ} \mathrm{C}$ was determined. For the composites, the initial decomposition temperature ( $T_{5 \%}$, temperature at $5 \%$ weight loss) and the maximum decomposition rate temperature (Td) were determined from the weight loss curve and the maximum value of weight loss derivative respectively.

Differential scanning calorimetry (DSC) experiments were conducted on a DSC2 (Mettler Toledo) with an intracooler (Julabo FT900) calibrated with an Indium standard before use. The samples weighing typically $6 \mathrm{mg}$ were first heated from $-20^{\circ} \mathrm{C}$ to $200^{\circ} \mathrm{C}$ at $10^{\circ} \mathrm{C} / \mathrm{min}$ and kept for $5 \mathrm{~min}$ to erase thermal history, followed by cooling to $-20^{\circ} \mathrm{C}$ and heating to $200^{\circ} \mathrm{C}$ at $10^{\circ} \mathrm{C} / \mathrm{min}$. Melting temperature $\left(T_{m}\right)$ and enthalpy $\left(\Delta \mathrm{H}_{\mathrm{m}}\right)$ were calculated from the second heating scan. The 
crystallinity $\left(X_{c}\right)$ of the PHB phase of the composites was determined by applying the following expression [35]:

$X_{c}(\%)=\frac{\Delta H_{m}}{w \cdot \Delta H_{m}^{0}} \times 100$

where $\Delta \mathrm{Hm}(\mathrm{J} / \mathrm{g})$ is the melting enthalpy of the polymer matrix, $\Delta \mathrm{H}{ }_{\mathrm{m}}$ is the melting enthalpy of $100 \%$ crystalline PHB (perfect crystal) $(146 \mathrm{~J} / \mathrm{g}$ ) [33] and $w$ is the polymer weight fraction of PHB in the blend.

Dumbbell $350 \mu \mathrm{m}$-thick samples were die-cut from the hot pressed films and tested according to ASTM D638 (Type IV) standard. Tensile tests were conducted in a universal testing machine (Shimatzu AGS-X 500N) at room temperature with a cross-head speed of $10 \mathrm{~mm} / \mathrm{min}$. The samples were conditioned to ambient conditions (25ㅇ $\mathrm{C}$ and $50 \% \mathrm{RH}$ ) for 24 hours before testing. A minimum of five specimens were measured for each sample and the average results with standard deviation were reported.

The water vapor permeability (WVP) of the PHB/Fiber composites was measured according to the ASTM E96 (2011) gravimetric method, using Payne permeability cups (Elcometer, Hermelle Argenteau, Belgium). Distilled water was placed inside the cup to expose the film (the exposed area was $9.6 \times 10^{-4} \mathrm{~m}^{2}$ ) to $100 \%$ relative humidity on one side. Once the films were secured, each cup was placed in a desiccator at $0 \%$ relative humidity provided by silica gel. The cups were weighed periodically $( \pm 0.0001 \mathrm{~g})$ and aluminum foil was used as a control to rule out vapor loss through the seal. WVP was calculated from the steady state permeation slopes obtained from the regression analysis of weight loss data over time. The lower limit of vapor permeability detection of the permeation cells was $\sim 1 \times 10^{-} \mathrm{kg} \mathrm{m} \mathrm{s}^{-1} \mathrm{~m}^{-2}$ Pa based on the weight loss through the seal in the aluminum samples. All measurements were performed in triplicate.

Vacuum assisted thermoforming study was conducted in a pilot plant (SB 53c, Illig, Helmut Roegele, Germany) equipped with an infrared emitter heating device. The mold used was a female rectangular tray having $40 \times 60 \times 20 \mathrm{~mm}$ (width $\times$ length $\mathrm{x}$ depth) with a maximum draw ratio of 5.2. Rectangular hot pressed sheets of a typical thickness of $350 \mu \mathrm{m}$ were used for this study. The sheets were stamped with a square grid pattern $(0.5 \times 0.5 \mathrm{~cm})$ in order to track the deformation occurred during their mold conformation. For all the experiments, the infrared heater was set to $600 \stackrel{\circ}{ } C$, while the heating time was changed in order to control the temperature of the polymer sheet. The sheet surface temperature was measured as a function of heating time, thus obtaining a relation between the heating time and the sheet temperature The thermoformability of $\mathrm{PHB}$ and $\mathrm{PHB} /$ Fiber composites was evaluated according to the 
methodology proposed in a previous work [36]. Briefly, this methodology allows classifying the quality of the thermoforming paying attention to three parts of the thermoformed trays: the "edges", "corners" and "thickness distribution". Each one was classified as "bad" (red color, cross sign), "intermediate" (blue color, wave sign) or "good" (green color, tick mark). This classification was used to stablish the thermoforming temperature ranges for each composition.

Disintegration tests were carried out according to the ISO 20200 standard [37]. Solid synthetic waste was prepared by mixing $10 \%$ of activated mature compost (VIGORHUMUS $\mathrm{H}-00$, purchased from Burás Profesional, S.A., Girona, Spain), 40\% sawdust, 30\% rabbit feed, 10\% corn starch, 5\% sugar, $4 \%$ corn seed oil and $1 \%$ urea. The water content of the mixture was adjusted to $55 \%$. Composite samples were cut from hot pressed films $\left(15 \times 15 \times 0.2 \mathrm{~mm}^{3}\right)$ and buried in compost bioreactors at 4-6 cm depth. The samples were placed inside mesh bags to simplify their extraction and allow the contact of the compost with the specimens. Bioreactors were incubated at $58^{\circ} \mathrm{C}$. The aerobic conditions were guaranteed by mixing the synthetic waste periodically and adding water according to the standard requirements. Three replicates of each sample were removed from the boxes at different composting times for analysis. Samples were washed with water and dried under vacuum at $40{ }^{\circ} \mathrm{C}$ until a constant mass. The disintegration degree was calculated by normalizing the sample weight to the initial weight with equation (3):

$D=\frac{m_{i}-m_{f}}{m_{i}} \times 100$

where $m_{i}$ is the initial dry mass of the test material and $m_{f}$ is the dry mass of the test material recovered at different incubation stages. The disintegration study was completed taking photographs for visual evaluation.

\section{II.3. Results and discussion}

\section{II.3.1. Fibers characterization}

Chemical, morphological and thermal characterization of the different fibers before and after the treatment were conducted by means of FTIR, WAXS, TGA and SEM (Figure II.2).

Table II.1 gathers the moisture and ash content of the fibers as received, the typical composition in terms of Holocellulose, Hemicelluloses, Cellulose and Lignin of the three fibers as reported in the literature, and the treatment yield as the ratio between the initial mass and the mass after the treatment. 
Table II.1. Composition and treatment yield of AS, RH and SG

\begin{tabular}{|l|l|l|l|}
\hline & AS & RH & SG \\
\hline Moisture (\%) & $8.6 \pm 2$ & $6.5 \pm 0.1$ & $5.6 \pm 0.1$ \\
\hline Ash (\%)* & $18 \pm 0.4$ & $20.2 \pm 0.2$ & $19 \pm 3$ \\
\hline Holocellulose (\%)** & $53.81^{\text {a) }}$ & 49,72 & $59^{\text {d) }}$ \\
\hline Hemicelluloses (\%)** & $7.56^{\text {a) }}$ & $18.6^{\text {b) }}$ & $21^{\text {d) }}$ \\
\hline Cellulose(\%)** & $46.25^{\text {a) }}$ & $31.13^{\text {b) }}$ & $38^{\text {d) }}$ \\
\hline Lignin(\%)** & $29.85^{\text {a) }}$ & $28.25^{\mathrm{b}}$ & $27^{\text {d) }}$ \\
\hline Silica (\%)** & - & $15-17^{\mathrm{c}}$ & - \\
\hline Treatment Yield(\%)* & $45 \pm 4$ & $41 \pm 5$ & $33 \pm 1$ \\
\hline
\end{tabular}

*This study

**Bibliography reported values: a) [58] , b) [59],c) [23], d)[60]

The moisture content of the three residues is below $10 \%$ in all cases after grinding and drying. The ash content in natural fibers can be attributed to the presence of minerals [38], i.e. the presence of silica in the rice husk [23] and calcium carbonate in the seagrass, as will be further discussed. The composition in terms of their major structural components, holocellulose (hemicellulose and cellulose) and lignin is also gathered in Table II.1. Holocellulose content is, for the three fibers, the major component (ranging from 50 to 60\%). AS is the one with highest expected cellulose content. The amount of lignin is similar for the three residues studied. The two-step treatment applied to the fiber powder aims formerly at removing all the non-cellulosic fraction of the material. Hence, the yield of the process is higher for those fiber sources with highest cellulose content.

In Fig. II.2 are plotted the FTIR spectra of the three fibers before and after the purification treatment. The band present in the absorbance region of $1700-1750 \mathrm{~cm}^{-1}$ is ascribed in the literature to either acetyl and carbonyl groups from carboxylic ester linkages in hemicelluloses and lignin [20,39], or to pectin, wax and natural fats [40,41]. In any case, this band should not be present in pure cellulose. In all three treated fibers this band disappears, evidencing the removal of the major part of non-cellulosic components by the chemical treatment. Also, the band in the $1200-1250 \mathrm{~cm}^{-1}$ region, ascribed to $-\mathrm{C}-\mathrm{O}$ stretching vibration of the acetyl groups in lignin and hemicelluloses, is reduced. The reduction of this band after treatment in AS and RH spectrum confirms the partial removal of these components $[20,40]$. The peak at $798 \mathrm{~cm}^{-1}$ in untreated $\mathrm{RH}$ is ascribed to silica vibration bonds and disappears after the purification treatment .The removal of the silica could happen by reaction with $\mathrm{NaOH}$ in accordance to Ndazi et al. [42]. With respect 
to the SG, the untreated SG spectrum presents a well-defined peak at $877 \mathrm{~cm}^{-1}$ and an intense band at $1420 \mathrm{~cm}^{-1}$. These signals could be related with the calcium carbonate impurities also detected in the WAXS pattern (shown in Fig II.2. b). After the treatment, the band at $877 \mathrm{~cm}^{-1}$ disappears and the band in the region $1290-1570 \mathrm{~cm}^{-1}$ is clearly reduced. These variations are indicative of the elimination of the major part of the calcium carbonate, as intended in the pretreatment with acetic acid. Finally, the broad band around $3300 \mathrm{~cm}^{-1}$ corresponds to $-\mathrm{OH}$ vibrations in cellulose and is clearly higher in treated fibers. According to Ndazi et al. [39] the increased intensity of this band could be related to a higher presence of the more reactive $-\mathrm{OH}$ groups in the fiber surfaces, which was the second objective of the fiber treatment.

Wide-angle X-ray scattering experiments were conducted in both untreated and treated fibers in order to estimate the crystallinity index $\left(C_{i}\right)$ of the fibers. Figure II.2b shows the WAXS patters of untreated and treated AS, RH and SG. Three different main peaks located at $2 \theta$ of around 16ㅇ, $22^{\circ}$ and $34 \circ$ are observed in all samples. These peaks are characteristics of (110), (002) and (004) planes of cellulose type I $[43,44]$. The presence of these main peaks after treatment indicates that cellulose type I crystalline structure does not change with the chemical attack. The peaks observed in the untreated SG diffraction patterns correspond to silica, calcium carbonate and calcium oxalate; which, according to several authors, are commonly found impurities in sea biomass $[44,45]$.

The crystallinity index calculated with Eq. 2 after Seagal method [34] for the different fibers before and after treatment is listed in Fig. II.2c. The values obtained are in agreement with the ones reported in the literature for similar raw materials and cellulose extracted from them by other procedures [45-47]. The increased crystallinity observed in all cases after treatment could be related with the removal of lignin and hemicelluloses (which are amorphous in nature), present in untreated lignocellulosic fibers [41]. In case of the SG the intensity of the peaks corresponding to silica, calcium carbonate and oxalate was also reduced, similarly to the results found by Bettaieb et al. [45]. The highest crystallinity determined in both untreated and treaded fibers corresponds to $\mathrm{RH}$.

In Figure II.2d the DTG curves of the untreated and treated AS, RH and SG are shown. The thermal degradation of untreated fibers occurs in a wide range of temperatures comprised between 200 and 600 으, corresponding to the thermal decomposition of their main components (pectin, hemicelluloses, lignin and cellulose) [48]. Hemicelluloses started their decomposition at around $200 \circ \mathrm{C}$ up to 310 . Cellulose decomposition takes place at higher temperatures in the rage $315-400^{\circ} \mathrm{C}$ with a maximum weight loss rate at around 350 ․ C. Lignin decomposition takes place slowly during the whole range of fiber degradation [49]. 


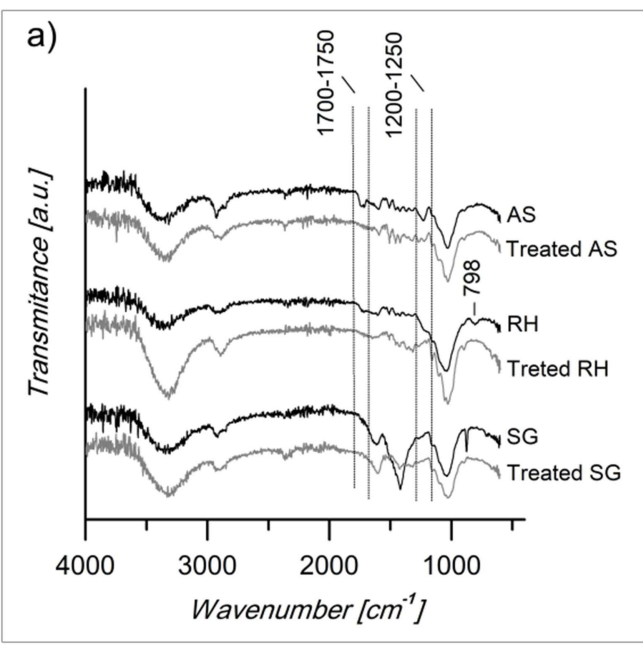

b).

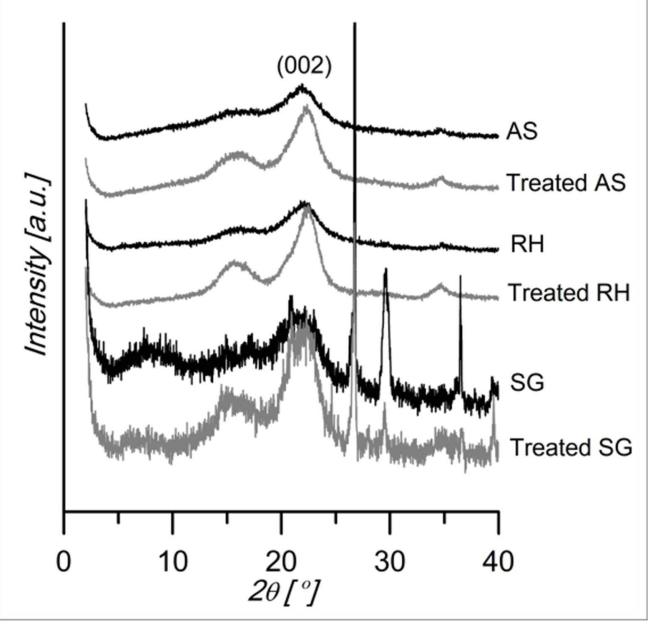

d)

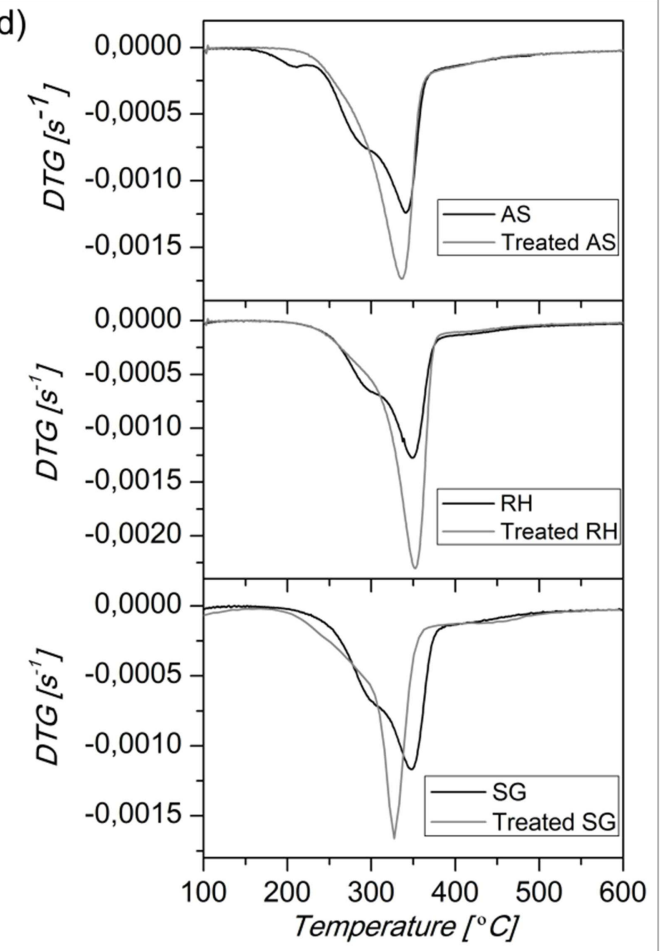

c)

\begin{tabular}{|c|c|c|}
\cline { 2 - 3 } \multicolumn{1}{c|}{} & \multicolumn{2}{c|}{ Ci (\%) } \\
\cline { 2 - 3 } \multicolumn{1}{c|}{} & Untreated & Treated \\
\hline AS & 42 & 57 \\
\hline RH & 47 & 66 \\
\hline SG & 30 & 50 \\
\hline
\end{tabular}

Figure II.2. Purification fiber results: a)FTIR spectra of AS, RH and SG fibers before and after the treatment; b) WAXS patterns of AS, RH and SG fibers before and after the treatment; c) Crystallinity index of AS, RH and SG fibers before and after the treatment; d) DTG curves of AS, RH and SG fibers before and after the treatment

As it can be observed in Figure II.2d, after treatment, the shoulder located between 200 and $310^{\circ} \mathrm{C}$ has been clearly reduced in all cases and a much narrower main degradation peak was found. These findings can be attributed to the partially removal of non-cellulosic components such as hemicelluloses and lignin [28] and they are consistent with the FTIR and WAXS results. Also, the main degradation peak was slightly shifted towards lower temperature. Ndacy et al [42] 
suggest that the displacement could be related with the removal of cementing material during the alkali treatment. The small shoulder located around $450{ }^{\circ} \mathrm{C}$ in treated fibers indicates that there is still some lignin remaining after treatment. It may suggest that the alkaline and peroxide treatment for these residues has been more efficient in the removal of hemicelluloses, fats and waxes than in the case of lignin.

Figure II. 3 shows the SEM micrographs of almond shell, Rice husk and Seagrass fibers before and after alkaline and peroxide treatment. The average size and the aspect ratio were estimated by image analysis.

Almond Shell powder (Figure II.3a) is mainly composed by particles of irregular shape. The average size of the particles is about $45 \mu \mathrm{m}$, and its aspect ratio is estimated to be around 2 . The biggest particles observed in Fig. II.3a and Fig. II.3b, can be described as aggregates of smaller particles. A kind of fibrillary structure is revealed in the biggest particles of the treated AS (see arrow in Fig. II.3b). The particle surface in the treated AS is characterized by a high roughness and porosity (see Fig. II.3c), however the average size, aspect ratio and irregular shape was not modified by the treatment.

Native RH powder is composed by particles of a broad range of sizes and different morphologies (Fig. II.3d). Big particles (rod and rectangular junks) as well as small fibers can be observed. After the treatment, the presence of big junks is more scarce and fibrillary shaped particles with more homogeneous size distribution can be observed. The average particle size is estimated of ca.70 $\mu \mathrm{m}$ and the aspect ratio of particles is of about 7. Figure II.3f shows a higher magnification detail of a $\mathrm{RH}$ particle, where it can be appreciated the fibrous morphology.

Seagrass raw powder (Fig. II.3g) is composed by a mixture of bigger and irregular shaped particles and smaller fibrillary particles. The heterogeneous aspect of this powder is due to its nature, since this waste is formed mainly by Posidonia Ocenica (balls and leaves) but also by accessory algae and some small sea sponges and corals. In Fig II.3g, it can be seen that some of the big particles present a tubular (hollow) structure. After treatment, Figure II.3h, some irregular shaped particles can be observed but a larger proportion of small-sized fibrillary particles. Upon magnification, a clear fibrillary structure with smooth surface is manifested (Fig. II.3i). The average particle size of the smallest particles is estimated of $25 \mu \mathrm{m}$ and up to $200 \mu \mathrm{m}$ for the longer fibers and the aspect ratio ranges from 2 up to 15. 

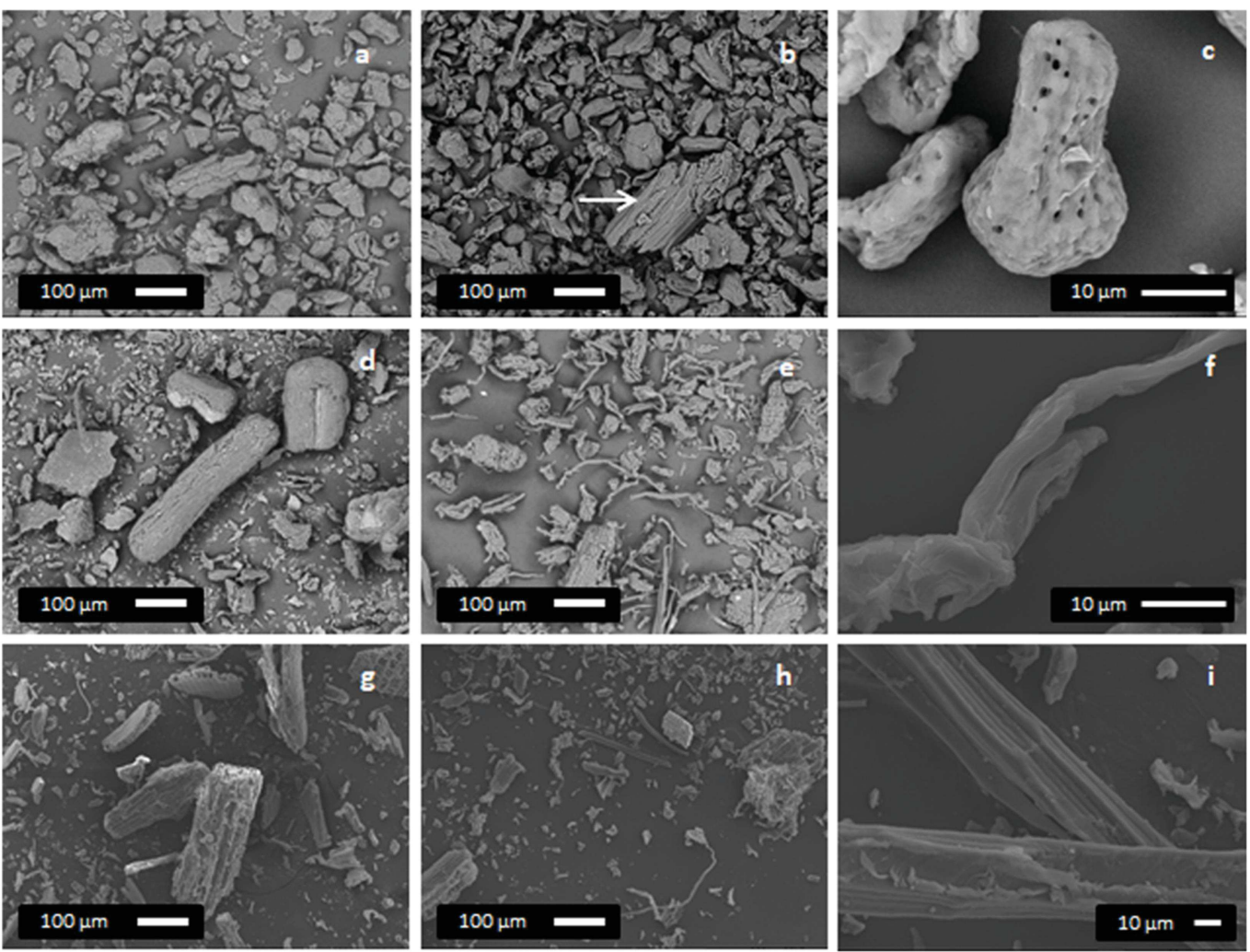

Figure II.3. SEM micrographs of AS (a-c), RH (d-f) and SG (g-i) fibers before treatment (left), after treatment (center) and high magnification image after treatment (right)

\section{II.3.2. Composites characterization}

After the incorporation of the fibers to the PHB as described in experimental section, the composites were analyzed as follows.

\section{II.3.2.1. Scanning electron microscopy (SEM)}

The morphology of PHB/fiber composites was studied by SEM on cryofractured surfaces. Representative micrographs of the composites studied are displayed in Figure II.4. Low magnification images of each composition have been used to present the fiber distribution within the PHB matrix. High magnification images have been used to show the interfacial interaction between the fiber and the polymer. 

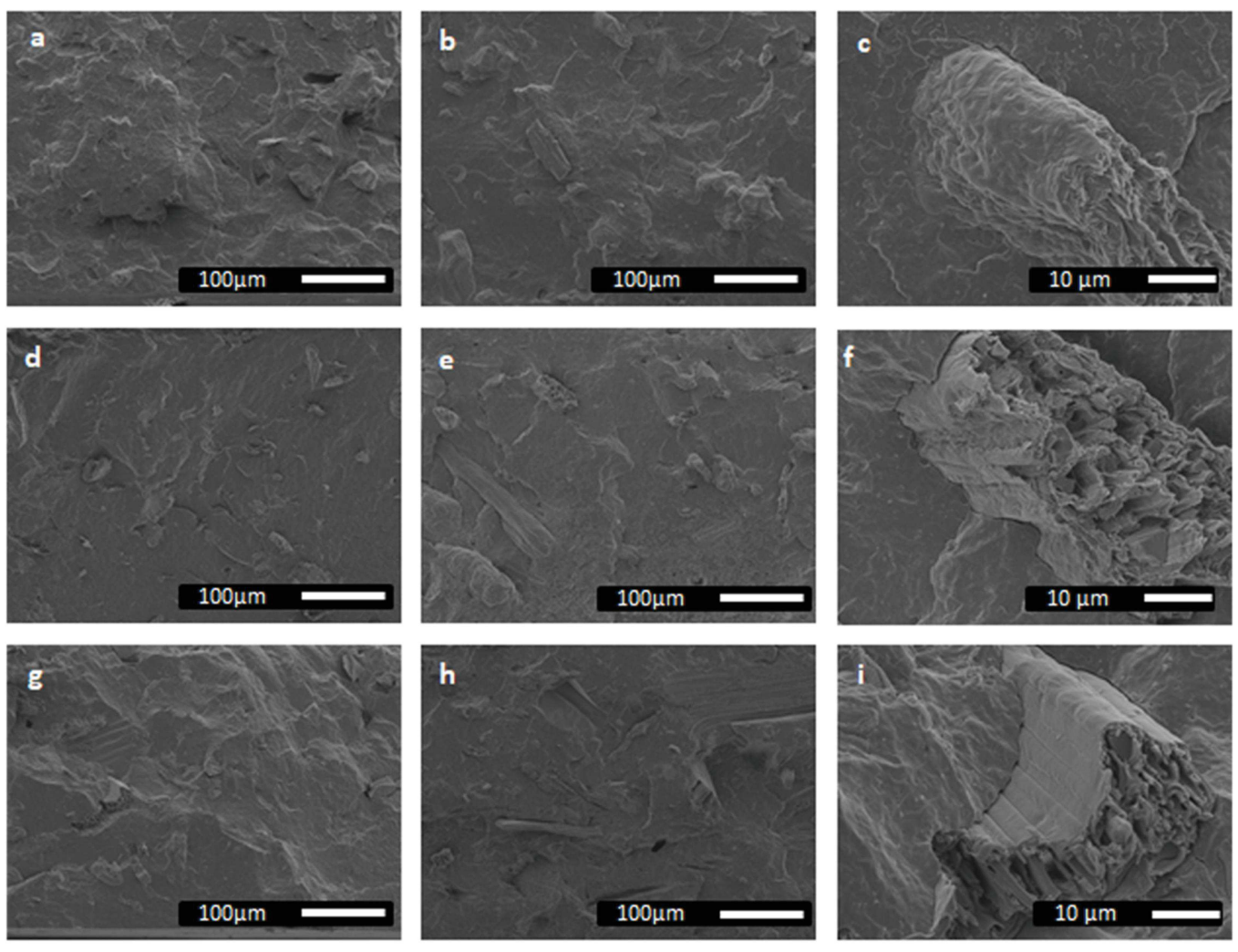

Figure II.4. SEM micrographs of PHB/AS (a-c), PHB/RH (d-f) and PHB/SG (g-i) composites with 10 phr fiber content (left), $20 \mathrm{phr}$ fiber content (center) and detail of fiber-matrix interface (right)

For all the composites, homogeneous distribution of the fibers was observed in all cases, i.e. individual fibers are detected homogeneously distributed along the polymer matrix, whilst the presence of fiber aggregates was not detected. These findings confirm that an effective compounding was achieved.

With respect to the fiber-matrix interaction, in all three cases, no clear pull-out effect has been found; on the contrary, broken individual fibers are detected throughout the cryofractured surface, thus revealing some interaction and a certain degree of load transfer between the matrix and the fiber. This interaction could be explained by the presence of reactive $-\mathrm{OH}$ groups created during the fiber treatment, thus improving the wettability of the fibers. [32].

However, the observation of the high magnification micrographs may unveil some differences among the fibers with respect to the interphase. The AS fiber presented in Fig.II.4c may exhibit 
higher degree of interaction than either RH or SG (in Fig.II.4f and Fig.II.4i, respectively). This statement is derived from the fully covering of the fiber by the PHB for the AS, whereas both the $\mathrm{RH}$ and the SG exhibit a small gap at the interface (showing some detachment of the fiber). The differences could be attributed to higher and favorable roughness of the AS fiber surface, with respect to the other ones (see Fig.II.3c). The presence of small pinholes on the AS fiber surface (c.f. Fig.II.4c) may enable the penetration of the molten polymer during compounding, which converts after cooling in an effective mechanical anchorage, yielding to a more effective adhesion.

\section{II.3.2.2. Thermogravimetric analysis (TGA)}

Thermal stability of PHB and PHB/fiber composites has been studied by TGA. The onset degradation temperature ( $T_{5 \%}$, calculated as the temperature at which a $5 \%$ weight loss occurs), the maximum degradation rate temperature corresponding to the main degradation steps $\left(T_{d 1}\right.$, $T_{d 2}$, corresponding to the DTG peaks for (1) the PHB matrix and (2) the cellulose) and the residue (\%) at $600{ }^{\circ} \mathrm{C}$ were determined; results are summarized in Table II.2.

Table II.2. TGA and DSC data of PHB and PHB/fiber composites TGA parameters

DSC parameters

\begin{tabular}{|c|c|c|c|c|c|c|}
\hline & $\begin{array}{l}T_{5 \%} \\
\text { (oC) }\end{array}$ & $\begin{array}{l}\mathrm{T}_{\mathrm{d} 1} \\
(\mathrm{o}) \text { ) }\end{array}$ & $\begin{array}{l}\mathrm{T}_{\mathrm{d} 2} \\
(\mathrm{o}) \text { ) }\end{array}$ & $\begin{array}{c}\text { Residue } \\
\text { (\%) }\end{array}$ & 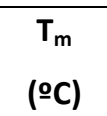 & $\begin{array}{l}X_{C} \\
(\%)\end{array}$ \\
\hline PHB & 275 & 295 & - & 1.6 & 171.3 & 74.7 \\
\hline PHB/10AS & 271 & 288 & 347 & 3.7 & 171.3 & 73.8 \\
\hline PHB/20AS & 267 & 281 & 342 & 5.0 & 170.3 & 76.2 \\
\hline PHB/10RH & 273 & 293 & 350 & 3.7 & 171.2 & 74.6 \\
\hline PHB/20RH & 267 & 283 & 347 & 6.7 & 169.0 & 71.2 \\
\hline PHB/10SG & 261 & 274 & 321 & 4.2 & 170.7 & 73.0 \\
\hline PHB/20SG & 257 & 270 & 322 & 6.7 & 170.7 & 72.6 \\
\hline
\end{tabular}

The thermal degradation of neat PHB takes place abruptly in a single weight loss step at 295으. As it has been reported, PHB degrades by the random chain scission mechanism leading to a reduction of molecular weight and resulting in the formation of volatile products such as crotonic acid [50]. Earlier thermal degradation was observed in all cases with the incorporation of the natural fibers. However, the thermal stability of PHB seems to be affected by both the filler 
content and the fiber type. The addition of $10 \mathrm{wt} . \% \mathrm{RH}$ and AS fibers does not significantly alter the thermal stability of PHB, but the incorporation of $10 \mathrm{wt}$.\% SG lead to a decrease in the onset and peak temperature of 14 and $21^{\circ} \mathrm{C}$, respectively. For the samples containing $20 \mathrm{wt} \%$ of fiber, the SG fibers reduces the maximum degradation temperature in $25 \circ \mathrm{C}$ while the incorporation of $\mathrm{RH}$ and $\mathrm{AS}$ reduces this temperature in 12 and $14^{\circ} \mathrm{C}$ respectively. Other authors reported the reduction of thermal stability of biopolyesters by the introduction of cellulosic fibers $[31,46,51]$.

\section{II.3.2.3. Differential scanning calorimetry (DSC)}

The influence of the amount and filler type in crystallization and melting behavior of PHB has been studied by DSC measurements. The main thermal parameters, obtained from second heating scans after thermal history erasing, are summarized in Table II.2.

Neat PHB present the melting temperature at $171.3^{\circ} \mathrm{C}$. The PHB crystallinity degree calculated by means of eq. (1) is $74.7 \%$. Neither the melting temperatures nor the crystallinity degree seem to be significantly affected by the presence of the different type and amount of fibers. These results are in agreement with other works reported in bibliography about polyhydroxyalkanoates filled with other cellulosic fibers $[11,52,53]$.

\section{II.3.2.4. Mechanical properties}

The mechanical behavior of PHB and its composites with 10 and 20 phr of Almond Shell, Rice Husk and Seagrass has been studied by tensile tests up to failure. Young Modulus, Tensile strength and elongation at break of the different composites are summarized in Fig. II.5. 

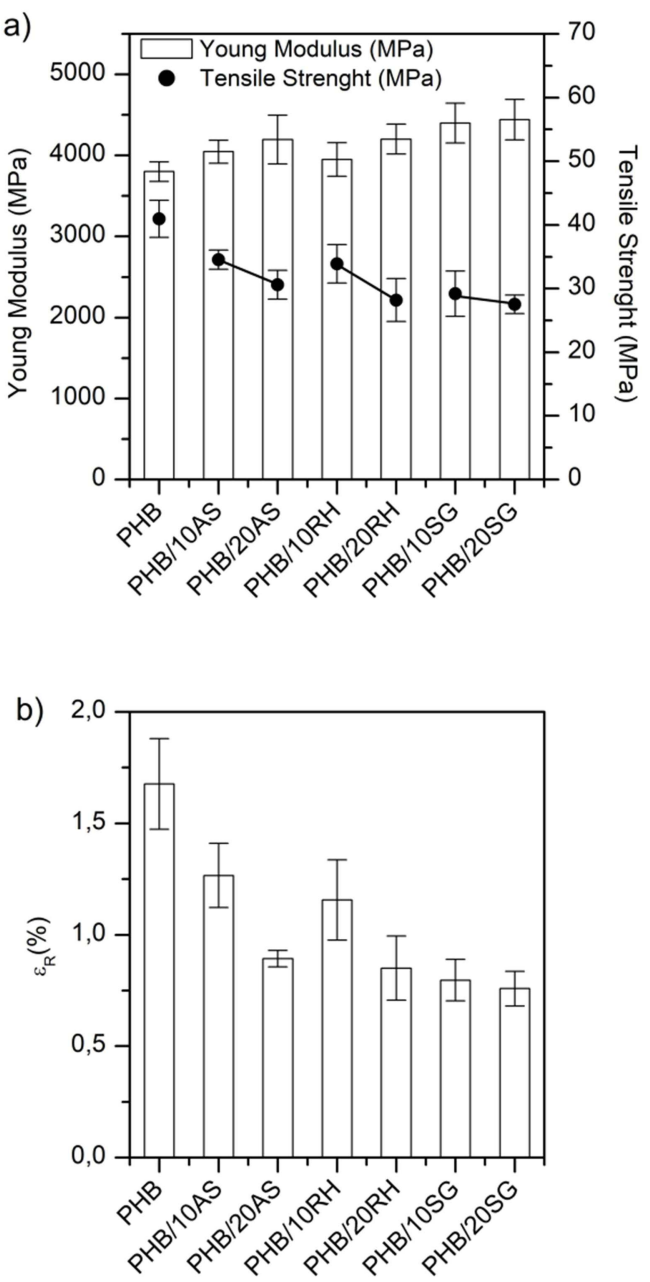

Figure II.5. Young's modulus and tensile strength (a) and elongation at break (b) of neat PHB and PHB/fiber composites

The mechanical properties of natural fiber reinforced composites depend on a number of parameters such as volume fraction of the fibers, fiber aspect ratio, fiber-matrix adhesion, stress transfer at the interface, and orientation. The tensile strength is more sensitive to the matrix properties and fiber-matrix adhesion whereas the modulus is more dependent on the fiber properties (whenever good interaction is achieved) [8]. 
A slight increase in the Tensile Modulus of Elasticity is observed for all the samples when the fibers are incorporated. A positive dependence on the increase in the modulus with the fiber content is found for the AS and $\mathrm{RH}$, while no differences between them are detected; however, for the SG, this trend is not visible. Moreover, this latter fiber yield to higher values of modulus of elasticity than AS and $\mathrm{RH}$. This difference, nevertheless, is not relevant (below 10\%)

With respect to the tensile strength and elongation at break, a clear decrease in both parameters was found with the fibers incorporation. The decrease in both parameters can be attributed to the intrinsic brittleness of the PHB matrix in addition to the stress concentrator effect of the fibers. Thus, the biggest particles would be acting as flaws in a brittle polymeric matrix, causing premature failure and not showing any reinforcement effect. Accordingly, this drop in tensile strength and elongation at break is more severe in composites containing the highest content of fibers (20 phr) and especially for PHB/SG composites (where particles were the largest, according to SEM observations). These drawbacks could be in theory improved by enhancing the interaction between the fiber and the matrix and will be the scope of future works.

\section{II.3.2.5. Barrier performance}

In terms of barrier performance of the biocomposites, an increase in Water Vapor Permeability was observed for all composites with respect to the neat PHB (as shown in Fig. II.6). This increment was more pronounced with an increase in the filler content for all the studied cases. Despite of the fact that the drop in barrier performance is significant in all cases, the incorporation of AS had the less impact in WVP when compared with the two other fillers. Similar results were reported in bibliography for natural filler reinforced composites [54], in which the increase in WVP was ascribed to the higher hygroscopicity of the fibers and preferential paths at the fiber matrix interface, with respect to the neat polymer matrix. 


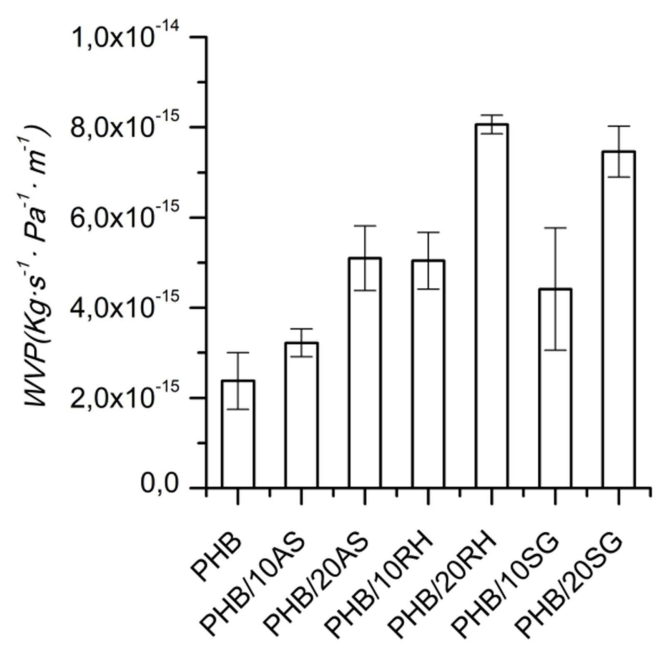

Figure II.6. Water Vapor Permeability (WVP) of neat PHB and PHB/fiber composites

\section{II.3.2.6. Thermoforming}

Thermoforming is a most popular processing technology in the food packaging sector and PHB is known to be difficult to thermoform due to a low melt elasticity of the sheet while having a narrow processing window [36]. The addition of a rigid fiber to a highly crystalline polymer would (a priori) most probably lead to a decrease in the thermoforming capacity of the polymer. However, as shown in Fig. II.7b, the incorporation of $10 \mathrm{phr}$ of AS to the PHB does not affect negatively to the thermoformability; rather on the contrary, a slight improvement in the quality of the thermoformed tray has been found.

In Fig. II.7 is summarized the evolution of thermoformability of PHB and PHB/10AS biocomposites as a function of temperature. As it can be observed in figure II.7a the thermoformability of PHB is slightly improved with the addition of $10 \mathrm{phr}$ Almond Shell: thickness distribution and mold reproduction ("edges" and "corners") are enhanced with respect to the pristine PHB. The thermoforming temperature range, with acceptable results obtained (shown in Fig. II.7 d) is surprisingly also extended. This unexpected enhancement of thermoformability performance achieved for the PHB/10AS composites may improve the use of this natural fiber-based biocomposites, especially in the food packaging industry. Nevertheless, further investigation is currently being performed, to shed light on this behavior. 


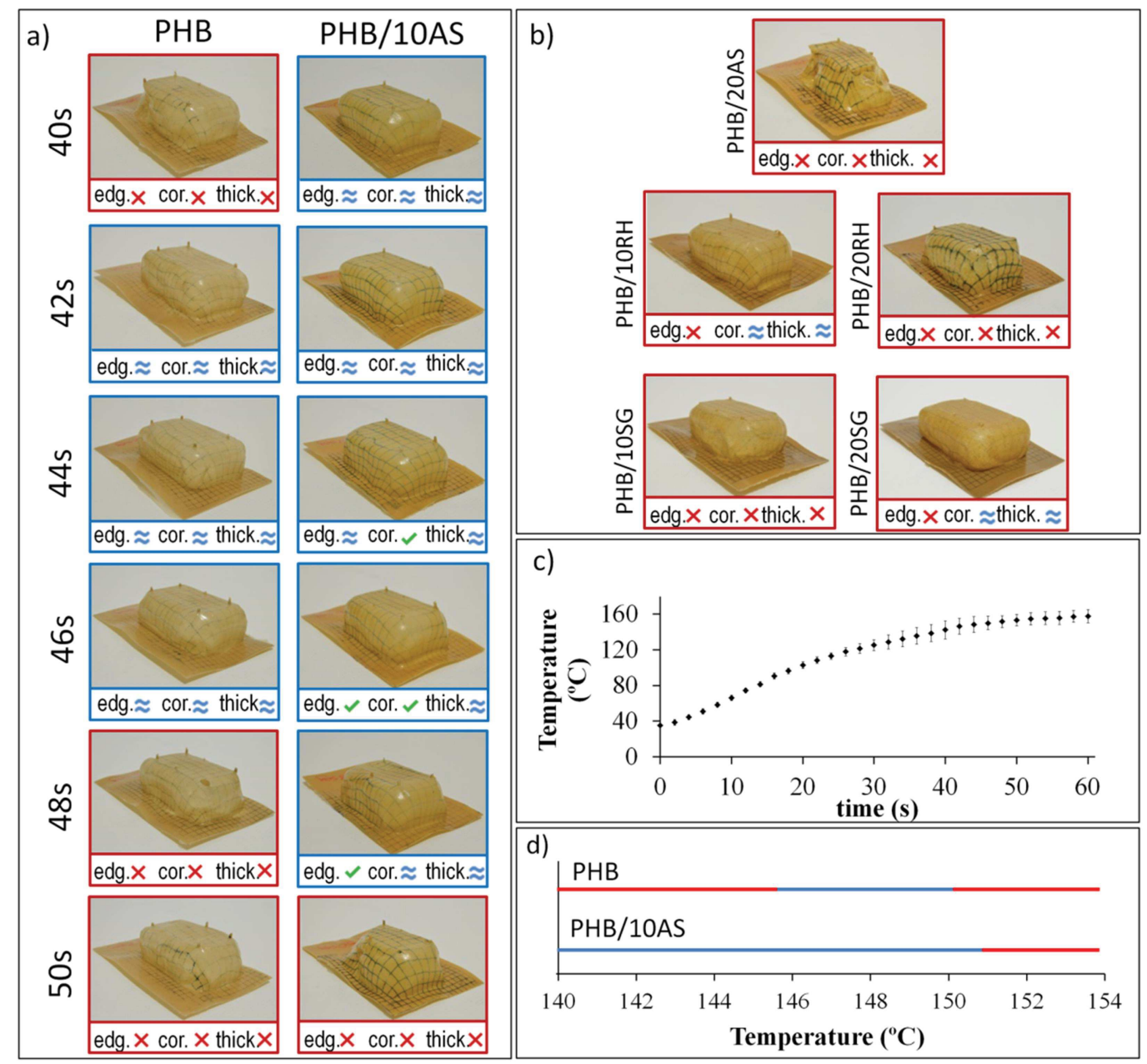

Figure II.7. a) Photographs of neat PHB and PHB/10 AS thermoforming trays as a function of heating time, b) representative thermoforming trays of PHB/fiber composites, c) Sheet temperature as a function of heating time, $d$ ) thermoforming temperature range for neat $\mathrm{PHB}$ and $\mathrm{PHB} / 10 \mathrm{AS}$ composite

\section{II.3.2.7. Disintegration in composting conditions}

$\mathrm{PHB}$ and $\mathrm{PHB} /$ Fiber composites disintegration in composting conditions was evaluated according to the ISO 20200 standard. The disintegration rate was determined by the measuring weight loss of the samples as a function of composting time. Results are represented in figure II.8. 
No appreciable weight loss was detected until the $20^{\text {th }}$ day of composting. From that day the disintegration rate increases abruptly. Total disintegration (considered when no fragments bigger than $2 \mathrm{~mm}$ can be recovered from compost) was reached at 35 days of composting. These findings are in agreement with previous reports [55].

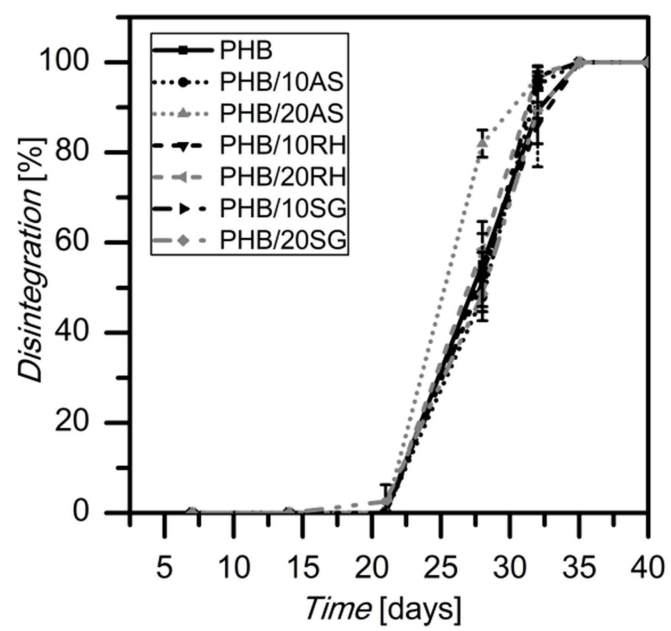

Figure II.8. Disintegration of neat PHB and PHB/fiber composites over time under composting conditions

No remarkable differences in weight loss rate were found among the different compositions studied, concluding that neither the fiber type nor the fiber content alters significantly the disintegration rate of PHB in the compositions range studied.

Figure II.9 show pictures of the samples at 0 and 28 days of composting. The visual examination of the samples reveals an evident surface roughening at the $4^{\text {th }}$ week of the compost assay, as well as clear physical changes. These observations are in accordance with a disintegration phenomenon that occurs by a gradually microorganism erosion from the surface to the bulk, as it has been reported in literature [55-57]. 


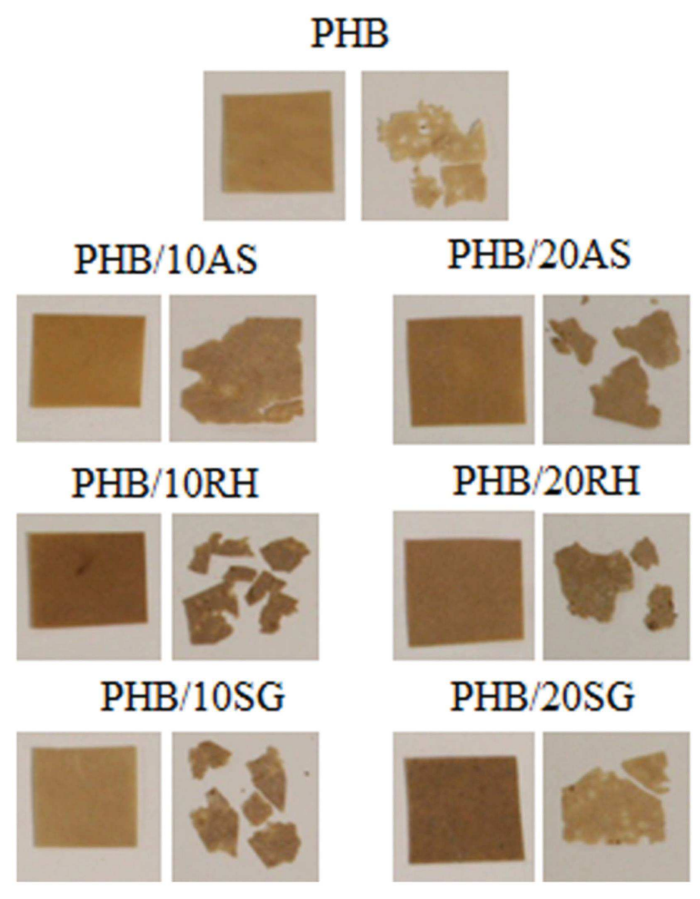

Figure II.9. Visual appearance of neat PHB and PHB/fiber composites at 0 days (left) and 28 days (right) of composting

\section{II.4. Conclusions}

Three different lignocellulosic wastes (almond shell, rice husk and seagrass) were compared as fillers in PHB/fiber composites obtained by melt blending with fiber contents up to $20 \mathrm{phr}$. The influence of the fiber type and the fiber content on morphology, thermal, mechanical, barrier properties, compostability and processability of PHB/fiber composites was studied.

Even though the type and content of the fibers did not affect the crystallization behavior of PHB, their differences in size and morphology induce some variations in the composite properties. SG residues are formed by a mixture of particles with a wide range of sizes and shapes, with high presence of impurities. RH fibers are characterized by a fibrillary shape with a smooth surface and high aspect ratio. AS, on the other hand, present irregular spheroidal shape with a very porous surface. 
All the studied fibers were suitable for their application in the development of fully compostable biocomposites for packaging applications. In that sense, all the fibers have demonstrated a mechanical reinforcing effect in terms of increase of elastic modulus, although the resulting barrier properties and thermal stability decreased in the presence of the fibers with respect to neat PHB.

In spite of the low aspect ratio of AS in comparison with SG and $\mathrm{RH}$, the particular characteristics of this residue seem to favor the mechanical anchoring of the polymer into its surface. It is worth to point out that the incorporation of AS supposed the smallest increase in permeability and the enhanced of the thermoformability of PHB (with the addition of $10 \mathrm{phr}$ AS).

These promising results suppose an interesting starting point for the valorization of these wastes in industrial food packaging applications.

\section{Acknowledgements}

The authors would like to thank the financial support for this research from Ministerio de Economia y Competitividad (AGL2015-63855-C2-2-R), Pla de Promoció de la Investigació de la Universitat Jaume I (UJI-B2016-35) and H2020 EU Project YPACK (H2020-SFS-2017-1, Reference 773872). Authors would like to acknowledge Servicios Centrales de Instrumentación (SCIC) of Universitat Jaume I for the use of FTIR, WAXS, TGA, DSC and SEM. We are also grateful to Raquel Oliver and Jose Ortega for experimental support.

\section{References}

[1] M.-A. Berthet, H. Angellier-Coussy, V. Guillard, N. Gontard, Vegetal fiber-based biocomposites: Which stakes for food packaging applications?, J. Appl. Polym. Sci. 133 (2016) 42528 (1-18). doi:10.1002/app.42528.

[2] T. Väisänen, A. Haapala, R. Lappalainen, L. Tomppo, Utilization of agricultural and forest industry waste and residues in natural fiber-polymer composites: A review, Waste Manag. 54 (2016) 62-73. doi:10.1016/j.wasman.2016.04.037.

[3] E. Bugnicourt, P. Cinelli, A. Lazzeri, V. Alvarez, Polyhydroxyalkanoate (PHA): Review of synthesis, characteristics, processing and potential applications in packaging, Express Polym. Lett. 8 (2014) 791-808. doi:10.3144/expresspolymlett.2014.82.

[4] S. Philip, T. Keshavarz, I. Roy, Polyhydroxyalkanoates: Biodegradable polymers with a range of applications, J. Chem. Technol. 247 (2007) 233-247. doi:10.1002/jctb.1667.

[5] A. K. Mohanty, M. Misra, G. Hinrichsen, Biofibres, biodegradable polymers and biocomposites: An 
overview, Macromol. Mater. Eng. 276-277 (2000) 1-24. doi:10.1002/(SICI)14392054(20000301)276:1<1::AID-MAME1>3.0.CO;2-W.

[6] M. George, M. Chae, D.C. Bressler, Composite materials with bast fibres: Structural, technical, and environmental properties, Prog. Mater. Sci. 83 (2016) 1-23. doi:10.1016/j.pmatsci.2016.04.002.

[7] J.K. Pandey, S.H. Ahn, C.S. Lee, A.K. Mohanty, M. Misra, Recent Advances in the Application of Natural Fiber Based Composites, Macromol. Mater. Eng. 295 (2010) 975-989. doi:10.1002/mame.201000095.

[8] D.N. Saheb, J.P. Jog, Natural fiber polymer composites: A review, Adv. Polym. Technol. 18 (1999) 351-363. doi:10.1002/(SICI)1098-2329(199924)18:4<351::AID-ADV6>3.3.CO;2-O.

[9] M. Avella, E. Martuscelli, B. Pascucci, M. Raimo, B. Focher, A. Marzetti, A new class of biodegradable materials: Poly-3-hydroxy-butyrate/steam exploded straw fiber composites. I. Thermal and impact behavior, J. Appl. Polym. Sci. 49 (1993) 2091-2103. doi:10.1002/app.1993.070491205.

[10] M. Avella, G. La Rota, E. Martuscelli, M. Raimo, P. Sadocco, G. Elegir, R. Riva, Poly(3hydroxybutyrate-co-3-hydroxyvalerate) and wheat straw fibre composites: Thermal, mechanical properties and biodegradation behaviour, J. Mater. Sci. 35 (2000) 829-836. doi:10.1023/A:1004773603516.

[11] M. Berthet, H. Angellier-coussy, D. Machado, L. Hilliou, A. Staebler, A. Vicente, N. Gontard, Exploring the potentialities of using lignocellulosic fibres derived from three food by-products as constituents of biocomposites for food packaging, Ind. Crop. Prod. 69 (2015) 110-122. doi:10.1016/j.indcrop.2015.01.028.

[12] S. Wong, R. Shanks, A. Hodzic, Properties of poly(3-hydroxybutyric acid) composites with flax fibres modified by plasticiser absorption, Macromol. Mater. Eng. 287 (2002) 647-655. doi:10.1002/14392054(200211)287:10<647::AID-MAME647>3.0.CO;2-4.

[13] S.G. Lee, S.-S. Choi, W.H. Park, D. Cho, Characterization of surface modified flax fibers and their biocomposites with PHB, Macromol. Symp. 197 (2003).

[14] R.A. Shanks, A. Hodzic, S. Wong, Thermoplastic biopolyester natural fiber composites, J. Appl. Polym. Sci. 91 (2004) 2114-2121. doi:10.1002/app.13289.

[15] H. Ma, C.W. Joo, Investigation of jute-lignin-poly (3-hydroxybutyrate) hybrid biodegradable composites with low water absorption, Fibers Polym. 12 (2011) 310-315. doi:10.1007/s12221-0110310-2.

[16] J.D.S. Macedo, M.F. Costa, M.I.B. Tavares, R.M.S.M. Thiré, Preparation and characterization of composites based on polyhydroxybutyrate and waste powder from coconut fibers processing, Polym. Eng. Sci. 50 (2010) 1466-1475. doi:10.1002/pen.21669.

[17] A. Kuciel, S., Liber-Kneć, Biocomposites based on PHB filled with wood or kenaf fibers, Polimery/Polymers. 56 (2011) 218-223.

[18] Food and Agriculture organization of the United Nations. (FAOSTAT Data- base), (n.d.). http://www.fao.org/faostat/en/\#data (accessed September 28, 2017).

[19] H. Pirayesh, A. Khazaeian, Using almond (Prunus amygdalus L.) shell as a bio-waste resource in wood based composite, Compos. Part B Eng. 43 (2012) 1475-1479. doi:10.1016/j.compositesb.2011.06.008.

[20] F.Z. El Mechtali, H. Essabir, S. Nekhlaoui, M.O. Bensalah, M. Jawaid, R. Bouhfid, A. Qaiss, Mechanical and Thermal Properties of Polypropylene Reinforced with Almond Shells Particles: 
Impact of Chemical Treatments, J. Bionic Eng. 12 (2015) 483-494. doi:10.1016/S16726529(14)60139-6.

[21] A. Sabbatini, S. Lanari, C. Santulli, C. Pettinari, Use of Almond Shells and Rice Husk as Fillers of Poly(Methyl Methacrylate) (PMMA) Composites, Materials (Basel). 10 (2017) 872(1-12). doi:10.3390/ma10080872.

[22] Y. Hamzeh, K.P. Ziabari, J. Torkaman, A. Ashori, M. Jafari, Study on the effects of white rice husk ash and fibrous materials additions on some properties of fiber-cement composites, J. Environ. Manage. 117 (2013) 263-267. doi:10.1016/j.jenvman.2013.01.002.

[23] R. Arjmandi, A. Hassan, K. Majeed, Z. Zakaria, Rice Husk Filled Polymer Composites, 2015 (2015).

[24] C. Wu, Preparation and Characterization of Polyhydroxyalkanoate Bioplastic-Based Green Renewable Composites from Rice Husk, 22(2014) 384-392. doi:10.1007/s10924-014-0662-y.

[25] F. Bertini, M. Canetti, A. Cacciamani, G. Elegir, M. Orlandi, L. Zoia, Effect of ligno-derivatives on thermal properties and degradation behavior of poly (3-hydroxybutyrate ) -based biocomposites, Polym. Degrad. Stab. 97 (2012) 1979-1987. doi:10.1016/j.polymdegradstab.2012.03.009.

[26] L.D. Alberti, O.F. Souza, D.Z. Bucci, I.O. Barcellos, Study on Physical and Mechanical Properties of PHB Biocomposites with Rice Hull Ash, Mater. Sci. Forum. 775-776 (2014) 557-561. doi:10.4028/www.scientific.net/MSF.775-776.557.

[27] I.T. Seoane, E. Fortunati, D. Puglia, V.P. Cyras, L.B. Manfredi, Development and characterization of bionanocomposites based on poly(3-hydroxybutyrate) and cellulose nanocrystals for packaging applications, Polym. Int. 65 (2016) 1046-1053. doi:10.1002/pi.5150.

[28] E. Fortunati, F. Luzi, D. Puglia, R. Petrucci, J.M.M. Kenny, L. Torre, Processing of PLA nanocomposites with cellulose nanocrystals extracted from Posidonia oceanica waste: Innovative reuse of coastal plant, Ind. Crops Prod. 67 (2015) 439-447. doi:10.1016/j.indcrop.2015.01.075.

[29] B. Ferrero, V. Fombuena, O. Fenollar, T. Boronat, R. Balart, Development of natural fiber-reinforced plastics (NFRP) based on biobased polyethylene and waste fibers from Posidonia oceanica seaweed, Polym. Compos. 36 (2015) 1378-1385. doi:10.1002/pc.23042.

[30] R. Khiari, Z. Marrakchi, M.N. Belgacem, E. Mauret, F. Mhenni, New lignocellulosic fibres-reinforced composite materials: A stepforward in the valorisation of the Posidonia oceanica balls, Compos. Sci. Technol. 71 (2011) 1867-1872. doi:10.1016/j.compscitech.2011.08.022.

[31] M. Seggiani, P. Cinelli, N. Mallegni, E. Balestri, M. Puccini, S. Vitolo, C. Lardicci, A. Lazzeri, New BioComposites Based on Polyhydroxyalkanoates and Posidonia oceanica Fibres for Applications in a Marine Environment, Materials (Basel). 10 (2017)326(1-13). doi:10.3390/ma10040326.

[32] J.D.D. Melo, L.F.M. Carvalho, A.M. Medeiros, C.R.O. Souto, C.A. Paskocimas, A biodegradable composite material based on polyhydroxybutyrate (PHB) and carnauba fibers, Compos. Part B Eng. 43 (2012) 2827-2835. doi:10.1016/j.compositesb.2012.04.046.

[33] Y.-M. Corre, S. Bruzaud, J.-L. Audic, Y. Grohens, Morphology and functional properties of commercial polyhydroxyalkanoates: A comprehensive and comparative study, Polym. Test. 31 (2012) 226-235. doi:10.1016/j.polymertesting.2011.11.002.

[34] L. Segal, J.J. Creely, A.E. Martin, C.M. Conrad, An Empirical Method for Estimating the Degree of Crystallinity of Native Cellulose Using the X-Ray Diffractometer, Text. Res. J. 29 (1959) 786-794. doi:10.1177/004051755902901003.

[35] L.N. Carli, J.S. Crespo, R.S. Mauler, PHBV nanocomposites based on organomodified montmorillonite and halloysite: The effect of clay type on the morphology and thermal and 
mechanical properties, Compos. Part A Appl. Sci. Manuf. 42 (2011) 1601-1608. doi:10.1016/j.compositesa.2011.07.007.

[36] J. González-Ausejo, E. Sanchez-Safont, J.M. Lagaron, R.T. Olsson, J. Gamez-Perez, L. Cabedo, Assessing the thermoformability of poly(3-hydroxybutyrate-co-3-hydroxyvalerate)/poly(acid lactic) blends compatibilized with diisocyanates, Polym. Test. 62 (2017) 235-245. doi:10.1016/j.polymertesting.2017.06.026.

[37] UNE-EN ISO, UNE-EN ISO 20200 Determinación del grado de desintegración de materiales plásticos bajo condiciones de compostaje simuladas en un laboratorio, (2006).

[38] T 211 om-02., Ash in wood, pulp, paper and paperboard: combustion at 525oC, TAPPI Test Methods. (2002).

[39] B.S. Ndazi, S. Karlsson, J. V. Tesha, C.W. Nyahumwa, Chemical and physical modifications of rice husks for use as composite panels, Compos. Part A Appl. Sci. Manuf. 38 (2007) 925-935. doi:10.1016/j.compositesa.2006.07.004

[40] A.K. Chanda, A. Hazra, M. Praveen Kumar, S. Neogi, S. Neogi, Chemical treatments of rice husk filler and jute fiber for the use in green composites, Fibers Polym. 16 (2015) 902-910. doi:10.1007/s12221-015-0902-3.

[41] N. Johar, I. Ahmad, A. Dufresne, Extraction, preparation and characterization of cellulose fibres and nanocrystals from rice husk, Ind. Crop. Prod. 37 (2012) 93-99. doi:10.1016/j.indcrop.2011.12.016.

[42] B.S. Ndazi, C. Nyahumwa, J. Tesha, Chemical and thermal stability of rice husks against alkali treatment, BioResources. 3 (2008) 1267-1277.

[43] R. Khiari, M.F. Mhenni, M.N. Belgacem, E. Mauret, Valorisation of Vegetal Wastes as a Source of Cellulose and Cellulose Derivatives, 19(2011) 80-89. doi:10.1007/s10924-010-0207-y.

[44] F. Bettaieb, R. Khiari, A. Dufresne, M.F.F. Mhenni, J.L.L. Putaux, S. Boufi, Nanofibrillar cellulose from Posidonia oceanica: Properties and morphological features, Ind. Crops Prod. 72 (2015) 97-106. doi:10.1016/j.indcrop.2014.12.060.

[45] F. Bettaieb, R. Khiari, M.L. Hassan, M.N. Belgacem, J. Bras, A. Dufresne, M.F. Mhenni, Preparation and characterization of new cellulose nanocrystals from marine biomass Posidonia oceanica, Ind. Crops Prod. 72 (2015) 175-182. doi:10.1016/j.indcrop.2014.12.038.

[46] D. Battegazzore, S. Bocchini, J. Alongi, A. Frache, F. Marino, Cellulose extracted from rice husk as filler for poly(lactic acid): preparation and characterization, Cellulose. 21 (2014) 1813-1821. doi:10.1007/s10570-014-0207-5.

[47] I. Urruzola, E. Robles, L. Serrano, J. Labidi, Nanopaper from almond (Prunus dulcis) shell, Cellulose. 21 (2014) 1619-1629. doi:10.1007/s10570-014-0238-y.

[48] A. Valdés, O. Fenollar, A. Beltrán, R. Balart, E. Fortunati, J.M. Kenny, M.C. Garrigós, Characterization and enzymatic degradation study of poly(??-caprolactone)-based biocomposites from almond agricultural by-products, Polym. Degrad. Stab. 132 (2016) 181-190. doi:10.1016/j.polymdegradstab.2016.02.023.

[49] H. Yang, R. Yan, H. Chen, D.H. Lee, C. Zheng, Characteristics of hemicellulose, cellulose and lignin pyrolysis, Fuel. 86 (2007) 1781-1788. doi:10.1016/j.fuel.2006.12.013.

[50] N. Grassie, E.J. Murray, P.A. Holmes, The thermal degradation of poly(-(d)- $\beta$-hydroxybutyric acid): Part 2-Changes in molecular weight, Polym. Degrad. Stab. 6 (1984) 95-103. doi:10.1016/01413910(84)90075-2. 
[51] E. Petinakis, X. Liu, L. Yu, C. Way, P. Sangwan, K. Dean, S. Bateman, G. Edward, Biodegradation and thermal decomposition of poly(lactic acid)-based materials reinforced by hydrophilic fillers, Polym. Degrad. Stab. 95 (2010) 1704-1707. doi:10.1016/j.polymdegradstab.2010.05.027.

[52] E.L. Sánchez-Safont, J. González-Ausejo, J. Gámez-Pérez, J.M. Lagarón, L. Cabedo, E.L. SanchezSafont, J. Gonzalez-Ausejo, J. Gamez-Perez, J.M. Lagaron, L. Cabedo, Poly(3-Hydroxybutyrate-co-3Hydroxyvalerate)/Purified Cellulose Fiber Composites by Melt Blending: Characterization and Degradation in Composting Conditions, J. Renew. Mater. 4 (2016) 123-132. doi:10.7569/JRM.2015.634127.

[53] P. Gatenholm, J. Kubát, A. Mathiasson, Biodegradable natural composites. I. Processing and properties, J. Appl. Polym. Sci. 45 (1992) 1667-1677. doi:10.1002/app.1992.070450918.

[54] E. Elena, M. Elena, M. Râp, O. Popa, PHB / Cellulose fibers based materials : physical, mechanical and barrier properties, Agric. Agric. Sci. Procedia. 6 (2015) 608-615. doi:10.1016/j.aaspro.2015.08.099.

[55] D. Puglia, E. Fortunati, D. a. D'Amico, L.B. Manfredi, V.P. Cyras, J.M. Kenny, Influence of organically modified clays on the properties and disintegrability in compost of solution cast poly(3hydroxybutyrate) films, Polym. Degrad. Stab. 99 (2014) 127-135 doi:10.1016/j.polymdegradstab.2013.11.013.

[56] Y.-X. Weng, Y.-Z.Y. Wang, X.-L. Wang, Y.-Z.Y. Wang, Biodegradation behavior of PHBV films in a pilot-scale composting condition, Polym. Test. 29 (2010) 579-587. doi:10.1016/j.polymertesting.2010.04.002.

[57] M.P. Arrieta, J. López, E. Rayón, a. Jiménez, Disintegrability under composting conditions of plasticized PLA-PHB blends, Polym. Degrad. Stab. (2014) 1-12. doi:10.1016/j.polymdegradstab.2014.01.034.

[58] M. Danish, M. Naqvi, U. Farooq, S. Naqvi, Characterization of South Asian Agricultural Residues for Potential Utilization in Future "energy mix," Energy Procedia. 75 (2015) 2974-2980. doi:10.1016/j.egypro.2015.07.604.

[59] Z. Wang, J. Li, J.P. Barford, K. Hellgradt, G. Mckay, A comparison of chemical treatment methods for the preparation of rice husk cellulosic fibers, Int. J. Environ. Agric. Res. 2 (2016) 67-77.

[60] M.C. Ncibi, V. Jeanne-Rose, B. Mahjoub, C. Jean-Marius, J. Lambert, J.J. Ehrhardt, Y. Bercion, M. Seffen, S. Gaspard, Preparation and characterisation of raw chars and physically activated carbons derived from marine Posidonia oceanica (L.) fibres, J. Hazard. Mater. 165 (2009) 240-249. doi:10.1016/j.jhazmat.2008.09.126. 


\section{CAPÍTULO III}

\section{Effect of the purification treatment on the valorization of natural cellulosic residues as fillers in PHB-based composites for short shelf life applications}

Estefanía Lidón Sánchez-Safont ${ }^{1}$, Abdulaziz Aldureid ${ }^{1}$, José María Lagarón ${ }^{2}$, José Gámez-Pérez ${ }^{1}$, Luis Cabedo ${ }^{1 *}$

1. Polymers and Advanced Materials Group (PIMA), Universitat Jaume I, Spain

2. Novel Materials and Nanotechnology Group, IATA, CSIC, Spain 


\section{CAPÍTULO IV}

\section{Study of the compatibilization effect of different reactive agents in $\mathrm{PHB} /$ natural fiber based composites}

Estefanía Lidón Sánchez-Safont ${ }^{1}$, Abdulaziz Aldureid ${ }^{1}$, José María Lagarón ${ }^{2}$, Luis Cabedo ${ }^{1}$, José Gámez-Pérez ${ }^{1}$.

1. Polymers and Advanced Materials Group (PIMA), Universitat Jaume I, Spain

2. Novel Materials and Nanotechnology Group, IATA, CSIC, Spain 


\section{CAPÍTULO V}

\section{PHBV/TPU/cellulose compounds for compostable injection molded parts with improved thermal and mechanical performance}

Sánchez-Safont, E.L. ${ }^{1}$; Arrillaga, A. ${ }^{2}$; Anakabe. J. ${ }^{2}$; Gamez-Perez-.J. ${ }^{1}$; Cabedo.L. ${ }^{1 *}$

1- Polymers and Advanced Materials Group (PIMA), Universitat Jaume I, Spain

2- Leartiker S. Coop., Xemein etorbidea 12, 48270 Markina-Xemein, Spain

\section{Graphical abstract}

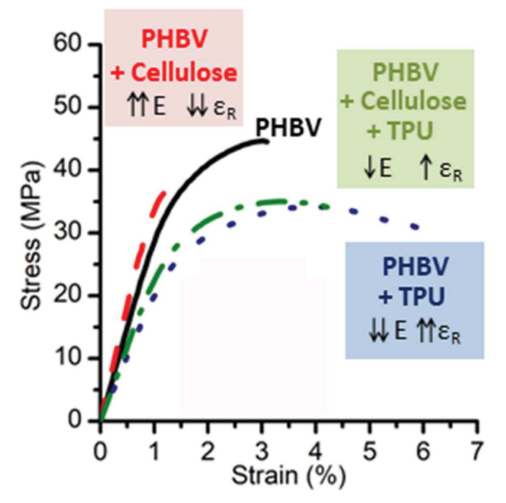

J. Appl. Polym. Sci. 2018, 47257. 


\begin{abstract}
Poly(hydroxybutyrate-co-hydroxyvalerate) (PHBV) is a biopolymer that has gained a lot of attention because of its biodegradability, good thermal resistance and balanced mechanical properties with respect to some commodity plastics. However, it presents two big limitations that hinder its potential application in replacing plastics for rigid injected parts: high cost and low toughness. Aiming at overcoming these limitations, the use of two additives in a PHBV matrix was explored: thermoplastic polyurethane (TPU) as an impact modifier and cellulose as reinforcing filler. Compounds of PHBV with different TPU and cellulose contents were prepared by extrusion and, subsequently, injection molding. The morphology, thermal and mechanical properties of the so-obtained materials were analyzed. Also, the biodisintegrability under standard composting conditions of the studied compositions was also assessed. The results of this work show that the obtained PHBV/TPU/Cellulose compounds are biodisintegrable and show balanced properties in terms of thermal resistance-stiffness-toughness. These properties point these compounds as potential candidates to replace commodities in rigid part applications that require biodesintegration in their end-of-life, being able to be processed in a conventional injection molding industrial facility.
\end{abstract}

\title{
V.1. Introduction
}

One of the most extended applications of polymeric materials are the injection molded rigid parts, for a wide range of products in automotive industry, domestic appliance, toys, biomedical, pack- aging, and so forth. Commonly used materials for injected applications include polypropylene (PP) and polystyrene (PS), high impact PS, or acrylonitrile-butadiene styrene $(A B S)$, and their use is widely extended because of their easily processing, low cost and overall mechanical properties (stiffness, tensile strength, and toughness), which makes them especially adequate for these type of applications. In addition, these materials usually have a high thermal resistance with heat deflection temperatures (HDTs) over 90 o $C$ that allow their use in applications where relatively high temperatures are required.

Nowadays there is an increasing interest in finding sustainable alternatives to these commodity polymers, in order to diminish the environmental impact associated to consumer products, and more specifically, the impact associated with their wastes. One of the most promising approaches driven to reduce the post-consumer plastics environmental impact is the use of 
biodegradable systems that enable their composting together with the organic fraction of the municipal wastes [1]. Polyhydroxyalkanoates (PHAs) are within the different biodegradable alternatives to rigid thermoplastics with a high HDT [2]. The PHAs are a family of bacterial polyesters that are biodegradable, biocompatible and non toxic [3-5]. In particular, poly(hydroxybutyrate-co-hydroxyvalerate) (PHBV), a thermoplastic copolyester from the PHAs family has gained a lot of attention because of its commercial availability, its physicochemical properties close to that of some of the commodities such as PP[6], because it can be processed using conventional thermoplastic equipment and have equilibrate mechanical properties in terms of stiffness and tensile strength. However, PHBV presents two big limitations that restrict its use in these type of applications: high cost and low toughness (low impact resistance) $[7,8]$.

With the aim of overcoming these two limitations, within an industrial approach, the addition of two different components to PHBV will be explored. In order to reduce the brittleness of PHBV, an elastomer as an impact modifier will be employed. Rubber toughening is one of the traditional approaches to improve toughness in brittle polymers consisting in the incorporation of a secondary dispersed elastomeric phase that acts as an impact modifier increasing the impactabsorbed energy of the resin [9]. This strategy has been recently applied in PHBV matrices using ethylene vinyl acetate [10], epoxidized natural rubber [11,12], poly(butadiene-coacrylonitrile)[13] or thermoplastic polyurethane (TPU) $[14,15]$ as the secondary elastomeric phase showing improvements in elongation at break and impact strength in different extents. In this work, an ester-based thermoplastic polyurethane (TPU) was studied as elastomer. The use of a TPU in a PHBV matrix has been previously studied by our group showing a great improvement in toughness maintaining the biodisintegrability in standard composting conditions of the final systems $[16,17]$. The addition of an elastomeric phase could lead to a reduction in the rigidity and the HDT of the system. That is why, the incorporation of a cheap reinforcing material such as cellulose could counterbalance this and contribute to the reduction of the final costs, preserving the sustainability of the final product [18]. The reinforcing material selected for the present study is a commercial purified alpha-cellulose that has demonstrated its efficiency in this system [19].

Thus, the purpose of this study is to verify that by making ternary blends based in PHBV with an impact modifier and a mechanical reinforcement component (TPU and cellulose in this case, respectively) the industrial applicability of PHBV in rigid part applications can be improved, even without the need of additional compatibilizers.

One issue that is commonly faced in polymer processing is the fact that the processing lab techniques (cast solvent, internal mixers, mini-extruders, etc.), like the ones used in the aforementioned earlier studies differ from the typical equipment used in industry, thus leading to 
different product properties. Therefore, in agreement with the objective of this work, all compounds were processed using conventional pilot plant scale and production-like conditions. Likewise, all the raw materials were chosen to be available commercially at large scale, so conclusions can be directly forwarded to industry.

\section{V.2. Experimental}

\section{V.2.1. Materials}

Poly(3-hydroxybutyrate-co-3-hydroxyvalerate) (PHBV) commertial grade with 3 wt\% valerate content was purchased from Tianan Biologic Material Co. (Ningbo, P.R. China) in pellet form (ENMAT Y1000P). Thermoplastic polyurethane (TPU) Elastollan ${ }^{\circledR} 890$ A $10 \mathrm{FC}$ was supplied by BASF (Germany). Purified alpha-cellulose fiber grade (TC90) from CreaFill Fibers Corp. (US) was used. According to the manufacturer's specifications, these fibers have an average fiber length of $60 \mu \mathrm{m}$ and an average fiber width up to $20 \mu \mathrm{m}$. The alpha-cellulose content is $>99.5 \%$.

\section{V.2.2. Sample preparation}

Before mixing, the three materials were dried. The PHBV and the TPU were dried at $80 \circ \mathrm{C}$ for at least $6 \mathrm{~h}$ in a DESTA DS06 HT Dehumidifier, whereas cellulose fibers were dried in laboratory oven (MEMMERT UNIVERSAL OVEN U) at 90ㄷ for a minimum of $16 \mathrm{~h}$..

PHBV/TPU/Cellulose blends (systems were prepared in a Labtech LTE ( $\varnothing=26 \mathrm{~mm}, \mathrm{~L} / \mathrm{D}$ ratio $=40$ ) co-rotating twin-screw extruder with a temperature profile from hopper to nozzle of $145 / 155 / 160 / 170{ }^{\circ} \mathrm{C}$ and $250 \mathrm{rpm}$ rotation speed. This profile is the one usually recommended for neat PHBV and all compounds were processed keeping the same conditions. All the components were manually premixed before extrusion (dry-blend) and fed to the main hopper by the extruder feeder at a speed of about $5 \mathrm{~kg} / \mathrm{h}$. The extruded material was cooled in a water batch and pelletized.

Material pellets were dry again $80{ }^{\circ} \mathrm{C}$ for $8 \mathrm{~h}$ (DESTA DSO6 HT) before injection process. Standardized tensile specimens (ISO-527 Type 1A) were injection molded in a DEMAG IntElect $100 \mathrm{~T}$ injection moulding machine ( 2 cavity mould), with an injection temperature of 185 o $\mathrm{C}$ at the nozzle. For neat PHBV, a holding pressure of 600 bar was applied for $12 \mathrm{~s}$, followed by 40 s of 
cooling time, being the mould temperature set at $60^{\circ} \mathrm{C}$. The same injection conditions were used for the rest of the compounds.

For the sake of comparison, neat PHBV was also processed under identical conditions to those of the different blends and composites.

Prior to any characterization all the samples were annealed at $80^{\circ} \mathrm{C}$ for 48 hours in order to obtain equivalent crystallinity and mechanical performance to aged samples.

Samples are named as $\mathrm{X} / \mathrm{Y} / \mathrm{Z}$ in the order PHBV/TPU/Cellulose were $\mathrm{X}, \mathrm{Y}$ and $\mathrm{Z}$ are the content of each component. The content of the additives TPU and Cellulose are expressed in phr refered to $100 \%$ PHBV matrix. As an example, the sample 100/30/10 corresponds to a weigth ratio of $100 \mathrm{~g}$ PHBV. with $30 \mathrm{~g}$ TPU and $10 \mathrm{~g}$ Cellulose. Table V.1 summarizes the compositions studied.

Table V.1. Compositions studied

\begin{tabular}{cccc}
\hline $\begin{array}{c}\text { Sample } \\
\text { PHBV/TPU/Cellulose (phr) }\end{array}$ & PHBV (\% wt) & TPU (\%wt) & Cellulose (\%wt) \\
\hline $\mathbf{1 0 0 / 0 / 0}$ & 100 & - & - \\
$\mathbf{1 0 0 / 1 0 / 0}$ & 90.9 & 9.1 & - \\
$\mathbf{1 0 0 / 3 0 / 0}$ & 76.9 & 23.1 & - \\
$\mathbf{1 0 0 / 0 / 1 0}$ & 90.9 & - & 9.1 \\
$\mathbf{1 0 0 / 0 / 3 0}$ & 76.9 & - & 23.1 \\
$\mathbf{1 0 0 / 1 0 / 1 0}$ & 83.3 & 8.3 & 8.3 \\
$\mathbf{1 0 0 / 1 0 / 3 0}$ & 71.4 & 7.2 & 21.4 \\
$\mathbf{1 0 0 / 3 0 / 1 0}$ & 71.4 & 21.4 & 7.2 \\
$\mathbf{1 0 0 / 3 0 / 3 0}$ & 62.5 & 18.7 & 18.7 \\
\hline
\end{tabular}

\section{V.2.3. Characterization}

The melt flow index (MFI) of the neat polymers and the different compounds was measured in a Tinius Olsen MP600 melt flow indexer according to ISO 1133 standard. The tests were performed at $185^{\circ} \mathrm{C}$ and $2.16 \mathrm{Kg}$ load.

Morphology of cellulose, neat PHBV, as well as the compounds were examined by scanning electron microscopy (SEM) using a high-resolution field-emission JEOL 7001F microscope. The 
fracture surfaces from impact-fractured specimens were coated by sputtering with a thin layer of Pt prior to SEM analysis. The size distribution of the dispersed phase of the blends was evaluated with ImageJ software (the number of spheres measured was in all cases $>600$ )

Tensile tests were conducted on ISO-527 type $1 \mathrm{~A}$ injection molded specimens in a universal testing machine Hounsfield H25K equipped with a $25 \mathrm{kN}$ load cell according to ISO-527-1:2012 standard.

Notched and unnotched Charpy impact tests were carried out by means of an ATS faar IMPats-15 impact pendulum with a 4J hammer according to ISO 179 standard. Samples were cut form injection molded bars.

Shore $D$ hardness of the obtained blends and composites was measured in a Zwick 3100 Shore D tester (Zwick GmbH, Germany).

Differential scanning calorimetry (DSC) experiments were conducted on a TA Instruments Q100 model calibrated with Indium and sapphire standards before use. Samples with a typical weight of 6-8 $\mathrm{mg}$ were obtained from injection molded specimens. Samples were first heated from $-40 \circ \mathrm{C}$ to $210^{\circ} \mathrm{C}$ at $10^{\circ} \mathrm{C} / \mathrm{min}$ and maintained 2 minutes to erase thermal history, cooled down to -40 ㅇ C and subsequently heated to $210 \stackrel{\circ}{\circ} \mathrm{C}$ at $10 \circ \mathrm{C} / \mathrm{min}$. Melting temperatures $\left(\mathrm{T}_{\mathrm{m}}\right)$ and enthalpies $\left(\Delta H_{m}\right)$, as well as crystallization temperatures $\left(T_{c}\right)$ and enthalpies $\left(\Delta H_{c}\right)$, were calculated from the second heating and cooling curves, respectively. The crystallinity $\left(X_{c}\right)$ of the PHBV phase of blends and composites was determined by applying the following expression [20]:

$$
X_{c}(\%)=\frac{\Delta H_{m}}{w \cdot \Delta H_{m}^{0}} \times 100
$$

Where $w$ is the PHBV weight fraction in the blend, $\Delta \mathrm{H}_{m}(\mathrm{~J} / \mathrm{g})$ is the melting enthalpy of the polymer matrix, and $\Delta \mathrm{H}^{\circ}{ }_{m}$ is the theoretical melting enthalpy of $100 \%$ crystalline PHB (perfect crystal) (146 J/g) [21]. This value is considered a good approximation for PHBV due to its low HV content [22]

Thermogravimetric analysis (TGA) of cellulose, as well as the PHBV, TPU and the compounds (from injection molded parts), were performed with a TG-STDA Mettler Toledo model TGA/STDA851e/LF/1600 analyzer. The samples with an initial mass of typically about $15 \mathrm{mg}$ were heated from 30 to $900^{\circ} \mathrm{C}$ at a heating rate of $10^{\circ} \mathrm{C} / \mathrm{min}$ under nitrogen flow. The thermal stability of cellulose, neat polymers and the blends and composites was evaluated and the residue at $900{ }^{\circ} \mathrm{C}$ was determined. The onset decomposition temperature (T5\%, temperature at $5 \%$ weight 
loss) and the maximum decomposition rate temperature (Td) were determined from the weight loss curve and the maximum value of weight loss derivative, respectively.

Heat deflection temperature (HDT) analyses were performed using a Deflex 687-2. A heating rate of $120^{\circ} \mathrm{C} / \mathrm{h}$ was used with an applied load of $1.8 \mathrm{MPa}$ in accordance with Method A of ISO 75 standard. Temperature signal was recorded until the sample deflects $0.35 \mathrm{~mm}$.

Disintegration tests were carried out with samples of $\left(15 \times 15 \times 0.2 \mathrm{~mm}^{3}\right)$ obtained from hot pressed plates (180ㄷ, $5 \mathrm{~min}$ and c.a. 40 bar). Tests were performed according to the ISO 20200 standard [23]. Solid synthetic waste was prepared by mixing $10 \%$ of activated mature compost (Vigorhumus H-00, purchased from Burás Profesional, S.A., Girona, Spain), 40\% sawdust, 30\% rabbit feed, $10 \%$ corn starch, $5 \%$ sugar, $4 \%$ corn seed oil and $1 \%$ urea. The water content of the mixture was adjusted to $55 \%$. The samples were placed inside mesh bags to simplify their extraction and allow the contact of the compost with the specimens, then buried in compost bioreactors at 4-6 cm depth. Bioreactors were incubated at 58으. The aerobic conditions were guaranteed by mixing the synthetic waste periodically and adding water according to the standard requirements. Three replicates of each sample were removed from the boxes at different composting times for analysis. Samples were washed with water and dried under vacuum at $40^{\circ} \mathrm{C}$ until a constant mass. The disintegration degree was calculated by normalizing the sample weight to the initial weight with equation (2):

$D=\frac{m_{i}-m_{f}}{m_{i}} \times 100$

where $m_{i}$ is the initial dry mass of the test material and $m_{f}$ is the dry mass of the test material recovered at different incubation stages. The disintegration study was completed by SEM micrographs of the disintegrated surface and by taking photographs for visual evaluation.

\section{V.3. Results and discussion}

\section{V.3.1. Samples processability}

Figure V.1 indicates the MFI values for the different blends, neat PHBV (previously processed at the same conditions than the blends to keep the same thermomechanical history) and raw TPU, measured at $185^{\circ} \mathrm{C}$. As a reference, it is considered that a value of MFI of 7 is enough to be able to fill by injection moulding process medium to high size parts. Results indicate that in all PHBV compositions the MFI is kept over this value, except on those formulations containing $30 \mathrm{phr}$ 
cellulose. The addition of $10 \mathrm{phr}$ TPU leads to an increase in the MFI values, but it does not increase any further when it is added at a higher load (30 phr). In any case the MFI variations are not critical at the procecessing conditions applied (see experimental section). All the compounds have been successfully obtained without needing any modification of the processing parameters and without producing significant degradation from their processability point of view (see TGA section).

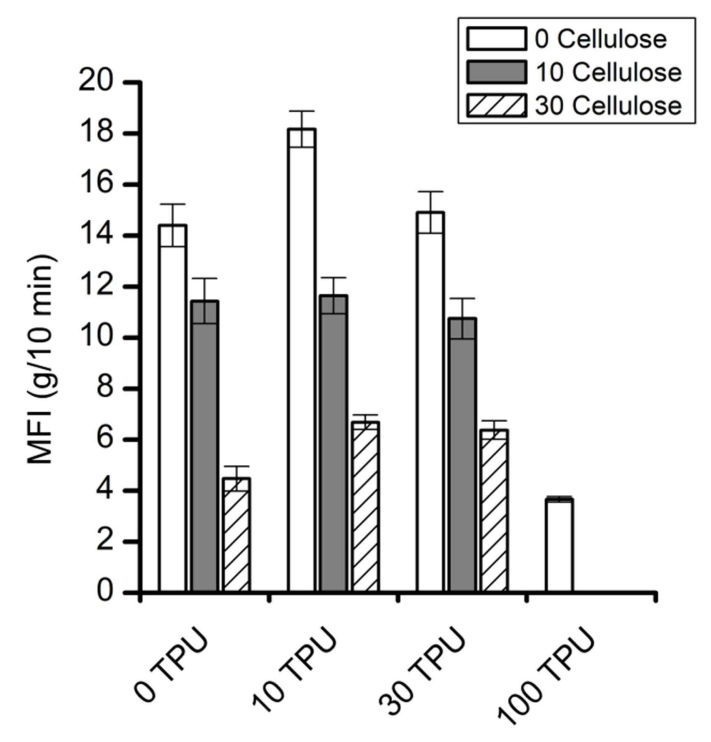

Figure V.1. Melt flow index (MFI) of neat PHBV and TPU and the PHBV/TPU/Cellulose compositions

\section{V.3.2.Blends and composites morphology}

The morphology of the cellulose fibers, the PHBV/TPU, PHBV/Cellulose and PHBV/TPU/cellulose blends has been examined by SEM. The TPU particle size, shape and their distribution in the blends have been analyzed, being the results summarized in Figure V.2 (for both systems, without and with cellulose).

The dominant morphology can be described, in all cases, as a two-phase morphology, revealing an immiscible polymeric system with a characteristic discrete-phase structure (DPS, or drop in matrix). The TPU appears as small spherical droplets in all the studied compositions, being homogeneously dispersed into the PHBV matrix. The sphere size frequency histograms, the d10, 
d50 and d90 values (i.e, the size under which 10, 50 or $90 \%$ of the particle distribution, respectively, lies) and representative micrographs are shown in Figure V.2

An increase in the size of the elastomeric droplets as the TPU content is increased is observed. The analysis of the results reveals that the distribution size is wider in the samples with the highest TPU content. The differences in size are principally detected in the d90 value, while d10 and $\mathrm{d} 50$ values remain practically unchanged for all the compositions. Hence, a considerable increase of $35 \%$ in d90 is found for blends with high TPU content, resulting in droplets with sizes above $1.5 \mu \mathrm{m}$. This fact might be ascribed to a coalescence phenomenon due to the low melt viscosity of the PHBV and the higher content or TPU.

The incorporation of the cellulose fibers in PHBV/TPU blends leads to a reduction in the size of the droplet disperse phase. For the sample 100/10/10, the average droplet size is reduced from $0.5 \mu \mathrm{m}$ to $0.3 \mu \mathrm{m}$ with the introduction of $10 \mathrm{phr}$ cellulose, finding a similar value of about $0.3 \mu \mathrm{m}$ for $100 / 10 / 30$. However, the most visible change in the droplet size is found for the $d 90$, where a decrease to almost half is detected for both 10 and $30 \mathrm{phr}$ cellulose. A similar trend is also found for the sample with highest TPU content. The reduction of the sphere size with the incorporation of the fillers can be explained by either the highest melt viscosity of the compositions (according with the lower MFI values, shown in Fig V.1), the effect of the fibers limiting the extent of coalescence, the droplet confinement and break due to the presence of fibers or because of the differences in local shearing during processing.

With respect to the interface of the TPU particles in the PHBV matrix, during SEM analysis it was observed that some of the droplets are partially covered by PHBV, as in Fig. V.2b -100/30/0 (thus indicating a coherent interface, in agreement with the good distribution of the TPU). However, detachment of the spheres is also detected in all compositions studied. These apparent contradictory observations may have its origin in the mode of failure of the specimens prior to SEM analysis, which were obtained after impact testing, as it will be discussed later on. 
a)
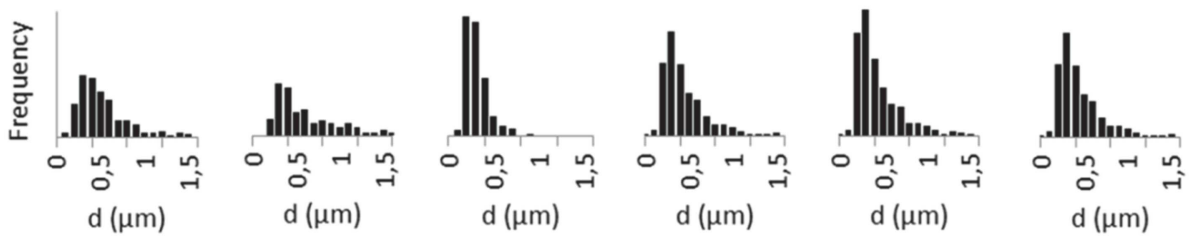

b)
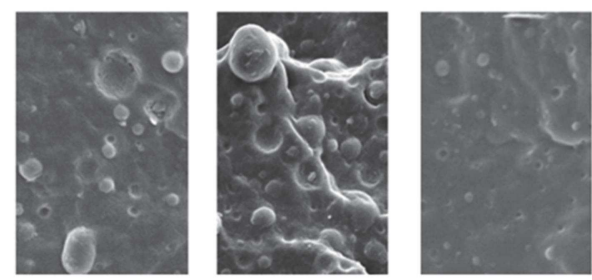

c) 1,2

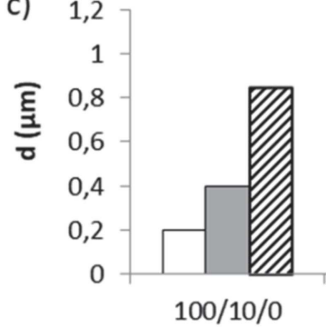

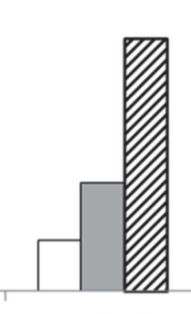

$100 / 30 / 0$
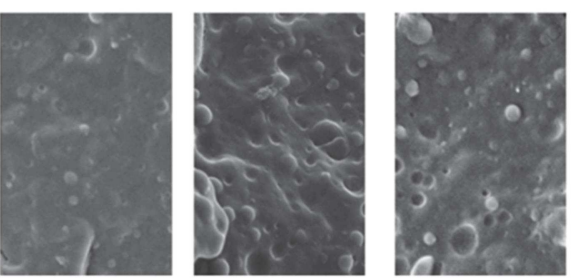

$1 \mu \mathrm{m}-$

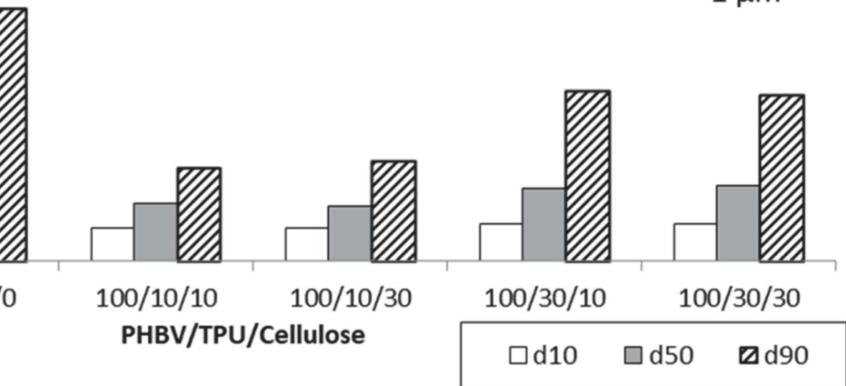

Figure V.2. Sphere size frequency histograms (a), representative micrographs of the drop-in-matrix morphology (b), and d10, d50 and d90 values of the TPU drops (c) for the PHBV/TPU/Cellulose blends

With respect to the fillers, Figure V.3 presents the SEM micrograph of the cellulose fibers. As shown, the cellulose fibers present a rod-shaped morphology with varying lengths up to $200 \mu \mathrm{m}$. The diameter of the fibers is in the 5-20 $\mu \mathrm{m}$ range and their average aspect ratio is of c.a.10. Figure V.4 present the morphology of the impact-fractured surfaces of different compounds. 


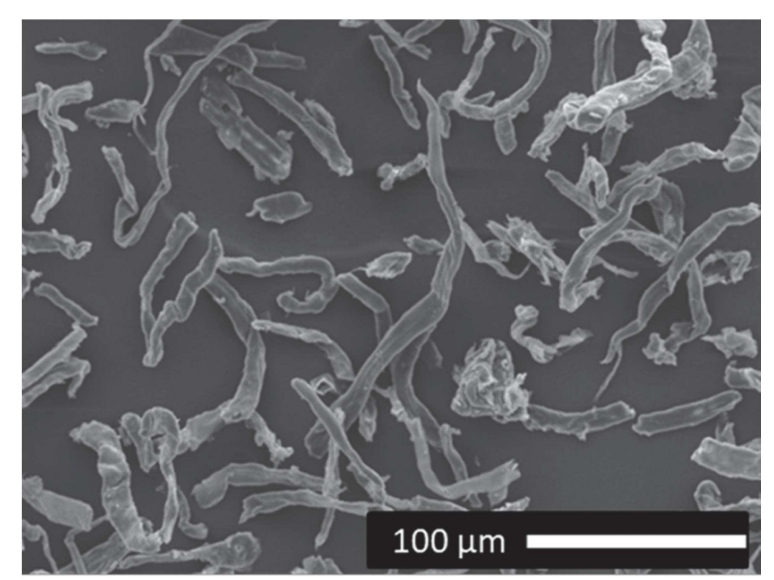

Figure V.3. SEM micrograph of cellulose fibers

Figure V.4a and Figure V.4b show representative low magnification images corresponding to PHBV/Cellulose composites with 10 and $30 \mathrm{phr}$ cellulose content, respectively, and a detail of the fiber/matrix interface. Even at high cellulose content formulations, homogeneous distribution of the fibers was observed. The presence of fiber aggregates has not been detected and the individual fibers appear homogeneously distributed throughout the polymer matrix, thus confirming that an effective compounding has been achieved. Similar trend was observed in PHBV/TPU/Cellulose composites. In order to analyze the interaction between the polymer and the cellulose fibers, high magnification micrographs of all PHBV/cellulose and PHBV/TPU/cellulose composites were used (Fig.V.4c-f). Broken fibers have been detected in all compositions, thus revealing some degree of interaction between the cellulose and the biopolyesters. This is in agreement with previous results [19] and could be attributed to the formation of a hydrogen-bonding-type interaction between carbonyl groups of PHBV and hydroxyl groups of the cellulose [24]. However, when analyzing the interphase, as for the TPU second phase, some detachment is also detected at some point, revealing a weak interphase interaction. 

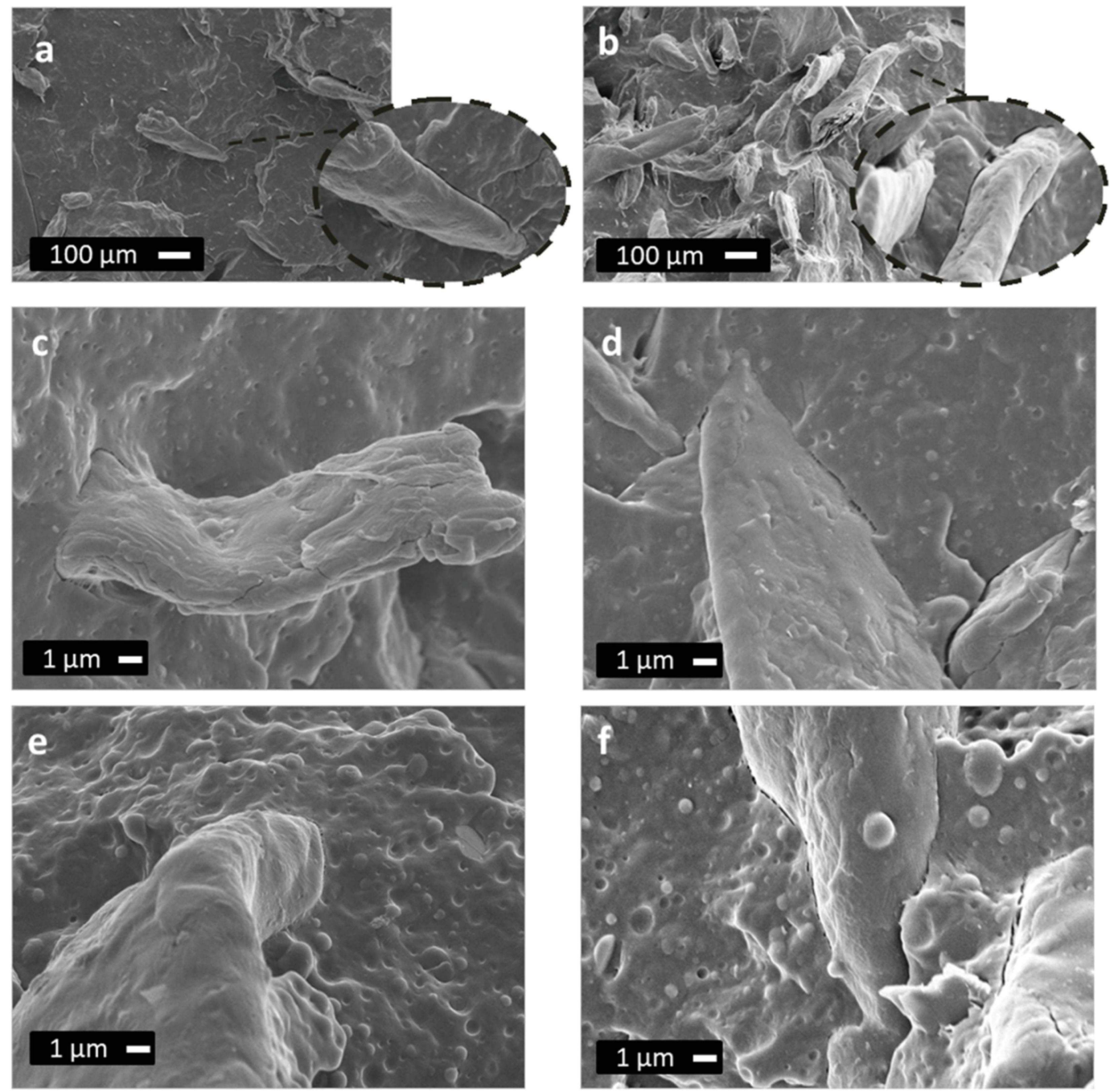

Figure V.4. SEM micrographs of PHBV/TPU/Cellulose blends: a)100/0/10, b)100/0/30, c)100/10/10, d) $100 / 10 / 30 ;$ e) $100 / 30 / 10$ and f) $100 / 30 / 30$

\section{V.3.3. Mechanical properties}

The mechanical properties of the neat PHBV and the blends with TPU and Cellulose have been evaluated by tensile tests up to failure. Young's modulus, maximum tensile strength and elongation at break of all compositions are gathered in Figure V.5. A representative stress-strain 
curve of neat PHBV and the blends containing the highest amount of TPU and/or Cellulose (30 phr), are also depicted in Figure V.5 (d) for clarification.
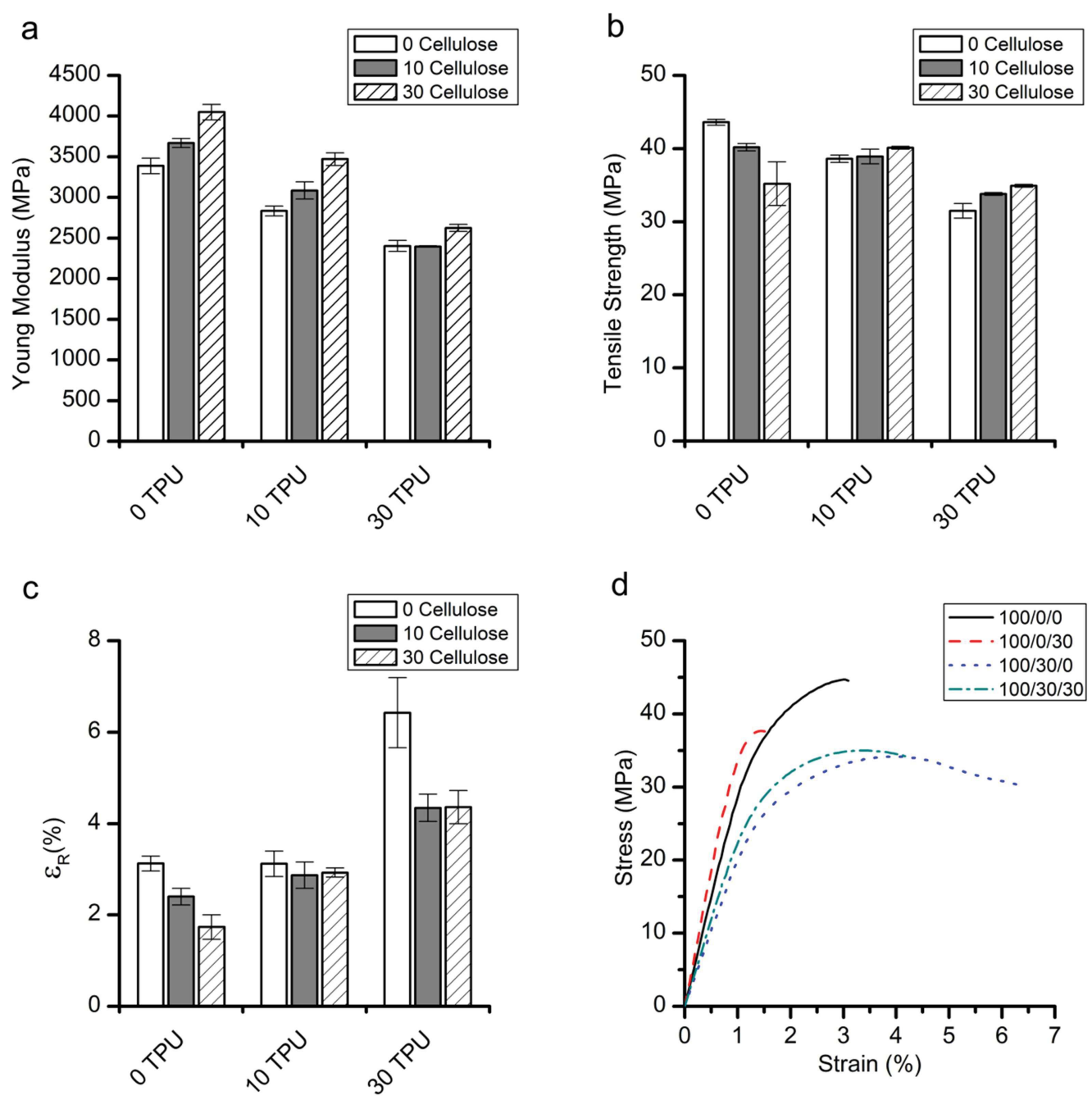

Figure V.5. Mechanical properties of the neat PHBV and PHBV/TPU/Cellulose blends. a) Young's modulus, b) tensile strength, c)elongation at break and d) representative stress-strain curves of neat PHBV and the binary and ternary systems containing the highest amount of additives TPU and/or Cellulose ( $30 \mathrm{phr}$ ) 
As it could be expected, the incorporation of TPU resulted in a reduction in the rigidity and tensile strength of the blend, along with an increase in the elongation at break and tensile static toughness, estimated from the area under the stress-strain curves (Figure V.6c). Thus, the tensile modulus of elasticity decreased from ca.3.4GPa for pristine PHBV to about 2.5GPa for the highest TPU content blend, the decrease being dependent on the TPU content. On the other hand, the incorporation of $30 \mathrm{phr}$ TPU supposed an increment of the elongation at break of $105 \%$ with respect to neat PHBV. This improvement is in accordance with other works reported in literature of PHBV/TPU blends with the same range of composition [17,25]. With respect to the static toughness, the TPU has a clear toughening effect resulting in almost a two-fold increase in the area beneath the stress-strain curve.

On the contrary, the incorporation of the cellulose fibers to the PHBV matrix results in an increase of the Young's modulus, showing a reinforcing effect, positively dependent upon the filler content. Concurrently, a reduction of the elongation-at-break and the static toughness with the cellulose content is also registered, thus revealing an embrittlement of the samples. The reduction in the ductility of the compound is such that the breaking takes place before yielding and, consequently, the tensile strength is also reduced with the incorporation of the fiber. This embrittlement can be explained in terms of a limited interaction between the fibers and the matrix. At small deformations there is a positive reinforcement effect, with an increase in elastic modulus. But once the strain overcomes a certain value, within the elastic deformation range, a detachment of the fiber occurs generating a void between the fiber and the polymer matrix, a flaw that can easily act as crack initiator, causing premature material failure $[12,26]$. Once the crack is nucleated, its propagation is straightforward throughout the PHBV matrix due to its intrinsic fragility.

The incorporation of cellulose fibers to PHBV/10TPU blends, thus obtaining the 100/10/10 and $100 / 10 / 30$ ternary systems, produces an increase in Young's modulus and tensile strength with respect to the unfilled blend, whereas their values of elongation at break remain practically unchanged. It is interesting to note that the composition 100/10/30 present similar overall mechanical properties than neat PHBV. With respect to the highest TPU content blends, the incorporation of the cellulose fibers did not result in a significant increase in the Young's modulus or tensile strength, while yielding in a reduction in elongation at break with respect to unfilled blends. However, when compared to the neat PHBV, there is a reduction in rigidity (about 25\%) but an enhancement in elongation at break (c.a. 40\%) and static toughness ( 25 and $32 \%$ for the 10 and 30 phr cellulose, respectively). 


\section{V.3.4. Impact test}

One of the key limitations for the use of PHBV for injection molded rigid parts is its relative low toughness when compared to oil-based counterparts (i.e.: ABS and PP). The strategy considered in the present work is the addition of an ester-based biodegradable TPU as impact modifier. Notched and unnotched Charpy impact tests were conducted on PHBV, PHBV/TPU and cellulosecontaining blends. The results of Charpy impact tests and the static toughness (as obtained from the area below the strain-stress curve) are summarized in FigureV. 6.

a)

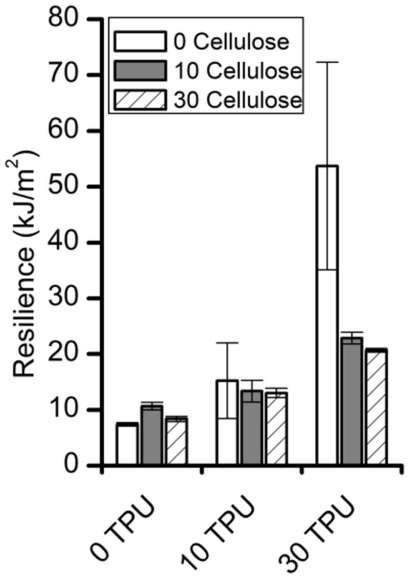

b)

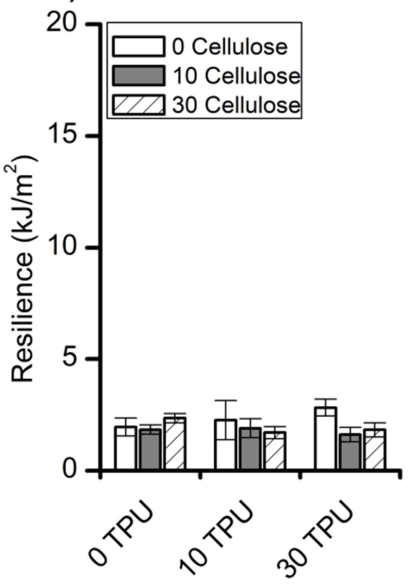

c)

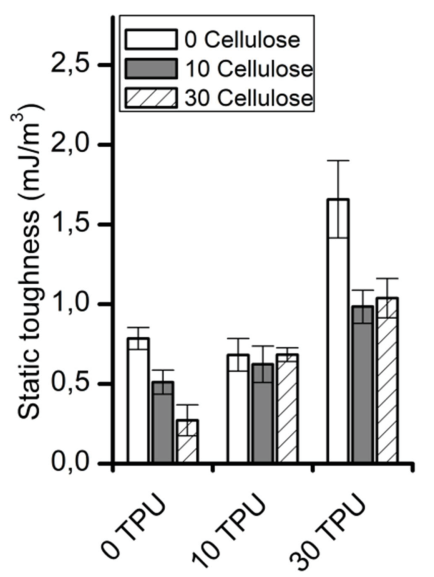

Figure V.6. Charpy impact results for unnotched specimens (a), notched specimens (b) and static toughness from the area below the strain-stress curve (c).

From data shown in Fig. V.6a, it can be deduced that the incorporation of TPU to the PHBV enhances the capacity of the blends to absorb impact energy. Hence, the resilience increase with the incorporation of the elastomer rises from 7.38 to $10.64 \mathrm{~kJ} / \mathrm{m}^{2}$ for $10 \mathrm{phr}$ TPU content and further up to $53.71 \mathrm{~kJ} / \mathrm{m} 2$ for $30 \mathrm{phr}$ TPU content. This trend is in agreement with the improvement in the static toughness, as obtained by tensile tests (Fig. V.6c). The good dispersion of the elastomeric phase in the PHBV observed in SEM images (Fig V.2b) could be the responsible of the good delivery of the stress and thus the enhancement of toughness [25].

However, the resilience values for the notched specimens are way below the unnotched ones; for instance, when comparing the neat PHBV with and without notch, the difference is of an order of magnitude. This evidences that the presence of a flaw (by means of the notch) plays a critical role 
in the impact strength of these materials. This behavior can be attributed to the intrinsic fragility of the PHBV (i.e. low tolerance to the presence of flaws), in the way that the crack propagation takes place without noticeable yielding of the matrix. For the notched compositions incorporating TPU, the toughening effect does not seem to be as effective as for the unnotched ones; thus confirming the crack preferential propagation pathway throughout the PHBV matrix. Moreover, attending to the SEM micrographs of the impact-fractured surfaces of the polymer blends (shown in Fig. V.2), the propagation of the crack occurs across the PHBV and through the TPU PHBV interphase, resulting in the observed detachment of the TPU particles. This fact evidences that the interfacial adhesion between both polymers is not very strong, limiting the reinforcement ability of the elastomeric phase when stress raisers, such as notches, are present in the samples.

The incorporation of the cellulose to the pure PHBV did not affect significantly the resilience of the polymer regardless the filler content, whether the tests were conducted with or without notch. For the ternary compounds, the toughening effect of the TPU is partially compromised by the presence of the cellulose, being this effect more remarkable for those with $30 \mathrm{phr}$ TPU. The reason behind this trend can be found in the detachment of the cellulose fibers during elastic deformation, which may act as flaws, as previously discussed in the mechanical properties section.

\section{V.3.5. Hardness}

Shore D hardness of neat PHBV and the developed compounds has been assessed. The results (summarized in Table V.2) are in accordance with the rigidity of the different compositions, i.e. a decrease with the incorporation of the TPU and a reinforcing effect provided by the cellulose.

Table V.2. Shore D hardness of the studied compositions

\begin{tabular}{ccc}
\hline PHBV/TPU/Cellulose & Shore D & STD.DEV. \\
\hline $\mathbf{1 0 0 / 0 / 0}$ & 81,3 & 1,0 \\
$\mathbf{1 0 0 / 1 0 / 0}$ & 77,9 & 1,4 \\
$\mathbf{1 0 0 / 3 0 / 0}$ & 75,6 & 1,1 \\
$\mathbf{1 0 0 / 0 / 1 0}$ & 83,4 & 1,3 \\
$\mathbf{1 0 0 / 0 / 3 0}$ & 84,4 & 1,1 \\
$\mathbf{1 0 0 / 1 0 / 1 0}$ & 80,7 & 0,9 \\
$\mathbf{1 0 0 / 1 0 / 3 0}$ & 82,5 & 0,5 \\
$\mathbf{1 0 0 / 3 0 / 1 0}$ & 75,6 & 1,2 \\
$\mathbf{1 0 0 / 3 0 / 3 0}$ & 78,6 & 1,6 \\
\hline
\end{tabular}




\section{V.3.6. DSC}

The thermal behavior of neat PHBV and the prepared blends are studied by DSC. The melting and crystallization enthalpies $\left(\Delta \mathrm{H}_{\mathrm{m}}\right.$ and $\left.\Delta \mathrm{H}_{\mathrm{c}}\right)$, characteristic temperatures $\left(T_{m}\right.$ and $\left.T_{c}\right)$, and the crystallinity $\left(X_{c}\right)$ are summarized in Table V.3.

Table V.3. DSC data of PHBV/TPU/Cellulose compounds.

\section{DSC parameters}

\begin{tabular}{|c|c|c|c|c|c|}
\hline PHBV/TPU/Cellulose & $\Delta H_{m}(J / g)$ & 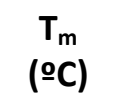 & $\Delta H_{c}(\mathrm{~J} / \mathrm{g})$ & $\begin{array}{c}T_{c} \\
\text { (oC) }\end{array}$ & $x_{c}(\%)$ \\
\hline $100 / 0 / 0$ & 94.1 & 173.9 & 86.7 & 119.4 & 64.5 \\
\hline $100 / 10 / 0$ & 80.8 & 171.2 & 74.8 & 110.3 & 60.9 \\
\hline $100 / 30 / 0$ & 67.2 & 170.2 & 61.9 & 105.6 & 59.9 \\
\hline $100 / 0 / 10$ & 85.4 & 173.8 & 77.9 & 121.1 & 64.4 \\
\hline $100 / 0 / 30$ & 74.6 & 172.7 & 67.9 & 119.9 & 66.4 \\
\hline $100 / 10 / 10$ & 75.8 & 173.5 & 70.7 & 111.5 & 62.4 \\
\hline $100 / 10 / 30$ & 66.3 & 172.4 & 60.8 & 109.6 & 63.7 \\
\hline $100 / 30 / 10$ & 61.5 & 169.7 & 56.5 & 107.0 & 59.0 \\
\hline $100 / 30 / 30$ & 57.8 & 170.9 & 53.3 & 107.0 & 63.4 \\
\hline
\end{tabular}

DSC results reveal that the addition of TPU to PHBV produces a slight decrease in both crystallinity and melting and crystallization temperatures of the blends in the composition range studied indicating that this component affects the crystallization process. These findings are in accordance with the previous works about PHBV/TPU blends reported in literature[15,17,25]. Such behavior can be explained by the inter-molecular interactions (i.e. dipole-dipole) between the phases in the liquid state, introducing some disorder in the system, which would be hampering the crystallization. Once crystallization takes place, the TPU phase is excluded from the crystals, giving a final completely segregated morphology. The addition of $10 \mathrm{phr}$ cellulose content to PHBV practically does not change neither the crystallization/melting temperatures nor the crystallinity index. A minimum increase in crystallinity has been found for the highest filler content (100/0/30) with respect to neat PHBV and in the ternary systems with respect to the 
unfilled PHBV/TPU compositions. However, in agreement with other studies, such small differences in crystallinity are not attributed to a nucleating effect of the cellulose [19, 27-29].

\section{V.3.7.TGA}

The thermal degradation behavior of neat PHBV, TPU, cellulose and their compounds was studied by thermogravimetric analysis. The TGA and their first derivatives curves are depicted in Figure V.7. The onset degradation temperature $\left(T_{5 \%}\right)$, the maximum degradation temperature $\left(T_{d}\right)$ and the weight residue at $600^{\circ} \mathrm{C}$ are summarized in Table V.4.

Table V.4. TGA data of PHBV/TPU/Cellulose compounds.

TGA parameters

\begin{tabular}{|c|c|c|c|}
\hline PHBV/TPU/Cellulose & $\mathrm{T}_{5 \%}(\mathrm{o} \mathrm{C})$ & $T_{d}(\circ C)$ & $\begin{array}{c}\text { Residue at } 600 \circ \mathrm{C} \\
\text { (\%) }\end{array}$ \\
\hline $100 / 0 / 0$ & 279 & 299 & 1.4 \\
\hline $100 / 10 / 0$ & 278 & 297 & 1.8 \\
\hline $100 / 30 / 0$ & 278 & 295 & 2.5 \\
\hline $100 / 0 / 10$ & 276 & 297 & 1.9 \\
\hline $100 / 0 / 30$ & 271 & 291 & 3.3 \\
\hline $100 / 10 / 10$ & 275 & 294 & 3.7 \\
\hline $100 / 10 / 30$ & 271 & 290 & 5.0 \\
\hline $100 / 30 / 10$ & 276 & 291 & 4.9 \\
\hline $100 / 30 / 30$ & 273 & 289 & 6.8 \\
\hline $0 / 100 / 0$ & 315 & 385 & 6.6 \\
\hline $0 / 0 / 100$ & 278 & 347 & 14.5 \\
\hline
\end{tabular}




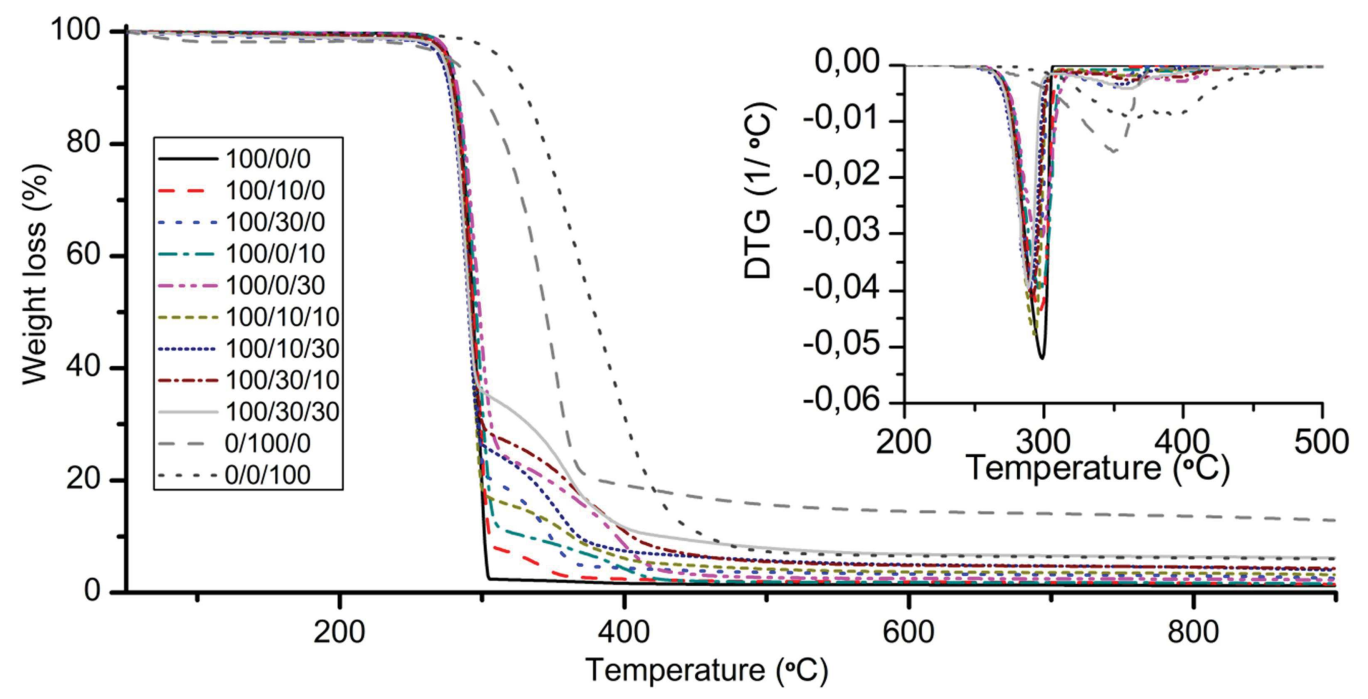

Figure V.7. TGA and DTG (inset) curves of neat PHBV, TPU and Cellulose and PHBV/TPU/Cellulose systems

As it is well reported, PHBV thermal degradation takes place abruptly in a single weight loss step by the chain scission reaction mechanism [30] with an onset at $279 \circ \mathrm{C}$ and the maximum degradation temperature at $299 \stackrel{\circ}{\circ}$. Cellulose thermal degradation also takes place in a single weight loss step around $347^{\circ} \mathrm{C}$, with a residue of $14.47 \%$ at $600 \circ \mathrm{C}$, in agreement with previous works [19,31]. Thermal degradation of TPU occurs between 300 and $450 \circ \mathrm{C}$ with a residual weight of about $6.5 \%$ at $600^{\circ} \mathrm{C}$. TPU DTG curve presents two peaks at 368 and $389{ }^{\circ} \mathrm{C}$ and a shoulder at around $425 \circ \mathrm{C}$. The first step of degradation is attributed to the scission of the urethane bond and to the release of the smaller molecules or unstable side chains followed by the chain scission at the $\beta$-position to the carbon-carbon double bond $[32,33]$

PHBV/TPU blends showed two degradation stages, of which the first stage was ascribed to the PHBV degradation while the second stage was from TPU degradation. The onset and maximum degradation temperatures of the blends with 10 and 30 phr TPU content are comparable to those corresponding to neat PHBV indicating that the presence of this component does not affect the thermal stability of PHBV, as it has been previously reported [17]. PHBV/Cellulose and PHBV/TPU/Cellulose compounds present two and three degradation steps respectively, according with the decomposition of their respective components. The incorporation of the cellulose fibers slightly decreases both the onset and maximum degradation temperatures, especially for the highest cellulose content (30 phr), in agreement with others works [19,34]. 


\section{V.3.8. HDT}

Heat deflection temperature represents the temperature at which the material losses its bearing load capacity and is a good parameter to predict the thermal resistance and dimensional stability of the materials in service. Figure V.8 shows the HDT-A of neat PHBV and the developed blends and composites.

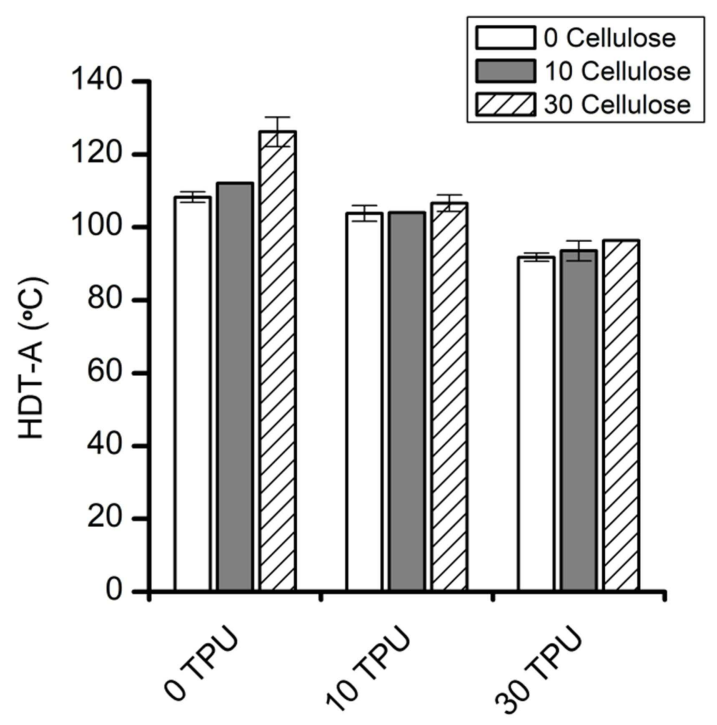

Figure V.8. HDT-A of neat PHBV and the PHBV/TPU/Cellulose blends

Neat PHBV presents a HDT-A at $108^{\circ} \mathrm{C}$. Cellulose addition improves this value up to $126^{\circ} \mathrm{C}$ for the highest content. Similar results were found in bibliography for neat PHBV and lignocellulosic based composites $[26,35,36]$. The improvement in HDT-A with the cellulose addition could be explained by the reinforcing effect induced by the fibers. Also, the increased crystallinity observed by the nucleating effect of the fibers may contribute to rise the HDT-A of the composites [12,35]. On the contrary, TPU incorporation produces a decrease of the HDT-A. Nevertheless, in spite of the negative impact of TPU in the thermal resistance of PHBV, the HDT-A remains in interesting values beyond $90^{\circ} \mathrm{C}$, and the incorporation of the cellulose to PHBV/TPU blends allows almost recover the HDT-A values to that of the neat PHBV. It is interesting to note that the thermal resistance of the blends and composites obtained is really superior to that 
corresponding to other common biopolymers (e.g. the HDT-A of Amorphous PLA, the main competitor of PHBV, is of c.a. 55으 [37])

\section{V.3.9. Disintegrability in composting conditions}

PHBV and PHBV/TPU/Cellulose disintegration in composting conditions was evaluated according to the ISO 20200 standard. The disintegration rate was determined by measuring the weight loss of the samples as a function of composting time. Results are represented in Figure V.9.

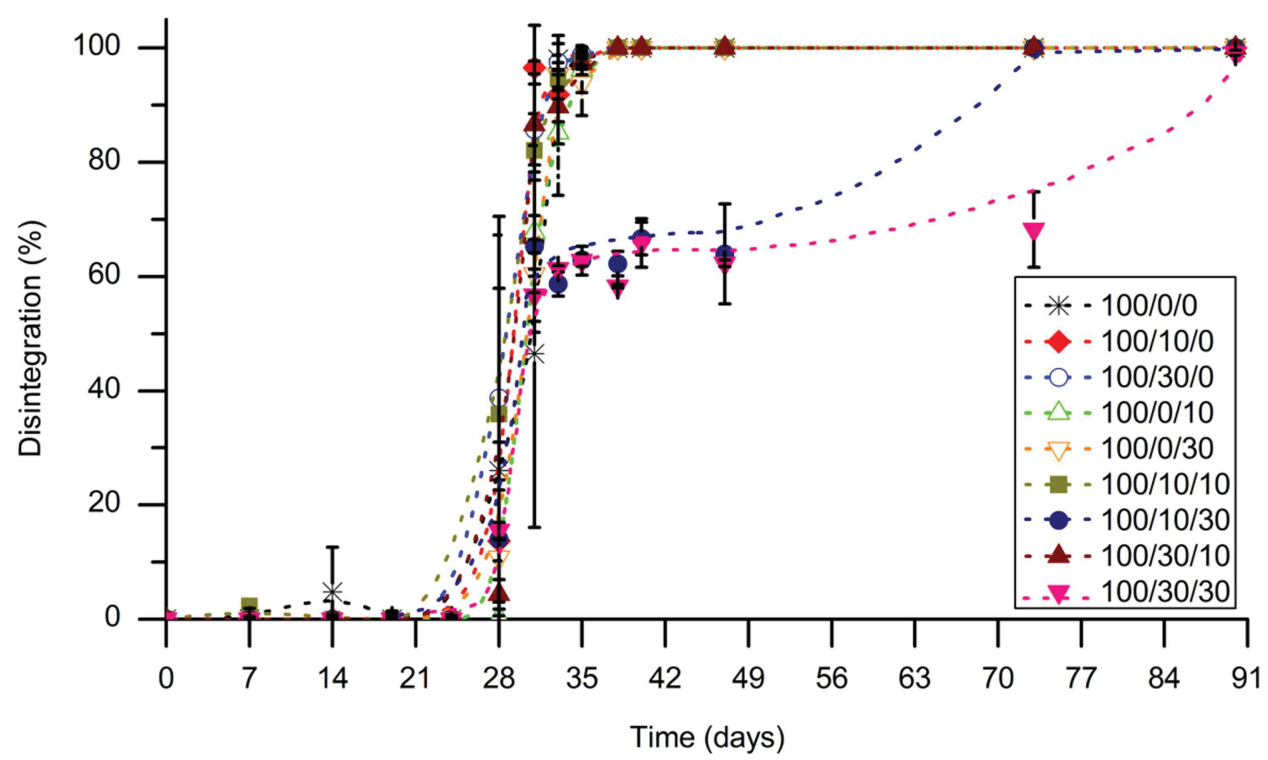

Figure V.9. Disintegration of neat PHBV and PHB/TPU/Cellulose systems over time under composting conditions

No appreciable weight loss was detected for any sample until the $28^{\text {th }}$ day of composting, thus revealing an induction period for the disintagration to take place. From that day onwards, no differences in the biodisintegrability behavior (i.e. full biodisintegration achieved before 40 days in agreement with literature reports [17]) has been detected in the studied samples with the exception of the ternary blends containing $30 \mathrm{phr}$ cellulose. No slowdown on the biodisintegration rate was found for the TPU containing samples regardless the slower biodegradation rate of the TPU under composting conditions when compared to PHBV or cellulose $[17,38,39]$. For the samples containing $30 \mathrm{phr}$ cellulose, a disintegration level around 60- 
$70 \%$ was reached at 30 days of composting (corresponding to approximately the PHBV content in the sample). At this point, the weight loss remains practically constant until 50 days of composting. Thus, in a last stage, the disintegration rate increases to achieve total disintegration at 73 days and 90 days for the compositions containing $10 \mathrm{phr}$ and $30 \mathrm{phr}$ TPU respectively. The slower biodisintegration rate of the high cellulose content composition may be seemed as counterintuitive (being the cellulose known as an easy biodegradable material), nevertheless the reason behind this behavior could be related to a formation of a percolative structure of cellulose fibers together with the TPU that hinders the biodeisintegration. The biodisintegration process starts from the surface [40-42] and advances primarily through the PHBV phase, thus leaving an interconnected fiber / TPU structure (see Figure V.10).

Photographs at different composting times were taken in order to assess the impact of composting process on the tested samples. The photographs are shown in Figure V.11.

Considerable surface erosion and fractures are found after 28 days in composting and after 35 days the samples are broken into small pieces, except for the triple systems 100/10/30 and $100 / 30 / 30$. As it has been discussed previously, the particular morphology of these samples causes a slowing down of the disintegration rate. For these samples, although color changes are detected from 35 days in compost, no clear surface damage is observed until 47 days of composting where disintegration rates increases.

Except for the 100/10/30 and 100/30/30 systems the rates and time periods of disintegration of the studied samples are within the same range of the values reported in literature for different PHA based materials [17,41-44]. In adition, , regardless of the rate of disintegration, all systems have reached more than $90 \%$ disintegration within the period of time established in ISO 20200 , so they can be considered biodisintegrable under composting conditions. 

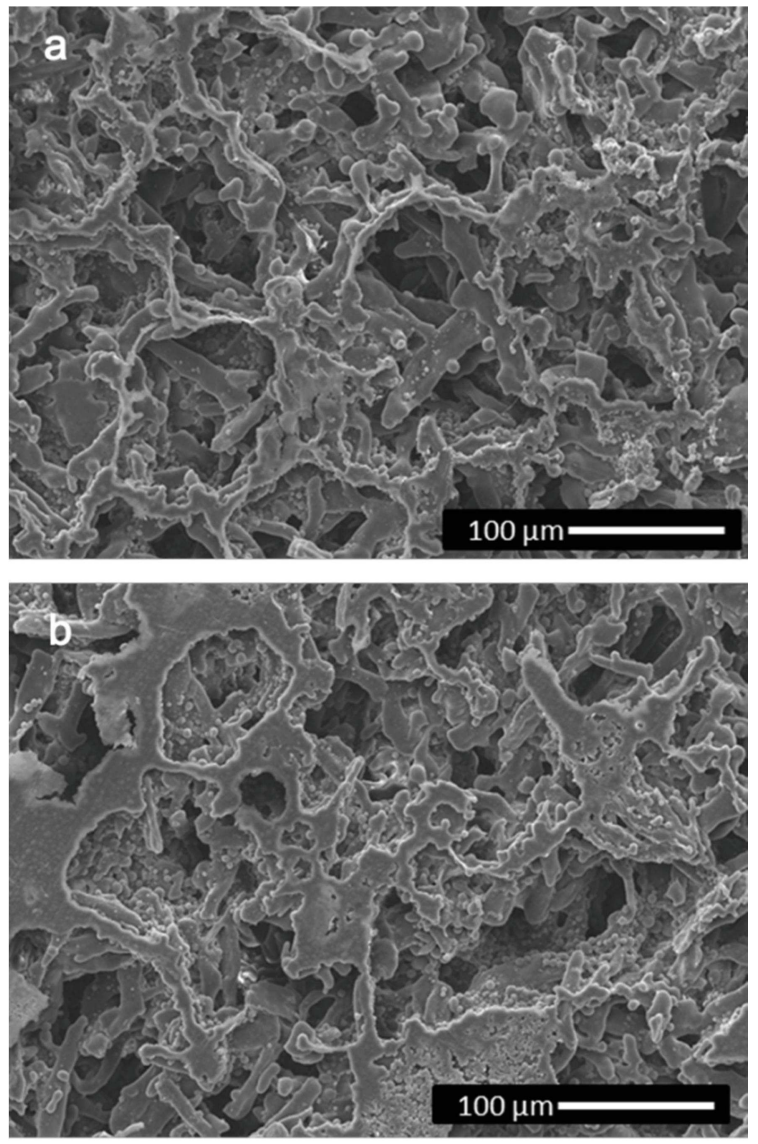

Figure V.10. SEM micrographs of the samples 100/10/30 (a) and 100/30/30 (b) at 47 days of composting test. 


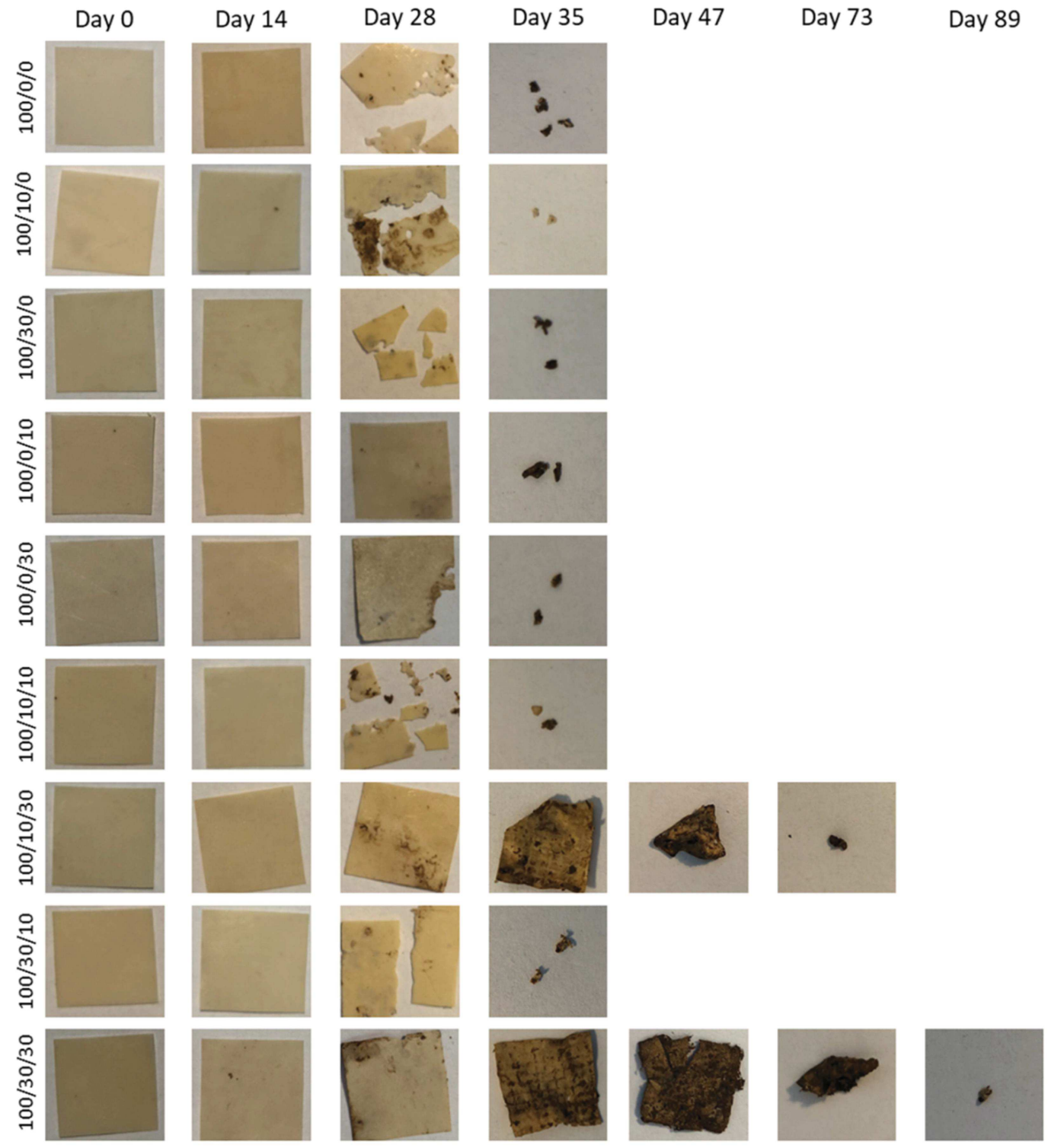

Figure V.11. Photographs of the studied samples at different composting times 


\section{V.4. General discussion}

When considering as a whole the data showed in the present work, it becomes clear the influence of each component in the studied compounds. First, the PHBV and the TPU show some degree of affinity between them. This is evidenced by the fact that there is a good dispersion of small droplets of TPU within the matrix; indeed, the MFI of the PHBV/TPU blends increases with respect to the original constituents. Discarding degradation and in agreement with the small size of the droplets, this type of behavior in melt viscosity of blends is typical of compatible, welldispersed systems submitted to low constant shear rates. This phenomenon is attributed to the low surface tension between the polymer phases, which enhances the flowability of the blend and therefore reduces its viscosity $[45,46]$. Indeed, this type of affinity is also supported by PHBV covering TPU droplets and by DSC thermograms, where crystallization is hampered by the TPU.

The mechanical properties of the blends are in agreement with this type of affinity, showing a decrease in elastic modulus and tensile stress, but higher deformation at break as the TPU fraction increases [17]. At high strain rates, such as in impact tests, TPU promotes plastic deformation thus enhancing the toughness of the blends with respect to neat PHBV. HDT values and hardness decrease with respect to PHBV, as one may expect by adding an elastomeric phase to a rigid polymer matrix.

Similarly, some chemical affinity between the PHBV matrix and the cellulose fibers can also be deduced by the good distributive dispersion of the cellulose within the matrix along with the observed polymer covering the fibers in SEM microscopy (as in Fig. V.4). The tensile properties also reflect this interaction between the PHBV and the cellulose, showing an increase in the elastic modulus. However, the nature of this adhesive interaction doesn't seem to be very strong, since the reinforcement effect does not withstand the elastic deformation of the matrix. The shear forces between PHBV and cellulose fibers during the tensile stress generate decohesion, resulting in flaws that initiate the crack propagation. The result is that despite of the sticky interaction between the matrix and the reinforcement, there is no increase in tensile strength nor toughness. At impact rates the performance of the composite is ruled by the matrix, but hardness and HDT is increased by the cellulose fibers.

When the compounds include both TPU and cellulose fibres, the reinforcement effect of the fibres is compensated by the softening effect of the TPU, finding some interesting combination of properties. Some compounds like 100/10/30 showed increased unnotched toughness, high HDT and similar values of elastic modulus and tensile strength as neat PHBV, but with the potential 
reduction in cost that implies the introduction of a cheaper filler as is the cellulose. We consider that the PHBV affinity with TPU and cellulose is much higher in molten state than once PHBV has crystallized, since carbonyl groups of PHBV are more exposed in its amorphous state and can interact with polar groups of TPU and cellulose. That explains the increase in elastic modulus and good phase dispersion, but the lack of effective reinforcement in tensile strength, which is dominated by the PHBV matrix.

Regarding the stability of the compounds, TGA analysis show that these are practically as stable as pristine PHBV, except for those containing $30 \mathrm{phr}$ cellulose. For those compounds the thermal degradation temperature was slightly reduced. Nevertheless, it is worthwhile noticing that in those cases, the onset and maximum degradation temperatures remain in values above the typical processing temperatures, so the decrease of thermal stability doesn't have a big impact on the overall performance of the composites. When they are tested under ISO20200 biodisintegration tests, the samples with TPU and high cellulose content did show an unexpected low biodisintegration rate. This phenomenon was explained by the fact that the cellulose can make a mesh and as the PHBV matrix is rapidly bio assimilated, the TPU particles, which biodegrade at lower rates, coalesce on top of the fibers, thus making a net of cellulose where microorganisms cannot easily access. Once the microorganisms reach the cellulose, the disintegration proceeds at the expected high rate.

\section{V.5. Conclussions}

In this work, PHBV compounds with an elastomeric phase (TPU) and cellulose fibers as reinforcement have been proved a technical reasonably good environmental friendly alternative to non-biodegradable oil based polymers for injection molding applications.

The results show a homogeneous distribution of the TPU and cellulose, well dispersed within the PHBV matrix. The fairly good affinity between PHBV and TPU and between PHBV and cellulose indicated that these systems might be compatible enough to be processed without any compatibilization agents.

TPU promotes plastic deformation and an increase in toughness, whereas cellulose increases the elastic modulus but yields premature break of the composites. Thus, adding cellulose to PHBV/TPU blends counteracts some of the loss of mechanical performance but maintaining the toughness improvements ascribed to TPU. 
Despite the affinity between the matrix and dispersed phases, the failure of the compounds was triggered by the limited bond strength at the interface of PHBV with the other phases.

\section{Acknowledgments}

The authors would like to thank the financial support for this research from Ministerio de Economia y Competitividad (AGL2015-63855-C2-2-R) and Pla de Promoció de la Investigació de la Universitat Jaume I (UJI-B2016-35). Authors would like to acknowledge Servicios Centrales de Instrumentación (SCIC) of Universitat Jaume I for the use of TGA and SEM. We are also grateful to Raquel Oliver and Jose Ortega for experimental support.

\section{References}

[1] H. Nakajima, P. Dijkstra, K. Loos, The Recent Developments in Biobased Polymers toward General and Engineering Applications: Polymers that are Upgraded from Biodegradable Polymers, Analogous to Petroleum-Derived Polymers, and Newly Developed, Polymers (Basel). 9 (2017) 523. doi:10.3390/polym9100523.

[2] N. Peelman, P. Ragaert, K. Ragaert, B. De Meulenaer, F. Devlieghere, L. Cardon, Heat resistance of new biobased polymeric materials, focusing on starch, cellulose, PLA, and PHA, J. Appl. Polym. Sci. 132 (2015) 42305 (1-15). doi:10.1002/app.42305.

[3] B. Laycock, P. Halley, S. Pratt, A. Werker, P. Lant, The chemomechanical properties of microbial polyhydroxyalkanoates, Prog. Polym. Sci. 38 (2013) 536-583. doi:10.1016/j.progpolymsci.2012.06.003.

[4] P.B.S. Albuquerque, C.B. Malafaia, Perspectives on the production, structural characteristics and potential applications of bioplastics derived from polyhydroxyalkanoates, Int. J. Biol. Macromol. 107 (2018) 615-625. doi:10.1016/j.jjbiomac.2017.09.026.

[5] Y. Wang, J. Yin, G.Q. Chen, Polyhydroxyalkanoates, challenges and opportunities, Curr. Opin. Biotechnol. 30 (2014) 59-65. doi:10.1016/j.copbio.2014.06.001.

[6] S. Pilla, Handbook of Bioplastics and Biocomposites Engineering Applications, 2011. doi:10.1002/9781118203699.

[7] G. Keskin, G. Kızıl, M. Bechelany, C. Pochat-Bohatier, M. Öner, Potential of polyhydroxyalkanoate (PHA) polymers family as substitutes of petroleum based polymers for packaging applications and solutions brought by their composites to form barrier materials, Pure Appl. Chem. 89 (2017) 18411848. doi:10.1515/pac-2017-0401.

[8] E. Bugnicourt, P. Cinelli, A. Lazzeri, V. Alvarez, Polyhydroxyalkanoate (PHA): Review of synthesis, characteristics, processing and potential applications in packaging, Express Polym. Lett. 8 (2014) 791-808. doi:10.3144/expresspolymlett.2014.82.

[9] Bragaw, C. G.,.The Theory of Rubber Toughening of Brittle Polymers, Ed., Multicomponent Polymer Systems. (1971) 86-106. doi:10.1021/ba-1971-0099.ch007. 
[10] S.H. El-Taweel, M. Khater, L. Martino, M.-A. Berthet, H. Angellier-Coussy, N. Gontard, C. Zhu, C.T. Nomura, J.A. Perrotta, A.J. Stipanovic, J.P. Nakas, Mechanical and Thermal Behavior of Blends of Poly(hydroxybutyrate-co-hydroxyvalerate) with Ethylene Vinyl Acetate Copolymer, J. Macromol. Sci. Part B. 54 (2015) 1225-1232. doi:10.1080/00222348.2015.1085274.

[11] B. Adams, M. Abdelwahab, M. Misra, A.K. Mohanty, Injection-Molded Bioblends from Lignin and Biodegradable Polymers: Processing and Performance Evaluation, J. Polym. Environ. 26 (2018) 2360-2373. doi:10.1007/s10924-017-1132-0.

[12] K. Zhang, M. Misra, A.K. Mohanty, Toughened sustainable green composites from poly(3hydroxybutyrate-co-3-hydroxyvalerate) based ternary blends and miscanthus biofiber, ACS Sustain. Chem. Eng. 2 (2014) 2345-2354. doi:10.1021/sc500353v.

[13] E.-S. Park, H.K. Kim, J.H. Shim, H.S. Kim, L.W. Jang, J.-S. Yoon, Compatibility of poly(butadiene-coacrylonitrile) with poly(L-lactide) and poly(3-hydroxybutyrate-co-3-hydroxyvalerate), J. Appl. Polym. Sci. 92 (2004) 3508-3513. doi:10.1002/app.20356.

[14] S. Wang, W. Chen, H. Xiang, J. Yang, Z. Zhou, M. Zhu, Modification and Potential Application of Short-Chain-Length Polyhydroxyalkanoate (SCL-PHA), Polymers (Basel). 8 (2016) 273. doi:10.3390/polym8080273.

[15] V. Jost, O. Miesbauer, Effect of different biopolymers and polymers on the mechanical and permeation properties of extruded PHBV cast films, J. Appl. Polym. Sci. 135 (2018) 46153. doi:10.1002/app.46153.

[16] J. González-Ausejo, E. Sánchez-Safont, L. Cabedo, J. Gamez-Perez, Toughness Enhancement of Commercial Poly (Hydroxybutyrate-co-Valerate) (PHBV) by Blending with a Thermoplastic Polyurethane (TPU), J. Multiscale Model. 7 (2016) 1640008(1-7). doi:10.1142/S1756973716400084.

[17] A. Martínez-Abad, J. González-Ausejo, J.M. Lagarón, L. Cabedo, Biodegradable poly(3hydroxybutyrate-co-3-hydroxyvalerate)/thermoplastic polyurethane blends with improved mechanical and barrier performance, Polym. Degrad. Stab. 132 (2016) 52-61. doi:10.1016/j.polymdegradstab.2016.03.039.

[18] Misra, M.; Pandey, J. K.; Mohanty, A. K. Biocomposites: Desing and Mechanical Performance, Elsevier Inc., Cambridge, UK, 2015.

[19] E.L. Sánchez-Safont, J. González-Ausejo, J. Gámez-Pérez, J.M. Lagarón, L. Cabedo, E.L. SanchezSafont, J. Gonzalez-Ausejo, J. Gamez-Perez, J.M. Lagaron, L. Cabedo, Poly(3-Hydroxybutyrate-co-3Hydroxyvalerate)/Purified Cellulose Fiber Composites by Melt Blending: Characterization and Degradation in Composting Conditions, J. Renew. Mater. 4 (2016) 123-132. doi:10.7569/JRM.2015.634127.

[20] L.N. Carli, J.S. Crespo, R.S. Mauler, PHBV nanocomposites based on organomodified montmorillonite and halloysite: The effect of clay type on the morphology and thermal and mechanical properties, Compos. Part A Appl. Sci. Manuf. 42 (2011) 1601-1608. doi:10.1016/j.compositesa.2011.07.007.

[21] P.J. Barham, A. Keller, E.L. Otun, P.A. Holmes, Crystallization and morphology of a bacterial thermoplastic: poly-3-hydroxybutyrate, J. Mater. Sci. 19 (1984) 2781-2794. doi:10.1007/BF01026954.

[22] M.-L. Cheng, Y.-M. Sun, Relationship between free volume properties and structure of poly(3hydroxybutyrate-co-3-hydroxyvalerate) membranes via various crystallization conditions, Polymer (Guildf). 50 (2009) 5298-5307. doi:10.1016/J.POLYMER.2009.09.035.

[23] UNE-EN ISO, UNE-EN ISO 20200 Determinación del grado de desintegración de materiales plásticos 
bajo condiciones de compostaje simuladas en un laboratorio, (2006).

[24] N. Hameed, Q. Guo, F.H. Tay, S.G. Kazarian, Blends of cellulose and poly(3-hydroxybutyrate-co-3hydroxyvalerate) prepared from the ionic liquid 1-butyl-3-methylimidazolium chloride, Carbohydr. Polym. 86 (2011) 94-104. doi:10.1016/j.carbpol.2011.04.016.

[25] S. Wang, H. Xiang, R. Wang, C. Peng, Z. Zhou, M. Zhu, Morphology and properties of renewable poly(3-hydroxybutyrate- co -3-hydroxyvalerate) blends with thermoplastic polyurethane, Polym. Eng. Sci. 54 (2013) 1113-1119. doi:10.1002/pen.23655.

[26] V. Nagarajan, M. Misra, A.K. Mohanty, New engineered biocomposites from poly(3hydroxybutyrate-co-3-hydroxyvalerate) (PHBV)/poly(butylene adipate-co-terephthalate) (PBAT) blends and switchgrass: Fabrication and performance evaluation, Ind. Crops Prod. 42 (2013) 461468. doi:10.1016/j.indcrop.2012.05.042.

[27] M.-A. Berthet, C. Mayer-Laigle, X. Rouau, N. Gontard, H. Angellier-Coussy, Sorting natural fibres: A way to better understand the role of fibre size polydispersity on the mechanical properties of biocomposites, Compos. Part A Appl. Sci. Manuf. 95 (2017) 12-21. doi:10.1016/j.compositesa.2017.01.011.

[28] M. Berthet, H. Angellier-coussy, D. Machado, L. Hilliou, A. Staebler, A. Vicente, N. Gontard, Exploring the potentialities of using lignocellulosic fibres derived from three food by-products as constituents of biocomposites for food packaging, Ind. Crop. Prod. 69 (2015) 110-122. doi:10.1016/j.indcrop.2015.01.028.

[29] P. Gatenholm, J. Kubát, A. Mathiasson, Biodegradable natural composites. I. Processing and properties, J. Appl. Polym. Sci. 45 (1992) 1667-1677. doi:10.1002/app.1992.070450918.

[30] Q.-S. Liu, M.-F. Zhu, W.-H. Wu, Z.-Y. Qin, Reducing the formation of six-membered ring ester during thermal degradation of biodegradable PHBV to enhance its thermal stability, Polym. Degrad. Stab. 94 (2009) 18-24. doi:10.1016/j.polymdegradstab.2008.10.016.

[31] M.D. Sanchez-Garcia, J.M. Lagaron, On the use of plant cellulose nanowhiskers to enhance the barrier properties of polylactic acid, Cellulose. 17 (2010) 987-1004. doi:10.1007/s10570-010-9430$\mathrm{x}$.

[32] A.K. Barick, D.K. Tripathy, Thermal and dynamic mechanical characterization of thermoplastic polyurethane/organoclay nanocomposites prepared by melt compounding, Mater. Sci. Eng. A. 527 (2010) 812-823. doi:10.1016/j.msea.2009.10.063.

[33] M. Herrera, G. Matuschek, A. Kettrup, Thermal degradation of thermoplastic polyurethane elastomers (TPU) based on MDI, Polym. Degrad. Stab. 78 (2002) 323-331. doi:10.1016/S01413910(02)00181-7.

[34] Y. Srithep, T. Ellingham, J. Peng, R. Sabo, C. Clemons, L.-S. Turng, S. Pilla, Melt compounding of poly (3-hydroxybutyrate-co-3-hydroxyvalerate)/nanofibrillated cellulose nanocomposites, Polym. Degrad. Stab. 98 (2013) 1439-1449. doi:10.1016/j.polymdegradstab.2013.05.006.

[35] R. Bhardwaj, A.K. Mohanty, L.T. Drzal, F. Pourboghrat, M. Misra, Renewable resource-based green composites from recycled cellulose fiber and poly(3-hydroxybutyrate-co-3-hydroxyvalerate) bioplastic, Biomacromolecules. 7 (2006) 2044-2051.

[36] L.V. Rossa, L.C. Scienza, A.J. Zattera, Effect of curauá fiber content on the properties of poly(hydroxybutyrate- co -valerate) composites, Polym. Compos. 34 (2013) 450-456. doi:10.1002/pc.22432.

[37] V. Nagarajan, A.K. Mohanty, M. Misra, Perspective on Polylactic Acid (PLA) based Sustainable 
Materials for Durable Applications: Focus on Toughness and Heat Resistance, ACS Sustain. Chem. Eng. 4 (2016) 2899-2916. doi:10.1021/acssuschemeng.6b00321

[38] Y.D. Kim, S.C. Kim, Effect of chemical structure on the biodegradation of polyurethanes under composting conditions, Polym. Degrad. Stab. 62 (1998) 343-352. doi:10.1016/S01413910(98)00017-2.

[39] G.T. Howard, Biodegradation of polyurethane: a review, Int. Biodeterior. Biodegradation. 49 (2002) 245-252. doi:10.1016/S0964-8305(02)00051-3.

[40] Y.-X. Weng, Y.-Z.Y. Wang, X.-L. Wang, Y.-Z.Y. Wang, Biodegradation behavior of PHBV films in a pilot-scale composting condition, Polym. Test. $29 \quad$ (2010) 579-587. doi:10.1016/j.polymertesting.2010.04.002.

[41] M.P. Arrieta, J. López, E. Rayón, a. Jiménez, Disintegrability under composting conditions of plasticized PLA-PHB blends, Polym. Degrad. Stab. (2014) 1-12. doi:10.1016/j.polymdegradstab.2014.01.034.

[42] D. Puglia, E. Fortunati, D. a. D’Amico, L.B. Manfredi, V.P. Cyras, J.M. Kenny, Influence of organically modified clays on the properties and disintegrability in compost of solution cast poly(3hydroxybutyrate) films, Polym. Degrad. Stab. 99 (2014) 127-135. doi:10.1016/j.polymdegradstab.2013.11.013.

[43] J. González-Ausejo, E. Sanchez-Safont, J.M. Lagaron, R.T. Olsson, J. Gamez-Perez, L. Cabedo, Assessing the thermoformability of poly(3-hydroxybutyrate-co-3-hydroxyvalerate)/poly(acid lactic) blends compatibilized with diisocyanates, Polym. Test. 62 (2017) 235-245. doi:10.1016/j.polymertesting.2017.06.026.

[44] E.L. Sánchez-Safont, A. Aldureid, J.M. Lagarón, J. Gámez-Pérez, L. Cabedo, Biocomposites of different lignocellulosic wastes for sustainable food packaging applications, Compos. Part B Eng. 145 (2018) 215-225. doi:10.1016/j.compositesb.2018.03.037.

[45] L.A. Utracki, M.R. Kamal, Melt rheology of polymer blends, Polym. Eng. Sci. 22 (1982) 96-114. doi:10.1002/pen.760220211.

[46] J.F. Carley, S.C. Crossan, Viscosities of molten polymer blends, Polym. Eng. Sci. 21 (1981) 249-258. doi:10.1002/pen.760210502. 


\section{CAPÍTULO VI}

\section{Toughness Enhancement of PHBV/TPU/Cellulose Compounds with Reactive Additives for Compostable Injected Parts in Industrial Applications}

\footnotetext{
Estefanía Lidón Sánchez-Safont ${ }^{1}$, Alex Arrillaga ${ }^{2}$, Jon Anakabe ${ }^{2}$, Luis Cabedo ${ }^{1}$ and Jose GamezPerez $^{1 *}$

1 Polymers and Advanced Materials Group (PIMA), Universitat Jaume I, 12071 Castellón, Spain; esafont@uji.es (E.L.S.-S.); Icabedo@uji.es (L.C.)

2 Leartiker S. Coop., Xemein Etorbidea 12A, 48270 Markina-Xemein, Spain; aarrillaga@leartiker.com (A.A.); janakabe@leartiker.com (J.A.)
}

\section{Graphical abstract}

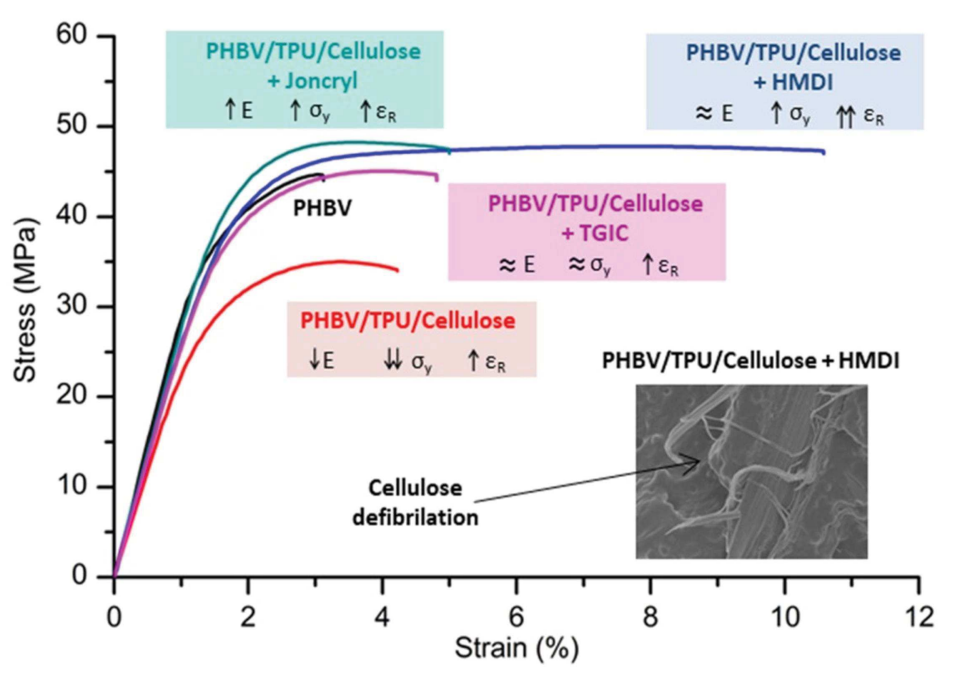

J. Int. J. Mol. Sci. 2018, 19, 2102. 


\begin{abstract}
Poly(3-hydroxybutyrate-co-3-valerate), PHBV, is a bacterial thermoplastic biopolyester that possesses interesting thermal and mechanical properties. As it is fully biodegradable, it could be an alternative to the use of commodities in single-use applications or in those intended for composting at their end of life. Two big drawbacks of PHBV are its low impact toughness and its high cost, which limit its potential applications. In this work, we proposed the use of a PHBVbased compound with purified $\alpha$-cellulose fibres and a thermoplastic polyurethane (TPU), with the purpose of improving the performance of PHBV in terms of balanced heat resistance, stiffness, and toughness. Three reactive agents with different functionalities have been tested in these compounds: hexametylene diisocianate (HMDI), a commercial multi-epoxy-functionalized styrene-co-glycidyl methacrylate oligomer (Joncryl ${ }^{\oplus}$ ADR-4368), and triglycidyl isocyanurate (TGIC). The results indicate that the reactive agents play a main role of compatibilizers among the phases of the PHBV/TPU/cellulose compounds. HMDI showed the highest ability to compatibilize the cellulose and the PHBV in the compounds, with the topmost values of deformation at break, static toughness, and impact strength. Joncryl and TGIC, on the other hand, seemed to enhance the compatibility between the fibres and the polymer matrix as well as the TPU within the PHBV.
\end{abstract}

\title{
Keywords
}

biopolyester; compatibilizer; cellulose; elastomer; toughening; biodisintegration; heat deflection temperature

\section{VI.1. Introduction}

Nowadays, the use of plastics is widely extended in almost all production fields, such as packaging, electronics, automotive, household, etc., and the market is dominated by the socalled commodities, traditional oil-based plastics. The growing concern over the environmental problems involved with petroleum-based polymers related to their non-renewable origin and poor biodegradability is leading the industry to replace current materials with biodegradable alternatives [1]. Therefore, researchers have been looking for alternatives that may be more environmentally sustainable, especially in short- and medium-term applications, such as packaging. Within this context, biopolyesters have received great attention, especially those that 


\section{SECCIÓN 3.- Resultados-CAPÍTULO VI}

are bio-sourced and biodegradable, as a way to overcome some of the waste management issues [2].

Among the different commercially available biopolyesters, one of the most promising candidates to replace commodities is the poly(3-hydroxybutyrate-co-3-valerate) (PHBV) [3-6]. PHBV is a bacterial thermoplastic biopolyester from the polyhydroxyalcanoates family that possesses physical properties comparable to conventional polyolefins, high static mechanical performance [7], and relatively high thermal resistance [8], while being fully biodegradable. However, two important drawbacks of PHBV are its low impact toughness and its cost, which is still quite high $[9,10]$. These disadvantages are a serious handicap for its use in applications in rigid packaging parts, for instance, that could be obtained by injection moulding.

One of the most promising eco-friendly approaches to reduce the manufacturing costs of PHBV while maintaining its biodegradability and sustainability is the development of natural fibrebased polymer composites. Indeed, it also improves its mechanical performance in terms of stiffness as well as thermal resistance [11]. On the other hand, in order to enhance the toughness of PHBV, several attempts have been reported in the literature, some of them related to blending with other polymers such as poly(butylene adipate-co-terephthalate) (PBAT) [12,13], polybutylene succinate (PBS) [14,15], or polycaprolactone (PCL) [12] or by the addition of impact modifiers such as ethylene vinyl acetate [16], epoxidized natural rubber [13,17], or thermoplastic polyurethane (TPU) $[12,18-20]$, showing in all cases great improvements in elongation at break.

In this work, we proposed the use of a purified $\alpha$-cellulose fibres and a thermoplastic polyurethane (TPU) with the purpose of improving the performance of PHBV in terms of balanced heat resistance, stiffness, and toughness without compromising biodisintegrability in composting conditions.

However, previous works have shown that the interaction of these fillers with PHA matrices was not very strong, resulting in low toughness and tensile strength [21,22]. Nonetheless, some strategies to improve the chemical affinity between the cellulose and other polyesters have been used in order to increase the reinforcement effect of the cellulose, such as fibre treatments or use of compatibilizers (reviewed by [11,23-26]).

From an industrial point of view, reactive extrusion is a convenient, cost-effective approach to improve the interfacial adhesion of the different phases via an in situ reaction during melt processing [27]. Within this objective, three reactive agents have been tested: (a) hexametylene diisocianate (HMDI); (b) (Joncryl ADR-4368), a commercial multi-epoxy-functionalized styrene- 
acrylic oligomer; and (c) triglycidyl isocyanurate (TGIC) (Figure VI.1). These reactive agents possess three different functional groups that could potentially react with the hydroxyl groups present at the cellulose surface and the ones from the alcohol and carboxylic acid groups at the polymer chain ends [28]. Some reports have been found in the literature about the use of diisocyanates as compatibilizers in biopolyester/fibre composites [29-31], PHBV/polylactic acid (PLA) blends [32], and PLA/TPU blends [33,34], showing good improvements in interfacial adhesion. Hao et al. showed improved interfacial adhesion in PLA/sisal fibre composites using Joncryl [35] and Nanthananon et al. reported similar improvements in PLA/eucalyptus fibre systems [36]. Furthermore, the use of Joncryl has also been proved efficient in the compatibilization of POM/TPU blends [37]. TGIC was successfully used to compatibilize polylactide/sisal fibre biocomposites [38].

In this work, the combined effect of TPU, cellulose fibres, and the use of three different reactive agents (HMDI, Joncryl ${ }^{\circ}$, and TGIC) is explored in order to improve the interfacial adhesion and compatibility of PHBV, TPU, and cellulose through reactive extrusion. This strategy is aimed at building a ternary system that will overcome the handicaps of PHBV that prevent its usage in injection-moulded applications in terms of cost, toughness, and thermal resistance.
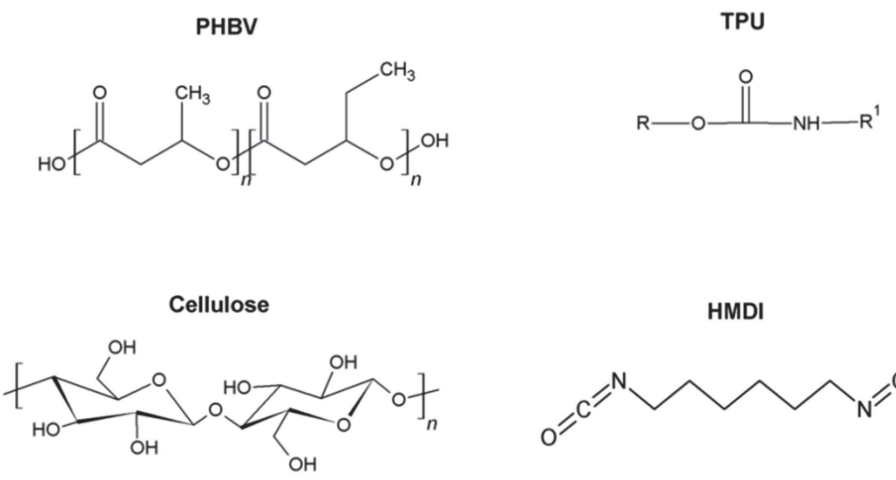<smiles>O=C=NCCCCCCN=C=O</smiles>
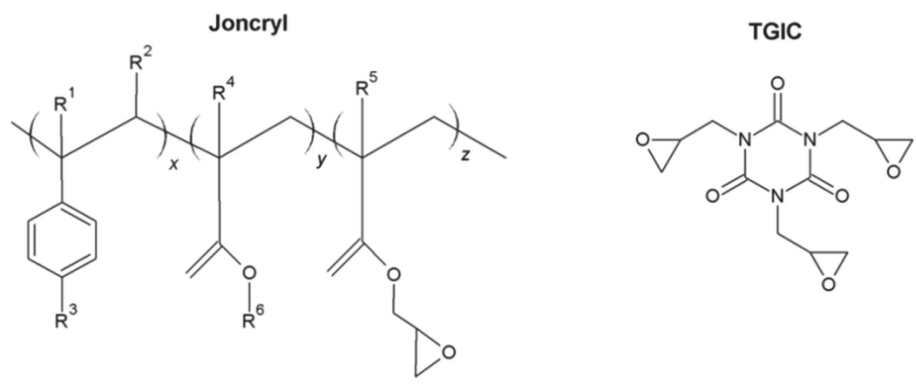

Figure VI.1. Chemical structures of materials used in this study. 


\section{VI.2. Results and Discussion}

\section{VI.2.1. Preparation of Compounds and Analysis of Their Processability}

PHBV/TPU/Cellulose triple systems with different content of additives (TPU and cellulose) and reactive agents (HMDI, Joncryl, and TGIC) were prepared by a co-rotating twin-screw extruder in the proportions described in Table VI.1.

Table VI.1. List of compounds and their composition

\begin{tabular}{cccccc}
\hline Sample & TPU & Cellulose & $\begin{array}{c}\text { HMDI } \\
\text { (phr) }\end{array}$ & Joncryl & TGIC \\
\hline Neat PHBV & - & - & - & - & - \\
PHBV/30T/10C** & 30 & 10 & - & - & - \\
\hline PHBV/30T/10C-0.3HMDI & 30 & 10 & 0.3 & - & - \\
\hline PHBV/30T/10C-0.5HMDI & 30 & 10 & 0.5 & - & - \\
\hline PHBV/30T/10C-1HMDI & 30 & 10 & 1 & - & - \\
\hline PHBV/30T/10C-0.3Joncryl & 30 & 10 & - & 0.3 & - \\
\hline PHBV/30T/10C-0.5Joncryl & 30 & 10 & - & 0.5 & - \\
\hline PHBV/30T/10C-1Joncryl & 30 & 10 & - & 1 & - \\
\hline PHBV/30T/10C-0.3TGIC & 30 & 10 & - & - & 0.3 \\
\hline PHBV/30T/10C-0.5TGIC & 30 & 10 & - & - & 0.5 \\
\hline PHBV/30T/10C-1TGIC & 30 & 10 & - & - & 1 \\
PHBV/30T/30C *** & 30 & 30 & - & - & - \\
\hline PHBV/30T/30C-0.3HMDI & 30 & 30 & 0.3 & - & - \\
\hline PHBV/30T/30C-0.5HMDI & 30 & 30 & 0.5 & - & - \\
\hline PHBV/30T/30C-1HMDI & 30 & 30 & 1 & - & - \\
\hline PHBV/30T/30C-0.3Joncryl & 30 & 30 & - & 0.3 & - \\
\hline PHBV/30T/30C-0.5Joncryl & 30 & 30 & - & 0.5 & - \\
\hline PHBV/30T/30C-1Joncryl & 30 & 30 & - & 1 & - \\
\hline PHBV/30T/30C-0.3TGIC & 30 & 30 & - & - & 0.3 \\
\hline PHBV/30T/30C-0.5TGIC & 30 & 30 & - & - & 0.5 \\
\hline PHBV/30T/30C-1TGIC & 30 & 30 & - & - & 1 \\
\hline
\end{tabular}

* phr refers to the 100 unit weight PHBV matrix; ${ }^{* *}$ PHBV/30T/10C corresponds to 71.4 wt \% PHBV, 21.4 wt \% TPU, and 7.2 wt \% cellulose; *** PHBV/30T/30C corresponds to 62.5 wt \% PHBV, 18.8 wt \% TPU, and 18.8 wt \% cellulose.

The melt flow index is a useful tool to predict the processability of materials in industrial equipment such as injection moulding and gives an indirect measurement of melt viscosity, as it is indirectly proportional to viscosity. Figure VI.2 represents the melt flow index values of neat 
PHBV and the compounds (PHBV/30T/10C and PHBV/30T/30C) with 0, 0.3, 0.5, and 1 phr reactive agents content.

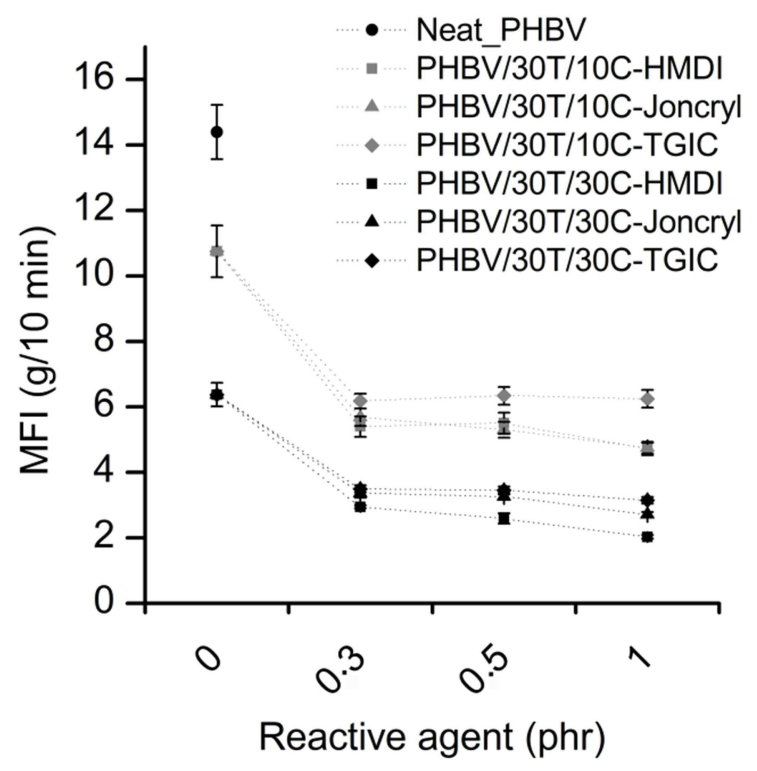

Figure VI.2. Melt flow index (MFI) of neat PHBV, PHBV/30T/10C, and PHBV/30T/30C with $0,0.3,0.5$, and 1 phr reactive agent content.

As seen in Figure VI.2, the addition of TPU and cellulose significantly decreases the melt fluidity of PHBV, especially for the highest cellulose content. This increment in melt viscosity is typical in fibre-based composites because of the increased shear produced by the restricted chain mobility induced by the fibres [39]. The addition of the different reactive agents in $0.3 \mathrm{phr}$ leads to a further drastic reduction of the melt fluidity. As the reactive agent content increases, the MFI values decrease slightly, except in the case of TGIC, where the compounds have similar melt indexes. Among the three reactive agents, the highest reduction in MFI is found in the compositions with HMDI. This reduction in fluidity with the incorporation of the reactive agents is indicative of some reactivity with the components of the system and can be related to a compatibilization between the fibres and the polymers and/or between the PHBV and the TPU [27].

With respect to the processability, the reduced fluidity of the compositions with the reactive agents led to increased injection pressure values. However, despite the low MFI values of the compounds, the injected samples were successfully obtained without any change in the processing parameters with respect to neat PHBV. 


\section{VI.2.2. Characterization}

The morphology of the PHBV/TPU/cellulose triple systems was analysed by scanning electron microscopy (SEM). Micrographs of PHBV/30T/10C and PHBV/30T/30C without reactive agents and with 1 phr of HMDI, Joncryl ${ }^{\circledR}$, and TGIC are depicted in Figures VI.3 and VI.4, respectively.

With respect to the fillers, in samples without reactive agent (Figures VI.3a and VI.4a), a good distribution of the fibres was observed, indicating good compounding and certain affinity between the fibres and the polymer matrix probably due to the formation of hydrogen bonds between the $-\mathrm{OH}$ groups of the fibre surface and PHBV [21,40,41]. However, some detachment of the fibres is also observed, indicating that the hydrogen bonding type is not enough to provide a strong adhesion between these phases. Regarding the fibre distribution, no remarkable differences were observed with the addition of the different reactive agents (Figures VI.3 and VI.4). Nevertheless, regarding the fibre-matrix interface, with the presence of the reactive agents the fibres seem to be well trapped by the polymer matrix, as broken fibres covered by the polymer were observed in all cases. In particular, in the case of HMDI (Figures VI.3c,d and VI.4c,d), the fibres appear broken in the longitudinal direction, and defibrillation was observed, indicating a cohesive failure. These observations suggest the strongest adhesion between the cellulose fibres and the PHBV, indicating a compatibilization effect.
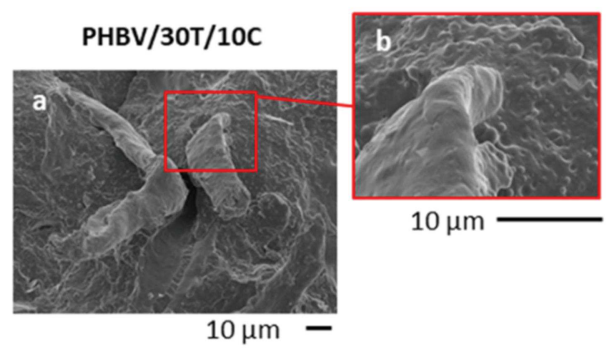

$10 \mu \mathrm{m}$

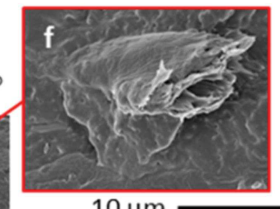

PHBV/30T/10C+1 Joncryl

e

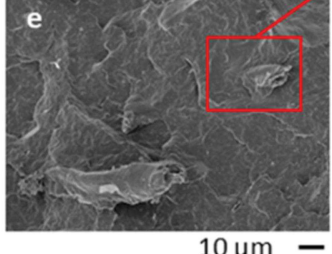

$10 \mu \mathrm{m}-$
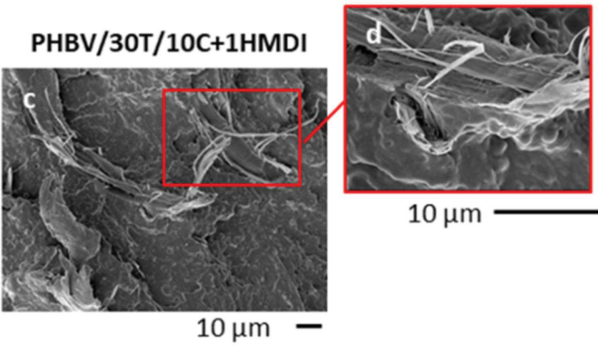

$10 \mu \mathrm{m}$

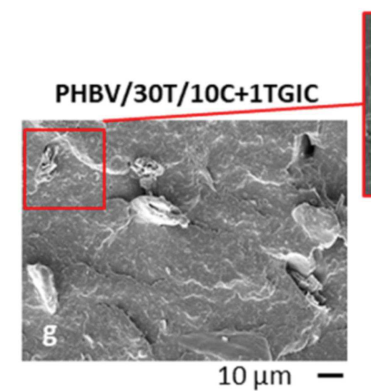

h

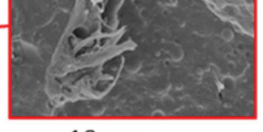

$10 \mu \mathrm{m}$

Figure VI.3. SEM micrographs of PHBV/30T/10C $(a, b)$ and PHBV/30T/10C with 1 phr of HMDI (c,d), Joncryl ${ }^{\circledR}(e, f)$, and TGIC (g,h). 

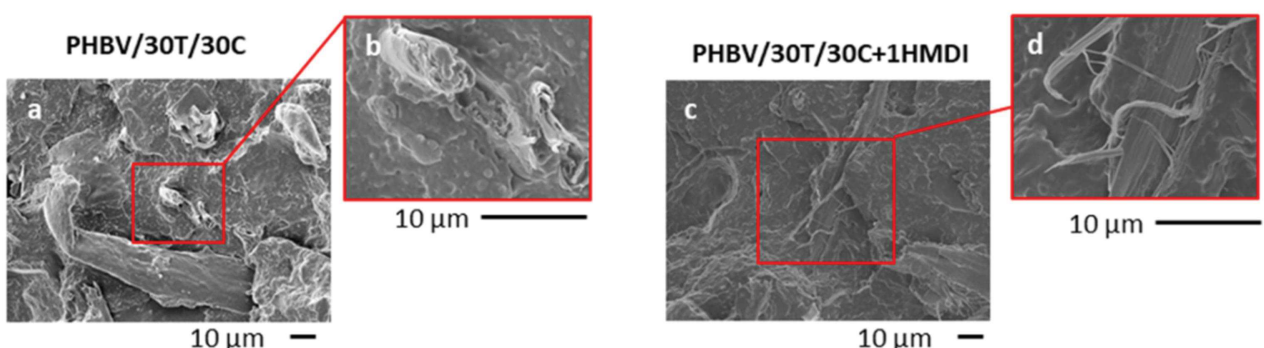

$10 \mu \mathrm{m}$ $10 \mu \mathrm{m}-$

$10 \mu \mathrm{m}-$
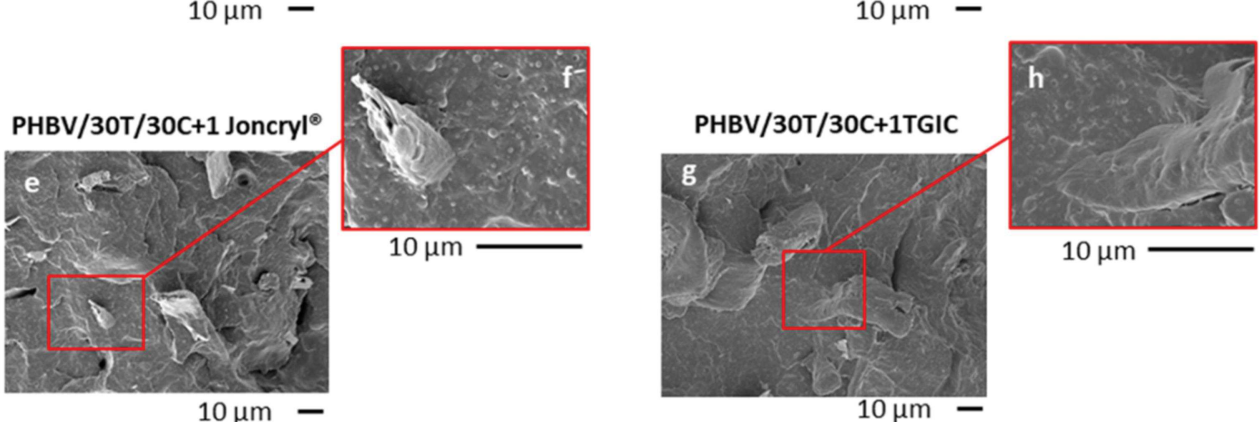

$10 \mu \mathrm{m}$

Figure VI.4. SEM micrographs of PHBV/30T/30C $(a, b)$ and PHBV/30T/30C with 1 phr of HMDI (c,d), Joncry ${ }^{\circledR}(e, f)$, and TGIC $(g, h)$.

With respect to the polymeric matrix, all the compositions present a drop in matrix morphology, where the disperse phase is the TPU, as shown in Figures VI.5 and VI.6. These figures show the SEM images of the polymeric matrix for the PHBV/30T/10 and PHBV/30T/30C composites, with and without the reactive agents. The droplet size distributions of the dispersed phase are also included in the aforementioned figures. The average domain size $(d)$, the estimated ligament distance, and the $d 10, d 50$, and d90 values are summarized in Table VI.2.

According to the measurements performed, the average domain size $(d)$ of the TPU is 0.416 and $0.420 \mu \mathrm{m}$ in PHBV/30T/10C and PHBV/30T/30C, respectively. Although some detachment of TPU is observed, the small size of the dispersed phase domains indicates a certain affinity between the phases. With the incorporation of the reactive agents the average TPU droplet size was reduced, as shown in Table VI.2. The highest droplet size reductions were obtained in the compounds containing the highest amount of cellulose with the reactive agents TGIC and Joncryl. In these cases, indeed, a slight dependence on the average domain size $(d)$ as the reactive agent content increases was observed in compounds with $10 \mathrm{phr}$ of Cellullose, but not in those with $30 \mathrm{phr}$ Cellulose.

Regarding compounds with HMDI, the reduction in the average domain size $(d)$ is lower with respect to the other reactive agents. In fact, the compound PHBV/30T/10C with $1 \mathrm{phr} \mathrm{HMDI}$ 
shows a similar value of $d$ as the compound without reactive agents, with the domain size distribution being slightly displaced to bigger sizes, presenting the highest $d 90$ value among all compounds. Nevertheless, the matrix ligament thickness of this system is in the same range as in the rest of the composites. 

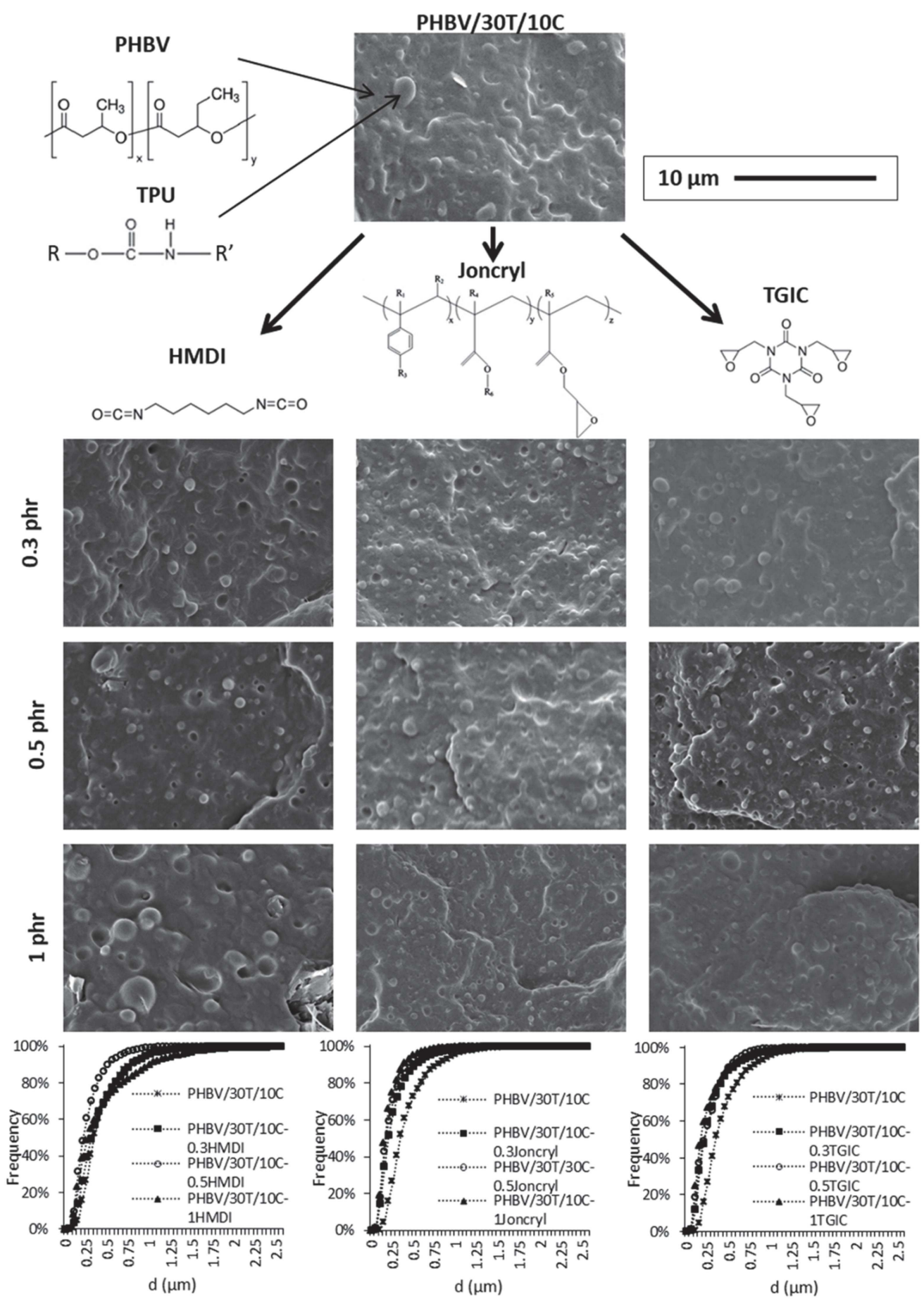

Figure VI.5. SEM images of the PHBV/30T/10C composites with the different reactive agents and cumulative frequency droplet size histograms of the dispersed phase. 

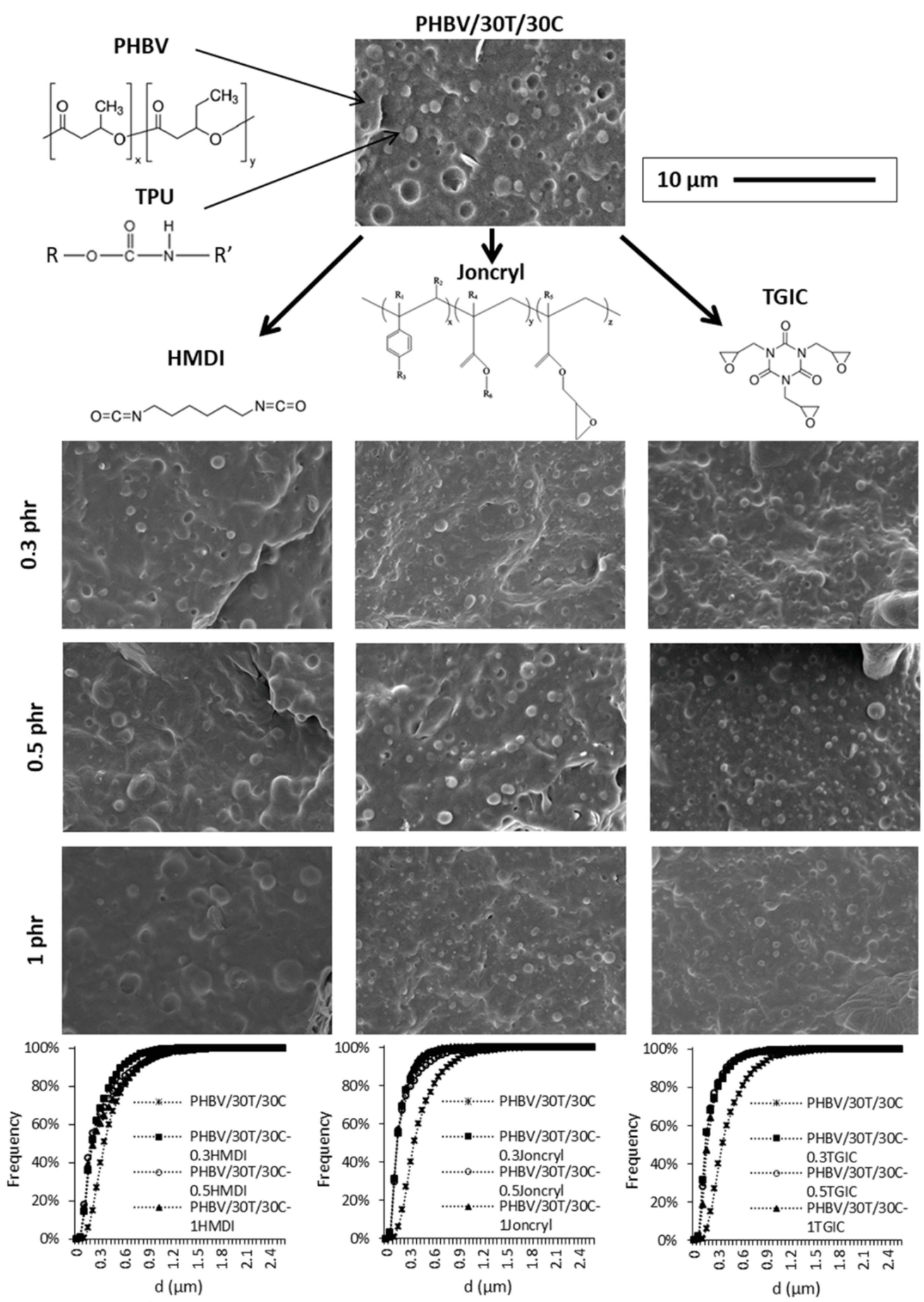

Figure VI.6. SEM images of the PHBV/30T/30C composites with the different reactive agents and cumulative frequency droplet size histograms of the dispersed phase. 
Table VI.2. Estimated d10, d50 and d90, average droplet size and ligament distance values of the TPU dispersed phase.

\begin{tabular}{|c|c|c|c|c|c|c|c|c|c|c|}
\hline \multirow{2}{*}{ (phr) } & \multicolumn{5}{|c|}{ PHBV/30T/10C } & \multicolumn{5}{|c|}{ PHBV/30T/30C } \\
\hline & $\begin{array}{c}\mathrm{d} 10 \\
(\mu \mathrm{m})\end{array}$ & $\begin{array}{c}d 50 \\
(\mu \mathrm{m})\end{array}$ & $\begin{array}{c}d 90 \\
(\mu \mathrm{m})\end{array}$ & $\begin{array}{c}d \\
(\mu \mathrm{m})\end{array}$ & $\begin{array}{c}\mathrm{T} \\
(\mu \mathrm{m})\end{array}$ & $\begin{array}{c}\mathrm{d} 10 \\
(\mu \mathrm{m})\end{array}$ & $\begin{array}{c}d 50 \\
(\mu \mathrm{m})\end{array}$ & $\begin{array}{c}\mathrm{d} 90 \\
(\mu \mathrm{m})\end{array}$ & $\begin{array}{c}d \\
(\mu \mathrm{m})\end{array}$ & $\begin{array}{c}\mathrm{T} \\
(\mu \mathrm{m})\end{array}$ \\
\hline 0 & 0.17 & 0.34 & 0.79 & 0.42 & 0.13 & 0.17 & 0.35 & 0.77 & 0.42 & 0.13 \\
\hline $0.3 \mathrm{HMDI}$ & 0.14 & 0.31 & 0.79 & 0.40 & 0.12 & 0.09 & 0.20 & 0.57 & 0.27 & 0.08 \\
\hline $0.5 \mathrm{HMDI}$ & 0.11 & 0.21 & 0.51 & 0.26 & 0.08 & 0.09 & 0.18 & 0.76 & 0.31 & 0.10 \\
\hline $1 \mathrm{HMDI}$ & 0.11 & 0.26 & 1.01 & 0.43 & 0.13 & 0.09 & 0.21 & 0.77 & 0.33 & 0.10 \\
\hline 0.3 Joncryl & 0.09 & 0.20 & 0.52 & 0.26 & 0.08 & 0.07 & 0.14 & 0.38 & 0.19 & 0.06 \\
\hline 0.5 Joncryl & 0.09 & 0.17 & 0.43 & 0.22 & 0.07 & 0.08 & 0.14 & 0.48 & 0.21 & 0.07 \\
\hline 1 Joncryl & 0.09 & 0.16 & 0.39 & 0.20 & 0.06 & 0.07 & 0.14 & 0.36 & 0.18 & 0.06 \\
\hline $0.3 \mathrm{TGIC}$ & 0.10 & 0.21 & 0.57 & 0.28 & 0.09 & 0.07 & 0.14 & 0.43 & 0.20 & 0.06 \\
\hline $0.5 \mathrm{TGIC}$ & 0.09 & 0.21 & 0.52 & 0.26 & 0.08 & 0.08 & 0.14 & 0.39 & 0.20 & 0.06 \\
\hline $1 \mathrm{TGIC}$ & 0.08 & 0.17 & 0.54 & 0.25 & 0.08 & 0.09 & 0.17 & 0.42 & 0.21 & 0.07 \\
\hline
\end{tabular}

Despite the differences in the size distributions, the droplet size and the estimated matrix ligament thickness $(\mathrm{T})$ are quite small for all compositions. As reported by $\mathrm{Wu}$ [42], the matrix ligament thickness plays an important role for rubber toughening in polymer blends. If the average matrix ligament thickness, defined as the surface-to-surface interparticle distance, is smaller than a critical value, the blend will be tough, whereas on the contrary the blend will be brittle. It can be concluded, from this analysis, that the use of TGIC and Joncryl reactive agents produced an enhanced compatibilization effect on the TPU domains within the PHBV/cellulose matrix.

\section{VI.2.2.1. Mechanical Properties}

Tensile tests up to failure were conducted in order to study the mechanical properties of neat PHBV and the compounds with and without reactive agents (HMDI, Joncryl, and TGIC). The Young's modulus, tensile yield strength, and elongation at break of the different compositions are shown in Figure VI.7. The representative strain-stress curves of neat PHBV and PHBV/TPU/cellulose composites with and without the highest level of reactive agents (1 phr) are also represented for the sake of clarity.

PHBV presents a typical stiff and brittle mechanical performance, with high values of elastic modulus and tensile strength and low elongation at break $(<5 \%)$. With respect to neat PHBV, the incorporation of TPU (30 phr) and cellulose (10 or $30 \mathrm{phr}$ ) leads to a reduction in the rigidity (about 25\%) and the tensile strength (about 20\%) and an enhancement in elongation at break 
(ca. $40 \%$ ) and static toughness (25\% and $32 \%$, respectively) [43]. This increase in elongation at break is related with both the good distribution and small droplet size of the dispersed elastomeric phase (TPU) $[19,20]$. On the other hand, although there is a certain affinity among the phases, this limited interaction is not enough to ensure an efficient load transfer to the cellulose fibres. Without strong adhesion, the fibres detach at low deformation values, lowering the tensile strength of the compound and acting as stress concentrators for premature material failure [44]. With the addition of the reactive agents to the compounds, the elastic modulus and the tensile strength clearly increase with respect to the PHBV/TPU/cellulose without them. These parameters are strongly influenced by the matrix-fibre interaction and their improvement indicates a better load transfer due to an enhanced adhesion [30]. For the 10 phr cellulose compounds, the different reactive agents show a similar impact in these parameters, regardless of their content, supposing an improvement in the elastic modulus of about $15 \%$ and an increase in the tensile strength of around $30 \%$. For the $30 \mathrm{phr}$ cellulose compounds, the highest rise in the tensile modulus was obtained with the addition of Joncryl ( $20 \%$ vs. ca. $10 \%$ for HMDI and TGIC). On the other hand, the tensile strength was improved by around $40 \%, 30 \%$, and $35 \%$ with the HMDI, Joncryl ${ }^{\circledR}$, and TGIC, respectively, reaching that of neat PHBV. 

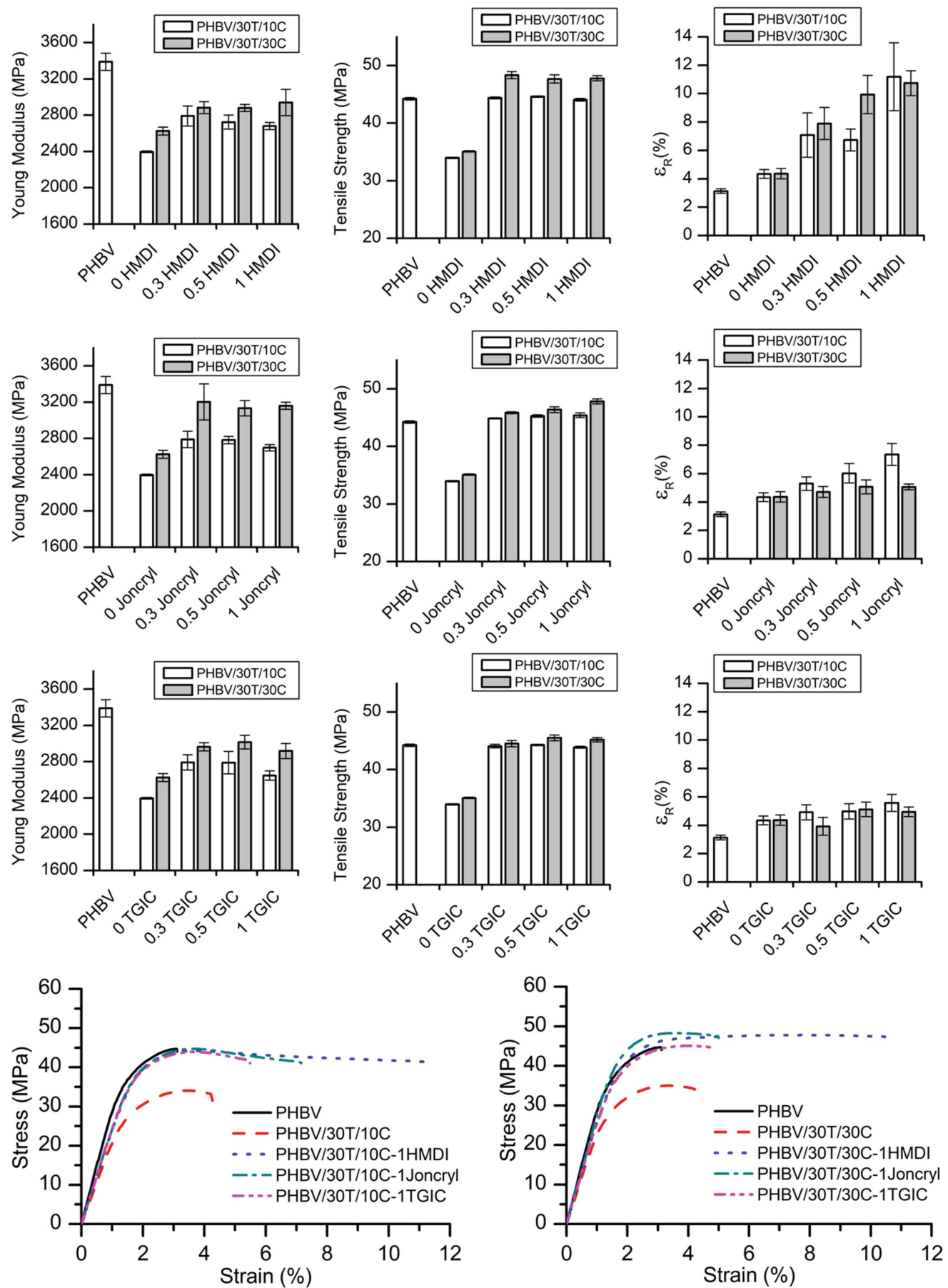

Figure VI.7. Mechanical properties of the neat PHBV and PHBV/TPU/Cellulose blends and representative stress-strain curves of neat PHBV, PHBV/30T/10C, and PHBV/30T/30C systems with and without 1 phr reactive agents. 


\section{SECCIÓN 3.- Resultados-CAPÍTULO VI}

These results reveal that the three tested reactive agents are effective at improving the interfacial adhesion of the cellulose with the polymeric matrix and are in accordance with the SEM observations and the MFI values, pointing to an increased interaction among the phases [45]. This conclusion is in agreement with some other works that have been reported in the literature, on biopolyester-fibre composites compatibilized with diisocyanates [29-31], Joncryl ${ }^{\circ}$ [35,36], or TGIC [38].

The biggest difference among the tested reactive agents with respect to their influence on the mechanical performance of the compounds is in the elongation at break. In all cases, this parameter was improved with respect to both neat PHBV and the compound without reactive agents. In Figure VI.6, looking at any PHBV/30T/10C compounds, as the reactive agent addition increases, the elongation at break rises too. On the other hand, in the case of the PHBV/30T/30C compounds, only the compounds with HMDI show an increase of elongation at break as the reactive agent content increases. This difference may point that the role of HMDI may not be the same as TGIC or Joncryl.

In fact, the compounds with the highest TGIC level (1 phr) show an increase in elongation at break of ca. $28 \%$ with respect to the uncompatibilized PHBV/30T/10C system and $13 \%$ for $\mathrm{PHBV} / 30 \mathrm{~T} / 30 \mathrm{C}$. Similarly, the addition of 1 phr Joncryl improved elongation at break by $70 \%$ in $\mathrm{PHBV} / 30 \mathrm{~T} / 10 \mathrm{C}$ and $16 \%$ in PHBV/30T/30C. However, the compounds with $1 \mathrm{phr}$ of HMDI showed an extraordinary enhancement of the elongation at break; the elongation at break was improved by $160 \%$ and $150 \%$ for compounds with 10 and 30 phr cellulose, respectively. Moreover, the static toughness (calculated from the area below the stress-strain curve) was enhanced by $320 \%$ and $340 \%$ with respect to the compound without reactive agents, and $420 \%$ and $450 \%$ with respect to neat PHBV.

\section{VI.2.2.2. Impact Resistance}

Figure VI.8 summarizes the values obtained from unnotched and notched Charpy's impact tests, along with the static toughness from tensile tests of neat PHBV and the compounds with and without the reactive agents.

It is known that PHBV is very brittle and therefore it presents very low values of resilience in both unnotched and notched Charpy's impact tests and low static toughness, as shown in Figure VI.7. In this figure it can be observed that the compounds with TPU and cellulose clearly show an improvement in toughness resistance in the case of unnotched impact tests (Figure VI.8a,d,g) [43]. This improvement could be attributed to the positive role that the elastomeric TPU phase 
plays in absorbing impact energy [46]. However, concerning the notched tests (Figure VI.8b,e,h), there is no such increase in the impact energy absorbed, probably because there is a preferred crack propagation pathway through the matrix/fibre interfaces, where the adhesion is not very strong, as previously pointed out when discussing the variations in the elastic modulus of the compounds.

Nevertheless, the addition of reactive agents significantly improves the notched impact properties of the composites, which is in agreement with the static toughness determined from the area below the stress-strain curves (Figure VI.8c,f,i). This enhancement of the matrix-fibre interface adds to the effect of the small droplet size of the elastomeric phase that implies a low ligament thickness $[42,47]$ and to by the enhanced interfacial interactions between TPU and PHBV [37], resulting in higher impact resistance in the presence of a notch. 
Unnotched

a

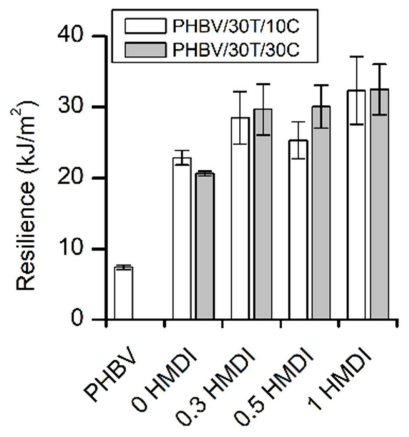

d

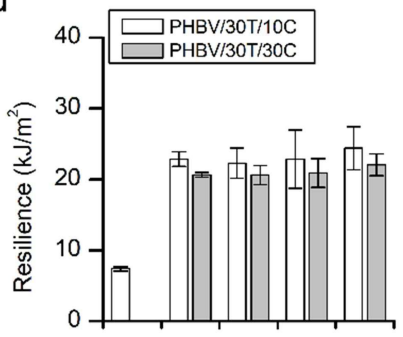

9
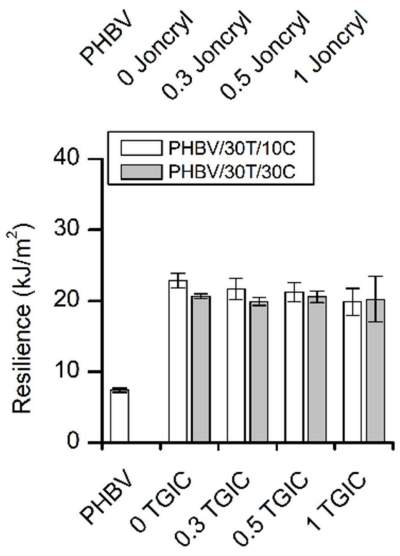

Notched

b

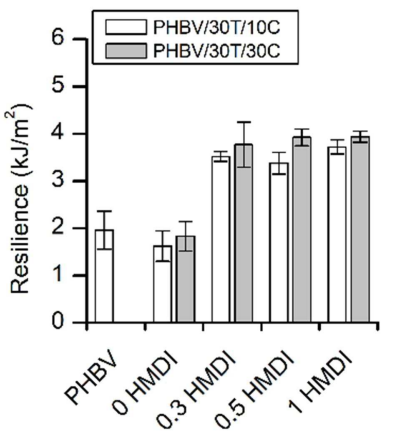

e

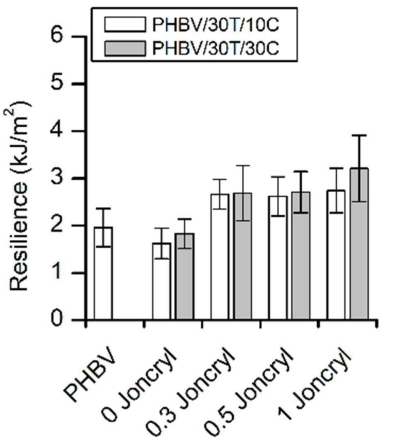

h

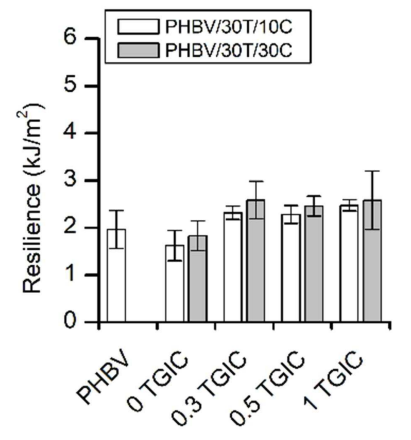

Static toughness
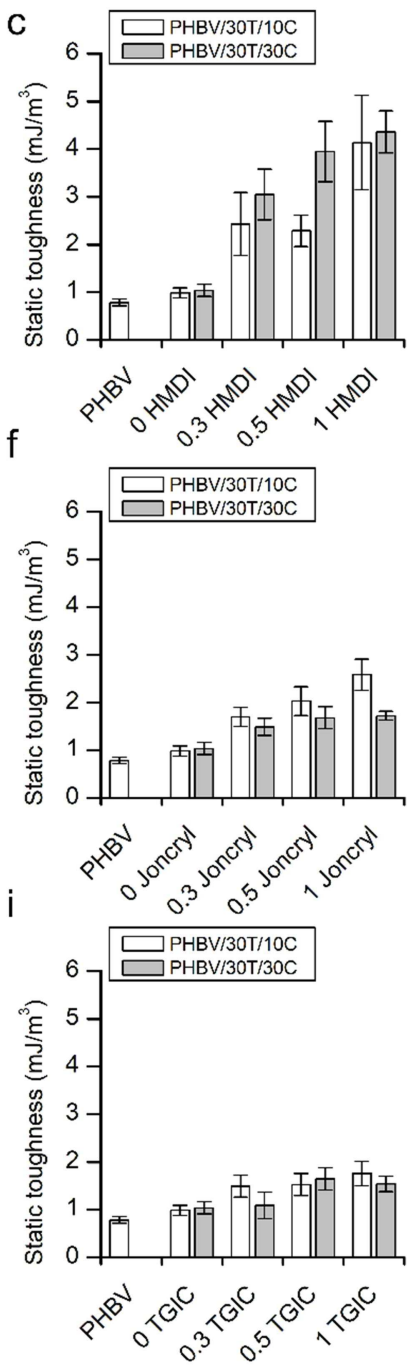

Figure VI.8. Charpy's impact results for unnotched specimens $(a, d, g)$, notched specimens $(b, e, h)$ and static toughness from the area below the strain-stress curve $(c, f, i)$.

When analysing the influence of the different reactive agents, the greatest increase in impact strength is obtained for composites with HMDI. For these composites, the absorbed impact energy was highly improved in both unnotched and notched impact tests, as well as in the static toughness (Figure VI.8a-c). Attending to the SEM micrographs of the impact fractured surfaces, with the HMDI addition (Figures VI.3 and VI.4) most of the fibres appear broken at their 
longitudinal direction, thus indicating a cohesive failure that confirms the presence of a very strong interface. This was not the case in compounds with the addition of TGIC or Joncryl.

In polymer matrix composites, when there is a weak interface between the second phase and the polymeric matrix, the detachment of the particles during tensile deformations leads to the formation of flaws and voids at the interface of the fibre and the matrix. Those voids can coalesce and act as either crack initiators or provide a fast propagation crack pathway, which eventually leads to the premature failure of the material $[13,48]$. With a stronger particle-matrix adhesion, the possibility of growth and merge of those internal flaws is reduced, so there is an effective load transfer between the two phases, improving the fracture toughness [30]. It can be said that when the shear strength at the particle-matrix interface is higher than the shear yielding of any of the phases, plastic deformation of any of them can occur, thus increasing the energy absorbed. Thus, reactive agents can play different roles, increasing the adhesion between the PHBV/TPU, PHBV/cellulose and TPU/cellulose interfaces.

The impact performance of the compounds with HMDI stands out over the other ones. In this case, it seems that HMDI strongly increases the adhesion between PHBV and cellulose, which results in a synergetic effect with the addition of the TPU. The well-dispersed elastomeric phase decreases the yield strength of the polymer matrix and the strong interaction between the polymer and the fibres allows effective load transfer without producing flaws at the interfaces. Moreover, the exceptional mechanical performance of these compositions in terms of elongation at break also suggests that HMDI could play a positive role in enhancing the interfacial adhesion between PHBV and TPU. Indeed, diisocyanates have demonstrated effectiveness in improving the compatibility of biopolyester/TPU blends, as has been reported by Dogan et al. [33,34].

TGIC and Joncryl, according to this reasoning, would not be so effective at enhancing the cellulose/PHBV interface, thus showing limited values of impact resistance, especially in the presence of a notch.

\section{VI.2.2.3. Heat Deflection Temperature HDT-A}

The thermal resistance of neat PHBV and PHBV/TPU/cellulose composites was evaluated by means of heat deflection temperature (HDT-A) measurements. The results are grouped in Table VI.3. 
Table VI.3. HDT-A values for neat PHBV and PHBV/TPU/cellulose systems with and without reactive agents.

\begin{tabular}{|c|c|c|c|c|}
\hline Sample & \multicolumn{4}{|c|}{ HDT-A $\left({ }^{\circ} \mathrm{C}\right)$} \\
\hline PHBV/TPU/Cellulose & & $0.3 \mathrm{phr}$ & $0.5 \mathrm{phr}$ & $1 \mathrm{phr}$ \\
\hline PHBV & $108 \pm 1$ & & & \\
\hline PHBV $/ 30 T / 10 C$ & $94 \pm 3$ & & & \\
\hline PHBV/30T/10C + HMDI & & $93 \pm 1$ & $98 \pm 3$ & $95 \pm 4$ \\
\hline PHBV/30T/10C + Joncryl & & $95 \pm 1$ & $98 \pm 3$ & $97 \pm 1$ \\
\hline PHBV/30T/10C + TGIC & & $90 \pm 3$ & $90 \pm 1$ & $90 \pm 3$ \\
\hline PHBV/30T/30C & $96 \pm 1$ & & & \\
\hline PHBV/30T/30C + HMDI & & $97 \pm 2$ & $99 \pm 2$ & $100 \pm 1$ \\
\hline PHBV/30T/30C + Joncryl & & $98 \pm 4$ & $97 \pm 3$ & $94 \pm 1$ \\
\hline PHBV $/ 30 T / 30 C+T G I C$ & & $104 \pm 3$ & $99 \pm 3$ & $99 \pm 1$ \\
\hline
\end{tabular}

The PHBV presents a relatively high thermal resistance, showing an HDT-A value of $108{ }^{\circ} \mathrm{C}$, in agreement with previously reported values $[8,49,50]$. The HDT values obtained for $\mathrm{PHBV} / 30 \mathrm{~T} / 10 \mathrm{C}$ and $\mathrm{PHBV} / 30 \mathrm{~T} / 30 \mathrm{C}$ are 94 and $96{ }^{\circ} \mathrm{C}$, respectively. In spite of the relatively high content of the elastomeric additive (30 phr), the thermal resistance is not that much lower. This is due to the positive role played by the cellulose fibres in terms of reinforcement. As is widely reported in literature, in fibre-based polymer composites the restricted mobility of polymer chains in the presence of fibres leads to an increase in the dimensional stability and, thus, higher temperatures are required to deform them [50].

The use of reactive agents did have a significant influence on HDT values, but a trend was not seen with variation on their relative content. For the compounds with the lowest cellulose content (10 phr), HDT values ranged between $90{ }^{\circ} \mathrm{C}(\mathrm{TGIC})$ and $98{ }^{\circ} \mathrm{C}$ (Joncryl ${ }^{\circ}$ ), compared with a value of $94{ }^{\circ} \mathrm{C}$ for the compound without reactive agents. On the other hand, for the $\mathrm{PHBV} / 30 \mathrm{~T} / 30 \mathrm{C}$ compounds, the thermal resistance was in almost all cases improved with HDT-A values around $100^{\circ} \mathrm{C}$ (especially $\mathrm{HMDI}$ and TGIC), being the HDT value for the compound without reactive agents $96^{\circ} \mathrm{C}$.

These results are in agreement with the improved rigidity of the samples in the presence of reactive agents. Indeed, since there is no dependence of the HDT value on increasing the content of reactive agents, crosslinking reactions among the polymer chains can be discarded, thus indicating that the effect of the reactive agents is only a consequence of the compatibilization of the different phases. The increase in the HDT of fibre-based composites is therefore related to the reinforcement of the cellulose fibres [51] and, along with the use of the studied reactive 
agents, allows for enhancing the toughness and mechanical performance of PHBV without drastically decreasing its thermal resistance.

\section{VI.2.2.4. Biodisintegration in Composting Conditions}

To explore the influence of cellulose content and the different reactive agents on the compostability of the PHBV/TPU/cellulose ternary systems, biodisintegration tests were conducted according to the ISO 20200 standard. The disintegration (weight loss) level over composting time is represented in Figure VI.9.

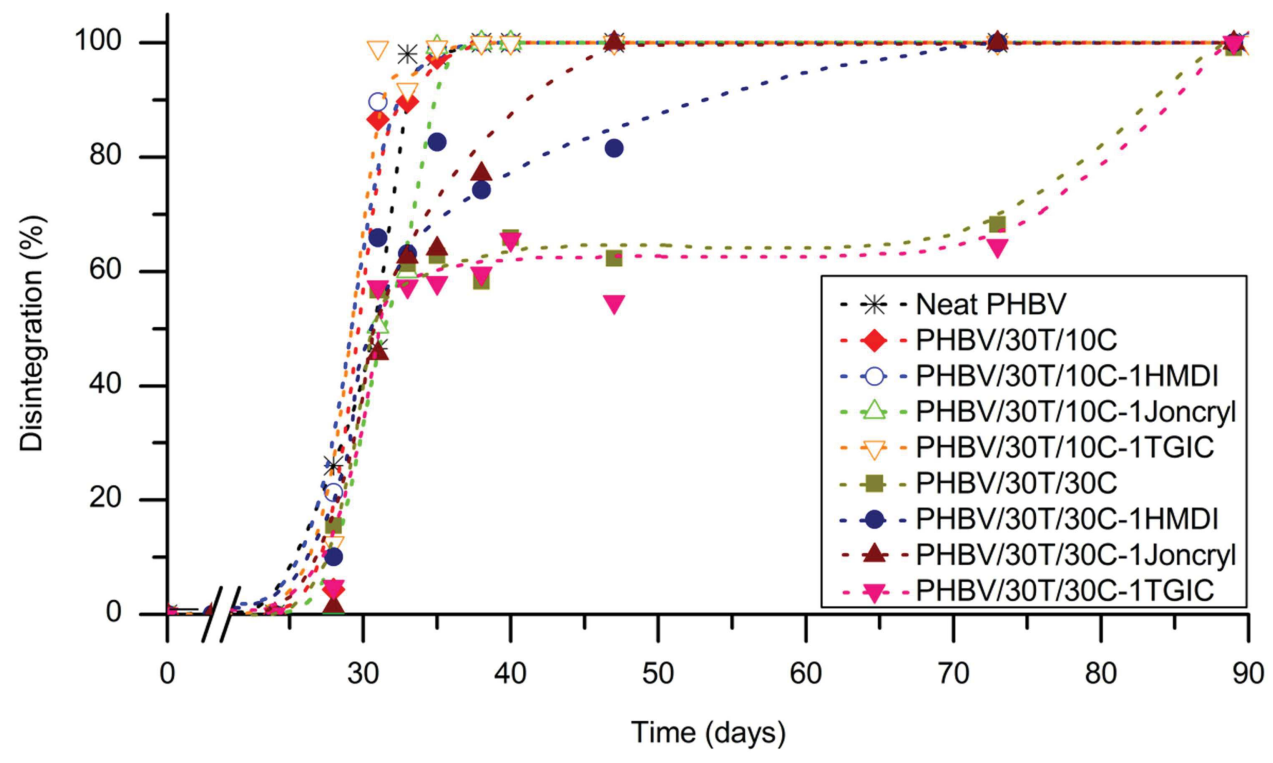

Figure VI.9. Disintegration in composting conditions of neat PHBV and PHB/TPU/cellulose systems with and without $1 \mathrm{phr}$ reactive agents.

In general, all the compositions studied can be considered biodisintegrable in composting conditions according to ISO 20200. As shown in Figure VI.9, the PHBV disintegration process starts after an incubation period of 28 days. At this time the disintegration rate drastically increases to achieve total disintegration at 38 days of composting, in accordance with previous works [20,52,53]. No differences in the biodisintegration rate were detected for the PHBV/TPU/cellulose composites containing $10 \mathrm{phr}$ cellulose, independent of the presence of reactive agents or the reactive agent type. 


\section{SECCIÓN 3.- Resultados-CAPÍTULO VI}

When the cellulose content was increased, the biodisintegration rate was, oddly, significantly reduced. To understand this occurrence, it must be taken into account how the samples were prepared and how biodisintegration takes place. For the composting tests, the specimens were obtained by hot pressing. Under the hot pressing conditions, the formation of a percolation mesh of interconnected cellulose fibres is favoured due to the high fibre-fibre affinity of the cellulose. This cellulose mesh is partially covered by TPU, which possess a low biodisintegration rate [20] with respect to PHBV and cellulose. Then, during the incubation time, a biofilm is formed at the surface of the testing specimen and the microbial advance occurs from the surface to the bulk, preferentially through the PHBV phase, as it is deduced by the stabilization of the disintegrated mass at around $60 \mathrm{wt} \%$ (approximately, the PHBV weight content) after 35 days of composting. We think that the TPU droplets, which take longer to biodisintegrate and are quite sticky at high temperature and moisture content, cover the fibres, limiting the access of the microbial advance to the cellulose.

This phenomenon causes a slowdown in the biodisintegration rate, but when the microorganisms have access to cellulose the weight loss rises rapidly and total disintegration is achieved within 90 days of composting. To validate this hypothesis, similar samples to those used for biodisintegration were placed for Soxhlet extraction of the PHBV phase with chloroform, and the resulting morphology analysed by SEM (Figure VI.10). TPU can be seen covering the fibres, partially confirming this reasoning.

Furthermore, PHBV/30T/30C composites showed different behaviour depending on the reactive agent added. The composition with TGIC presented a similar trend to the composition without reactive agent (that is, a slowdown at $60 \%$ weight loss); the ones with HMDI presented a fast biodisintegration of about $80 \%$ after 33 days of composting, reaching complete disintegration at day 73 ; and the composition with Joncryl was totally degraded after 47 days. These differences in the biodisintegration rates among PHBV/30T/30C composites with different reactive agents could be influenced by the interactions of the reactive agents with the fibres, the PHBV, and the TPU. It is hypothesized that when there is a high interaction between the cellulose and the PHBV (promoted by the reactive agents), the microorganisms can access the cellulose more easily and the biodisintegration is completed earlier. On the contrary, when the PHBV-cellulose interaction is weak, the TPU can be easily located at the fibres surface, hindering the microbial advance. When looking at the SEM pictures of the compounds after Soxhlet extraction (Figure VI.10), there is more polymer covering the fibres in the case of no reactive agent or TGIC addition than in the case of the compounds with HMDI and Joncryl, supporting the aforementioned reasoning. 


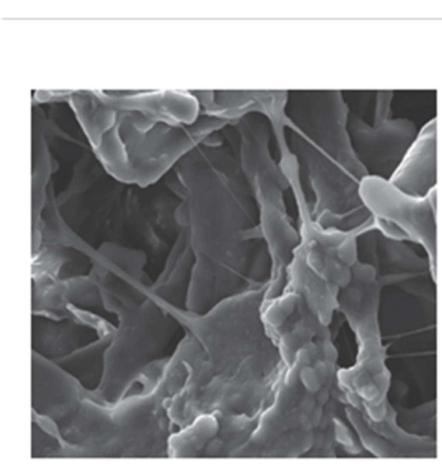

PHBV/30T/30C

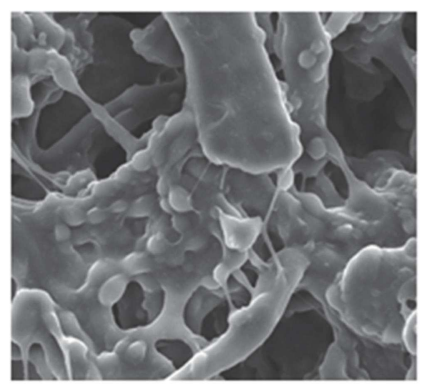

PHBV/30T/30C+1Joncryl

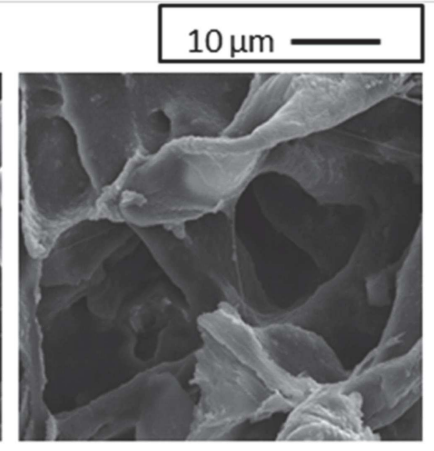

PHBV/30T/30C+1HMDI

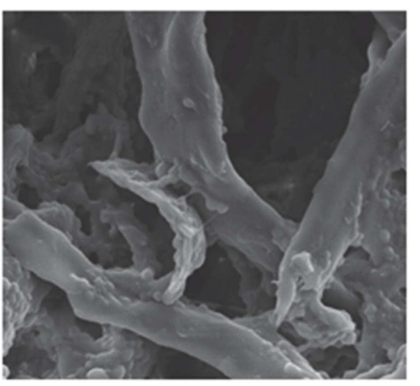

PHBV/30T/30C+1TGIC

Figure VI.10. SEM micrographs of PHBV/30T/30C samples with and without 1 phr reactive agents after Soxhlet extraction.

\section{3. Experimental}

\section{VI.3.1. Materials}

Poly(3-hydroxybutyrate-co-3-hydroxyvalerate) (PHBV) commercial grade with 3 wt \% valerate content was purchased from Tianan Biologic Material Co. (Ningbo, China) in pellet form (ENMAT Y1000P). Thermoplastic polyurethane (TPU) Elastollan 890 A $10 \mathrm{FC}$ was supplied by BASF (Ludwigshafen, Germany). Purified alpha-cellulose fibre grade (TC90) (alpha-cellulose content >99.5\%) from CreaFill Fibers Corp. (Chestertown, MD, USA) was used. The reactive agents hexamethylene diisocyanate (HMDI) and triglycidyl isocyanurate (TGIC) were supplied by SigmaAldrich (Spain) and the Joncryl 4368 was purchased from BASF (Ludwigshafen, Germany). 


\section{VI.3.2. Sample Preparation}

The PHBV and TPU used in this study were dried at $80{ }^{\circ} \mathrm{C}$ for at least $6 \mathrm{~h}$ in a DESTA DSO6 HT dehumidifying dryer and the cellulose was dried in a lab oven (Memmert universal oven $U$, Schwabach, Germany) at $90^{\circ} \mathrm{C}$ for a minimum of $16 \mathrm{~h}$ prior to the blending step, whilst the three reactive agents ( $\mathrm{HMDI}$, Joncryl, and TGIC) were used as received.

PHBV/TPU/cellulose triple systems with different content of additives (TPU and cellulose) and reactive agents (HMDI, Joncryl, and TGIC) (see Table VI.1) were prepared in a Labtech LTE (Samutprakarn, Thailand) $(\varnothing=26 \mathrm{~mm}, \mathrm{~L} / \mathrm{D}$ ratio $=40)$ co-rotating twin-screw extruder. The temperature profile was set at $145 / 155 / 160 / 170{ }^{\circ} \mathrm{C}$ from hopper to nozzle, the rotation speed was $250 \mathrm{rpm}$, and the feeding speed was about $5 \mathrm{~kg} / \mathrm{h}$. All the components were manually drymixed before extrusion except HMDI, which was dispensed at the feeding zone by means of a peristaltic pump (Watson Marlow 120 S/R, Sondika, Spain). The extruded material was cooled in a water bath and pelletized (MAAG PRIMO S pelletizer, Stuttgart, Germany).

Material pellets were dried again at $80{ }^{\circ} \mathrm{C}$ for $8 \mathrm{~h}$ (DESTA DSO6 HT) before the injection process. Standardized tensile specimens (ISO-527 Type 1A) were injection-moulded in a DEMAG IntElect $100 \mathrm{~T}$ injection moulding machine (Schwaig, Germany) with an injection temperature of $185^{\circ} \mathrm{C}$ at the nozzle. A holding pressure of 600 bars was applied for $12 \mathrm{~s}$, followed by $40 \mathrm{~s}$ of cooling time. For the sake of comparison, neat PHBV was also processed under identical conditions.

Prior to any characterization, all the samples were annealed at $80{ }^{\circ} \mathrm{C}$ for $48 \mathrm{~h}$ in order to obtain equivalent crystallinity and mechanical performance to aged samples.

\section{VI.3.3. Characterization}

The melt flow index (MFI) of the different compounds was measured in a Tinius Olsen MP600 (Surrey, England) melt flow indexer according to the ISO 1133 standard. The tests were performed at $185^{\circ} \mathrm{C}$ and $2.16 \mathrm{~kg}$ load.

The morphology of the PHBV/30T/10C and PHBV/30T/30C triple systems with and without reactive agents (HMDI, Joncryl and TGIC) was examined by scanning electron microscopy (SEM) using a high-resolution field-emission JEOL 7001F microscope (Japan). The fracture surfaces from impact-fractured specimens were previously coated by sputtering with a thin layer of Pt. From selected representative SEM images (at 2500x magnification), the diameters of the droplets 
corresponding to the dispersed phase were measured using Fiji software (ImageJ 1.51j8). The number of droplets measured in all cases was higher than 600 . From the individual measures, the following parameters were determined: the average droplet size $(d)$ and the droplet size distribution parameters $\mathrm{d} 10, \mathrm{~d} 50$, and $\mathrm{d} 90$ (corresponding to the size where $10 \%, 50 \%$, and $90 \%$ of the droplets are included, respectively). The matrix ligament thickness $(T)$ was also estimated, according to Wu's equation [42]:

$T=d\left[\left(\frac{\pi}{6 \varphi_{r}}\right)^{\frac{1}{3}}-1\right]$

where $d$ is the average domain size of the dispersed phase and $\varphi_{r}$ is the volume fraction of the dispersed phase, determined as follows:

$$
\varphi_{r}=\frac{\rho_{m} w_{r}}{\left(\rho_{r} w_{m}+\rho_{m} w_{r}\right)^{\prime}}
$$

where $\rho_{m}$ and $\rho_{r}$ are the densities of the matrix and dispersed phases, respectively, and $w_{m}$ and $w_{r}$ are their weight fractions.

Tensile tests were conducted on ISO-527 type $1 \mathrm{~A}$ injection-moulded specimens in a Hounsfield $\mathrm{H} 25 \mathrm{~K}$ universal testing machine (Surrey, England) equipped with a $25 \mathrm{kN}$ load cell according to the ISO-527-1:2012 standard.

Notched and unnotched Charpy impact tests were carried out by means of an ATS faar IMPats-15 (Segrate, Italy) impact pendulum with a $4 \mathrm{~J}$ hammer according to the ISO 179 standard. Samples were cut from injection-moulded bars.

Heat deflection temperature (HDT) analyses were performed using a Deflex 687-2 (Barcelona, Spain). A heating rate of $120^{\circ} \mathrm{C} / \mathrm{h}$ was used with an applied load of $1.8 \mathrm{MPa}$ in accordance with Method A of ISO 75 standard. The temperature was recorded until the sample deflects $0.35 \mathrm{~mm}$.

Biodisintegration tests were carried out with samples $\left(15 \times 15 \times 0.2 \mathrm{~mm}^{3}\right)$ obtained from hotpressed plates $\left(180^{\circ} \mathrm{C}, 5 \mathrm{~min}\right.$, and ca. $40 \mathrm{bar}$ ). Tests were performed according to the ISO 20200 standard [54]. Solid synthetic waste was prepared by mixing $10 \%$ of activated mature compost (VIGORHUMUS H-00, purchased from Buras Profesional, S.A., Girona, Spain), 40\% sawdust, 30\% rabbit feed, $10 \%$ corn starch, $5 \%$ sugar, $4 \%$ corn seed oil, and $1 \%$ urea. The water content of the mixture was adjusted to $55 \%$. The samples were placed inside mesh bags to simplify their extraction and allow the contact of the compost with the specimens, and then were buried in compost bioreactors at $4-6 \mathrm{~cm}$ depth. Bioreactors were incubated at $58{ }^{\circ} \mathrm{C}$. The aerobic 
conditions were guaranteed by periodically mixing the synthetic waste and adding water according to the standard requirements. Three replicates of each sample were removed from the boxes at different composting times for analysis. Samples were washed with water and dried under a vacuum at $40{ }^{\circ} \mathrm{C}$ until a constant mass. The disintegration degree was calculated by normalizing the sample weight to the initial weight with Equation (3):

$$
D=\frac{m_{i}-m_{f}}{m_{i}} \times 100,
$$

where $m_{i}$ is the initial dry mass of the test material and $m_{f}$ is the dry mass of the test material recovered at different incubation stages. Moreover, the morphology of the films prepared for the composting tests was analysed by SEM after the Soxhlet extraction with chloroform of the PHBV phase.

\section{4. Conclusions}

In this study three reactive agents used in reactive extrusion (HMDI, Joncryl, and TGIC) were tested in PHBV/TPU/cellulose for injection moulding applications that require biodisintegration in composting conditions. The influence of the cellulose content, the reactive agent type and the reactive agent content, were analysed. It was observed that the incorporation of TPU and cellulose in PHBV led to a reduction in the tensile elastic modulus and tensile strength, but an enhancement in elongation at break, with an overall increase in static toughness attributed to the toughening effect of the TPU. However, the addition of the reactive agents to the compounds resulted in a rise in the tensile strength and elastic modulus up to values close to or higher than neat PHBV and an increase in the value of strain at break with respect to the compounds without reactive agents.

In terms of impact resistance, the addition of the reactive agents improved the toughness of the compounds in notched and unnotched configurations. Furthermore, even though the TPU in the compounds causes a decrease in the thermal strength with respect to neat PHBV, the addition of cellulose up to $30 \mathrm{phr}$ with the reactive agents was able to moderate this drop.

Those results indicate that the reactive agents play a main role as compatibilizers among the phases of the PHBV/TPU/cellulose compounds. HMDI showed the highest ability to compatibilize the cellulose and the PHBV in the compounds, with the topmost values of deformation at break and static toughness. Joncryl and TGIC, on the other hand, seemed to enhance the compatibility between the fibres and the polymer matrix as well as the TPU within the PHBV. 
The findings of this work point to a route to modify the properties of PHBV (and PHAs in general) through blending with reactive agents, which can help to overcome some of the difficulties that these materials encounter in standard applications.

Author Contributions: Formal analysis, E.L.S.-S.; Funding acquisition, L.C. and J.G.-P.; Investigation, E.L.S.-S.; Methodology, E.L.S.-S., A.A., J.A., L.C. and J.G.-P.; Resources, A.A. and J.A.; Supervision, J.G.-P.; Writing-original draft, E.L.S.-S.; Writing-review \& editing, A.A., J.A., L.C. and J.G.-P.

\section{Acknowledgments}

The authors acknowledge financial support for this research from the Ministerio de Economia $y$ Competitividad (AGL2015-63855-C2-2-R) and the Pla de Promoció de la Investigació de la Universitat Jaume I (UJI-B2016-35). The authors thank Servicios Centrales de Instrumentación (SCIC) of Universitat Jaume I for the use of SEM. We are also grateful to Raquel Oliver and Jose Ortega for experimental support.

\section{References}

[1] Plastics Europe-Association of Plastics Manufacturers. Plastics-the Facts 2017: Analysis of European Plastics Production, Demand and Waste Data. Available online: http://www. plasticseurope.org/en/resources/publications/plastics-facts-2017 (accessed on 2 February 2018).

[2] Rujnić-Sokele, M.; Pilipović, A. Challenges and opportunities of biodegradable plastics: A mini review. Waste Manag. Res. 35 (2017) 132-140, doi:10.1177/0734242X16683272.

[3] Cunha, M.; Fernandes, B.; Covas, J.A.; Vicente, A.A.; Hilliou, L. Film blowing of PHBV blends and PHBV-based multilayers for the production of biodegradable packages. J. Appl. Polym. Sci. 133 (2016) 42165 (1-11) doi:10.1002/app.42165.

[4] Laycock, B.; Halley, P.; Pratt, S.; Werker, A.; Lant, P. The chemomechanical properties of microbial polyhydroxyalkanoates. Prog. Polym. Sci. 38 (2013) 536-583, doi:10.1016/j.progpolymsci.2012.06.003.

[5] Albuquerque, P.B.S.; Malafaia, C.B. Perspectives on the production, structural characteristics and potential applications of bioplastics derived from polyhydroxyalkanoates. Int. J. Biol. Macromol. 107 (2018) 615-625, doi:10.1016/j.jijbiomac.2017.09.026.

[6] Wang, Y.; Yin, J.; Chen, G.Q. Polyhydroxyalkanoates, challenges and opportunities. Curr. Opin. Biotechnol. 30 (2014) 59-65.

[7] Pilla, S. Handbook of Bioplastics and Biocomposites Engineering Applications; John Wiley \& Sons: Hoboken, NJ, USA, 2011; ISBN 9780470626078. 
[8] Peelman, N.; Ragaert, P.; Ragaert, K.; De Meulenaer, B.; Devlieghere, F.; Cardon, L. Heat resistance of new biobased polymeric materials, focusing on starch, cellulose, PLA, and PHA. J. Appl. Polym. Sci. 132 (2015) 42305 (1-15). doi:10.1002/app.42305.

[9] Keskin, G.; Kızıl, G.; Bechelany, M.; Pochat-Bohatier, C.; Öner, M. Potential of polyhydroxyalkanoate (PHA) polymers family as substitutes of petroleum based polymers for packaging applications and solutions brought by their composites to form barrier materials. Pure Appl. Chem. 89 (2017) 18411848, doi:10.1515/pac-2017-0401.

[10] Bugnicourt, E.; Cinelli, P.; Lazzeri, A.; Alvarez, V. Polyhydroxyalkanoate (PHA): Review of synthesis, characteristics, processing and potential applications in packaging. Express Polym. Lett. 8 (2014) 791-808, doi:10.3144/expresspolymlett.2014.82.

[11] Väisänen, T.; Haapala, A.; Lappalainen, R.; Tomppo, L. Utilization of agricultural and forest industry waste and residues in natural fiber-polymer composites: A review. Waste Manag. 54 (2016) 62-73, doi:10.1016/j.wasman.2016.04.037.

[12] Jost, V.; Miesbauer, O. Effect of different biopolymers and polymers on the mechanical and permeation properties of extruded PHBV cast films. J. Appl. Polym. Sci. 135 (2018) 46153, doi:10.1002/app.46153.

[13] Zhang, K.; Misra, M.; Mohanty, A.K. Toughened sustainable green composites from poly(3hydroxybutyrate-co-3-hydroxyvalerate) based ternary blends and miscanthus biofiber. ACS Sustain. Chem. Eng. 2 (2014) 2345-2354, doi:10.1021/sc500353v.

[14] Chikh, A.; Benhamida, A.; Kaci, M.; Pillin, I.; Bruzaud, S. Synergistic effect of compatibilizer and sepiolite on the morphology of poly(3-hydroxybutyrate-co-3-hydroxyvalerate)/poly(butylene succinate) blends. Polym. Test. 53 (2016) 19-28, doi:10.1016/j.polymertesting.2016.05.008.

[15] Ma, P.; Hristova-Bogaerds, D.G.; Lemstra, P.J.; Zhang, Y.; Wang, S. Toughening of PHBV/PBS and PHB/PBS Blends via In situ Compatibilization Using Dicumyl Peroxide as a Free-Radical Grafting Initiator. Macromol. Mater. Eng. 297 (2012) 402-410, doi:10.1002/mame.201100224.

[16] El-Taweel, S.H.; Khater, M. Mechanical and Thermal Behavior of Blends of Poly(hydroxybutyrate-cohydroxyvalerate) with Ethylene Vinyl Acetate Copolymer. J. Macromol. Sci. Part. B. 54 (2015) 12251232, doi:10.1080/00222348.2015.1085274.

[17] Adams, B.; Abdelwahab, M.; Misra, M.; Mohanty, A.K. Injection-Molded Bioblends from Lignin and Biodegradable Polymers: Processing and Performance Evaluation. J. Polym. Environ. 26 (2018) 2360-2373. doi:10.1007/s10924-017-1132-0.

[18] Wang, S.; Chen, W.; Xiang, H.; Yang, J.; Zhou, Z.; Zhu, M. Modification and Potential Application of Short-Chain-Length Polyhydroxyalkanoate (SCL-PHA). Polymers 8 (2016) 273, doi:10.3390/polym8080273.

[19] González-Ausejo, J.; Sánchez-Safont, E.; Cabedo, L.; Gamez-Perez, J. Toughness Enhancement of Commercial Poly (Hydroxybutyrate-co-Valerate) (PHBV) by Blending with a Thermoplastic Polyurethane (TPU). J. Multiscale Model. 7 (2016) 1640008(1-7), doi:10.1142/S1756973716400084.

[20] Martínez-Abad, A.; González-Ausejo, J.; Lagarón, J.M.; Cabedo, L. Biodegradable poly(3hydroxybutyrate-co-3-hydroxyvalerate)/thermoplastic polyurethane blends with improved mechanical and barrier performance. Polym. Degrad. Stab. 132 (2016) 52-61, doi:10.1016/j.polymdegradstab.2016.03.039.

[21] Bhardwaj, R.; Mohanty, A.K.; Drzal, L.T.; Pourboghrat, F.; Misra, M. Renewable resource-based green composites from recycled cellulose fiber and poly(3-hydroxybutyrate-co-3-hydroxyvalerate) bioplastic. Biomacromolecules 7 (2006) 2044-2051. 
[22] Sánchez-Safont, E.L.; Aldureid, A.; Lagarón, J.M.; Gámez-Pérez, J.; Cabedo, L. Biocomposites of different lignocellulosic wastes for sustainable food packaging applications. Compos. Part. B Eng. 145 (2018) 215-225, doi:10.1016/j.compositesb.2018.03.037.

[23] Satyanarayana, K.G.; Arizaga, G.G.C.; Wypych, F. Biodegradable composites based on lignocellulosic fibers-An overview. Prog. Polym. Sci. $34 \quad$ (2009) 982-1021, doi:10.1016/j.progpolymsci.2008.12.002.

[24] Pereira, P.H.F.; Rosa, M.D.F.; Cioffi, M.O.H.; Benini, K.C.C.D.C.; Milanese, A.C.; Voorwald, H.J.C.; Mulinari, D.R. Vegetal fibers in polymeric composites: A review. Polímeros 25 (2015) 9-22, doi:10.1590/0104-1428.1722.

[25] Wei, L.; McDonald, A. A Review on Grafting of Biofibers for Biocomposites. Materials 9 (2016) 303(1-23), doi:10.3390/ma9040303.

[26] Misra, M.; Pandey, J.K.; Mohanty, A.K. Biocomposites: Design and Mechanical Performance; Elsevier Inc.: Amsterdam, The Netherlands, 2015; ISBN 9781782423942.

[27] Muthuraj, R.; Misra, M.; Mohanty, A.K. Biodegradable compatibilized polymer blends for packaging applications: A literature review. J. Appl. Polym. Sci. 135 (2018) 45726, doi:10.1002/app.45726.

[28] Stenstad, P.; Andresen, M.; Tanem, B.S.; Stenius, P. Chemical surface modifications of microfibrillated cellulose. Cellulose 15 (2008) 35-45, doi:10.1007/s10570-007-9143-y.

[29] Jiang, L.; Chen, F.; Qian, J.; Huang, J.; Wolcott, M.; Liu, L.; Zhang, J. Reinforcing and Toughening Effects of Bamboo Pulp Fiber on Poly(3-hydroxybutyrate-co-3-hydroxyvalerate) Fiber Composites. Ind. Eng. Chem. Res. 49 (2010) 572-577, doi:10.1021/ie900953z.

[30] Zarrinbakhsh, N.; Mohanty, A.K.; Misra, M. Improving the interfacial adhesion in a new renewable resource-based biocomposites from biofuel coproduct and biodegradable plastic. J. Mater. Sci. 48 (2013) 6025-6038, doi:10.1007/s10853-013-7399-1.

[31] Anderson, S.; Zhang, J.; Wolcott, M.P. Effect of Interfacial Modifiers on Mechanical and Physical Properties of the PHB Composite with High Wood Flour Content. J. Polym. Environ. 21 (2013) 631639, doi:10.1007/s10924-013-0586-y.

[32] González-Ausejo, J.; Sánchez-Safont, E.; Lagarón, J.M.; Balart, R.; Cabedo, L.; Gámez-Pérez, J. Compatibilization of poly(3-hydroxybutyrate-co-3-hydroxyvalerate)-poly(lactic acid) blends with diisocyanates. J. Appl. Polym. Sci. 134 (2017) 1-11, doi:10.1002/app.44806.

[33] Dogan, S.K.; Reyes, E.A.; Rastogi, S.; Ozkoc, G. Reactive compatibilization of PLA/TPU blends with a diisocyanate. J. Appl. Polym. Sci. 131 (2014) 40251 (1-10) doi:10.1002/app.40251.

[34] Dogan, S.K.; Boyacioglu, S.; Kodal, M.; Gokce, O.; Ozkoc, G. Thermally induced shape memory behavior, enzymatic degradation and biocompatibility of PLA/TPU blends: "Effects of compatibilization". J. Mech. Behav. Biomed. Mater. 71 (2017) 349-361, doi:10.1016/j.jmbbm.2017.04.001.

[35] Hao, M.; Wu, H.; Qiu, F.; Wang, X. Interface Bond Improvement of Sisal Fibre Reinforced Polylactide Composites with Added Epoxy Oligomer. Materials 11 (2018) 398(1-22), doi:10.3390/ma11030398.

[36] Nanthananon, P.; Seadan, M.; Pivsa-Art, S.; Hiroyuki, H.; Suttiruengwong, S. Biodegradable polyesters reinforced with eucalyptus fiber: Effect of reactive agents. In AIP Conference Proceedings; AIP Publishing: Melville, NY, USA, 2017; p. 70012.

[37] Tang, W.; Wang, H.; Tang, J.; Yuan, H. Polyoxymethylene/thermoplastic polyurethane blends compatibilized with multifunctional chain extender. J. Appl. Polym. Sci. 127 (2013) 3033-3039, doi:10.1002/app. 37538. 
[38] Hao, M.; Wu, H. Effect of in situ reactive interfacial compatibilization on structure and properties of polylactide/sisal fiber biocomposites. Polym. Compos. 39 (2018) E174-E187, doi:10.1002/pc.24484.

[39] Ferrero, B.; Fombuena, V.; Fenollar, O.; Boronat, T.; Balart, R. Development of natural fiberreinforced plastics (NFRP) based on biobased polyethylene and waste fibers from Posidonia oceanica seaweed. Polym. Compos. 36 (2015) 1378-1385, doi:10.1002/pc.23042.

[40] Hameed, N.; Guo, Q.; Tay, F.H.; Kazarian, S.G. Blends of cellulose and poly(3-hydroxybutyrate-co-3hydroxyvalerate) prepared from the ionic liquid 1-butyl-3-methylimidazolium chloride. Carbohydr. Polym. 86 (2011) 94-104, doi:10.1016/J.CARBPOL.2011.04.016.

[41] Mechanical and biodegradation performance of short natural fibre polyhydroxybutyrate composites. Polym. Test. 32 (2013) 1603-1611.

[42] Wu, S. Phase structure and adhesion in polymer blends: A criterion for rubber toughening. Polymer 26 (1985) 1855-1863, doi:10.1016/0032-3861(85)90015-1.

[43] Sánchez-Safont, E.L.; Arrillaga, A.; Anakabe, J.; Gamez-Perez, J. ; Cabedo, L. PHBV/TPU/Cellulose compounds for compostable injection molded parts with improved thermal and mechanical performance. J. Appl. Polym. Sci., submitted.

[44] Seggiani, M.; Cinelli, P.; Mallegni, N.; Balestri, E.; Puccini, M.; Vitolo, S.; Lardicci, C.; Lazzeri, A. New Bio-Composites Based on Polyhydroxyalkanoates and Posidonia oceanica Fibres for Applications in a Marine Environment. Materials 10 (2017) 326(1-13), doi:10.3390/ma10040326.

[45] Yatigala, N.S.; Bajwa, D.S.; Bajwa, S.G. Compatibilization improves physico-mechanical properties of biodegradable biobased polymer composites. Compos. Part. A Appl. Sci. Manuf. 107 (2018) 315325, doi:10.1016/j.compositesa.2018.01.011.

[46] Wang, S.; Xiang, H.; Wang, R.; Peng, C.; Zhou, Z.; Zhu, M. Morphology and properties of renewable poly(3-hydroxybutyrate-co-3-hydroxyvalerate) blends with thermoplastic polyurethane. Polym. Eng. Sci. 54 (2014) 1113-1119, doi:10.1002/pen.23655.

[47] Margolina, A.; Wu, S. Percolation model for brittle-tough transition in nylon/rubber blends. Polymer 29 (1988) 2170-2173, doi:10.1016/0032-3861(88)90108-5.

[48] Nagarajan, V.; Misra, M.; Mohanty, A.K. New engineered biocomposites from poly(3hydroxybutyrate-co-3-hydroxyvalerate) (PHBV)/poly(butylene adipate-co-terephthalate) (PBAT) blends and switchgrass: Fabrication and performance evaluation. Ind. Crops Prod. 42 (2013) 461468, doi:10.1016/j.indcrop.2012.05.042.

[49] Muthuraj, R.; Misra, M.; Mohanty, A.K. Reactive compatibilization and performance evaluation of miscanthus biofiber reinforced poly(hydroxybutyrate-co-hydroxyvalerate) biocomposites. J. Appl. Polym. Sci. 134 (2017) 44860 (1-10) doi:10.1002/app.44860.

[50] Rossa, L.V.; Scienza, L.C.; Zattera, A.J. Effect of curauá fiber content on the properties of poly(hydroxybutyrate-co-valerate) composites. Polym. Compos. 34 (2013) 450-456, doi:10.1002/pc.22432.

[51] Buchdahl, R. Mechanical properties of polymers and composites-Vols. I and II, Lawrence, E. Nielsen, Marcel Dekker, Inc.; New York, 1974, Vol. I 255 pp. Vol. II 301 pp. Vol. I \$24.50, Vol. II \$28.75. J. Polym. Sci. Polym. Lett. Ed. 13 (1975) 120-121, doi:10.1002/pol.1975.130130214.

[52] González-Ausejo, J.; Sanchez-Safont, E.; Lagaron, J.M.; Olsson, R.T.; Gamez-Perez, J.; Cabedo, L. Assessing the thermoformability of poly(3-hydroxybutyrate-co-3-hydroxyvalerate)/poly(acid lactic) blends compatibilized with diisocyanates. Polym. Test. 62 (2017) 235-245, doi:10.1016/j.polymertesting.2017.06.026. 
[53] Sánchez-Safont, E.L.; González-Ausejo, J.; Gámez-Pérez, J.; Lagarón, J.M.; Cabedo, L. Poly(3Hydroxybutyrate-co-3-Hydroxyvalerate)/Purified Cellulose Fiber Composites by Melt Blending: Characterization and Degradation in Composting Conditions. J. Renew. Mater. 4 (2016) 123-132, doi:10.7569/JRM.2015.634127.

[54] Determinación del Grado de Desintegración de Materiales Plásticos Bajo Condiciones de Compostaje Simuladas en un Laboratorio; UNE-EN ISO UNE-EN ISO 20200; ISO: Geneva, Switzerland, 2006. 
"La verdad es lo que es, y sigue siendo verdad aunque se piense al revés"

(Antonio Machado)

SECCIÓN 4.-Análisis general de resultados 
Esta tesis se ha centrado en la obtención y caracterización de compuestos basados en polihidroxialcanoatos (PHA) y fibras de origen lignocelulósico con el objetivo de obtener materiales compostables de coste reducido encaminados a aplicaciones de corta vida útil como el envasado o el desarrollo de productos desechables (cubertería de un solo uso, pajitas, etc.).

Empleando como materiales de base polihidroxibutirato (PHB) y poli(hidroxibutirato-cohidroxivalerato) (PHBV) se han obtenido compuestos mediante la adición de fibras de origen lignocelulósico tanto comerciales (TC90), como procedentes de residuos vegetales (AS, RH, SG). Se ha estudiado la adición de una fase elastomérica como modificador de impacto (TPU) con el fin de mejorar la tenacidad en sistemas PHBV/TC90. Se ha evaluado la eficiencia de distintos agentes reactivos como compatibilizantes de las distintas fases tanto en los sistemas dobles (PHA/fibra) como en los triples (PHBV/TPU/TC90).

En un primer bloque (Capítulos I-IV) se han desarrollado distintos compuestos PHA/fibra con el objetivo de estudiar su relación composición-estructura-propiedades, valorar la idoneidad de diferentes fibras procedentes de residuos como materiales de refuerzo en este tipo de sistemas, mejorar la compatibilidad fibra/matriz, así como analizar algunos aspectos fundamentales para su aplicabilidad en la industria del envasado y el efecto del envejecimiento sobre su comportamiento mecánico, sus propiedades barrera, su procesabilidad y su biodesintegrabilidad en condiciones de compostaje.

En un segundo bloque (Capítulos $\boldsymbol{V}$-VI), bajo un enfoque mucho más industrial, se han obtenido compuestos triples PHBV/TPU/Celulosa con el objetivo de mejorar la aplicabilidad del PHBV en la fabricación de productos de pieza inyectada, estudiado el efecto de incorporación de celulosa y del TPU sobre las propiedades del PHBV y la compatibilización de las fases.

Con el propósito de dar respuesta a los objetivos específicos marcados en esta investigación, a continuación se estudian, bajo una perspectiva global, los resultados obtenidos en los diferentes trabajos recogidos en los distintos capítulos de esta tesis.

\section{a) Características de las fibras y efecto del tratamiento de purificación}

Para poder valorar la idoneidad de las fibras procedentes de residuos como materiales de refuerzo en sistemas PHA/fibra y tener una mayor compresión de la influencia del tipo de fibra y su pureza sobre las propiedades de los compuestos, resulta necesario analizar las características de las mismas, de qué dependen dichas características y cómo influyen sobre estas los tratamientos de purificación empleados. 
Como ha sido analizado en el Capítulo II, tanto la composición como las características morfológicas y distribución de tamaños de partícula de las fibras están íntimamente relacionadas con su naturaleza. Así, además de presentar diferentes características morfológicas y diferentes contenidos de sus componentes principales (lignina, hemicelulosas y celulosa), la cáscara de arroz $(\mathrm{RH})$, por ejemplo, presenta un elevado contenido en sílice y el residuo de SG presenta una elevada proporción de impurezas (carbonatos, sílice, oxalato cálcico). Por lo que, a la hora de la utilización de residuos como fuente de fibras para su uso como refuerzo, resulta evidente la necesidad de estudiar cada caso en particular e incluso adaptar las operaciones de acondicionamiento y/o tratamiento. Así, por ejemplo, en el caso del SG es necesario someter a las fibras a diferentes prelavados para poder eliminar las impurezas presentes antes de ser utilizadas.

La composición química de las fibras, principalmente, su contenido en celulosa, hemicelulosas y lignina, determinan su estabilidad térmica, ya que la lignina y las hemicelulosas comienzan su degradación térmica a temperaturas inferiores a las de la celulosa. La cristalinidad relativa de las fibras también se ve afectada por el contenido en lignina y hemicelulosas, ya que se trata de componentes amorfos en la naturaleza, pero también de las características concretas de la celulosa de la que se compone cada tipo de fibra. Así, fibras con contenidos comparables de celulosa pueden presentar cristalinidades distintas, como es el caso del RH y el SG.

Las fibras procedentes de residuos empleadas en esta tesis han sido utilizadas sin ningún tratamiento previo (exceptuando operaciones de secado y reducción de tamaño) o bien, sometidas a dos tratamientos de purificación dirigidos a eliminar las impurezas y los componentes no celulósicos de la fibra, principalmente lignina, hemicelulosas y ceras. El primero de ellos (en adelante T1) (Capítulo II) ha consistido en un tratamiento combinado con hidróxido de sodio y peróxido de hidrogeno y el segundo ha sido un tratamiento combinado con hidróxido de sodio y ácido peracético (T2) (Capítulo III).

El tratamiento T2 (Capitulo III) ha demostrado ser más eficiente en la eliminación de componentes no celulósicos que el tratamiento T1 (Capítulo II).

Ambos tratamientos conducen a un aumento del índice de cristalinidad relativa y una mejora de la estabilidad térmica de las fibras, lo que indica la eliminación parcial de componentes no celulósicos. No obstante, en el caso del tratamiento T2 tanto el índice de cristalinidad relativa, como las temperaturas de inicio de degradación térmica y de máxima velocidad de degradación son comparables a las correspondientes a una celulosa comercial (TC90) de alta pureza (>99.5\% $\alpha$-celulosa). La eliminación y/o reducción de lignina y hemicelulosas queda evidenciada por FTIR, 
así como de otros componentes como las ceras o la sílice, en el caso del RH. La eliminación de estos componentes da lugar a una mayor cantidad de grupos $-\mathrm{OH}$ reactivos en la superficie de las fibras como se desprende de los resultados obtenidos mediante esta técnica.

Además, ambos tratamientos introducen modificaciones morfológicas en las fibras, como ha sido observado por SEM. En el caso de la cáscara de almendra, ambos tratamientos dan lugar a una mayor rugosidad de la superficie de las partículas aunque el tamaño de partícula no se ve prácticamente afectado. En el caso del RH los tratamientos conducen a una desfibrilación de las partículas obteniéndose una mayor rugosidad superficial, una distribución de tamaños de partícula más uniforme y una mayor relación de aspecto ( $~ 7$ en el caso de T1 y 20 en el caso de T2). En el caso del SG (únicamente tratamiento T1), el tratamiento conduce también a una reducción del tamaño de partícula y mayor uniformidad de tamaños.

Estas modificaciones, tanto químicas como morfológicas, pueden considerarse a priori favorables para el uso al que van destinadas las fibras. No obstante, para valorar la necesidad o no de un tratamiento en vistas a minimizar etapas de procesado o reducir costes deben tenerse en cuenta otros factores como se analizará en los siguientes apartados.

\section{b) Análisis de la relación composición-estructura-propiedades en compuestos PHA/fibra}

Para poder realizar una valoración adecuada de la aplicabilidad de compuestos PHA/fibra, así como evaluar la idoneidad de las distintas fibras utilizadas como refuerzo en este tipo de materiales, resulta necesario conocer y comprender de forma clara la relación composición estructura -propiedades que determinará su comportamiento.

De este modo, a partir de los resultados obtenidos para los distintos materiales estudiados en esta investigación, en los siguientes subapartados se analiza el efecto de la incorporación de fibra sobre las propiedades mecánicas, la cristalinidad y la estabilidad térmica de los materiales obtenidos tratando de establecer las relaciones generales existentes entre el contenido, tipo y/o pureza de la fibra, la morfología del compuesto y sus propiedades.

\section{b.1.) Comportamiento mecánico}

El comportamiento mecánico de los compuestos estudiados está principalmente determinado por la interacción fibra/matriz en la medida en que la adhesión entre ambas fases sea capaz de garantizar una eficaz transferencia de esfuerzos en la interfase. Por tanto, dicho comportamiento se ve influenciado tanto por el contenido de fibra, como por el tipo y pureza de la misma, siendo este último uno de los factores más determinantes. 
En líneas generales, en todos los compuestos estudiados se ha observado un incremento de la rigidez (módulo elástico y módulo de almacenamiento) al incorporar las fibras que indica un efecto de refuerzo. Dicho efecto de refuerzo, presenta una tendencia creciente con el contenido de fibra independientemente del tipo y/o pureza de la fibra (Capítulos $\boldsymbol{l}, \boldsymbol{I} \boldsymbol{y} \boldsymbol{V}$ ). Asimismo, tanto en las composiciones procesadas por mezclado en fundido en mezclador interno (Capítulos I y II) como en las obtenidas por extrusión doble husillo (Capítulos III-V) se ha observado una buena dispersión de las fibras y distribución homogénea de las mismas sin detectarse presencia de aglomerados. Ambos resultados indican que existe cierta afinidad entre la matriz y la fibra. A pesar de ello, otros parámetros como la resistencia mecánica y, en mayor medida, la elongación a rotura se ven afectados negativamente con la incorporación de las fibras no tratadas (Capítulo III) o las fibras tratadas mediante el tratamiento T1 (Capítulo II), que ha demostrado ser menos eficiente en la eliminación de componentes no celulósicos, lo que puede dar lugar a una falta de adhesión interfacial. En efecto, la fragilidad intrínseca del polímero, unida a la falta de adhesión interfacial, hacen que a cierto nivel de esfuerzo las fibras actúen como concentradores de tensiones dando lugar a un fallo prematuro del material. En condiciones de falta de adhesión interfacial, las diferencias entre los distintos tipos de fibra no han sido muy notables. No obstante, es importante destacar que en aquellas fibras que presentan una mayor uniformidad de tamaños y una mayor rugosidad superficial, la caída en elongación a rotura y resistencia mecánica es menor demostrando la contribución de estos factores geométricos a la interacción fibra/matriz.

Una mayor pureza de las fibras permite mejorar la adhesión fibra/matriz lo que se ve reflejado en un incremento de la resistencia mecánica con respecto a la matriz y una menor reducción de la elongación a rotura, como se ha demostrado en el caso de las fibras purificadas mediante el tratamiento T2 y las fibras de celulosa comercial (Capítulos III y IV). En efecto, como ha sido observado en los ensayos de LEFM, en los compuestos con fibras no tratadas se ha observado una reducción en el factor crítico de intensidad de tensiones $\left(K_{I C}\right)$ experimental que evidencia el fallo prematuro del material por un mecanismo de capa débil (presencia de ceras e impurezas superficiales). Como ha sido mencionado anteriormente, el tratamiento de purificación da lugar a una mayor cantidad de grupos $-\mathrm{OH}$ reactivos en la superficie de las fibras que pueden establecer puentes de hidrógeno con los carbonilos del PHB. Además, las modificaciones morfológicas que introduce el tratamiento, sobre todo, la rugosidad superficial, favorecen el anclaje mecánico de la fibra con la matriz, como ocurre, por ejemplo, en el caso de la cáscara de almendra.

El efecto positivo de una mayor pureza sobre la interacción fibra/matriz ha sido corroborado también por SEM ya que, en general, se ha observado una mayor interacción de las fibras 
tratadas (tanto T1 como T2) y de la celulosa comercial con el polímero que en el caso de las no tratadas (menor presencia de pull-outs y cierta cobertura de las fibras por el polímero). Sin embargo, aunque la pureza puede tener un efecto positivo en la interacción fibra/matriz, la naturaleza de dicha interacción es débil.

\section{b.2.) Cristalinidad}

La cristalinidad de los compuestos se ve afectada tanto por las condiciones del procesado (historia térmica) como por la presencia de las fibras. Como ha sido estudiado en los Capítulos III $\boldsymbol{y} \boldsymbol{I V}$, a velocidades de enfriamiento elevadas (condiciones de procesado), las fibras parecen dificultar el movimiento de las cadenas poliméricas impidiendo parcialmente el desarrollo de cristalinidad durante el envejecimiento. En efecto, mientras que en el PHB puro se observa un aumento de cristalinidad de alrededor del $20 \%$ en muestras envejecidas 100 días respecto a muestras recién procesadas, en el caso de los compuestos, dicho aumento de cristalinidad es mucho menor dando lugar a cristalinidades inferiores a las del PHB puro en las muestras envejecidas. Sin embargo, en condiciones dinámicas y velocidades lentas de enfriamiento (condiciones del ensayo de DSC) donde las cadenas poliméricas presentan elevada movilidad no se observan diferencias significativas en este parámetro entre los compuestos y el PHB puro.

\section{b.3.) Estabilidad térmica}

La estabilidad térmica de los compuestos PHA/fibra se ve afectada tanto por el contenido en fibra como por la pureza de la misma. En el caso de las fibras no tratadas (Capítulo III) y de las fibras tratadas mediante el tratamiento T1 (Capítulo II), la incorporación de las fibras da lugar a una reducción tanto de la temperatura de inicio de degradación como de máxima degradación térmica con respecto al PHB debido a la presencia de los componentes no celulósicos. Dicha reducción en la estabilidad térmica es mayor al incrementar el contenido de fibra. En el caso de las fibras purificadas mediante el tratamiento T2 y las fibras de celulosa comercial (Capítulo III), la estabilidad térmica del PHB no se ve afectada en el rango de composiciones estudiadas. En el caso de los sistemas PHBV/celulosa comercial (Capítulos $\boldsymbol{I} \boldsymbol{y} \boldsymbol{V}$ ) la estabilidad térmica del PHB no se ve afectada hasta un contenido del $25 \%$ en fibra en el caso de los materiales obtenidos en mezclador interno (Capítulo I) y 30 phr en los obtenidos por extrusión doble husillo e inyección (Capítulo V). En este caso la degradación a altos contenidos de fibra puede atribuirse a un efecto de cizalla durante el procesado. No obstante, en cualquier caso, tanto el inicio de degradación térmica como de máxima degradación tiene lugar por encima de las temperaturas habituales de procesado y de servicio de estos materiales. 


\section{c) Compatibilización de sistemas PHB/fibra mediante extrusión reactiva}

El uso de diisocianato de hexametileno (HMDI) como agente de compatibilización ha demostrado ser efectivo en sistemas PHB/fibra (Capítulo IV). No obstante, su eficiencia depende fuertemente de la pureza de la fibra. El HMDI puede reaccionar con los grupos $-\mathrm{OH}$ de la superficie de las fibras para formar enlaces uretano, así como con los finales de cadena del polímero. Como se ha visto anteriormente, tanto en las fibras purificadas como en la celulosa comercial de alta pureza existe una mayor cantidad $-\mathrm{OH}$ reactivos expuestos en la superficie favoreciendo la compatibilización lo que se traduce en un aumento sustancial de la resistencia mecánica, manteniendo el módulo elástico y manteniendo, e incluso incrementando ligeramente, la elongación a rotura respecto a los compuestos no compatibilizados, lo que da lugar a una mayor tenacidad estática. Dicha mejora del comportamiento mecánico indica una mayor adhesión entre la fibra y la matriz. De hecho en las observaciones realizadas mediante microscopia SEM se observa una mayor cobertura de las fibras por el polímero, una unión más estrecha en la interfase y la presencia de fibras rotas en dirección longitudinal indicando un fallo cohesivo. Esta mayor interacción entre las fibras y la matriz se ve también reflejada en un mayor impedimento del movimiento catenario como se desprende de los resultados de DMA y DSC. Por el contrario, en el caso de las fibras no tratadas, el HMDI no tiene ningún efecto sobre la adhesión fibra/matriz, de hecho resulta, incluso, negativo desde el punto de vista mecánico debido a la menor cantidad de $-\mathrm{OH}$ reactivos en la superficie y al efecto de "capa débil" ejercido por las impurezas y ceras presentes en la superficie.

El resto de agentes reactivos estudiados (DCP, RDGE y TGIC) no han demostrado un efecto claro de compatibilización. No obstante, resulta interesante comentar el caso particular del DCP. De los resultados obtenidos en DSC, se deduce que este agente reactivo promueve el entrecruzamiento de la matriz ya que se observa una reducción apreciable de la cristalinidad y la temperatura de fusión tanto a altas como bajas velocidades de enfriamiento. Sin embargo, las propiedades mecánicas en su conjunto se mantienen en valores similares a los correspondientes al compuesto PHB/TC90. Dicho balance de propiedades mecánicas-cristalinidad podría considerarse favorable desde el punto de vista de su procesabilidad.

\section{d) Idoneidad de las fibras procedentes de residuos como refuerzos en compuestos basados en PHA}

En líneas generales, todas las fibras estudiadas pueden considerarse adecuadas para su uso como como refuerzo en compuestos basados en PHA. No obstante, aspectos como la naturaleza de la fibra, la aplicación o no de un tratamiento de purificación, el uso de agentes compatibilizantes o 
el contenido de fibra determinan las propiedades finales del compuesto, principalmente, de su comportamiento mecánico y su estabilidad térmica. En la Tabla 4.1 se muestra, a modo de resumen, el efecto de los factores que mayor influencia tienen en el comportamiento mecánico y la estabilidad térmica de compuestos PHA/fibra. El color de las flechas indica el efecto positivo (verde) o negativo (rojo) de cada factor sobre los distintos parámetros y el sentido de la flecha la tendencia al alza o a la baja del mismo, en los casos en los que la influencia no es tan marcada se indica con el símbolo $\approx$.

Tabla 4.1. Influencia de las fibras sobre el comportamiento mecánico y la estabilidad térmica de compuestos PHA/fibra.

\begin{tabular}{|c|c|c|c|c|}
\hline & $\begin{array}{l}\text { Módulo } \\
\text { elástico }\end{array}$ & $\begin{array}{c}\text { Resistencia } \\
\text { Mecánica }\end{array}$ & $\begin{array}{c}\text { Elongación a } \\
\text { rotura }\end{array}$ & $\begin{array}{c}\text { Estabilidad } \\
\text { térmica }\end{array}$ \\
\hline Pureza de la fibra & $=$ & & $=1$ & 1 \\
\hline \multicolumn{5}{|l|}{ Contenido de fibra } \\
\hline Rugosidad superficial & $=1$ & $=1$ & $=1$ & - \\
\hline Agente Compatibilizante & $=1 *$ & . $*$ & $=1 *$ & - \\
\hline
\end{tabular}

* En el caso de fibras de alta pureza, para fibras no tratadas el efecto es negativo

La combinación de propiedades mecánicas y estabilidad térmica más favorable se obtiene mediante el uso de fibras de alta pureza y un agente compatibilizante. Además, aunque el contenido en fibra tiene un efecto negativo sobre la estabilidad térmica, al incorporar fibras de alta pureza esta propiedad no se ve afectada hasta contenidos relativamente altos de fibra, por lo que a priori, el beneficio en la reducción de costes sería mayor.

Sin embargo, y precisamente desde el punto de vista de minimizar las etapas de proceso y reducir en mayor medida los costes, se plantea la cuestión de la necesidad o no de someter a las fibras a un tratamiento de purificación o de la necesidad de utilizar agentes compatibilizantes. Como ya ha sido analizado, para obtener una mejora sustancial de las prestaciones mecánicas, el uso de un agente compatibilizante no permite sustituir el tratamiento de purificación dado que la eficacia de dicho agente depende en gran medida de la pureza de la fibra. Por otro lado, aun en el caso más desfavorable, que correspondería al uso de fibras no tratadas, tanto desde el punto de vista mecánico como de estabilidad térmica, estas propiedades se mantienen en valores relativamente aceptables. Por lo que, dependiendo de las exigencias concretas del producto al que vayan a ser destinados estos materiales deberá valorarse el coste-beneficio de cada una de las opciones. 


\section{SECCIÓN 4.- Análisis general de resultados}

Por ejemplo, para aplicaciones de bajo valor añadido, en las que los materiales no vayan a estar sometidos a temperaturas muy por encima del ambiente puede ser admisible cierta degradación térmica. Si, además, las prestaciones mecánicas no van a ser muy exigentes, el uso de fibras sin ningún tipo de tratamiento puede ser la opción más viable desde el punto de vista económico. Estos materiales podrían ser interesantes, por ejemplo, en ciertas aplicaciones agrícolas o de jardinería en las que el material debe cumplir su función durante un corto periodo de tiempo y posteriormente degradarse en el ambiente.

Para otro tipo de aplicaciones en las que las exigencias mecánicas o térmicas sean más importantes ya debería valorarse la opción de tratamiento y uso de agentes de compatibilización más adecuada, como es el caso de la industria del envasado.

\section{e) Aplicabilidad de compuestos PHA/fibra en la industria del envasado}

Además del coste y de un balance aceptable de propiedades mecánicas y térmicas, algunos factores que deben considerarse a la hora de evaluar la aplicabilidad de este tipo de materiales en la industria del envase son sus propiedades barrera, el efecto del envejecimiento sobre su comportamiento mecánico, su procesabilidad y, por supuesto, su biodesintegrabilidad en condiciones de compostaje, considerando el compostaje como una de las opciones más viables para la gestión de sus residuos.

\section{e.1.) Efecto del envejecimiento}

Como ha sido descrito en la sección Marco teórico, uno de los puntos débiles de los polihidroxialcanoatos es que experimentan una fragilización muy acusada con el tiempo. Dicha fragilización se debe al efecto combinado del desarrollo de cristalización secundaria y al envejecimiento físico de la fase amorfa. Tal y como ha sido analizado en los capítulos III y IV, el PHB experimenta un incremento de cristalinidad notable tras varias semanas de ser procesado. Por otro lado, como ha sido discutido en el apartado b.2. de esta sección, el aumento de cristalinidad con el tiempo es menor en los compuestos que en el PHB puro, dando lugar a una menor cristalinidad respecto al PHB puro en las muestras envejecidas. Los resultados obtenidos sugieren que existe interacción tanto de las fibras como de los diferentes agentes reactivos con el polímero, que afecta tanto a la cristalinidad como a la fase fase amorfa, y por tanto, al proceso de envejecimiento. En efecto, aunque la fragilización de los compuestos con el tiempo es notable, la reducción de tenacidad es menos acusada que en el PHB puro. En este sentido, sería conveniente realizar un estudio en mayor profundidad. 


\section{e.2.) Propiedades barrera}

La incorporación de fibras al PHB ejerce un efecto negativo en las propiedades barrera de los compuestos estudiados (Capítulo II). En general, la permeabilidad al agua (WVP) aumenta con la presencia de las fibras y con su contenido, aunque existen diferencias entre los distintos tipos de fibra, siendo la AS la que menor aumento produce. Este efecto se atribuye a la elevada higroscopicidad de las fibras y la presencia de caminos preferentes de difusión en la interfase. Aunque, a priori, estos resultados podrían considerarse negativos para la aplicabilidad de estos materiales en la industria del envasado alimentario, una elevada permeabilidad al agua no debe considerarse excluyente. En efecto, esta propiedad podría resultar adecuada, por ejemplo, para el envasado de productos que necesiten aireación (frutas o verduras) y, en el caso de aplicaciones de alta barrera, este tipo de materiales podría ser adecuado como capa estructural de bajo coste en sistemas multicapa en los que la barrera la proporciona otra de las capas especialmente diseñada para ese propósito.

\section{e.3) Procesabilidad}

Los compuestos desarrollados no han presentado dificultades de procesado en el rango de composiciones estudiado. Asimismo, aunque se ha observado cierta reducción de la estabilidad térmica para altos contenidos de fibra o en el caso del uso de fibras no purificadas, en cualquier caso, tanto el inicio de degradación térmica como de máxima degradación tiene lugar por encima de las temperaturas habituales de procesado, como ha sido analizado en el apartado b.3. de esta sección. Por tanto, a efectos de compounding los materiales desarrollados son aptos para su procesado industrial.

No obstante, resulta particularmente interesante evaluar su termoconformabilidad, ya que se trata de una de las técnicas más extendidas en sectores como el de envasado.

En el capítulo Il se ha evaluado la termoconformabilidad de los compuestos PHB/fibra (AS, RH y SG), evidenciando las dificultades que presenta el PHB para su conformado mediante esta técnica y, especialmente, con la incorporación de fibras. Como ha sido descrito en la sección Marco teórico, la elevada cristalinidad del PHB, junto con su elevada temperatura de fusión, hacen que presente una estrecha ventana de procesado. Además, su elevada rigidez hasta temperaturas cercanas a la de fusión, unida a la baja viscosidad en fundido hace que en las inmediaciones de Tm (condiciones del termoconformado) y a elevadas velocidades y relaciones de estirado, la lámina presente una baja estabilidad mecánica. Esto da lugar a fenómenos de flacidez que resultan en una distribución de espesores y reproducibilidad de molde, en general, deficientes. Asimismo, la elevada cristalinidad da lugar a contracciones durante el enfriamiento que 
introducen tensiones y defectología. En general, la presencia de las fibras da lugar a un empeoramiento de la termoconformabilidad del PHB tanto en lo que se refiere a reproducibilidad del molde como a la distribución de espesores. No obstante, en el caso de la composición PHB/AS (Capítulo II) se han conseguido obtener bandejas termoconformadas con características aceptables, comparables al PHB e incluso ligeramente superiores. En el Capítulo IV, la termoconformabilidad del compuesto PHB/T_RH /HMDI ha sido verificada. En este caso se ha obtenido una buena reproducibilidad del molde y una distribución de espesores aceptable mediante el ajuste de los parámetros de operación.

Estos resultados son muy prometedores para la aplicabilidad de estos materiales en la obtención de productos termoconformados. Probablemente, cuando existe una buena interacción fibra/matriz (podría deberse a un anclaje mecánico por las características superficiales en el caso de la AS y químico en el caso del T_RH compatibilizado con HMDI), la fibra puede contribuir a actuar como soporte mecánico de la lámina.

En definitiva, los resultados obtenidos se pueden considerar muy positivos como punto de partida para profundizar en la investigación de la termoconformabilidad de este tipo de materiales y puede ser objeto de trabajos futuros derivados de esta investigación como se comentará en la próxima sección.

\section{e.4.) Biodesintegrabilidad en condiciones de compostaje}

Tal como ha sido estudiado en los Capítulos $\boldsymbol{I}, \boldsymbol{I} \boldsymbol{y} \boldsymbol{I V}$, todos los materiales desarrollados han demostrado ser biodesintegrables en condiciones de compostaje normalizadas (ISO 20200). Ni el tipo, ni el contenido de fibra, así como la presencia de agentes reactivos han tenido un efecto negativo sobre la compostabilidad del PHB y el PHBV, obteniéndose tiempos y velocidades de degradación similares en todos los casos.

\section{f) Mejora de la aplicabilidad del PHBV para la fabricación de productos de pieza inyectada}

En general, para aplicaciones de pieza rígida inyectada, los materiales empleados deben ser fácilmente procesables, de bajo coste y deben presentar un buen balance de propiedades mecánicas en términos de rigidez y tenacidad. Para aquellas aplicaciones en las que el material deba soportar temperaturas relativamente elevadas (por ejemplo recipientes para bebidas o comida caliente o para microondas) se requiere, además, una elevada resistencia térmica (alta HDT), y en el caso de productos desechables (por ejemplo cubertería de un solo uso), es deseable su biodegradabilidad. 
Junto al beneficio económico que supone la incorporación de una fase de bajo coste al PHBV, en esta tesis se ha explorado el efecto de la incorporación de un modificador de impacto, poliuretano termoplástico (TPU), como estrategia de mejora de la tenacidad con el propósito de favorecer la aplicabilidad del PHBV en la fabricación de productos de pieza inyectada. Los compuestos ternarios PHBV/TPU/Celulosa desarrollados en esta tesis han demostrado presentar un buen balance de propiedades en términos de rigidez/tenacidad/resistencia térmica incluso sin necesidad de compatibilización de las fases (Capítulo $\boldsymbol{V}$ ). No obstante, al utilizar agentes reactivos de compatibilización ( $\mathrm{HMDI}$, Joncryl ${ }^{\circledR}, \mathrm{TGIC}$ ), se produce una extraordinaria mejora de las propiedades mecánicas de los compuestos explotando los beneficios aportados tanto por la fibra como por el TPU, particularmente, en el caso del HMDI (Capítulo VI). Además, en el rango de composiciones estudiado, todos los materiales obtenidos han presentado facilidad de procesado y han resultado ser biodesintegrables en condiciones de compostaje controladas (ISO 20200).

La celulosa ejerce un efecto de refuerzo sobre el PHBV y aumenta la HDT, aunque reduce su ductilidad. EI TPU por el contrario, aunque a expensas de reducir su rigidez y su HDT, incrementa notablemente la tenacidad del PHBV. Aun tratándose de una mezcla inmiscible (morfología “drop in matrix"), la existencia de cierta afinidad entre el PHBV y el TPU, como se desprende de los resultados de MFI y DSC y de la buena dispersión de la fase elastomérica en la matriz de PHBV y el reducido tamaño de gota y de distancia de ligamento entre partículas de la fase dispersa, promueve la deformación plástica mejorando tanto la tenacidad estática del material como su resistencia al impacto. La combinación de ambos aditivos produce un efecto intermedio, es decir, la celulosa permite compensar en cierta medida la perdida de rigidez y de resistencia térmica obtenida mediante la adición TPU. Al incorporar los distintos agentes reactivos se produce la compatibilización de las distintas fases, lo que produce un efecto sinérgico de los dos aditivos para un nivel de rigidez aceptable, tanto el límite elástico momo la elongación a rotura mejoran sustancialmente respecto al PHBV puro y la HDT se mantiene en interesantes valores por encima de $90^{\circ} \mathrm{C}$. Mientras que el TGIC y el Joncryl tienen un mayor efecto sobre la interacción entre las fases poliméricas, el HMDI tiene una mayor influencia sobre la adhesión fibra matriz. Es en este último caso en el que se obtienen unos incrementos mayores de tenacidad, demostrando el papel determinante que juega la interfase para garantizar una eficaz transferencia de esfuerzos $y$ mantener la deformación plástica del material.

Estos resultados resultan particularmente satisfactorios desde el punto de vista de transferencia industrial. Considerando que todas las composiciones han sido obtenidas mediante técnicas y condiciones de operación a escala semi industrial y todos los materiales empleados están disponibles comercialmente su escalabilidad industrial podría considerarse casi directa. Además, 
por supuesto de su compostabilidad, de la contribución positiva a la reducción de costes al introducir una cantidad relativamente alta de celulosa ( $30 \mathrm{phr}$ ) y al buen balance de propiedades, la relativamente elevada resistencia térmica (HDT $>90 \circ \mathrm{C}$ ) resulta especialmente interesante, dado que les permite competir con otros biopolímeros presentes en el mercado que no consiguen satisfacer satisfactoriamente este requisito, como por ejemplo el PLA.

Tal como se ha planteado en el capítulo introductorio de esta tesis, considerando la problemática asociada a los productos de un solo uso elaborados con plásticos convencionales y a las directrices legales encaminadas a ordenar su prohibición y sustitución por materiales biodegradables a corto plazo (2020), los materiales desarrollados se plantean como una alternativa medioambiental y técnicamente viable. Así, por ejemplo, para el caso de la fabricación de productos como cubiertos, vasos, tazas, etc. que van a estar en contacto con comidas o bebidas calienten y que requieren unas prestaciones de una combinación equilibrada de rigidez y tenacidad resultan particularmente aptos. 
“A menudo, el gran descubrimiento y lo más importante, es que una cierta pregunta se encuentra"

(Max Wertheimer)

SECCIÓN 5.-Conclusiones y trabajos futuros 


\subsection{Conclusiones}

A partir de los resultados obtenidos en esta investigación se pueden extraer las siguientes conclusiones:

\section{$\underline{\text { Tratamiento de las fibras }}$}

- La composición, presencia de impurezas, características morfológicas, cristalinidad relativa y estabilidad térmica de las fibras dependen de su naturaleza (fuente vegetal). Dicha dependencia hace necesaria la adaptación de las operaciones de acondicionamiento de las fibras a cada caso en particular antes de su uso.

- El tratamiento combinado con hidróxido de sodio y ácido peracético (T2) ha demostrado ser más efectivo en la eliminación de componentes no celulósicos que el tratamiento combinado con hidróxido de sodio y peróxido de hidrógeno (T1). Ambos tratamientos introducen modificaciones morfológicas en las fibras (desfibrilación, aumento de rugosidad superficial) y permiten eliminar parte de las impurezas y componentes no celulósicos de las fibras dejando expuestos una mayor cantidad de grupos $-\mathrm{OH}$ reactivos libres en su superficie. La eliminación de dichos componentes supone una mejora de la estabilidad térmica de las fibras y un incremento de su cristalinidad relativa.

\section{Compuestos PHA/fibra}

- La valorización de fibras lignocelulósicas procedentes de residuos de cáscara de almendra (AS), de cáscara de arroz (RH) y de la limpieza municipal de playas (SG) como refuerzo en compuestos basados en PHB ha demostrado ser técnicamente viable.

- La incorporación de las fibras estudiadas (TC90, AS, RH y SG) a matrices de PHB y/o PHBV produce un aumento del módulo elástico que tiene una dependencia positiva con el contenido de fibra y la rugosidad superficial de la misma.

- La incorporación de fibras no tratadas al PHB da lugar a una reducción de la resistencia mecánica y la elongación a rotura de los compuestos. Esto se debe a la presencia de impurezas, ceras y componentes no celulósicos en la superficie de las fibras que actúan como capa débil, que se manifiesta en una pobre adhesión fibra-matriz. Un tratamiento de purificación incrementa la resistencia mecánica y la elongación a rotura de los compuestos con respecto al uso de fibras no tratadas. 
- El uso de un agente reactivo (diisocianato de hexametileno, HMDI) permite mejorar la adhesión fibra-matriz en compuestos PHB/fibra lo que se traduce en un incremento de la resistencia mecánica, deformación a rotura y la tenacidad estática con respecto al PHB puro. Sin embargo, la eficacia del agente reactivo depende de la pureza de la fibra en la medida que existan suficientes grupos $-\mathrm{OH}$ libres en la superficie de las fibras capaces de reaccionar con el compatibilizante.

- Los agentes reactivos DCP, RDGE y TGIC no han demostrado un efecto compatibilizante en compuestos PHB/Celulosa.

- La estabilidad térmica de los compuestos PHA/fibra mejora con la pureza de la fibra y disminuye con el contenido de fibra.

- El termoconformado de compuestos PHA/fibra es técnicamente viable a partir de las composiciones estudiadas.

- La biodesintegrabilidad del PHB no se ve afectada por la presencia de las fibras ni de los agentes reactivos.

\section{Compuestos PHBV/TPU/Celulosa para aplicaciones de pieza inyectada}

- La incorporación de fibras de celulosa de alta pureza y poliuretano termoplástico (TPU) a la matriz de PHBV permite obtener sistemas triples PHBV/TPU/Celulosa para aplicaciones de pieza inyectada con un buen balance de propiedades en términos de rigidez-tenacidad-resistencia térmica, incluso sin necesidad de compatibilización de las fases manteniendo su biodesintegrabilidad en condiciones de compostaje.

- La compatibilización de las fases en sistemas triples PHBV/TPU/Celulosa mediante extrusión reactiva utilizando como agentes reactivos HMDI, Joncryl y TGIC potencia el efecto sinérgico de los beneficios aportados por la celulosa (refuerzo, resistencia térmica) y por el TPU (tenacidad). El agente reactivo HMDI es el que proporciona un mayor incremento de la tenacidad.

- La facilidad de procesado y las prestaciones de los sistemas PHBV/TPU/Celulosa obtenidos a partir de materiales disponibles comercialmente y técnicas de procesado convencionales a escala semi-industrial aseguran la viabilidad técnica de estos materiales para aplicaciones de pieza inyectada. 


\subsection{Trabajos futuros}

Las composiciones obtenidas en esta tesis han demostrado ser técnicamente viables para su aplicación en el desarrollo de productos de corta vida útil, especialmente aquellos con un final de vida dirigido al compostaje. No obstante, para una efectiva transferencia de estos resultados a la industria sería conveniente ampliar los estudios en diferentes aspectos.

Ampliar el estudio de compostabilidad para validar que se cumplen los requisitos de biodegradabilidad y ecotoxicidad del compost establecidos en la norma EN 13432 para poder etiquetar estos materiales como compostables. Así como, realizar estudios de análisis del ciclo de vida de las composiciones desarrolladas.

Realizar un análisis de costes en profundidad para verificar la reducción de costes con la incorporación de la fibra y el impacto de las operaciones de acondicionamiento, los diferentes tratamientos y el uso de aditivos sobre el coste final del producto.

Para aquellas aplicaciones dirigidas al contacto alimentario, sería conveniente realizar ensayos de migración en las composiciones en las que se han utilizado agentes reactivos.

Ampliar el estudio de termoconformabilidad y evaluar su escalabilidad utilizando moldes de geometrías similares a las empleadas en la industria y la operación en continuo.

En trabajos anteriores del grupo se obtuvieron mezclas de PHBV/PLA compatibilizadas con diisocianatos que demostraron mejorar, en gran medida, la termoconformabilidad del PHBV. Sería interesante explorar la adición de fibras a estas composiciones ya que los diisocianatos han demostrado ser eficientes tanto en la compatibilización de las fases poliméricas como en la compatibilización de la fibra con la matriz. Teniendo en cuenta estas consideraciones, se podría lograr, potencialmente, un equilibrio entre la mejora de la termoconformabilidad, la reducción de costes y las prestaciones mecánicas de estas composiciones. Asimismo, sería interesante evaluar las composiciones desarrolladas en esta tesis para pieza inyectada (PHBV/TPU/Celulosa) en aplicaciones de film, dado que los resultados obtenidos hacen pensar que estas composiciones tendrían a priori un buen comportamiento en termoconformado.

Desde el punto de vista medioambiental resultaría interesante explorar el uso de otros aditivos, por ejemplo, la sustitución del TPU utilizado por otros TPU de base PHA, y el uso de diferentes agentes y técnicas de compatibilización que permitan extender el concepto "green" del producto. 
ANEXOS 


\section{ANEX0 1.- Publicaciones}

\section{Publicaciones derivadas de este trabajo:}

- $\quad$ E.L. Sánchez-Safont, J. González-Ausejo, J. Gámez-Pérez, J.M. Lagarón, L. Cabedo, Poly(3Hydroxybutyrate-co-3-Hydroxyvalerate)/Purified Cellulose Fiber Composites by Melt Blending: Characterization and Degradation in Composting Conditions, J. Renew. Mater. 4 (2016) 123-132. doi:10.7569/JRM.2015.634127.

- E.L. Sánchez-Safont, A. Aldureid, J.M. Lagarón, J. Gámez-Pérez, L. Cabedo, Biocomposites of different lignocellulosic wastes for sustainable food packaging applications, Compos. Part B Eng. $145 \quad$ (2018) 215-225. doi:10.1016/j.compositesb.2018.03.037.

- E.L. Sánchez-Safont, A. Arrillaga, J. Anakabe, J. Gamez-Perez, L. Cabedo, PHBV/TPU/cellulose compounds for compostable injection molded parts with improved thermal and mechanical performance, J. Appl. Polym. Sci. (2018) 47257. doi:10.1002/app.47257.

- E.L. Sánchez-Safont, A. Arrillaga, J. Anakabe, L. Cabedo, J. Gamez-Perez, Toughness enhancement of $\mathrm{PHBV} / \mathrm{TPU} /$ cellulose compounds with reactive additives for compostable injected parts in industrial applications, Int. J. Mol. Sci. 19 (2018) 2102. doi:10.3390/ijms19072102.

\section{Otras publicaciones:}

- J. González-Ausejo E. Sánchez-Safont, L. Cabedo, J. Gamez-Perez, Toughness Enhancement of Commercial Poly (Hydroxybutyrate-co-Valerate) (PHBV) by Blending with a Thermoplastic Polyurethane (TPU), J. Multiscale Model. 7 (2016) 1640008. doi:10.1142/S1756973716400084.

- J. González-Ausejo, E. Sanchez-Safont, J.M. Lagaron, R.T. Olsson, J. Gamez-Perez, L. Cabedo, Assessing the thermoformability of poly(3-hydroxybutyrate-co-3hydroxyvalerate)/poly(acid lactic) blends compatibilized with diisocyanates, Polym. Test. 62 (2017) 235-245. doi:10.1016/j.polymertesting.2017.06.026.

- J. González-Ausejo, E. Sánchez-Safont, J.M. Lagarón, R. Balart, L. Cabedo, J. GámezPérez, Compatibilization of poly(3-hydroxybutyrate-co-3-hydroxyvalerate)-poly(lactic acid) blends with diisocyanates, J. Appl. Polym. Sci. 134 (2017) 1-11. doi:10.1002/app.44806.

- L.C. Jennifer González-Ausejo, Estefania Sánchez-Safont, José Gámez-Pérez, On the use of tris(nonylphenyl) phosphite as a chain extender in melt-blended poly(hydroxybutyrate-co-hydroxyvalerate)/clay nanocomposites: Morphology, 
thermal stability, and mechanical properties, J. Appl. Polym. Sci. 133 (2016). doi:10.1002/app.42971

\section{Comunicaciones en congresos:}

- E.L. Sánchez-Safont, J. Gamez-Perez, A. Arrillaga, J. Anakabe, L. Cabedo. Performance enhancement of PHBV based compounds. Polymar2018. Aegean Sea

- Patricia Feijoo Domínguez, Armando Matos Mendez, Abdulaziz Aldureid, Tomás Emilio Aznar Pérez, Estefanía Lidón Sánchez-Safont, José María Lagarón, José Gámez-Pérez, Luis Cabedo. Improving the thermoformability of bioplastics: PHB-based blends. Polymar 2018. Aegean Sea

- Abdulaziz Aldureid, Estefanía Lidón Sánchez-Safont, José María Lagarón, José GámezPérez, Luis Cabedo. Influence of cellulose morphology and surface treatment on properties of PHB/Cellulose composites. Polymar2018. Aegean Sea

- José Gámez-Pérez, Estefanía Sánchez-Safont, Abdulaziz Aldoureid, José María Lagarón, Luis Cabedo. Toughness enhancement of PHBV: A key issue for the massive use of this biodegradable thermoplastic in packaging applications. WCCE-2018. Valencia, España

- $\quad$ L. Cabedo, E. Sánchez-Safont, A. Aldureid, T. Aznar, A. Arrillaga, J. Anakabe, S. TorresGiner, J.M. Lagarón, J. Gámez-Pérez. PHA-based Blends and Composites: New Materials for Sustainable Packaging Applications. GEP, 2018. Punta Umbría, España.

- José Gámez-Pérez, Estefanía Sánchez-Safont, Abdulaziz Aldoureid, José María Lagarón, Luis Cabedo. How to improve PHBV performance to replace commodities in packaging applications. CNMAT 2018, Salamanca, España

- J. Gámez-Pérez, E. Sánchez-Safont, A. Aldureid, J.M. Lagarón, L. Cabedo. On the use of polyester reactive extrusion chain extenders as cellulose fibre/PHB compatibilizers. Biopol 2017, Mons, Bélgica

- L. Cabedo, J. González-Ausejo, E. Sánchez-Safont, A. Aldureid, J.M. Lagarón, J. GámezPérez. Improving the industrial applicability of PHBV to the packaging sector. Biopol 2017, Mons, Bélgica

- L. Cabedo, J.González-Ausejo, E. Sánchez-Safont, A. Aldureid, J.M. Lagarón, J. GámezPérez. Fostering the usability of PHA to the biodegradable packaging sector. 9th International Conference of the African Materials Research Society. Gaborone, Botswana. 
- Estefania Sánchez-Safont, Andrea Gruber, Miguel Oury, Jose Gamez-Perez, Luis Cabedo. Espumas de nanocompuestos polímero/arcilla obtenidas mediante liofilización. JIP 2017, Tarragona, España

- Estefania Sánchez-Safont, Nathalia Díaz, Abdulaziz Aldureid, lleana Recalde Ruiz, José Maria Lagarón, Jose Gamez-Perez, Luis Cabedo. Valorizartion of cellulosic agro-based residues in PHB based composites for food packaging applications. JIP 2017, Tarragona, España

- lleana Recalde Ruiz; Estefanía Sánchez-Safont; Julio Cesar Velazquez-Infante; Luis Cabedo; José Gámez-Pérez.Mejora de las propiedades mecánicas y barrera de materiales biodegradables para el envasado de alimento IV Congreso Internacional de Ingeniería Química, Biotecnología y Alimentaria (CIIQBA 2016), La Habana, Cuba

- E.L. Sánchez-Safont, A. Muñoz, L. Cabedo, J.C. Jarque, J. Gamez-Perez. Obtention and characterization of $\mathrm{PVOH} / \mathrm{clay}$ hybrid foamed systems using the freeze-drying technique. NANOTEC2016, Valencia, España

- J. Gamez-Perez, E. L. Sánchez-Safont, A. Porras, A. Barba , L. Cabedo. The effect of graphite addition into polymer/clay foamed composites obtained by freeze-drying. NANOTEC2016 Valencia, España

- González-Ausejo, J; Sánchez-Safont, E.; Cabedo, L.; Gámez-Pérez, J. Toughness enhancement of commercial poly(hydroxyl butyrate-co-valerate) (PHBV) by blending with a thermoplastic polyurethane (TPU). 15th International Conference on Fracture and Damage Mechanics

- Luis Cabedo Mas; Jennifer González Ausejo; Sánchez-Safont E.; Martínez-Abad A.; Fabra M.J.; Lagarón J.M, Gámez-Pérez, J. Estrategias para mejorar la aplicabilidad del Poli(3Hidroxivalerato-co-3-Hidroxibutirato (PHBV) al sector del envasado. XIV Reunión del grupo especializado de polímeros (GEP2016) de la RSEQ y RSEF. Burgos, España

- Jennifer González Ausejo; Sánchez Safont Estefania; Lagarón José María; Balart Rafael; Luis Cabedo Mas; José Gámez Pérez. Extending the usability of PHBV in thermoformings stages. MoDeSt 2016. Krakow, Polonia

- Alejandra Muñoz-Galindo, Estefanía Sánchez Safont, Alejandro Porras, Juan Carlos Jarque, Luis Cabedo, Jose Gamez-Perez. Obtención y caracterización de materiales híbridos polímero/arcilla espumados mediante liofilización. XIV Congreso Nacional de Materiales. Gijón, España

- González-Ausejo, J; Sanchez-Safont, E.; Izquierdo-Escrig, R; Balart, R.; Cabedo, L; GámezPérez, J. Use of poly(hexamethylene) diisocyanate as compatibilizer in PHBV/PLA blends. BIOPOL 2015. San Sebastián, España 
- Jennifer González Ausejo; Sánchez-Safont E.; Lagarón J.M.; José Gámez Pérez; Luis Cabedo Mas. Enhancement of the thermoformability of PHBV by blending with a TPU. JIP-JEPO2015. San Sebastián, España

- Jennifer González Ausejo; Sánchez-Safont E.; José Gámez Pérez; Luis Cabedo Mas. Mejora de la termoconformabilidad de PHBV mediante mezclas biodegradables con poliuretano. III Congreso I+D+i Campus de Alcoi. Creando Sinergias. Alcoi, España

- Sánchez-Safont Estefanía; Jennifer González Ausejo; José Gámez Pérez; Lagarón José María; Luis Cabedo Mas. Cellulose fiber reinforced PHBV composite with improved performance at high temperature. COST Action FP1205. Iasi, Rumanía

- Sánchez-Safont E.; Guevara F.; Jennifer González Ausejo; José Gámez Pérez; Lagarón J.M.; Luis Cabedo Mas. Caracterización y biodegradación en condiciones de compostaje de compuesto de PHBV / Microcelulosa. GEP 2014. Girona, España

- Jennifer González Ausejo; Sánchez-Safont E; José Gámez Pérez; Luis Cabedo Mas. Efecto de la adición de extensores de cadena sobre la estabilidad térmica durante el procesado de PHBV. GEP 2014. Girona, España

- Jennifer González Ausejo; Estefanía Sánchez Safont; José Gámez Pérez; Luis Cabedo Mas. Development and characterization of PHBV-clay nanocomposites by melt blending with improved thermal stability. BIOPOL 2013. Roma, Italia

- José Gámez Pérez; Jennifer González Ausejo; Estefanía Sánchez Safont; Luis Cabedo Mas. Kinetics of thermal decomposition of poly (3-hidroxybutyrate-co-3-hidroxyvalerate) (PHBV)_Effect of processing and chain extenders. POLYMAR 2013. Barcelona, España

- Fabrizio Guevara; Jennifer González Ausejo; Estefanía Sánchez Safont; José Gámez Pérez; Jose María Lagarón; Luis Cabedo Mas. PHBV/Microcelullose composites: Characterization and biodegradation in composting conditions. POLYMAR 2013. Barcelona, España

- Estefanía Sánchez Safont; Jennifer González Ausejo; José Gámez Pérez; Luis Cabedo Mas. Thermally Stabilized PHBV nanocomposites: obtention and characterization. POLYMAR 2013. Barcelona, España 


\title{
ANEXO 2.- Pimera página de las publicaciones de esta tesis
}

\section{CAPÍTULO I}

\author{
Poly(3-Hydroxybutyrate-co-3-Hydroxyvalerate)/ \\ Purified Cellulose Fiber Composites by Melt Blending: \\ Characterization and Degradation in Composting Conditions
}

Estefanía Lidón Sánchez-Safont'ㄹ, Jennifer González-Ausejo', José Gámez-Pérez¹, José María Lagarón², and Luis Cabedo ${ }^{\text {lx }}$

${ }^{1}$ Polymers and Advanced Materials Group (PIMA), Jaume I University, 12071 Castelló de la Plana, Spain

${ }^{2}$ Novel Materials and Nanotechnology Group, IATA, CSIC, Calle Agustín Escardino, 7 Paterna, Valencia, Valencia 46980 Spain

Received November 06, 2015; Accepted December 30, 2015

ABSTRACT: Novel biodegradable composites based on poly(3-hydroxybutirate-co-3-hydroxyvalerate) (PHBV) and different contents of purified alpha-cellulose fibers $(3,10,25$ and $45 \%)$ were prepared by melt blending and characterized. The composites were characterized by scanning electron microscopy (SEM), wide-angle X-ray scattering (WAXS) experiments, thermogravimetric analysis (TGA), differential scanning calorimetry (DSC), dynamic mechanic analysis (DMA) and Shore D hardness measurements. Disintegrability under composting conditions was studied according to the ISO 20200 standard. Morphological results showed that high dispersion of the fibers was achieved during mixing. Good adhesion on the fiber-matrix interface was also detected by SEM. The addition of low and medium cellulose contents did not result in lower thermal resistance with respect to the neat PHBV. A reinforcing effect of the cellulose fibers was detected in all samples, this effect being more pronounced at high temperatures. The composting results show that the addition of the fibers did not affect the disintegrability of the PHBV, and thus compostable "green" low-cost PHBV/cellulose composites can be obtained.

KEYWORDS: PHBV, cellulose, composites, biodegradation, ISO 20200 


\section{CAPÍTULO II}

Composites Part B 145 (2018) 215-225

\begin{tabular}{|c|c|c|}
\hline & Contents lists available at ScienceDirect & $\begin{array}{l}\mathrm{s} \\
\text { composires }\end{array}$ \\
\hline 5 & Composites Part B & 80 \\
\hline ELSEVIER & journal homepage: www.elsevier.com/locate/compositesb & - \\
\hline
\end{tabular}

Biocomposites of different lignocellulosic wastes for sustainable food packaging applications

Estefanía Lidón Sánchez-Safont " , Abdulaziz Aldureida , José María Lagarón ${ }^{\mathrm{b}}$, José Gámez-Pérez Luis Cabedo ${ }^{\mathrm{a}}$,

- PoObmers and Advanced Materials Group (PDMA), Universitat Jame $L$ Spoin 'Nowel Materials and Nenotechodogy Group, LATA, CSKC, Spain

ARTICLEINFO

Keywordic

PHB

Natural fiber

Blodegradable

Biocomposite
A B S T R A C T

The suitability of three local lignocellulosic wastes i.e. almond shell (AS), rice husk (RH) and seagrass (SG) as fillers in PHB/Fiber composites applications has been studied. PHB/Fiber composites with $10 \mathrm{phr}$ and $20 \mathrm{ph}$ fiber content were prepared by melt blending. The influence of the fiber type (size, morphology and origin) and content on the morphological, mechanical and thermal properties of the as obtained composites has been assessed. To evaluate the potential use in food packaging applications, the barrier performance to water, thermoforming ability and disintegration in controlled composting conditions of the composites were also studied. All the fibers have demonstrated to be apt for their use as fillers in PHB/Fiber composites, showing a re. inforcing effect without affecting the crystallinity and the disintegration rate of PHB. The thermal stability and the water barrier performance of the composites were reduced by the presence of the fibers. Nevertheless, the addition of AS resulted in the best balance of properties, in terms of permeability and mechanical properties, finding an enhancement of the thermoforming ability of PHB when 10 phr of AS was added. 


\section{CAPÍTULO IV}

\section{Applied Polymer}

PHBV/TPU/cellulose compounds for compostable injection molded parts with improved thermal and mechanical performance

Estefania Lidón Sánchez-Safont, ${ }^{1}$ Alex Arrillaga, ${ }^{2}$ Jon Anakabe, ${ }^{2}$ Jose Gamez-Perez, ${ }^{1}$ Luis Cabedo $\odot^{1}$ ${ }_{1}^{1}$ Polymers and Advanced Materials Group (PIMA), Universitat Jaume I, Av. Vicent Sos Baynat s/n, 12071 Castello, Spain

2Leartiker S. Coop., Xemein etorbidea 12, 48270 Markina-Xemein, Spain

Correspondence to: L. Cabedo (Icabedo@uji.es)

ABSTRACT: Poly(hydroxybutyrate-co-valerate) (PHBV) is a biopolymer that has gained a lot of attention because of its biodegradability, good thermal resistance, and balanced mechanical properties with respect to some commodity plastics. However, it presents two big limitations that hinder its potential application in replacing plastics for rigid injected parts: high cost and low toughness. Aiming at overcoming these limitations, the use of two additives in a PHBV matrix was explored: thermoplastic polyurethane (TPU) as an impact modifier and cellulose as reinforcing filler. Compounds of PHBV with different TPUs and cellulose contents were prepared by extrusion and, subsequently, injection molding. The morphology, thermal, and mechanical properties of the so-obtained materials were analyzed. Also, the biodisintegrability under standard composting conditions of the studied compositions was also assessed. The results of this work show that the obtained PHBV/TPU/cellulose compounds are biodisintegrable and show balanced properties in terms of thermal resistance-stiffness-toughness. These properties point these compounds as potential candidates to replace commodities in rigid part applications that require biodisintegration in their end-of-life, being able to be processed in a conventional injection molding industrial facility. 02018 Wiley Periodicals, Inc. J. Appl. Polym. Sci. 2018, 136, 47257.

KEYWORDS: biodisintegration; biopolyester; cellulose; elastomer; heat deflection temperature; toughening

Received 28 May 2018; accepted 13 September 2018

DOI: 10.1002/app.47257 


\title{
CAPÍTULO V
}

\section{Toughness Enhancement of PHBV/TPU/Cellulose Compounds with Reactive Additives for Compostable Injected Parts in Industrial Applications}

\author{
Estefania Lidón Sánchez-Safont ${ }^{1}$, Alex Arrillaga ${ }^{2}$, Jon Anakabe ${ }^{2} \odot$, Luis Cabedo ${ }^{1} \odot$ and \\ Jose Gamez-Perez ${ }^{1, *}$ \\ 1 Polymers and Advanced Materials Group (PIMA), Universitat Jaume I, 12071 Castellon, Spain; \\ esafonteruji.es (E.L.S.-S.); lcabedoruji.es (LC.) \\ 2 Leartiker S. Coop., Xemein Etorbidea 12A, 48270 Markina-Xemein, Spain; aarrillagađleartiker.com (A.A.); \\ janakabeखleartiker.com (J.A.) \\ - Correspondence: gamezeuji.es; Tel.: +34-964-728194
}

Received: 25 June 2018; Accepted: 17 July 2018; Published: 19 July 2018

\begin{abstract}
Poly(3-hydroxybutyrate-co-3-valerate), PHBV, is a bacterial thermoplastic biopolyester that possesses interesting thermal and mechanical properties. As it is fully biodegradable, it could be an alternative to the use of commodities in single-use applications or in those intended for composting at their end of life. Two big drawbacks of PHBV are its low impact toughness and its high cost, which limit its potential applications. In this work, we proposed the use of a PHBV-based compound with purified $\alpha$-cellulose fibres and a thermoplastic polyurethane (TPU), with the purpose of improving the performance of PHBV in terms of balanced heat resistance, stiffness, and toughness. Three reactive agents with different functionalities have been tested in these compounds: hexametylene diisocianate (HMDI), a commercial multi-epoxy-functionalized styrene-co-glycidyl methacrylate oligomer (Joncryl ${ }^{\infty}$ ADR-4368), and triglycidyl isocyanurate (TGIC). The results indicate that the reactive agents play a main role of compatibilizers among the phases of the PHBV/TPU/cellulose compounds. HMDI showed the highest ability to compatibilize the cellulose and the PHBV in the compounds, with the topmost values of deformation at break, static toughness, and impact strength. Joncryl ${ }^{2}$ and TGIC, on the other hand, seemed to enhance the compatibility between the fibres and the polymer matrix as well as the TPU within the PHBV.
\end{abstract}

Keywords: biopolyester; compatibilizer; cellulose; elastomer; toughening; biodisintegration; heat deflection temperature 


\section{ANEXO 3.- Lista de abreviaturas y símbolos}

3HB: 3-hidroxibutirato

3HV: 3-hidroxivalerato

AS: Cáscara de almendra

BD: Butanediol

BN: Nitruro de boro

DCP: Dicumyl perxide

DCP: Peróxido de dicumilo

DER: Resina epoxy

DMA: Dinamyc Mechanical Analisys

DSC: Diferencial Scanning Calorimetry

ENR: Caucho natural epoxidado

EUA: Estados Unidos

EVA: Etilvinilacetato

FTIR: Fourier Transformed Infrared

Spectroscopy

HB: Hidroxibutirato

HDPE: Polietileno de alta densidad

HDT: Temperatura de defexión al calor

HHp: Hidroxiheptanoato

HHx: Hidroxihexanoato
HMDI: Hexa methylene diisocyanate

HV: Hidrocivalerato

ICl: Imperial Chermical Industries

IUPAC: International Union of Pure and Applied Chemistry

LCA: Life Cycle Assessment

LCT: Life Cycle Thinking

LDPE: Polietileno de baja densidad

LEFM: Linear Elastic Fracture Mechanics

MAF: Fase amorfa de alta movilidad

MCL: Longitud de cadena media

MFI: Melt Flow Index

$\mathrm{NaOH}$ : Hidróxido de sodio

P(3HB): Poli(3-hidroxibutirato)

P(3HV): Poli(3-hidroxivalerato)

PAA: Ácido peracético

PBAT: Adipato-terftalato de polibutileno

PBAT: Poly(butylene adipate-coterephtalate)

PBS: Poli(succinato de butileno) 
PCL: Policaprolactona/poli ( $\varepsilon$-caprolactona)

PET: Tereftalato de polietileno

PGA: Poli(ácido glicólico)

PHA: Polihidroxialcanoato

PHA-g-MA: Anhídrido maleico

PHAs: Polihidroxialcanoatos

PHB: Polihidroxibutirato

PHBV:

Poli(hidroxibutirato-co-

hidroxivalerato)

PLA: Poliácido láctico

pMDI: Poli diisocianato de difenilmetano

PMMA: Poly methyl methacrylate

PP: Polipropileno

PPBB: Propiedades barrera

PPMM: Propiedades mecanicas

PS: Poliestireno

PVA: Poli(alcohol vinílico)

PVC: Policloruro de vinilo

RAF: Fracción rígida amorfa
RDGE: Resorcinol diglycidyl ether

RH: Cáscara de arroz

SA: Ácido succínico

SCL: Longitud de cadena corta

SEM: Scanning Electron Microscopy

SG: Posidonia oceanica

TC90: Fibra de celulosa de alta pureza

TGA: Termogravimetric Analisys

TGIC: Triglycidyl isocyanurate

TPU: Poliuretano termoplástico

USA: Estados Unidos de America

WAXS: Wide angle $X$ ray scattering

WVP: Permeabilidad al agua 


\section{ANEXO 4.- Índice de tablas y figuras}

Figura 1. Estructura de la tesis $x v i$

Figura 1.1. Situación actual de la demanda de plásticos y de la generación y tratamiento de los residuos asociados en la Unión Europea (Fuente: Plastics Europe [1,3]) ..... 3

Tabla 1.1. Ejemplos de aplicación de los plásticos convencionales más usados en el sector del

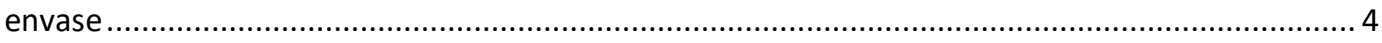

Figura 1.2. Jerarquía de gestión de bioresiduos ...................................................................... 7

Figura 1.3. Opciones de economía circular de bioplásticos ..................................................... 8

Figura 1.4. Metodología seguida en los Capítulos I-IV (la nomenclatura abreviada utilizada en esta figura se puede consultar en la lista de abreviaturas y símbolos) ................................................. 12 Figura 1.5. Metodología seguida en los Capítulos V y VI (la nomenclatura abreviada utilizada en esta figura se puede consultar en la lista de abreviaturas y símbolos) 14 Figura 1.6. Publicaciones relacionadas con polihidroxialcanoatos (a) y con compuestos de matriz polimérica basados en fibras vegetales (b) (fuente:Scopus [45]) 16

Figura 2.1. Micrografía de una sección ultrafina de una célula de Azotobacter chroococcum tratada con ácido fenilacético en la que se observan gránulos de PHB [Imagen publicada por Nuti y colaboradores en la revista Canadian Journal of Microbiology en 1972 [37]].

Figura 2.2. Estructura general de los PHA [Imagen adaptada de la referencia [28]].................... 29 Figura 2.3. Niveles estructurales en polímeros semicristalinaos [Imagen adaptada de la referencia [64]]

Figura 2.4. Micrografías ópticas de esferulitas de PHB mostrando grietas y fisuras [Imágenes publicadas por Barham y eller en la revista Journal of Polymer Science Part B: Polymer Physics en 1986 [60] ].

Figura 2.5. Representación esquemática del modelo de tres fases y del modelo "continuum of mobility" propuesto por Esposito et al.[79].[Imagen tomada de la referencia [79]]

Figura 2.6. Mecanismo de degradación térmica de los PHA [Imagen extraída de la referencia [50] (adaptada de la referencia [89])]

Tabla 2.1. Propiedades promedio del PHB y el PHBV en comparación con el PLA y algunos polímeros de uso común (PP, PE, PET) [Datos extraídos de las referencias [14,54,64,88,92]] ...... 36 Figura 2.7. Logotipo de envase compostable de acuerdo a la norma EN 13432......................... 46 Figura 2.8. Representación esquemática de la estructura de las fibras lignocelulósicas .............. 49 Tabla 2.2. Principales ventajas e inconvenientes de las fibras lignocelulósicas en materiales compuestos de matriz polimérica [adaptada de la referencia [179]] 52 
Figure I.1. SEM micrographs of cellulose fibers and PHBV/cellulose composites (a) cellulose low magnification (500x), (b) cellulose high magnification (150x), (c) PHBV-3C (500x) and (d) PHBV45C (500x).

Figure I.2. WAXS patterns of the cellulose, the neat PHBV and the PHBV/cellulose composites with 3, 10, 25 and $45 \mathrm{wt} \%$ of cellulose.

Figure I.3. DSC thermograms of a) the cooling scan and b) the heating scan and of the neat PHBV and the PHBV/cellulose composites containing 3, 10, 25 and 45 wt\% of cellulose. ..................... 93

Table I.1. Crystallization and melting parameters obtained by DSC of neat PHBV and $\mathrm{PHBV} /$ cellulose composites.

Figure I.4. TGA curves of neat PHBV and PHBV/cellulose composites. .................................... 95

Table I.2. Parameters obtained from thermogravimetric analyses of neat PHBV and its

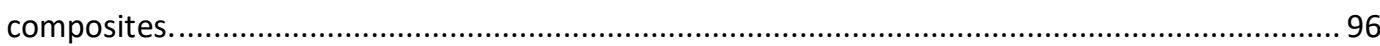

Figure I.5. Storage modulus and Tan- $\delta$ curves obtained from the DMA of neat PHBV and its composites

Table I.3. Storage modulus at diferent temperatures and Shore D hardness of PHBV and $\mathrm{PHBV} /$ cellulose composites. .97

Figure I.6. Disintegrability (\%) of PHBV and PHBV/cellulose composites under composting conditions as a function of time. .98

Figure I.7. Visual aspect of PHBV and PHBV/cellulose samples after 0,28 and 42 days in composting conditions

Figure I.8. SEM micrograph of the sample with $45 \%$ of cellulose contentent (PHBV-45C) at 40 days of the composting test. 100

Figure II. 1. Schematic representation of the treatments applied to the three residues (AS, RH and SG) and the visual appearance before and after the treatment 111

Table II.1. Composition and treatment yield of AS, RH and SG 116

Figure II.2. Purification fiber results: a)FTIR spectra of AS, RH and SG fibers before and after the treatment; b) WAXS patterns of $\mathrm{AS}, \mathrm{RH}$ and SG fibers before and after the treatment; $\mathrm{c}$ ) Crystallinity index of AS, RH and SG fibers before and after the treatment; d) DTG curves of AS, $\mathrm{RH}$ and SG fibers before and after the treatment 118 Figure II.3. SEM micrographs of AS (a-c), RH (d-f) and SG (g-i) fibers before treatment (left), after treatment (center) and high magnification image after treatment (right). 120 Figure II.4. SEM micrographs of PHB/AS (a-c), PHB/RH (d-f) and PHB/SG (g-i) composites with 10 phr fiber content (left), 20 phr fiber content (center) and detail of fiber-matrix interface (right) 
Figure II.5. Young's modulus and tensile strength (a) and elongation at break (b) of neat PHB and

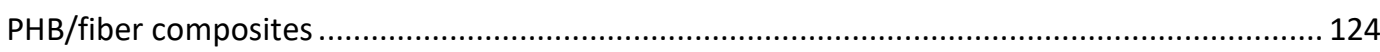

Figure II.6. Water Vapor Permeability (WVP) of neat PHB and PHB/fiber composites ............... 126

Figure II.7. a) Photographs of neat PHB and PHB/10 AS thermoforming trays as a function of heating time, b) representative thermoforming trays of $\mathrm{PHB} /$ fiber composites, c) Sheet temperature as a function of heating time, d) thermoforming temperature range for neat $\mathrm{PHB}$ and $\mathrm{PHB} / 10 \mathrm{AS}$ composite

Figure II.8. Disintegration of neat PHB and PHB/fiber composites over time under composting conditions 128

Figure II.9. Visual appearance of neat PHB and PHB/fiber composites at 0 days (left) and 28 days (right) of composting 129

Figure III.1. Scheme of SENB specimens 143

Figure III.2. SEM micrographs of the untreated and treated RH and AS fibers, the commercial cellulose (TC90), and EDX microanalysis of RH fibers 145

Figure III.3. WAXS patterns of TC90 and untreated and treated AS and RH fibers..................... 146

Figure III.4. FTIR spectrograms of TC90 and untreated and treated AS and RH fibers 147

Figure III.5. Weight loss (a) and DTG (b) curves corresponding to TC90 and untreated and treated AS and RH fibers 148

Figure III.6. SEM micrographs of PHB/TC90, PHB/U_AS, PHB/T_AS, PHB/U_RH and PHB/T_RH composites 150

Figure III.7. Tensile modulus (a), Tensile strength (b) and elongation at break (c) of neat PHB and the composites. 151

Figure III.8. LEFM results: representative force-displacement curve (a), KIC values of neat PHB and the composites (b), and representative SEM micrographs of the fractured specimens (c) ......... 153 Figure III.9. Storage modulus ( $\left.\mathrm{G}^{\prime}\right)$ and Tan $\delta$ (inset) evolution with temperature of neat PHB and the composites 155

Table III.1. DSC parameters of neat PHB and the composites 156

Figure III.10. Weight loss (a) and DTG (b) curves corresponding to neat PHB and the composites.

Table III.2. Thermal parameters obtained from TGA for neat PHB and the composites .............. 158

Figure IV.1. Chemical structures of PHB, cellulose and the reactive agents.............................. 170

Table IV.1. Summary of studied formulations .......................................................................... 172

Figure IV.2. SEM micrographs of PHB/TC90 composites with and without reactive agents. Low magnification images (left) and high magnification images (right) 176 
Table IV.2. DSC parameters for neat PHB with and without reactive agents and PHB/TC90 composites with and without reactive agents....

Figure IV.3. Representative stress-strain curves of neat PHB and PHB/TC90 composites with reactive agents.

179

Table IV.3. Mechanical parameters corresponding to tensile tests performed at 0 days and after 15 days of ageing at room temperature 180

Figure IV.4. Elastic modulus (a), tensile strength (b) and elongation at break (c) of aged samples of neat $\mathrm{PHB}$ and $\mathrm{PHB} / \mathrm{TC} 90$ composites with and without reactive agents 181

Figure IV.5. Storage modulus ( $\mathrm{G}^{\prime}$ ) and $\tan \delta$ (inset) evolution with temperature for neat PHB and $\mathrm{PHB} / \mathrm{TC90}$ composites with reactive agents. 182

Figure IV.6. SEM micrographs of $\mathrm{PHB} / \mathrm{U}_{-} \mathrm{RH}$ (a), PHB/U_RH/HMDI (b), PHB/T_RH (c) and $\mathrm{PHB} / \mathrm{T}_{-} \mathrm{RH} / \mathrm{HMDI}(\mathrm{d})$ 184

Figure IV.7. Elastic modulus (a), tensile strength (b), elongation at break (c) and static toughness (d) of neat PHB, PHB/U_RH and PHB/T_RH composites with and without reactive agents. ....... 185 Figure IV.8. PHB/T_RH/HMDI thermoformed tray .................................................................. 186 Figure IV.9. Disintegration of neat PHB and the studied composites over time under standard composting conditions (ISO 20200) 187

Figure IV.10. Pictures of neat PHB and the studied composites at different composting times.. 189

Table V.1. Compositions studied 204

Figure V.1. Melt flow index (MFI) of neat PHBV and TPU and the PHBV/TPU/Cellulose compositions. 207

Figure V.2. Sphere size frequency histograms (a), representative micrographs of the drop-inmatrix morphology (b), and d10, $d 50$ and $d 90$ values of the TPU drops (c) for the

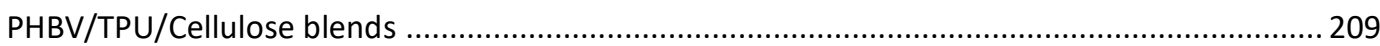

Figure V.3. SEM micrograph of cellulose fibers ….................................................................. 210

Figure V.4. SEM micrographs of PHBV/TPU/Cellulose blends: a)100/0/10, b)100/0/30, c) $100 / 10 / 10$, d)100/10/30; e)100/30/10 and f)100/30/30 211

Figure V.5. Mechanical properties of the neat PHBV and PHBV/TPU/Cellulose blends. a) Young's modulus, b) tensile strength, c)elongation at break and d) representative stress-strain curves of neat PHBV and the binary and ternary systems containing the highest amount of additives TPU and/or Cellulose (30 phr)..... 212

Figure V.6. Charpy impact results for unnotched specimens (a), notched specimens (b) and static toughness from the area below the strain-stress curve (c). 214

Table V.2. Shore D hardness of the studied compositions 215

Table V.3. DSC data of PHBV/TPU/Cellulose compounds 216 
Table V.4. TGA data of PHBV/TPU/Cellulose compounds.

Figure V.7. TGA and DTG (inset) curves of neat PHBV, TPU and Cellulose and PHBV/TPU/Cellulose systems 218

Figure V.8. HDT-A of neat PHBV and the PHBV/TPU/Cellulose blends 219

Figure V.9. Disintegration of neat PHBV and PHB/TPU/Cellulose systems over time under composting conditions 220

Figure V.10. SEM micrographs of the samples 100/10/30 (a) and 100/30/30 (b) at 47 days of composting test.

Figure V.11. Photographs of the studied samples at different composting times ...................... 223

Figure VI.1. Chemical structures of materials used in this study............................................. 235

Table VI.1. List of compounds and their composition........................................................ 236

Figure VI.2. Melt flow index (MFI) of neat PHBV, PHBV/30T/10C, and PHBV/30T/30C with 0, 0.3, 0.5 , and 1 phr reactive agent content.

Figure VI.3. SEM micrographs of PHBV/30T/10C $(a, b)$ and PHBV/30T/10C with $1 \mathrm{phr}$ of $\mathrm{HMDI}$ $(c, d)$, Joncryl ${ }^{\circledR}(e, f)$, and TGIC $(g, h)$..... 238

Figure VI.4. SEM micrographs of PHBV/30T/30C $(a, b)$ and PHBV/30T/30C with 1 phr of HMDI $(c, d)$, Joncryl ${ }^{\circledR}(e, f)$, and TGIC $(g, h)$.....

Figure VI.5. SEM images of the PHBV/30T/10C composites with the different reactive agents and cumulative frequency droplet size histograms of the dispersed phase. 241 Figure VI.6. SEM images of the PHBV/30T/30C composites with the different reactive agents and cumulative frequency droplet size histograms of the dispersed phase. 242 Table VI.2. Estimated d10, d50 and d90, average droplet size and ligament distance values of the TPU dispersed phase.

Figure VI.7. Mechanical properties of the neat PHBV and PHBV/TPU/Cellulose blends and representative stress-strain curves of neat PHBV, PHBV/30T/10C, and PHBV/30T/30C systems with and without 1 phr reactive agents 245

Figure VI.8. Charpy's impact results for unnotched specimens $(a, d, g)$, notched specimens (b,e,h) and static toughness from the area below the strain-stress curve $(c, f, i)$ 248

Table VI.3. HDT-A values for neat PHBV and PHBV/TPU/cellulose systems with and without reactive agents. 250

Figure VI.9. Disintegration in composting conditions of neat PHBV and PHB/TPU/cellulose systems with and without 1 phr reactive agents 251

Figure VI.10. SEM micrographs of PHBV/30T/30C samples with and without 1 phr reactive agents after Soxhlet extraction. 
Tabla 4.1. Influencia de las fibras sobre el comportamiento mecánico y la estabilidad térmica de

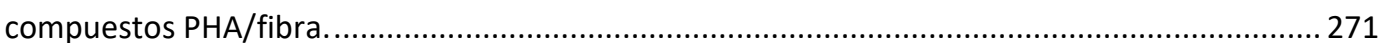

